\title{
ELUCIDAÇÃO DE MECANISMOS REACIONAIS EM REGIME LONGE DO EQUILÍBRIO TERMODINÂMICO
}

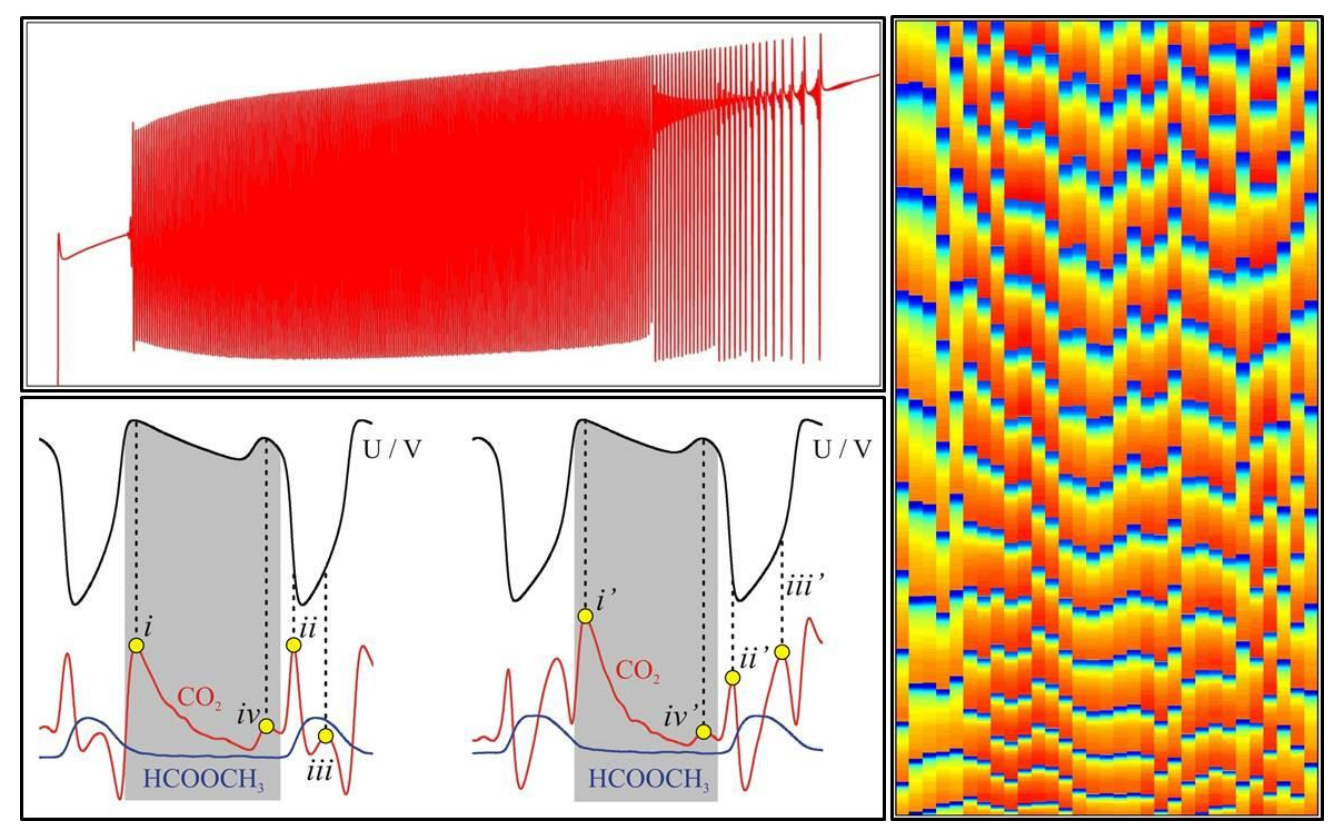

\section{Exemplar revisado}

O exemplar original encontra-se em acervo reservado na Biblioteca do IQSC-USP

RAPHAEL NAGAO DE SOUSA ORIENTADOR: PROF. DR. HAMILTON VARELA 

RAPHAEL NAGAO DE SOUSA

\section{ELUCIDAÇÃO DE MECANISMOS REACIONAIS EM REGIME LONGE DO EQUILÍBRIO TERMODINÂMICO}

Tese apresentada no Instituto de Química de São Carlos da Universidade de São Paulo para obtenção do título de Doutor em Química.

Área de concentração: Físico-Química

ORIENTADOR: PROF. DR. HAMILTON VARELA 

"Dedico este trabalho aos meus pais, Vrsulino $e$ Yuriko, e irmão, Alexandre pelo apoio, incentivo, referência e valores. Não há palavras que expressem minha eterna gratidão." 



\section{AgRADECIMENTOS}

Essa tese de doutorado é resultado de um trabalho contínuo, dinâmico e colaborativo, não restrito apenas ao período do doutoramento, mas desde minha chegada a São Carlos. A oportunidade de conviver com pessoas excepcionais tanto no âmbito acadêmico quanto fora deste, realmente fez toda a diferença. Gostaria, portanto, de agradecer primeiramente minha família: meus pais Ursulino e Yuriko, e irmão Alexandre por terem me provido a condição inicial para uma educação de qualidade além de me apoiarem constantemente em todos os sentidos durante minha trajetória acadêmica e por toda minha vida.

Agradeço aos meus mentores: Prof. Hamilton Varela pela orientação exemplar, profissionalismo, liberdade de pensamento na investigação científica e confiança depositada; e Prof. Ernesto R. Gonzalez pelo apoio, disponibilidade, e por ter me introduzido à Dinâmica Não-Linear. Gostaria de agradecer também ao Prof. Irving R. Epstein e Prof. Milos Dolnik (Brandeis University) pela hospitalidade, orientação e sobretudo pela oportunidade concedida de trabalhar em um ambiente de excelência em Sistemas Complexos.

Aos meus amigos de longa data e colegas em geral que tive a oportunidade de conviver e aprender muito sobre Química. Turma Bacharelado em Química 2003: Daniel Komatsu, Denis Massucato, Rafael Mori, Rafael Frederici, Ricardo, Emanuel, Léa, Maurício, Evandro, Tiago Munari; Laboratório de Auto-organização Dinâmica: Elton, Adriano, Hyrla, Paulo, Emerson, Eduardo, Murilo, Nickson, Marcelo, Graziela, Débora, Cristiane, André, Andressa, Loriz, Caio, Prof. Roberto B. Lima; Grupo de Eletroquímica IQSC/USP: Luciano, Amanda, Emília, Maurício Prieto, Prof. Flávio Colmati, Prof. Giusepe Câmara, Profa. Janaína Garcia, Janaína Gomes, Manuel, Prof. Eduardo Ciapina, Prof. Camilo Angelucci, Otávio, Bruno Previdelo, Sabrina, Gustavo Pio, Vanessa, Liliane, Luis Felipe, Prof. Fábio H. B. de Lima, Prof. Germano Tremiliosi, Prof. Edson A. Ticianelli; Funcionários do IQSC/USP: Jonas, Maristela, Janete, Valdecir, Silvia, Andréia, Bernadete, Alex, Edinho, Ednelson; ICMC/USP: Rogério Miguel; EESC/USP: Prof. Daniel Varela; Brandeis University: Delora, Támás, Daniel, Masahiro, Sridhar, Reva, Viktor, Prof. Vladimir Vanag, Prof. Seth Fraden, Ning Li, Nicollete, John, Helen, Pier, Asher, Frank, Jorge; UFRJ: Prof. Roberto Faria; FHI: Prof. Markus Eiswirth; República Minha Tia: Stênio, Vinícius, Fábio, Hebert, Dionísio, Jesus. República Fióte de Bordoké: Tiago Silva, Euripides, Gustavo Tokoro, Márcio Matuk, Marcos Paulo, Rubens. As discussões sobre ciência, política, esporte, arte, filosofia e assuntos gerais foram primordiais para o meu crescimento pessoal e profissional. 
Em especial gostaria de agradecer ao Bruno, Pietro, Daniel, Gustavo, Silvia, Melke e Adriana pela referência acadêmica, amizade, discussões científicas de alto nível, apoio e conselhos em momentos difíceis. Registro também meus agradecimentos ao Rodrigo, Alberto, Márcio, Eduardo, Alfredo, Narcisa, Andréia e respectivas famílias pelas palavras de incentivo.

Ainda que na reta final deste período, deixo meus agradecimentos a minha noiva Leidimara, pelo incentivo, planejamento em conjunto, compreensão, e companheirismo, além do nosso amor que me faz muito feliz.

Agradeço ao Instituto de Química de São Carlos da Universidade de São Paulo pelo ambiente de excelência em pesquisa, ensino e extensão o qual pude usufruir nesses 11 anos. À Fundação de Amparo à Pesquisa do Estado de São Paulo (FAPESP, processo: 2009/00153-6) e a Coordenação de Aperfeiçoamento de Pessoal de Nível Superior (CAPES, processo: 0337110) pelas bolsas de doutorado concedidas.

Por fim, agradeço a Deus por tudo o que feito em minha vida. 
七転び八起き (nanakorobi yaoki)

Provérbio Japonês 



\section{RESUMO}

NAGAO, R. Elucidação de Mecanismos Reacionais em Regime Longe do Equilíbrio Termodinâmico. 2013. Tese de Doutorado - Instituto de Química de São Carlos, Universidade de São Paulo, São Carlos, 2013.

A formação espontânea de padrões espaço-temporais auto-organizados longe do equilíbrio termodinâmico é um comportamento característico de sistemas de reação-transporte. De fato, essa estruturação espacial pode ser entendida como um comportamento coletivo de um grande número de elementos individuais no sistema. Consequentemente o padrão emerge como o resultado da interação entre a dinâmica local dessas subunidades e o mecanismo de acoplamento espacial. Dinâmica não-linear do tipo multi-estável, excitável e oscilatória são exemplos típicos de padrões temporais complexos geralmente associados à estruturação espacial. Nesta tese de doutorado são apresentadas duas frentes de trabalho utilizando-se da dinâmica química não-linear na elucidação de mecanismos reacionais longe do equilíbrio termodinâmico: (a) a investigação da natureza química e efeito do drift nas séries temporais transientes em osciladores eletroquímicos. A análise da evolução temporal do parâmetro de bifurcação foi baseada em um método empírico de estabilização, sendo o acúmulo superficial de espécies oxigenadas o principal responsável pelo drift; (b) o desacoplamento das rotas eletroquímicas paralelas na formação de $\mathrm{CO}_{2}$ pela combinação de experimentos, modelagem e simulações numéricas durante a eletro-oxidação oscilatória de metanol em platina policristalina. O efeito dos ânions perclorato e sulfato nas reações paralelas foi investigado por meio da produção global de $\mathrm{CO}_{2}$ e $\mathrm{HCOOCH}_{3}$. Notavelmente, ânions sulfato inibiram mais fortemente a atividade catalítica proveniente da via direta em contraste com a pequena alteração na via indireta. Em paralelo às duas frentes de trabalho, foi construído um setup experimental com a finalidade de acompanhar a evolução espaço-temporal de uma reação eletroquímica com um sistema de aquisição de dados multicanal. A descrição do processo de confecção da célula e eletrodo de trabalho multicanal, o tratamento de dados e alguns resultados experimentais preliminares são inseridos como um capítulo adicional. A ideia central dessa tese converge na obtenção de informações da cinética química envolvida que não é observada em condições próximas ao equilíbrio termodinâmico. Essa interpretação pode ser utilizada como uma metodologia alternativa no estudo da eletrocatálise em reações químicas complexas.

Palavras-chave: cinética química, dinâmica não-linear, auto-organização, oscilações. 


\begin{abstract}
NAGAO, R. Elucidation of Reaction Mechanisms under Far From Thermodynamic Equilibrium Regime. 2013. Doctoral Thesis - Instituto de Química de São Carlos, Universidade de São Paulo, São Carlos, 2013.

The spontaneous formation of self-organized spatiotemporal patterns under far from thermodynamic equilibrium conditions is a characteristic behavior in reaction-transport systems. Indeed, this spatial structuration can be understood as a collective behavior of a large number of individual elements in the system. Consequently the pattern emerges as a result of the interaction between the local dynamic of these subunits and the spatial coupling. Multistable, excitable and oscillatory nonlinear dynamics are typical examples of complex temporal patterns usually associated to the spatial structuration. In this doctoral thesis, two work fronts are presented using the nonlinear chemical dynamics in the elucidation of reaction mechanisms under far from thermodynamic equilibrium regime: (a) the investigation of the chemical nature and effect of the drift in the transient time-series in electrochemical oscillators. The analysis of the temporal evolution of the bifurcation parameter was based on an empiric method of stabilization, being the slow accumulation of oxygenated species the main responsible for the drift; (b) the decoupling of the parallel electrochemical routes for $\mathrm{CO}_{2}$ production by a combination of experiments, modeling and numerical simulations during the oscillatory electro-oxidation of methanol on polycrystalline platinum. The effect of perchlorate and sulfate anions in the parallel reactions was investigated by the global production of $\mathrm{CO}_{2}$ and $\mathrm{HCOOCH}_{3}$. Remarkably, sulfate anions inhibited more strongly the catalytic activity from direct pathway in contrast to the small alteration in the indirect pathway. In parallel to the two work fronts, an experimental setup was built in order to obtain a spatiotemporal evolution of a electrochemical reaction with a multichannel data acquisition system. A description of the confection process of the cell and the multichannel working electrode, data treatment and some preliminary experimental results are included as an additional chapter. The main idea of this thesis converges in the obtainment of chemical kinetic information which is not observed in conditions close to the thermodynamic equilibrium. This interpretation might be used as an alternative methodology in the study of electrocatalysis in complex chemical reactions.
\end{abstract}

Keywords: chemical kinetics, nonlinear dynamics, self-organization, oscillations. 


\section{LISTA DE FIGURAS}

Figura 1.1 - Estruturas de Turing simuladas a partir de um sistema de reação-difusão. [8] ....27

Figura 2.1 - Produção de entropia $d_{i} S$ associada a processos irreversíveis dentro do sistema e a

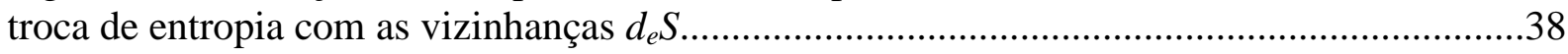

Figura 2.2 - Classificação e representação dos estados estacionários em um sistema de

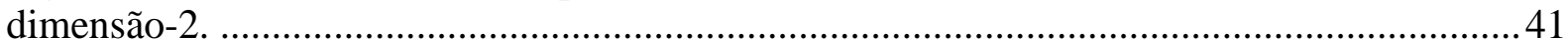

Figura 2.3 - Esquema genérico da emergência da bifurcação de Hopf subcrítica sob uma perturbação externa por um parâmetro de bifurcação, $\mu$........................................................ 42

Figura 2.4 - Classificação e representação dos estados estacionários em um sistema de dimensão-3. Para maiores detalhes ver ref. [99] .................................................................. 43

Figura 2.5 - Esquema ilustrativo da formação de oscilações de modo misto por meio da interação do ciclo limite com um ponto de sela-nó ou sela-foco do tipo II.

Figura 2.6 - Evolução de diferentes estados dinâmicos I vs. t para o modelo eletroquímico genérico [33] e respectivas projeções no espaço de fase no plano $\theta v s$. $\phi$. Ponto fixo estável $\rightarrow$ ciclo limite $\rightarrow$ órbita homoclínica $\rightarrow$ atrator estranho.

Figura 2.7 - Circuito elétrico equivalente de uma interface eletrificada sob controle potenciostático.

Figura 2.8 - Perfis estacionários obtidos a partir do modelo genérico para oscilador eletroquímico do tipo HN-NDR. [33] (a) curva em forma de "N" relativo aos processos faradaicos, (b) isoterma de adsorção da espécie bloqueante e (c) processo global, em azul, resultante da combinação das curvas em vermelho e preto.

Figura 2.9 - Esquema genérico da interação entre os ciclos de retroalimentação positivo e negativo responsáveis pelas oscilações observadas na reação de eletro-oxidação de moléculas orgânicas pequenas.

Figura 3.1 - Esquema genérico do circuito eletroquímico utilizado Imagem cortesia de H. Varela. 56

Figura 3.2 - Representação esquemática da célula espectro-eletroquímica: (1) eletrodo de trabalho (ET), (2) contato de Au do ET, (3) contra eletrodo (CE), (4) eletrodo de referência (ER), (5) fluxo de gás (entrada e saída); e do aparato de DEMS on line: (a) controle eletrônico do espectrômetro de massas, (b) quadrupolo e detector, (c1 e c2) câmara principal e précâmara, (d1 e d2) bomba turbo molecular, (e) bomba mecânica, e (f) conector e válvula do sistema de vácuo. Imagem cortesia de D. A. Cantane [115].

Figura 4.1 - Esquema das etapas reacionais para a eletro-oxidação de metanol utilizadas no modelo. As séries temporais experimentais e calculadas no Capítulo 6 seguem o padrão de cores adotado neste esquema reacional, vermelho: $\mathrm{CO}_{2}$, azul: $\mathrm{HCOOCH}_{3}$ e verde: $\mathrm{HCO}_{\mathrm{ad}}$....66

Figura 5.1 - (a) Voltametria cíclica conduzida a dU/dt $=0,05 \mathrm{~V} \mathrm{~s}^{-1}$ (linha preta) para platina policristalina em $\left[\mathrm{HClO}_{4}\right]=0,1 \mathrm{~mol} \mathrm{~L}^{-1}$ como eletrólito de suporte e (b) contendo $0,5 \mathrm{~mol} \mathrm{~L}-1$ 
de $\mathrm{H}_{3} \mathrm{COH}$. Varredura galvanodinâmica a dj/dt $=3,32 \mu \mathrm{A} \mathrm{cm} \mathrm{cm}^{-2}$ (linha vermelha) e sua região expandida para a mesma composição dada em (b).

Figura 5.2 - Série temporal obtida durante a eletro-oxidação de metanol a j=1,00 mA cm${ }^{-2}$. A seguinte sequência espontaneamente se desenvolve: nascimento das oscilações harmônicas por meio de um estado estacionário (ee), transição para oscilações de modo misto, e a morte das oscilações em torno de 371 segundos. Eletrólito: $\left[\mathrm{HClO}_{4}\right]=0,1 \mathrm{~mol} \mathrm{~L}^{-1}$ e $\left[\mathrm{H}_{3} \mathrm{COH}\right]=0,5$ $\mathrm{mol} \mathrm{L}{ }^{-1} . \mathrm{T}=25 \pm 1{ }^{\circ} \mathrm{C}$

Figura 5.3 - Período-1 e oscilações de modo misto estabilizadas por meio da VGN em diferentes taxas para a densidade de corrente inicial $\mathrm{j}=1,00 \mathrm{~mA} \mathrm{~cm}{ }^{-2}$. (a) $-2,39 \mu \mathrm{A} \mathrm{s}^{-1} \mathrm{~cm}^{-2}$, (b) $-1,00 \mu \mathrm{A} \mathrm{s}^{-1} \mathrm{~cm}^{-2}$, (c) $-1,33 \mu \mathrm{A} \mathrm{s}^{-1} \mathrm{~cm}^{-2}$ e (d) $-0,58 \mu \mathrm{A} \mathrm{s}^{-1} \mathrm{~cm}^{-2}$. Eletrólito: $\left[\mathrm{HClO}_{4}\right]=$ $0,1 \mathrm{~mol} \mathrm{~L}{ }^{-1}$ e $\left[\mathrm{H}_{3} \mathrm{COH}\right]=0,5 \mathrm{~mol} \mathrm{~L}^{-1} . \mathrm{T}=25 \pm 1^{\circ} \mathrm{C}$.

Figura 5.4 - Projeção bidimensional dos atratores reconstruídos em coordenadas de potencial pela Figura 5.3, utilizando o método do atraso em (a) $\tau=0,203 \mathrm{~s}$, (b) $\tau=0,203 \mathrm{~s}$, (c) $\tau=0,190$ s e (d) $\tau=0,174 \mathrm{~s}$. 80

Figura 5.5 - Séries temporais de potencial (linha preta) em diferentes valores de sítios superficiais f e potencial médio $\phi_{\mathrm{m}}$ calculado (linha vermelha) $\operatorname{com} \beta=0$, respectivamente. (a) $\mathrm{f}=1$ e $\phi_{\mathrm{m}}=59,9$, (b) $\mathrm{f}=0,65$ e $\phi_{\mathrm{m}}=74,4$, (c) $\mathrm{f}=0,30$ e $\phi_{\mathrm{m}}=142,9$.

Figura 5.6 - Séries temporais de potencial (linha preta) e potencial médio $\phi_{\mathrm{m}}$ (linha vermelha) calculados para $\alpha=1,0.10^{-4}$ e (a) $\beta=0$, (b) $\beta=0,125.10^{-4}$, (c) $\beta=1,0.10^{-4}$. 83

Figura 5.7 - Mapeamento do número de ciclos para oscilações de potencial de período-1 em função dos parâmetros $\alpha$ e $\beta$. Cada elemento da malha $(200 \times 200)$ representa uma série temporal.

Figura 5.8 - Esquema ilustrativo para a acumulação de uma espécie adsorvida e desconhecida $S$, durante três etapas (a) $t_{0}$, (b) $t_{1}$ e (c) $t_{2}$. 90

Figura 5.9 - Evolução do (a) potencial médio e (b) potencial do eletrodo durante a eletrooxidação galvanodinâmica de formaldeído sobre platina policristalina. Detalhes das oscilações são mostradas nas janelas (c)-(h). Eletrólito: $\left[\mathrm{H}_{2} \mathrm{SO}_{4}\right]=0,5 \mathrm{~mol} \mathrm{~L}^{-1}$ e $[\mathrm{HCHO}]=$ $0,1 \mathrm{~mol} \mathrm{~L}^{-1}$.

Figura 5.10 - Esquema genérico da interação entre os ciclos de retroalimentação (sistema rápido) com o drift (sistema lento) na geração de oscilações não-compensadas. 95

Figura 6.1 - Esquema reacional simplificado para a eletro-oxidação de metanol 101

Figura 6.2 - (a) voltametria cíclica a dU/dt $=0,01 \mathrm{~V} \mathrm{~s}^{-1}$ e fragmentos de massa $\mathrm{m} / \mathrm{z}=$ (b) $44 \mathrm{e}$ (c) 60 monitorados simultaneamente durante a eletro-oxidação de metanol. $\left[\mathrm{H}_{3} \mathrm{COH}\right]=2,0$ $\mathrm{mol} \mathrm{L}^{-1},\left[\mathrm{HClO}_{4}\right]=0,5 \mathrm{~mol} \mathrm{~L}^{-1}$ e $\mathrm{T}=20^{\circ} \mathrm{C}$. 104

Figura 6.3 - Série temporal a j =0,35 $\mathrm{mA} \mathrm{cm}^{-2}$ do (a) potencial do eletrodo durante a eletrooxidação de metanol acompanhadas pelos fragmentos de massa $\mathrm{m} / \mathrm{z}=$ (b) 44 e (c) 60 . $\left[\mathrm{H}_{3} \mathrm{COH}\right]=2,0 \mathrm{~mol} \mathrm{~L}^{-1},\left[\mathrm{HClO}_{4}\right]=0,5 \mathrm{~mol} \mathrm{~L}^{-1}$ e T $=20^{\circ} \mathrm{C}$. 105 
Figura 6.4 - Series temporais simuladas usando as Equações 4.25 até 4.31 para: (a) $\phi$, potencial da dupla camada; (b) $v_{5}+v_{9}, \mathrm{CO}_{2}$ total; (c) $x_{2}$, recobrimento de $\mathrm{HCO}$; (d) $v_{5}, \mathrm{CO}_{2}$ da via indireta (e) $v_{9}, \mathrm{CO}_{2}$ da via direta. Ver Capítulo 4 - Seção 4.2 para maiores detalhes....... 106

Figura 6.5 - Voltametrias cíclicas (índice 1) monitoradas simultaneamente com os fragmentos de massa $\mathrm{m} / \mathrm{z}=44$ (índice 2) e 60 (índice 3) durante a eletro-oxidação de metanol sob eletrodo de platina à $\left[\mathrm{H}_{3} \mathrm{COH}\right]=0,5 \mathrm{~mol} \mathrm{~L}^{-1}$ (item (a)) e 2,0 $\mathrm{mol} \mathrm{L}^{-1}$ (item (b)) em eletrólito aquoso de $\mathrm{HClO}_{4}$ (linha preta) e $\mathrm{H}_{2} \mathrm{SO}_{4}$ (linha vermelha). $\left[\mathrm{HClO}_{4}\right]=\left[\mathrm{H}_{2} \mathrm{SO}_{4}\right]=0,5 \mathrm{~mol} \mathrm{~L}{ }^{-1}$. $\mathrm{dU} / \mathrm{dt}=0,01 \mathrm{~V} \mathrm{~s}^{-1}$ e $\mathrm{T}=20^{\circ} \mathrm{C}$.

Figura 6.6 - Séries temporais de período-1 (linha preta) durante a eletro-oxidação de metanol à $\left[\mathrm{H}_{3} \mathrm{COH}\right]=0,5 \mathrm{~mol} \mathrm{~L}^{-1}$ (item (a)) e 2,0 mol L-1 (item (b)) em solução aquosa de $\mathrm{HClO}_{4}$ (índice 1 à 3) e $\mathrm{H}_{2} \mathrm{SO}_{4}$ (índice 4 à 6) sob densidade de corrente aplicada $\mathrm{j}=0,30 \mathrm{~mA} \mathrm{~cm}{ }^{-2}$ acompanhadas pelos fragmentos de massa $\mathrm{m} / \mathrm{z}=44$ (linha vermelha) e 60 (linha azul). Picos $i$ ou $i$ ' representam contribuições da via indireta e $i i$ ou $i i$ ' para a via direta. Detalhes adicionais na Figura 6.5.

Figura 6.7 - Evolução temporal do fragmento de massa $\mathrm{m} / \mathrm{z}=44$ durante a eletro-oxidação de metanol em diferentes densidades de corrente aplicadas: $\mathrm{j}=0,20 \mathrm{~mA} \mathrm{~cm}^{-2}$ até $0,40 \mathrm{~mA} \mathrm{~cm}^{-2} \mathrm{e}$ $\left[\mathrm{H}_{3} \mathrm{COH}\right]=2,0 \mathrm{~mol} \mathrm{~L}^{-1}$ em solução aquosa de (a) $\mathrm{HClO}_{4} \mathrm{e}$ (b) $\mathrm{H}_{2} \mathrm{SO}_{4}$. A linha vertical tracejada indica o pico de $\mathrm{CO}_{2}$ proveniente da oxidação de monóxido de carbono (i.e. pico $i$ ou $i$ '). Detalhes adicionais na Figura 6.5.

Figura 6.8 - Contribuição dos picos de $\mathrm{CO}_{2}$ da via: (a) indireta (pico $i$ ou $i$ ') e (b) direta (picos ii e iii ou ii' e iii') em função do tempo com $\mathrm{j}=0,30 \mathrm{~mA} \mathrm{~cm}^{-2}$. Experimentos realizados em solução aquosa de $\mathrm{HClO}_{4}$ (linha preta) e $\mathrm{H}_{2} \mathrm{SO}_{4}$ (linha vermelha) nas concentrações de metanol 0,5 mol L ${ }^{-1}$ (ćŕrculos preenchidos) e 2,0 $\mathrm{mol} \mathrm{L}^{-1}$ (círculos abertos). Dados obtidos pela deconvolução dos picos de $\mathrm{CO}_{2}$ apresentados na Figura 6.6. 112

Figura 6.9 - Séries temporais de período-2 (linha preta) durante a eletro-oxidação de metanol em $\left[\mathrm{H}_{3} \mathrm{COH}\right]=0,5 \mathrm{~mol} \mathrm{~L}^{-1}$ (item (a) com j =0,35 $\mathrm{mA} \mathrm{cm}^{-2}$ ) e 2,0 $\mathrm{mol} \mathrm{L}^{-1}$ (item (b) com j = $0,40 \mathrm{~mA} \mathrm{~cm}{ }^{-2}$ ) em solução aquosa de $\mathrm{HClO}_{4}$ (índice 1 à 3 ) e $\mathrm{H}_{2} \mathrm{SO}_{4}$ (índice 4 à 6) acompanhadas pelos fragmentos de massa $\mathrm{m} / \mathrm{z}=44$ (linha vermelha) e 60 (linha azul). Detalhes adicionais na Figura 6.5.

Figura 6.10 - Detalhes das oscilações de período-2 apresentadas na Figura 6.9 para soluções aquosas de (a) $\mathrm{HClO}_{4}$ e (b) $\mathrm{H}_{2} \mathrm{SO}_{4}$ em $\left[\mathrm{H}_{3} \mathrm{COH}\right]=2,0 \mathrm{~mol} \mathrm{~L}^{-1}$ 117

Figura 8.1 - Função de acoplamento eletroquímica não-local, $\mathrm{H}_{\mathrm{B}}\left(\mid \mathrm{x}\right.$ - $\left.\mathrm{x}^{\prime} \mid\right)$ em função da coordenada angular x' para a configuração de um eletrodo anular unidimensional sob diferentes valores de B. Figura adaptada de Christoph et al. [201].... 129

Figura 8.2 - Modelo esquemático representando a disposição dos eletrodos na célula eletroquímica multicanal. Eletrodo de trabalho: ET, contra-eletrodo: CE, eletrodo de referência: ER, potencial aplicado: $U$, corrente individual: $i_{\text {ind }}$, corrente coletiva: $i_{\text {coll }}$, resistência individual: $\mathrm{R}_{\text {ind, }}$, resistência coletiva: $\mathrm{R}_{\text {colll, }}$, raio do ET: $\mathrm{r}$. 132

Figura 8.3 - (a) célula eletroquímica multicanal: (1), tampa rosqueada superior: (2) e inferior: (3), controle de altura para RE: (4), entrada: (5) e saída: (6) de Ar; (b) eletrodo de trabalho; (c) conexões e cabeamento para sistema de aquisição de dados multicanal. 
Figura 8.4 - Programação em diagrama de blocos construído em ambiente Labview para aquisição de dados.

Figura 8.5 - Painel frontal utilizado como interface de usuário contendo: gráfico corrente/tempo com canais selecionáveis: Gráfico de Comparação; histórico temporal total: Histórico Total; gráfico bidimensional \#canal/tempo com resolução espaço-temporal: Resolução Espaço-Temporal; Armazenamento de dados: Entrada/Saída de Dados.

Figura 8.6 - (a) STD com controle de amplificação, filtro passa-baixa e linha de base, (b) visão superior e (c) frontal. Potenciômetros shunt: (1)-(3), amplificação: (4) e linha de base: (5). 138

Figura 8.7 - Fluxograma referente ao setup experimental de aquisição de dados multicanal durante medidas eletroquímicas espacialmente resolvidas.

Figura 8.8 - Oscilações potenciostáticas sincronizadas (i.e. eletrodos fortemente acoplados) durante a eletro-oxidação de ácido fórmico em platina policristalina. (a) densidade de corrente total correspondente à soma das correntes individuais, (b) resolução espaço-temporal dos 32 eletrodos de trabalho. $[\mathrm{HCOOH}]=0,5 \mathrm{~mol} \mathrm{~L}^{-1}$ e $\left[\mathrm{H}_{2} \mathrm{SO}_{4}\right]=0,1 \mathrm{~mol} \mathrm{~L}^{-1}, \mathrm{R}_{\text {ind }}=1 \mathrm{k} \Omega, \mathrm{R}_{\text {coll }}=30$ $\mathrm{k} \Omega, \mathrm{U}=8 \mathrm{~V}, \xi=0,99$. 141

Figura 8.9 - Oscilações potenciostáticas dessincronizadas (i.e. eletrodos fracamente acoplados) durante a eletro-oxidação de ácido fórmico em platina policristalina. (a) densidade de corrente total correspondente à soma das correntes individuais, (b) resolução espaçotemporal dos 32 eletrodos de trabalho. $[\mathrm{HCOOH}]=0,5 \mathrm{~mol} \mathrm{~L}^{-1}$ e $\left[\mathrm{H}_{2} \mathrm{SO}_{4}\right]=0,1 \mathrm{~mol} \mathrm{~L}^{-1}, \mathrm{R}_{\text {ind }}$ $=1 \mathrm{M} \Omega, \mathrm{R}_{\mathrm{coll}}=5 \mathrm{k} \Omega, \mathrm{U}=10 \mathrm{~V}, \xi=0,14$. 142

Figura A1 - Deconvolução dos picos de $\mathrm{CO}_{2}(\mathrm{~m} / \mathrm{z}=44)$ em solução aquosa de ácido (a) perclórico e (b) súlfurico com $\left[\mathrm{H}_{3} \mathrm{COH}\right]=2,0 \mathrm{~mol} \mathrm{~L}^{-1} \mathrm{e} \mathrm{j}=0,30 \mathrm{~mA} \mathrm{~cm}{ }^{-2}$. $\left[\mathrm{HClO}_{4}\right]=\left[\mathrm{H}_{2} \mathrm{SO}_{4}\right]$ $=0,5 \mathrm{~mol} \mathrm{~L}^{-1}$ e $\mathrm{T}=20^{\circ} \mathrm{C}$. A deconvolução foi conduzida com uma linha de base no pico de mínimo local das oscilações. Este procedimento resultou na produção relativa de $\mathrm{CO}_{2}$ dada na Figura 6.8 178

Figura A2 - Produção de $\mathrm{CO}_{2}$ em função da densidade de corrente aplicada em regime oscilatório à $\left[\mathrm{H}_{3} \mathrm{COH}\right]=2,0 \mathrm{~mol} \mathrm{~L}^{-1}$ em solução aquosa de ácido perclórico (item (a) e (b)) e sulfúrico (item (c) e (d)), $\left[\mathrm{HClO}_{4}\right]=\left[\mathrm{H}_{2} \mathrm{SO}_{4}\right]=0,5 \mathrm{~mol} \mathrm{~L}^{-1}$ e $\mathrm{T}=20^{\circ} \mathrm{C}$. A deconvolução foi conduzida com uma linha de base adotada em condições de circuito aberto (i.e. 0,33 V)..179

Figura A3 - Programação em diagrama de blocos construído em ambiente Labview para a calibração do ganho e linha de base individual dos canais. 180

Figura A4 - Painel frontal utilizado como interface de usuário referente à programação dada na Figura A3. Nota-se o valor da amplificação e a posição da linha de base de cada canal...181

Figura A5 - Circuito elétrico pertencente ao STD. Controle do resistor shunt, amplificação e linha de base estão disponíveis nessa configuração. 


\section{LISTA DE TABELAS}

Tabela 4.1 - Parâmetros e condições iniciais para a integração numérica do modelo cinético HN-NDR modificado.

Tabela 4.2 - Parâmetros e condições iniciais para a integração numérica do modelo cinético da eletro-oxidação de metanol.

Tabela 5.1 - Número de ciclos oscilatórios em função de diferentes taxas da VGN em $\mu \mathrm{A} \mathrm{s}{ }^{-1}$ $\mathrm{cm}^{-2}$. 


\section{Lista de Abreviaturas e Siglas}

AGN

AGP

ATR

BZ

CIMA

$\mathrm{CE}$

DAS

DEMS

ER

ERH

ET

EDO

FKN

HPLC

LH

ML

NDR

STD

SEIRAS
Acoplamento Global Negativo

Acoplamento Global Positivo

Attenuated Total Reflection

Belousov-Zhabotinsky

Chlorite-Iodide-Malonic Acid

Contra-Eletrodo

Data Acquisition System

Differential Electrochemical Mass Spectrometry

Eletrodo de Referência

Eletrodo de Referência de Hidrogênio

Eletrodo de Trabalho

Equação Diferencial Ordinária

Field, Körös e Noyes

High Performance Liquid Chromatography

Langmuir-Hinshelwood

Monolayers

Negative Differential Resistance

Signal Treatment Device

Surface Enhanced Infrared Absorption Spectroscopy 


\section{LISTA DE SÍMBOLOS}

dS

$\mathrm{d}_{\mathrm{i}} \mathrm{S}$

$\mathrm{d}_{\mathrm{e}} \mathrm{S}$

$\mathrm{t}$

$\mathbf{x}$

$\mu$

f

J

C

I

$\lambda$

$\mathrm{U}$

$\mathrm{U}_{\mathrm{m}}$

$\mathrm{dU} / \mathrm{dt}$

c

$\mathrm{c}_{\mathrm{m}}$

$c^{b}$

I

$\mathrm{I}_{0}$

$\mathrm{I}_{\mathrm{c}}$

$\mathrm{I}_{\mathrm{F}}$

$\mathrm{I}_{\mathrm{F}, \mathrm{m}}$

$\mathrm{j}$

J

$\mathrm{dj} / \mathrm{dt}$

$\phi$

$\phi_{\mathrm{m}}$

$\phi_{\mathrm{e}}$

$\mathrm{Z}_{\mathrm{F}}$

n

F

variação de entropia

variação de entropia proveniente de processos irreversíveis

variação de entropia pela troca de matéria e energia

tempo

vetor composto pelas variáveis $x_{i} \operatorname{com} i=1, \ldots, n$

vetor composto pelos parâmetros $\mu_{i} \operatorname{com} i=1, \ldots, n$

vetor composto pelas funções $f_{i} \operatorname{com} i=1, \ldots, n$

matriz Jacobiana

vetor composto pelas constantes $\mathrm{c}_{i} \operatorname{com} i=1, \ldots, n$

matriz identidade

autovalor

potencial aplicado (ou do eletrodo)

potencial do eletrodo médio

velocidade de varredura em $\mathrm{V} \mathrm{s}^{-1}$

concentração de uma espécie genérica

concentração de uma espécie genérica média

concentração de uma espécie genérica no seio da solução

corrente aplicada (ou total)

corrente aplicada inicial

corrente capacitiva

corrente faradaica

corrente faradaica média

densidade de corrente

densidade de corrente local

velocidade de varredura em $\mathrm{A} \mathrm{s}^{-1} \mathrm{~cm}^{-2}$

potencial da dupla camada

potencial da dupla camada médio

potencial elétrico

impedância faradaica

número de elétrons

constante de Faraday 
A

$\mathrm{A}_{\mathrm{G}}$

$A_{R}$

$\mathrm{A}_{\mathrm{F}}$

$\mathrm{R}_{\mathrm{u}}$

$\mathrm{R}_{\mathrm{c}}$

$\mathrm{R}_{\mathrm{ext}}$

$\mathrm{R}_{\text {ind }}$

$\mathrm{R}_{\text {coll }}$

$\gamma$

$\xi$

k

$\mathrm{k}_{\mathrm{m}}$

$\mathrm{k}_{i}$

$\mathrm{k}_{\mathrm{P}}$

$v_{i}$

$v_{\mathrm{F}}$

$\alpha$

$\beta$

$\omega$

$\delta$

$\tau$

$\theta$

$\theta_{\mathrm{T}}$

$\theta_{\mathrm{d}}$

$\theta_{\text {I }}$

$\theta_{\mathrm{C}-\mathrm{H}}$

$\theta_{\text {O-C }}$

$\theta_{\mathrm{HxO}}$

$\theta_{\mathrm{A}}$

$\theta_{\mathrm{HCO}}$

$\theta_{\mathrm{OH}}$

$\theta_{\mathrm{CO}}$

área de um eletrodo genérico

área geométrica do eletrodo

área real do eletrodo

área livre do eletrodo

resistência não compensada

resistência compensada

resistência externa

resistência individual

resistência coletiva

razão entre $R_{c}$ e $R_{u}$

fator de acoplamento

constante de velocidade de uma reação elementar genérica

constante de velocidade de uma reação elementar genérica média

constante de velocidade de uma reação elementar $i \operatorname{com} i=1, \ldots, n$

constante de velocidade de uma reação elementar de envenenamento

velocidade de uma reação elementar $i \operatorname{com} i=1, \ldots, n$

soma das velocidades de reações faradaicas

taxa de variação do drift

taxa de compensação da varredura galvanodinâmica negativa

coeficiente de transferência

espessura da camada difusional de Nernst

atraso temporal

recobrimento de uma espécie genérica

recobrimento total

recobrimento da espécie responsável pelo drift

recobrimento dos intermediários reacionais

recobrimento de espécies adsorvidas pelo carbono

recobrimento de espécies adsorvidas pelo oxigênio

recobrimento de espécies oxigenadas

recobrimento de ânions

recobrimento de $\mathrm{HCO}$ adsorvido

recobrimento de $\mathrm{OH}$ adsorvido

recobrimento de $\mathrm{CO}$ adsorvido 


$\begin{array}{ll}\theta_{\mathrm{HCOOH}} & \text { recobrimento de } \mathrm{HCOOH} \text { adsorvido } \\ \theta_{\mathrm{HCOO}} & \text { recobrimento de } \mathrm{HCOO} \text { adsorvido } \\ \mathrm{m} / \mathrm{z} & \text { razão massa/carga } \\ {\left[\mathrm{H}_{3} \mathrm{COH}\right]} & \text { concentração molar de } \mathrm{H}_{3} \mathrm{COH} \\ {[\mathrm{HCHO}]} & \text { concentração molar de } \mathrm{HCHO} \\ {[\mathrm{HCOOH}]} & \text { concentração molar de } \mathrm{HCOOH} \\ {\left[\mathrm{HClO}_{4}\right]} & \text { concentração molar de } \mathrm{HClO}_{4} \\ {\left[\mathrm{H}_{2} \mathrm{SO}_{4}\right]} & \text { concentração molar de } \mathrm{H}_{2} \mathrm{SO}_{4} \\ \mathrm{f} & \text { função de decaimento exponencial dos sítios livres } \\ \mathrm{f}_{\mathrm{aq}} & \text { frequência de aquisição } \\ \mathrm{f}_{\mathrm{varr}} & \text { frequência de varredura } \\ \mathrm{T} & \text { temperatura } \\ \mathrm{D} & \text { coeficiente de difusão } \\ \mathrm{H}_{\mathrm{B}} & \text { função de acoplamento }\end{array}$





\section{SUMÁRIO}

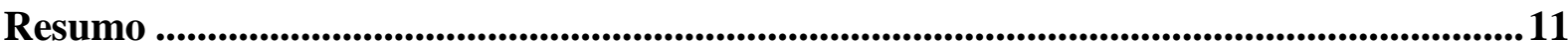

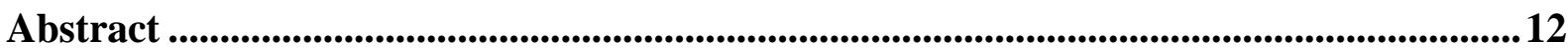

Lista de Figuras ...............................................................................................................13

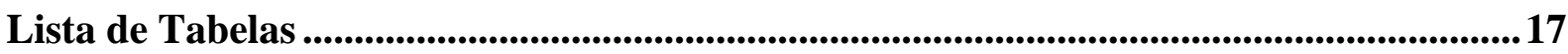

Lista de Abreviaturas e Siglas .........................................................................................18

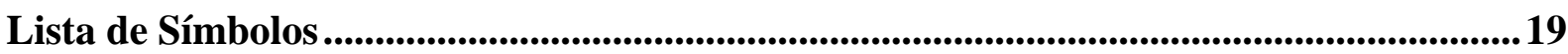

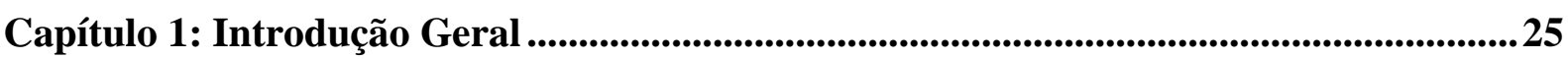

1.1 Formação de Padrões Auto-Organizados ................................................................. 27

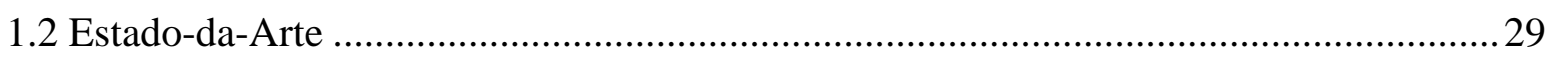

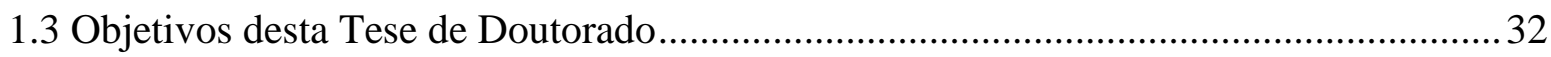

Capítulo 2: Teoria e Conceitos ...................................................................................................35

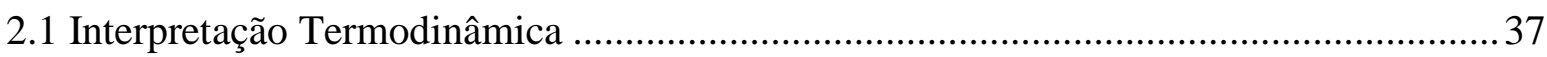

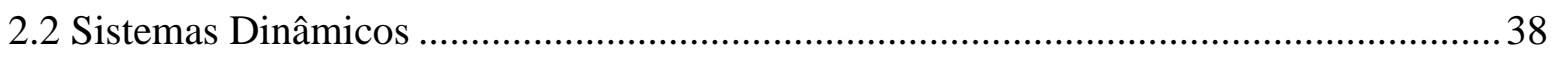

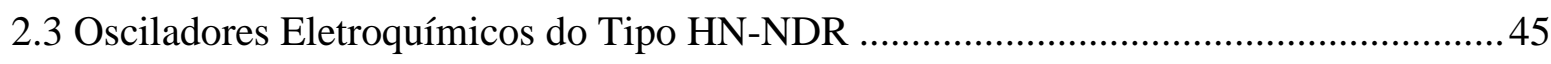

Capítulo 3: Procedimento Experimental.......................................................................................53

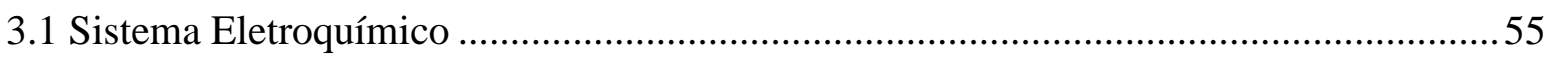

3.2 Sistema Eletroquímico Acoplado ao Espectrômetro de Massas .....................................57

Capítulo 4: Modelagem e Simulações Numéricas.....................................................................61

4.1 Implementação do Drift nas Séries Temporais Eletroquímicas ....................................63

4.2 Modelagem Mecanística para a Eletro-oxidação de Metanol .........................................66

Capítulo 5: Estabilização de Séries Temporais Transientes Eletroquímicas...................... 71

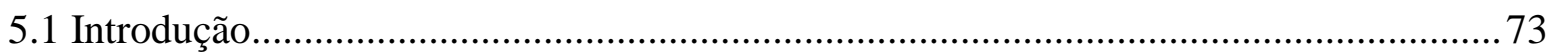

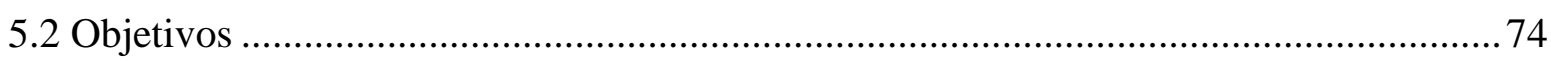

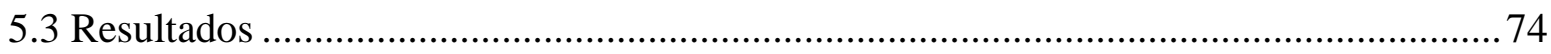

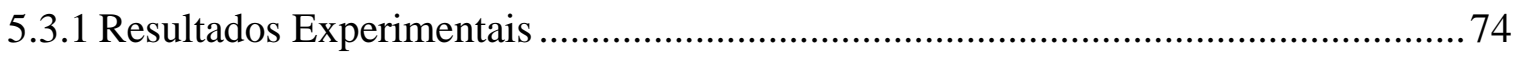

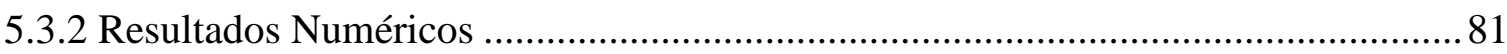

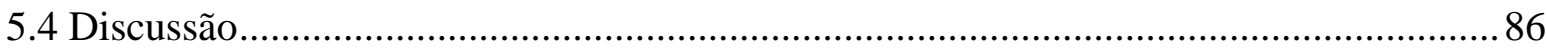

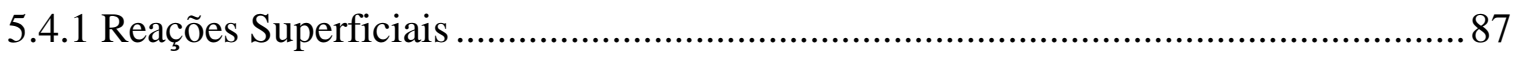

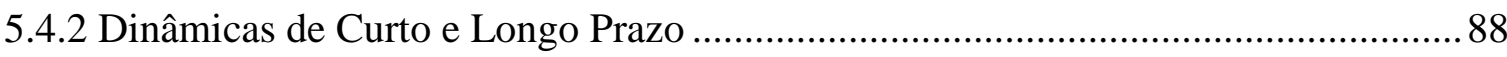


5.4.3 O problema das Séries Não-Estacionárias............................................................. 95

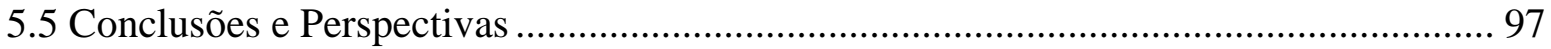

Capítulo 6: Desacoplamento e Efeito de Ânions nas Vias Paralelas de Produção de $\mathrm{CO}_{2}$ durante a Eletro-oxidação de Metanol.............................................................................. 99

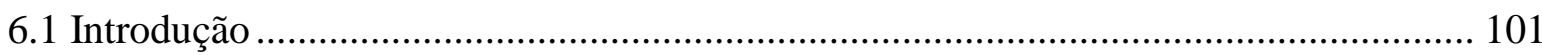

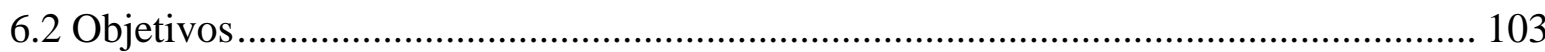

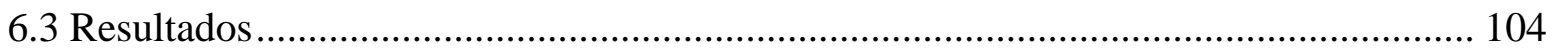

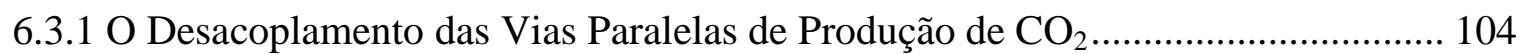

6.3.2 A Influência da Adsorção Inibitória de Ânions nas Vias Paralelas ........................ 108

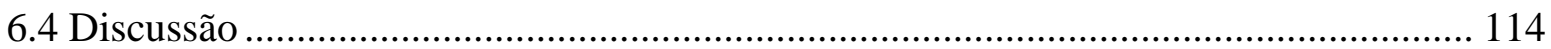

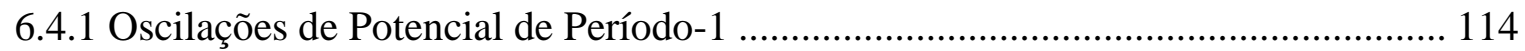

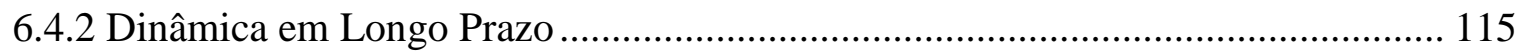

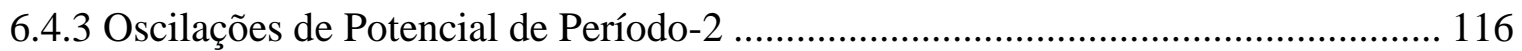

6.4.4 Considerações Mecanísticas ................................................................................. 118

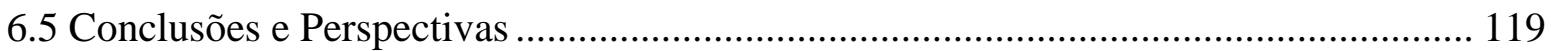

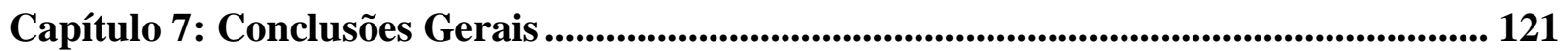

Capítulo 8: Trabalhos Futuros - Sistema de Aquisição de Dados Multicanal ................ 125

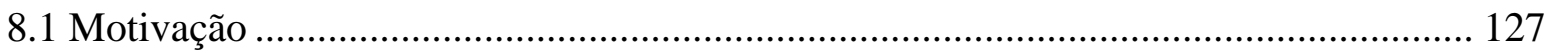

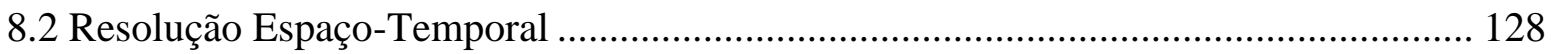

8.3 Eletrodo de Trabalho e Célula Eletroquímica Multicanal ............................................ 131

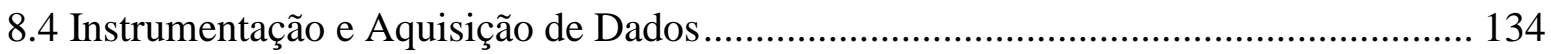

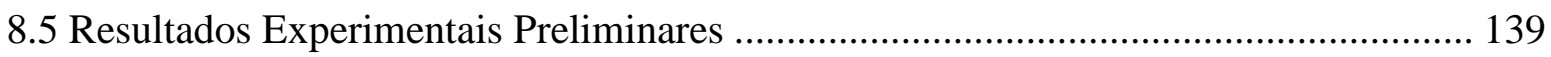

Capítulo 9: Referências Bibliográficas...................................................................... 145

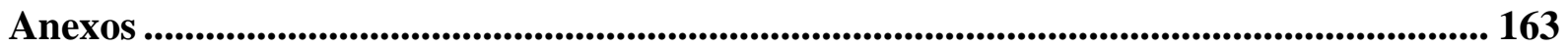




\section{Capítulo 1}

\section{INTRODUÇÃO GERAL}

Neste capítulo será abordado o tema central da linha de pesquisa e a correlação com os estudos mecanísticos em regime longe do equilíbrio termodinâmico. Uma seção contemplando o estado-da-arte será apresentada, exaltando os aspectos relevantes a serem investigados. Por fim, a problemática geral é discutida e os objetivos dessa tese de doutorado são traçados. 



\subsection{Formação de Padrões Auto-Organizados}

A formação espontânea de padrões auto-organizados expressa como uma coerência no tempo e espaço das subunidades que compõe o sistema é um fenômeno frequentemente encontrado em sistemas físicos, químicos e biológicos quando mantidos suficientemente afastados do equilíbrio termodinâmico. [1-3] O comportamento coletivo dessas subunidades resulta em um ordenamento em escala usualmente superior às dimensões em nível molecular. Neste contexto, a abundância de exemplos em sistemas biológicos não surpreende dada a variedade de formação de estruturas complexas pelo agrupamento sinérgico dos elementos individuais. A propagação de pulsos elétricos em sistemas neurais e a contração mecânica cardíaca podem ser citadas como exemplos. [4, 5] A manutenção dessa estruturação altamente ordenada exige o consumo contínuo de energia e exportação de entropia para as vizinhanças. [6]

A primeira formulação matemática que mimetiza esse comportamento emergente foi publicada em 1952 por Alan Turing com o artigo The Chemical Basis of Morphogenesis. [7] Baseado em um sistema de reação-difusão, um modelo químico relativamente simples foi capaz de reproduzir a estruturação espacial complexa encontrada em sistemas biológicos. Estruturas de Turing na forma de pontos e listras são mostradas na Figura 1.1.

Figura 1.1 - Estruturas de Turing simuladas a partir de um sistema de reação-difusão. [8]

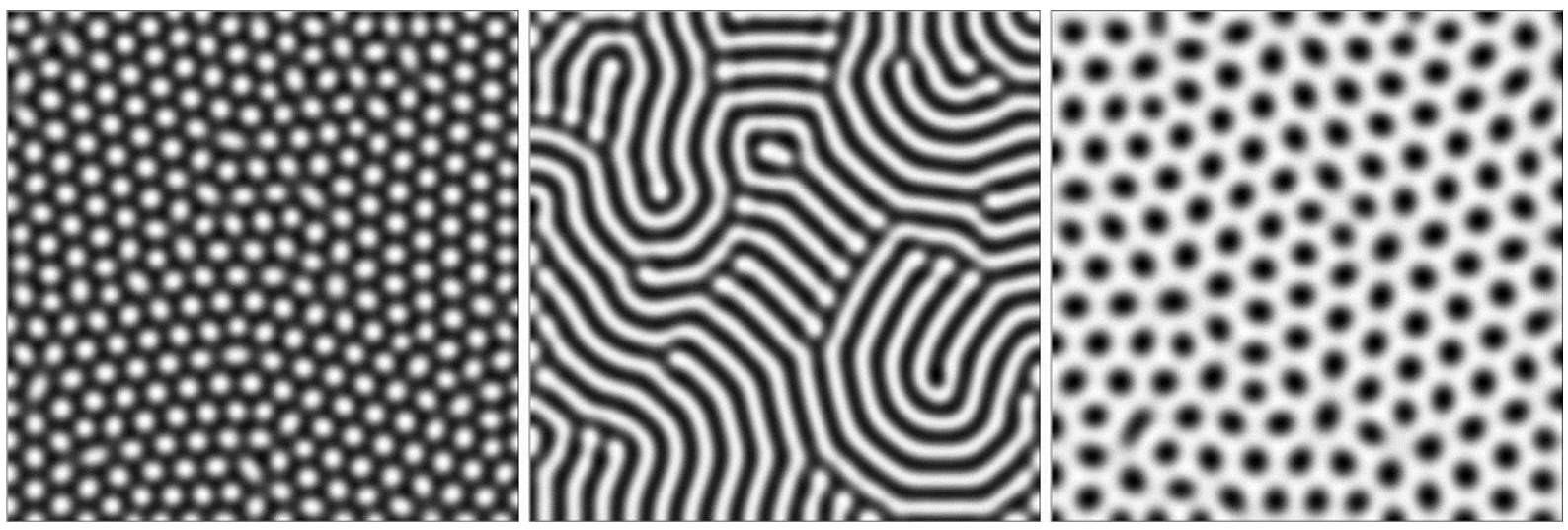

É inquestionável que grande progresso no entendimento de sistemas vivos tem sido fruto do estudo da formação de padrões auto-organizados em sistemas modelo. [9-11] Exemplos experimentais dessa arquitetura química como a propagação de ondas, espirais e alvos, tão bem quanto estruturas estacionárias como pontos e listras são usualmente encontrados em sistemas baseados na celebrada reação de Belousov-Zhabotinsky (BZ). [1215] Diversas reações que comtemplam os requerimentos básicos para a emergência de auto- 
organização têm sido descobertas, [16-20] dentre essas, as reações eletroquímicas se mostraram promissoras neste sentido. [21-27] Como já conhecido, os sistemas eletroquímicos são considerados abertos, o que possibilita a exportação de entropia proveniente dos processos irreversíveis, são facilmente controláveis por meio de parâmetros acessíveis experimentalmente e são regidos pela cinética eletroquímica de Bluter-Volmer que possui uma evolução não-linear. [28-30] Dinâmicas multi-estável, excitável e oscilatória são respostas temporais complexas encontradas nesses sistemas. [31-34]

Reações que envolvem oscilações entre as concentrações das espécies reacionais estão presentes na natureza, controlando vários processos fisiológicos como a regulação hormonal, ritmos circadianos, funções cardíacas, neuronais e etc. [35, 36] Estes ciclos naturais que podem ser referidos como processos de auto-organização temporal são associados a processos regulatórios como a homeostase. Utilizando-se de um oscilador químico genérico, Ruoff [37, 38] demonstrou que a regulação do ambiente interno encontrada em organismos vivos, a fim de manter uma condição estável, é ajustada pelo conjunto de etapas elementares no mecanismo reacional subjacente às variações de temperatura. Notavelmente, compensação de temperatura é apenas encontrada quando a dissipação é maximizada. [39]

Fenômeno emergente em conjuntos de osciladores químicos tem sido relatado. [40-46] O comportamento coletivo entre os osciladores individuais é sujeito a diferentes transições espaço-temporais mediante o alcance e magnitude dos acoplamentos envolvidos ou a comunicação paralela entre as subunidades. Possivelmente, a resposta usualmente encontrada sobre uma população de osciladores é a sincronização de fase. Essa conectividade em uníssono descrita pelo trabalho pioneiro de Kuramoto é dependente de um valor crítico do parâmetro de acoplamento caracterizado por um crescimento sigmoidal da amplitude coletiva dos osciladores. [47] Acredita-se que este comportamento em uníssono presente em sistemas nervosos é um dos possíveis responsáveis pela realização de tarefas sofisticadas como cognição e memória associativa. [4]

Comportamento temporal complexo associado à estruturação espacial também tem sido encontrado durante a eletro-oxidação de moléculas orgânicas pequenas com potencial de uso em sistemas de armazenamento e conversão de energia. [34] Observações experimentais recentes mostraram que instabilidades dinâmicas na forma de oscilações em células a combustível resultam em uma eficiência de operação superior em comparação a quando operadas em condições estacionárias. [48] A morfologia, período e amplitude das oscilações se mostraram como parâmetros de controle da eficiência da célula [49, 50]. Estruturação 
espaço-temporal também tem sido observada nesse sistema. [51-54] Essa classe de osciladores tem sido utilizada frequentemente na caracterização temporal em sistemas dinâmicos, [55-57] no estudo da formação, seleção e evolução de padrões espaço-temporais auto-organizados na interface sólido/líquido, [58-60] e recentemente utilizada na elucidação de mecanismos reacionais. [61, 62] Progresso significativo no entendimento da dinâmica tem sido alcançado devido à riqueza de padrões temporais observados nesses sistemas. O mapeamento do diagrama de bifurcação resulta em uma estruturação universal relacionada ao acoplamento de diferentes bifurcações o que justifica a variabilidade encontrada da resposta temporal. [63]

Considerando que as ferramentas fundamentais de caracterização da série temporal são provenientes do campo dos Sistemas Dinâmicos, nota-se que a maioria dos trabalhos relacionados ao estudo da formação de padrões espaço-temporais possui uma abordagem descritiva e raramente uma interpretação do mecanismo molecular regente tem sido proposta. No entanto, com a criação de novos grupos de pesquisas interdisciplinares, questões fundamentais têm sido abordadas com diferentes interpretações, contribuindo assim para a criação de um cenário mais amplo e um melhor entendimento do comportamento dinâmico.

\subsection{Estado-da-Arte}

Dado o elevado número de variáveis e a complexidade intrínseca no acoplamento das etapas reacionais, o estudo da evolução de padrões temporais em sistemas eletroquímicos tem se limitado a observação de variáveis globais. [32-34] O comportamento dinâmico tem sido caracterizado pela análise de estabilidade linear e modelos genéricos têm sido suficientes para reproduzir os aspectos básicos do sistema. No entanto, como observado, a eletro-oxidação de moléculas orgânicas pequenas pertencentes à mesma classe de osciladores, [64] com estrutura e número de elementos atômicos similares, apresentam uma dinâmica completamente diferente e altamente dependente do mecanismo reacional. [34] A interpretação da dinâmica fica restrita, portanto, não apenas à análise das variáveis globais, mas à identificação das etapas elementares e intermediários da reação que contribuem para a análise completa.

O entendimento das propriedades emergentes nos quais muitas variáveis são tratadas simultaneamente é característica de uma abordagem sistêmica. A Química de Sistemas surgiu como uma tentativa de capturar a complexidade resultante da interação de uma rede de espécies químicas na resolução de problemas como a origem e síntese da vida. [65] Em vez de 
uma abordagem separada por diversos campos, é adotado um tratamento interdisciplinar, gerando assim uma análise mais abrangente e integradora. [66] De fato, redes moleculares têm sido utilizadas no entendimento do mecanismo reacional. [67-69] Sob esta perspectiva, uma taxonomia dos osciladores químicos homogêneos foi proposta por Epstein et al. [70, 71] com a finalidade de se obter um cenário geral do mecanismo reacional oscilatório. $\mathrm{O}$ repertório, composto por intermediários reacionais, catalisadores e substratos orgânicos, é separado por famílias de osciladores que se interconectam entre si, gerando uma rede de espécies moleculares. Essa combinação é capaz de identificar e classificar as possíveis variantes dos osciladores centrais e fornecer uma referência para o desenho de novos osciladores químicos.

A importância do conhecimento dos intermediários de reação e das respectivas etapas elementares de formação e consumo dessas espécies é primordial no desenho de um oscilador químico. Na década de 1970, Field, Körös e Noyes (FKN) combinaram uma abordagem termodinâmica e cinética para propor um mecanismo detalhado da reação BZ e obtiveram um comportamento oscilatório das concentrações das espécies reacionais. [72] Juntamente com avanços da termodinâmica de não-equilíbrio, [73, 74] o mecanismo FKN proveu a evidência necessária de que oscilações químicas era um fenômeno legítimo de estudos. Desde então, o modelo teórico Oregonator, [75] baseado no mecanismo FKN, tem sido utilizado sistematicamente no estudo da formação de padrões espaço-temporais na reação BZ.

Outra evidência da importância do mecanismo reacional foi proposta por Epstein e colaboradores [8] na descrição química da formação das estruturas de Turing. A primeira observação experimental [76] foi publicada aproximadamente 40 anos depois das predições teóricas propostas por Turing. [7] A grande dificuldade de se obter esse tipo de padrão é a necessidade de se encontrar duas espécies com coeficientes de difusão muito diferentes, o que não é um requerimento facilmente obtido em soluções aquosas. A reação Clorito - Iodeto Ácido Malônico (Chlorite - Iodide - Malonic Acid, CIMA) foi uma boa escolha adotada para o estudo da formação das estruturas de Turing, pois o indicador presente no meio reacional liga-se reversivelmente com íons iodeto formando um complexo, e portanto, diminui a difusão efetiva desses íons em até uma ordem de magnitude. [77] Diferentes sistemas reacionais capazes de gerar estruturas de Turing foram propostos utilizando-se de um agente externo na diminuição do coeficiente de difusão aparente de uma espécie em particular. [78]

Em sistemas eletroquímicos, a eletro-oxidação de ácido fórmico tem sido utilizada como sistema modelo no estudo da formação de padrões espaço-temporais. [58-60] A grande 
vantagem reside no fato da oxidação proceder por um mecanismo reacional simples o que permite o processo de modelagem. Neste contexto, diversos mecanismos reacionais ligeiramente diferentes foram propostos, e uma boa congruência com os experimentos tem sido obtida. Nota-se, no entanto, que nestes trabalhos não há um consenso geral da natureza do intermediário ativo. [79-81] A primeira evidência experimental deste intermediário (i.e. formiato duplamente ligado) foi mostrada por Osawa e colaboradores [82-84] durante a eletro-oxidação oscilatória de ácido fórmico sobre platina policristalina acompanhada pela técnica de espectroscopia de infravermelho in situ na configuração de reflexão total atenuada (Surface Enhanced Infrared Absorption Spectroscopy in Attenuated Total Reflection, ATRSEIRAS). Experimentos recentes, ainda realçam a decomposição oxidativa de formiato a $\mathrm{CO}_{2}$ como o intermediário ativo na eletro-oxidação de ácido fórmico. [85-87] O mesmo intermediário também tem sido atribuído a via direta na eletro-oxidação de formaldeído e metanol. [88, 89]

Apesar da presença de alguns intermediários em comum, e uma categorização bem definida das classes dos osciladores e variáveis essenciais, [64] a eletro-oxidação de moléculas orgânicas pequenas procede com uma dinâmica oscilatória baseada em período, amplitude e morfologia muito diferentes. Exemplos incluem as reações de eletro-oxidação de ácido fórmico, formaldeído, metanol, etanol, etileno glicol, propanol e etc. Um levantamento dos osciladores eletrocatalíticos conhecidos envolvendo essa classe específica pode ser encontrado na ref. [90] De forma geral, a variável global tem sido utilizada na caracterização do sistema dinâmico e raramente uma abordagem detalhada do mecanismo molecular foi proposta na descrição do comportamento dinâmico. Diferentemente do observado em osciladores químicos homogêneos, não existe uma taxonomia bem definida para este tipo de osciladores eletrocatalíticos. Assim, a obtenção de informações sobre o mecanismo reacional em regime oscilatório pode trazer uma contribuição importante na construção de um cenário geral do mecanismo. Seguindo esta direção, Varela e colaboradores têm mostrado que a eletro-oxidação em regime oscilatório pode trazer algumas características únicas que contribuem na elucidação de alguns aspectos mecanísticos como, por exemplo: o fenômeno de (sobre)compensação de temperatura durante uma reação superficial; [39] a possibilidade do desacoplamento de vias paralelas; $[61,62]$ e a estimativa direta de parâmetros cinéticos. $[91,92]$

Com base nos argumentos apresentados, foi possível estabelecer algumas diretrizes que guiaram o desenvolvimento desta tese de doutorado. Ênfase foi dada na correlação entre 
os aspectos dinâmicos observados em regime oscilatório com o mecanismo molecular regente. Esta linha de pensamento foi auxiliada pelo avanço em paralelo da eletrocatálise fundamental da eletro-oxidação de moléculas orgânicas pequenas. A seguir, serão estabelecidos os objetivos gerais desta tese, reforçando os principais aspectos que foram explorados.

\subsection{Objetivos desta Tese de Doutorado}

Como observado, a maioria dos trabalhos que envolvem a eletro-oxidação de moléculas orgânicas pequenas esta relacionada com a caracterização da dinâmica do sistema. Existe uma carência de informações sobre a interpretação do mecanismo molecular envolvido no comportamento dinâmico, sobretudo em padrões temporais complexos. Este é usualmente descrito por meio da análise de estabilidade linear e respectiva classificação dos estados estacionários. O conhecimento do mecanismo reacional e propriedades da interface sólido/líquido podem fornecer uma melhor compreensão do fenômeno em si e frequentemente possibilitam uma previsão do comportamento dinâmico. Neste sentido, a presente tese de doutorado visa contribuir no entendimento da eletro-oxidação oscilatória de metanol sobre platina policristalina. Duas frentes de trabalho são apresentadas na extração de informações do mecanismo reacional quando o sistema se encontra suficientemente afastado do equilíbrio termodinâmico.

A primeira parte visa o entendimento do efeito e da identificação da natureza química da deriva (do inglês, drift) [93] encontrado nas séries temporais sob controle galvanostático. A problemática foi abordada por meio de um método empírico de compensação do transiente, utilizando o potencial médio como sonda, e validado via um modelo cinético genérico. A segunda parte consiste na análise do desacoplamento das vias reacionais paralelas de produção de $\mathrm{CO}_{2}$ pela combinação integrada de experimentos, modelagem e simulações numéricas. Acesso aos intermediários de reação foi obtido pelo acoplamento da célula eletroquímica a um espectrômetro de massas, o que possibilitou o estudo do efeito dos ânions perclorato e sultato nos caminhos reacionais paralelos e identificação dos precursores nos picos de $\mathrm{CO}_{2}$ presentes na série temporal.

Esta tese de doutorado é dividida nas seguintes seções. No Capítulo 2, uma introdução da teoria e alguns conceitos do campo de Sistemas Dinâmicos são abordados com a finalidade de facilitar o entendimento dos resultados. O procedimento experimental e de modelagem são 
apresentados nos Capítulos 3 e 4, respectivamente. Em seguida, o Capítulo 5 trata das séries temporais transientes em osciladores eletroquímicos e o Capítulo 6 é referente ao desacoplamento e efeito de ânions na produção de $\mathrm{CO}_{2}$ durante a eletro-oxidação de metanol. Uma conclusão geral é delineada no Capítulo 7, enfatizando a ideia central da tese. Finalmente, o Capítulo 8 corresponde à perspectiva de trabalhos futuros no estudo da formação de padrões espaço temporais auto-organizados em sistemas eletroquímicos. Todas as referências são encontradas no Capítulo 9. 



\section{CApítulo 2}

\section{TEORIA E CONCEITOS}

Dado o linguajar particular do campo dos Sistemas Dinâmicos e sua pouca difusão na comunidade Química, são apresentados neste capítulo alguns aspectos da teoria assim como conceitos fundamentais necessários para o entendimento dos resultados que seguem nos próximos capítulos. 



\subsection{Interpretação Termodinâmica}

A emergência de padrões auto-organizados em sistemas químicos está intimamente relacionada com a exportação de entropia do sistema para as vizinhanças. Necessariamente, o sistema deve ser aberto de forma a permitir a troca de energia e matéria. Assim a mudança de entropia em um intervalo de tempo infinitesimal $d t$ em um sistema aberto pode ser escrita como a combinação de duas partes, [6]

$\mathrm{dS}=\mathrm{d}_{\mathrm{i}} \mathrm{S}+\mathrm{d}_{\mathrm{e}} \mathrm{S}$

em que $d_{i} S$ descreve os processos irreversíveis dentro do sistema o qual deve ser zero no estado de equilíbrio ou positivo como postula a Segunda Lei da Termodinâmica, [94]

$\mathrm{d}_{\mathrm{i}} \mathrm{S} \geq 0$

o termo $d_{e} S$, por sua vez refere-se às trocas de energia e matéria com as vizinhanças e pode assumir sinal positivo ou negativo. Um esquema ilustrativo é representado na Figura 2.1. Em sistemas isolados não há fluxo de entropia, e portanto, $d_{e} S=0$. Neste caso, o sistema tende a aumentar monotonicamente a entropia até um valor máximo, atingindo um estado de equilíbrio termodinâmico. Este aumento da entropia por meio de processos irreversíveis é espontâneo uma vez que o número de microestados disponíveis aumenta a probabilidade do sistema de atingir o estado de equilíbrio. [95]

Por outro lado, Prigogine e colaboradores [1,2] demonstraram que em um sistema aberto, em vez de um estado de equilíbrio, há o alcance de um estado estacionário com produção mínima de entropia. A análise de estabilidade indica que o estado estacionário é estável se o sistema está perto do equilíbrio termodinâmico onde uma aproximação linear é mantida (i.e. relações de reciprocidade de Onsager). Quando o sistema esta longe do equilíbrio termodinâmico, o estado estacionário torna-se instável mediante flutuações e uma coerência tanto no tempo quanto no espaço é encontrada. Neste conjunto de parâmetros, há a formação espontânea de padrões espaço-temporais auto-organizados os quais Prigogine batizou de estruturas dissipativas. $[73,74]$ 
Figura 2.1 - Produção de entropia $d_{i} S$ associada a processos irreversíveis dentro do sistema e a troca de entropia com as vizinhanças $d_{e} S$.

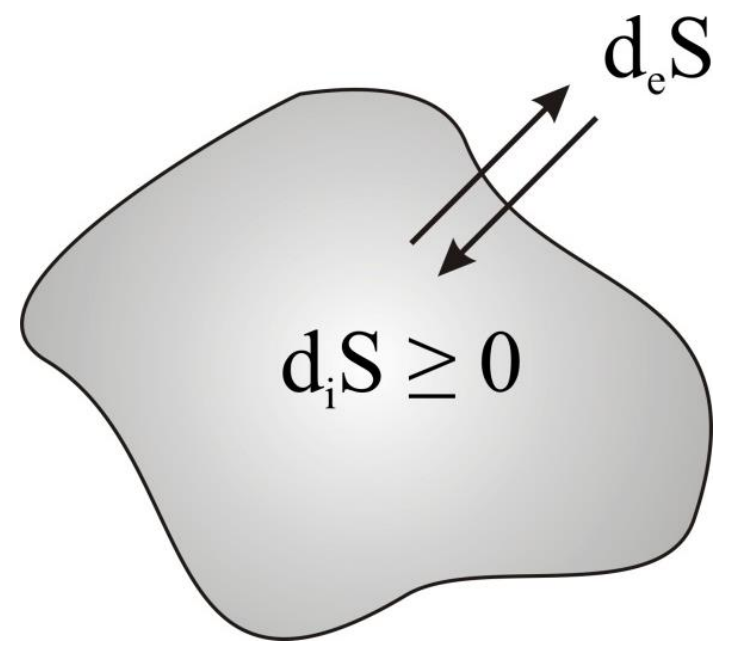

\subsection{Sistemas Dinâmicos}

Instabilidades cinéticas como dinâmica multiestável, excitável e oscilatória são exemplos de padrões temporais auto-organizados. A dinâmica temporal que rege a evolução dessa estruturação espacial pode ser descrita como um conjunto de equações diferenciais ordinárias (EDO) não-lineares e acopladas, [96, 97]

$$
\begin{aligned}
& \frac{\mathrm{d} x_{1}}{\mathrm{dt}}=f_{1}\left(x_{1}, x_{2}, \ldots, x_{\mathrm{n}} ; \mu_{1}, \mu_{2}, \ldots, \mu_{\mathrm{m}}\right) \\
& \frac{\mathrm{d} x_{2}}{\mathrm{dt}}=f_{2}\left(x_{1}, x_{2}, \ldots, x_{\mathrm{n}} ; \mu_{1}, \mu_{2}, \ldots, \mu_{\mathrm{m}}\right) \\
& \vdots \\
& \frac{\mathrm{d} x_{\mathrm{n}}}{\mathrm{dt}}=f_{\mathrm{n}}\left(x_{1}, x_{2}, \ldots, x_{\mathrm{n}} ; \mu_{1}, \mu_{2}, \ldots, \mu_{\mathrm{m}}\right)
\end{aligned}
$$

Na forma vetorial, o conjunto de EDO pode ser escrito como,

$$
\frac{\mathrm{d} \mathbf{x}}{\mathrm{dt}}=\mathbf{f}(\mathbf{x}, \boldsymbol{\mu})
$$

com $\mathbf{x} \in \mathbb{R}^{\mathrm{n}}, \mathrm{t} \in \mathbb{R}^{1}$ e $\boldsymbol{\mu} \in \mathbb{R}^{\mathrm{m}}$. Nesta notação, $\mathbf{x}$ é um vetor referente ao conjunto de variáveis linearmente independentes presentes no sistema, $\boldsymbol{\mu}$ também é um vetor e representa os 
parâmetros que usualmente são mantidos constantes e t refere-se ao tempo. A função f é nãolinear e obedece à algum principio físico. Em sistemas físico-químicos esta função representa a conservação de massa e/ou carga no balanço geral das leis cinéticas de velocidade. O sistema dinâmico não-linear dado na Equação 2.6 é determinístico e diferenciável, e adicionalmente, pode ser considerado autônomo caso f não tenha uma dependência explícita no tempo. [98]

Quando o sistema dinâmico não-linear autônomo $n$-dimensional se encontra no estado estacionário (índice ee) sob um valor constante do parâmetro de controle,

$\mathbf{f}\left(\mathbf{x}_{e \boldsymbol{e}}, \boldsymbol{\mu}\right)=0$

é possível analisar a estabilidade do sistema por meio de uma pequena perturbação $\delta$ em $\mathbf{x}_{e e}$,

$\mathbf{x}=\mathbf{x}_{e e}+\delta \mathbf{x}$

Expandindo em uma série de Taylor,

$\mathbf{f}(\mathbf{x})=\mathbf{f}\left(\mathbf{x}_{e e}\right)+\mathbf{J}\left(\mathbf{x}_{e e}\right)\left(\mathbf{x}-\mathbf{x}_{e e}\right)+\ldots$

em que,

$\mathbf{J}\left(\mathbf{x}_{e e}\right)=\left(\begin{array}{ccc}\left.\frac{\partial f_{1}(\mathbf{x})}{\partial x_{1}}\right|_{\mathbf{x}=\mathbf{x}_{e e}} & \cdots & \left.\frac{\partial f_{1}(\mathbf{x})}{\partial x_{\mathrm{n}}}\right|_{\mathbf{x}=\mathbf{x}_{e e}} \\ \vdots & \ddots & \vdots \\ \left.\frac{\partial f_{\mathrm{n}}(\mathbf{x})}{\partial x_{1}}\right|_{\mathbf{x}=\mathbf{x}_{e e}} & & \left.\frac{\partial f_{\mathrm{n}}(\mathbf{x})}{\partial x_{\mathrm{n}}}\right|_{\mathbf{x}=\mathbf{x}_{e e}}\end{array}\right)$

e desprezando os termos de alta ordem uma vez que há o interesse exclusivamente das soluções perto do estado estacionário, a linearização do sistema dinâmico resulta na forma, 
$\frac{\mathrm{d} \delta \mathbf{x}}{\mathrm{dt}}=\mathbf{J}\left(\mathbf{x}_{e e}\right) \delta \mathbf{x}$

em que J é a matriz Jacobiana. A solução pode ser escrita como uma combinação linear do tipo,

$\delta \mathbf{x}(\mathrm{t})=\mathrm{c}_{1} \mathrm{e}^{\lambda_{1} \mathrm{t}}+\ldots+\mathrm{c}_{\mathrm{n}} \mathrm{e}^{\lambda_{\mathrm{n}} \mathrm{t}}$

Os autovalores $\lambda$ podem ser obtidos através da relação,

$(\mathbf{J}-\lambda \mathbf{I}) \mathbf{C}=0$

em que $\mathbf{C}$ é o vetor dos coeficientes $\mathrm{c}_{i} \operatorname{com} i=1,2, \ldots, n$ e $\mathbf{I}$ a matriz identidade. A análise da estabilidade linear no estado estacionário sob um espaço de fase bidimensional $\mathbf{x} \in \mathbb{R}^{2}$ resulta em uma equação característica quadrática para os autovalores,

$\lambda^{2}+\lambda \operatorname{tr}(\mathbf{J})+\operatorname{det}(\mathbf{J})=0$

com soluções não triviais,

$\lambda_{1,2}=\frac{1}{2}\left[\operatorname{tr} \mathbf{J} \pm \sqrt{(\operatorname{tr} \mathbf{J})^{2}-4(\operatorname{det} \mathbf{J})}\right]$

Nas quais trJ e detJ denotam o traço e o determinante do Jacobiano, respectivamente. A Figura 2.2 exemplifica os diferentes tipos de soluções encontradas na Equação 2.15.

Um caso interessante surge quando existe uma variação do parâmetro de controle, $\mu$. À medida que este parâmetro aumenta, o sistema se afasta da região linear onde os princípios termodinâmicos extremos são válidos, e atinge uma região crítica em que o estado estacionário torna-se instável. Esta transição qualitativa na dinâmica do sistema é denominada de bifurcação. O termo bifurcação é genérico e alguns exemplos específicos serão discutidos nesta seção. Quando a análise de estabilidade linear é realizada com pelo menos duas 
variáveis linearmente independentes o sistema pode ser susceptível a bifurcação de Hopf (i.e. nascimento das oscilações) que é caracterizada por uma solução contendo um par de autovalores com números complexos puramente imaginários, $\operatorname{tr}(\mathbf{J})=0 \mathrm{e} \operatorname{det}(\mathbf{J})>0$. Oscilações autossustentadas são observadas quando $\operatorname{tr}(\mathbf{J})>0$ e $\operatorname{det}(\mathbf{J})>0$, satisfazendo o teorema de Poincaré-Bendixson. [96]

Figura 2.2 - Classificação e representação dos estados estacionários em um sistema de dimensão-2.

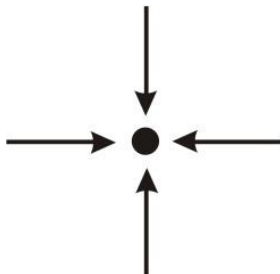

ponto fixo estável ponto fixo instável $\left(-\lambda_{1},-\lambda_{2}\right)$

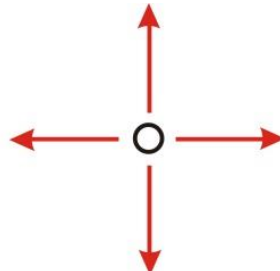

$\left(+\lambda_{1},+\lambda_{2}\right)$

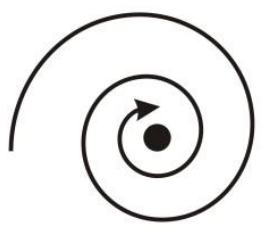

foco estável $(-\sigma \pm \omega \mathrm{i})$

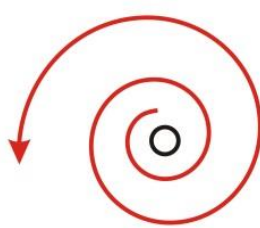

foco instável $(+\sigma \pm \omega \mathrm{i})$

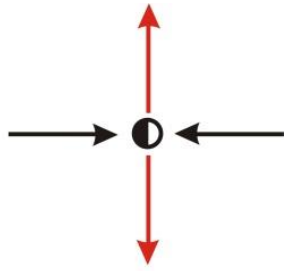

sela $\left(-\lambda_{1},+\lambda_{2}\right)$

A bifurcação de Hopf pode ser classificada como supercrítica ou subcrítica dependendo do estágio inicial do nascimento das oscilações. Se o aumento do parâmetro de controle (ou de bifurcação) resultar no nascimento de oscilações com pequena amplitude e morfologia quasi-senoidal, a categoria da bifurcação é do tipo supercrítico, porém se as oscilações surgirem de maneira súbita, a bifurcação é classificada como subcrítica. A diferenciação entre uma bifurcação de Hopf supercrítica e subcrítica pode ser dada pela presença de histerese quando variado $\mu$.

As trajetórias das oscilações entre as variáveis podem ser expressas como uma projeção no espaço de fase, plano: $x_{1}$ vs. $x_{2}$, que basicamente indica o estado do sistema. Usualmente esta representação temporal condensada é conhecida como ciclo limite. A Figura 2.3 representa um esquema genérico da emergência de uma bifurcação de Hopf subcrítica a partir da variação de um parâmetro de bifurcação. O ciclo limite é um atrator, no sentido de que as trajetórias pertencentes à bacia de atração tendem inexoravelmente para o ciclo. Como observado na Figura 2.3, para pequenos valores de $\mu$ o sistema é estável. O afastamento do equilíbrio resulta na formação de dois atratores coexistentes: um ponto fixo estável e um ciclo limite (círculo azul). Entre os dois atratores reside um ciclo instável (círculo azul pontilhado) que é comprimido com o aumento de $\mu$ até colidir com o ponto fixo estável, tornando-o instável. Subitamente o ciclo limite com grande amplitude aparece como o único atrator no espaço de fase. 
Figura 2.3 - Esquema genérico da emergência da bifurcação de Hopf subcrítica sob uma perturbação externa por um parâmetro de bifurcação, $\mu$.

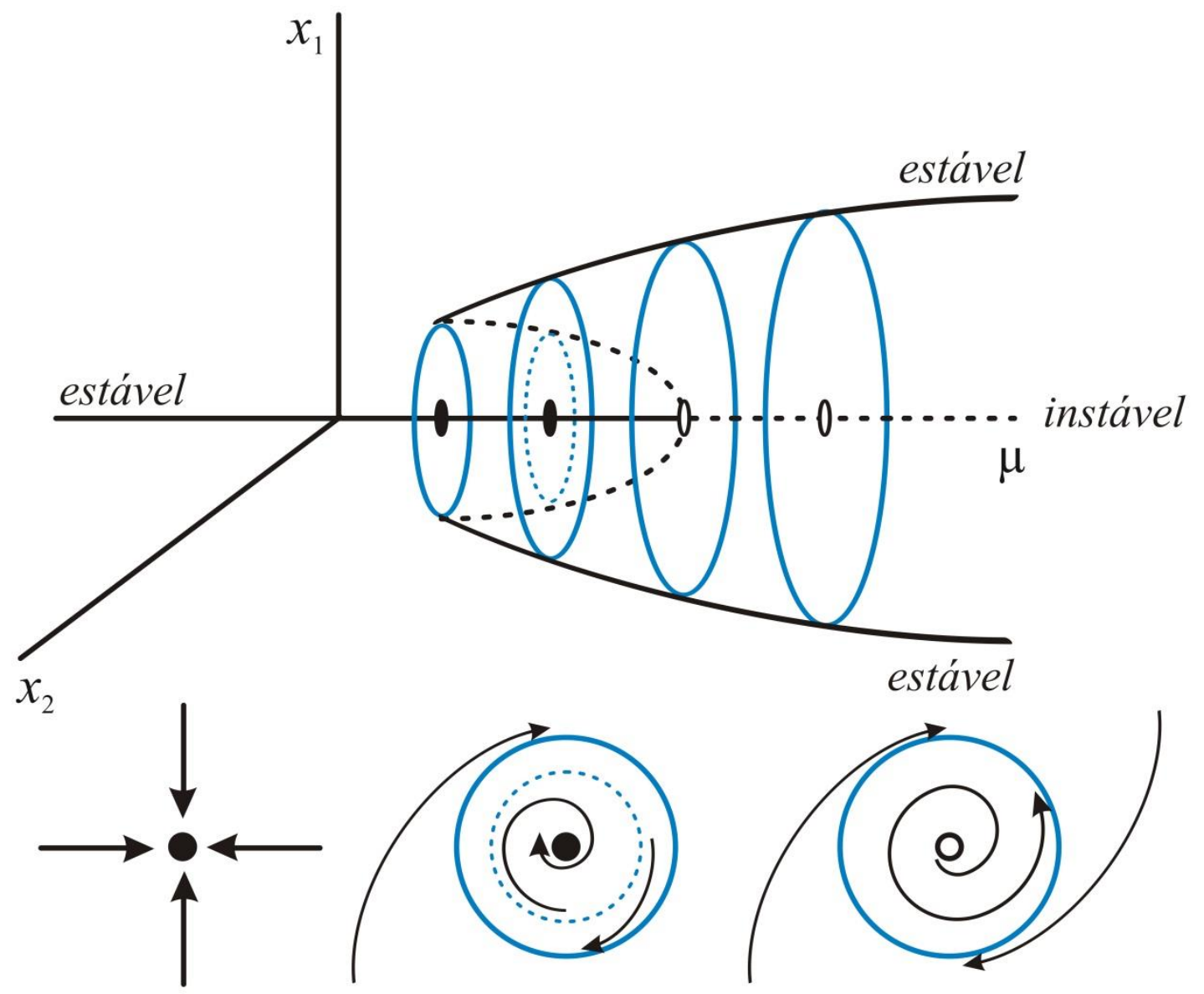

Ritmos periódicos são vastamente encontrados em diversos tipos de sistemas. [35, 36] No entanto, diferentemente de sistemas totalmente conservativos (e.g. oscilações de um pêndulo) que podem ser tratados por um oscilador harmônico, oscilações em sistemas químicos emergem apenas quando este se encontra suficientemente longe do equilíbrio termodinâmico e permite a dissipação em forma de entropia. De forma geral, sistemas químicos apresentam uma alta complexidade devido ao elevado número de variáveis e reações acopladas o que justifica a grande gama de padrões temporais observados experimentalmente. Oscilações de modo misto e caos são exemplos típicos de padrões temporais que requerem ao menos três graus de liberdade, $\mathbf{x} \in \mathbb{R}^{3}$. [96, 97]

Neste contexto, a Figura 2.4 representa as diferentes soluções para o estado estacionário em um sistema de dimensão-3. Note que além dos pontos fixos e focos, há também a interação destes comportamentos dinâmicos com os pontos de sela. Oscilações de 
Figura 2.4 - Classificação e representação dos estados estacionários em um sistema de dimensão-3. Para maiores detalhes ver ref. [99]

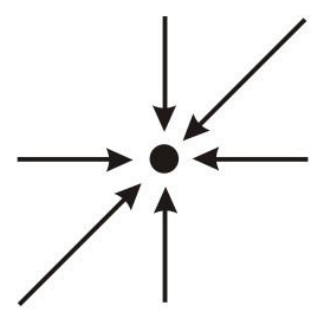

ponto fixo estável ponto fixo instável

$\left(-\lambda_{1},-\lambda_{2},-\lambda_{3}\right)$

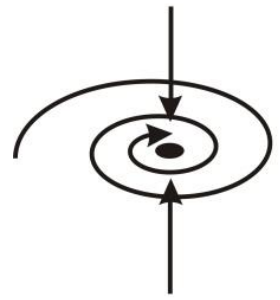

foco estável

$\left(-\lambda_{1},-\sigma \pm \omega \mathrm{i}\right)$

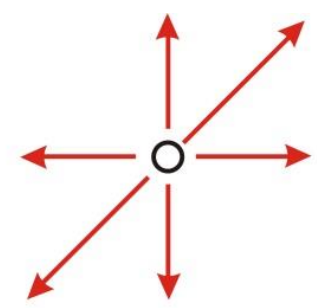

$\left(+\lambda_{1},+\lambda_{2},+\lambda_{3}\right)$

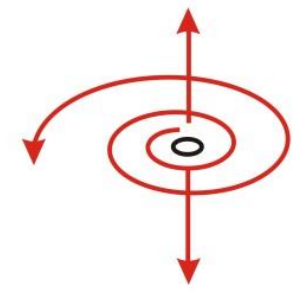

foco instável $\left(+\lambda_{1},+\sigma \pm \omega \mathrm{i}\right)$

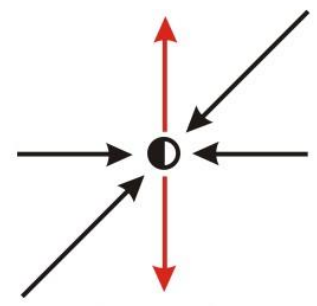

sela-nó tipo I

$\left(+\lambda_{1},-\lambda_{2},-\lambda_{3}\right)$

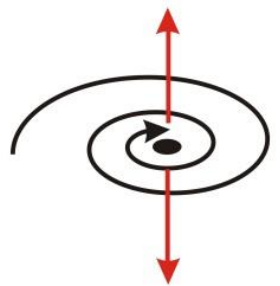

sela-foco tipo I

$\left(+\lambda_{1},-\sigma \pm \omega \mathrm{i}\right)$

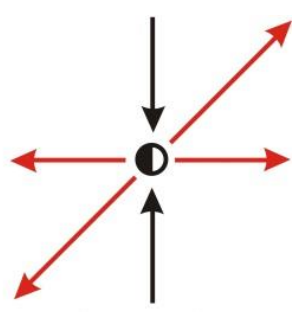

sela-nó tipo II

$\left(-\lambda_{1},+\lambda_{2},+\lambda_{3}\right)$

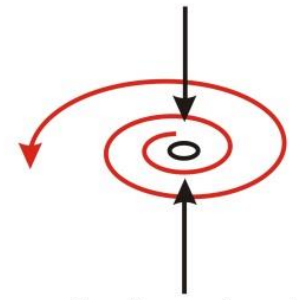

sela-foco tipo II

$\left(-\lambda_{1},+\sigma \pm \omega \mathrm{i}\right)$

Figura 2.5 - Esquema ilustrativo da formação de oscilações de modo misto por meio da interação do ciclo limite com um ponto de sela-nó ou sela-foco do tipo II.

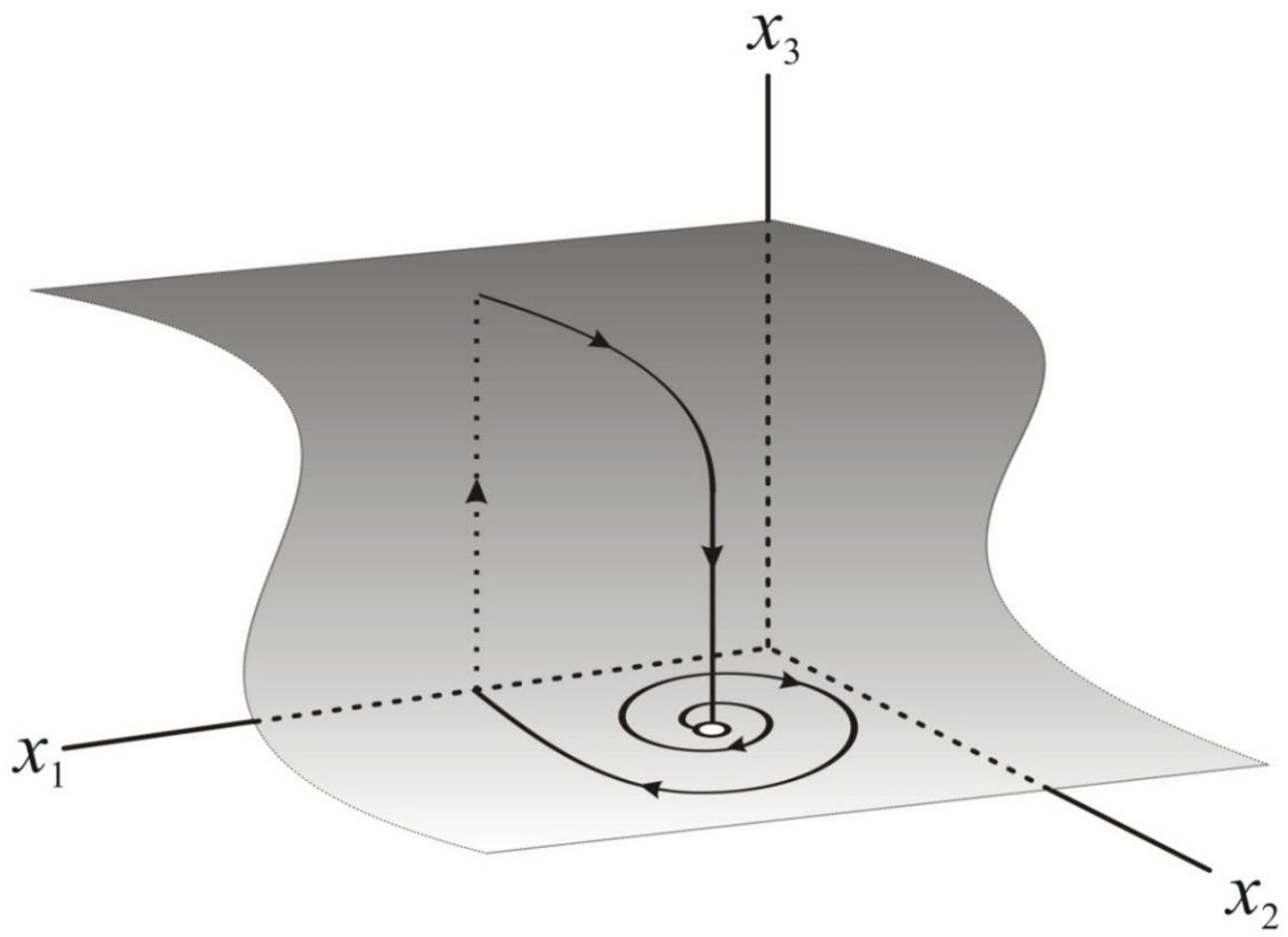


Figura 2.6 - Evolução de diferentes estados dinâmicos I vs. t para o modelo eletroquímico genérico [33] e respectivas projeções no espaço de fase no plano $\theta v s$. $\phi$. Ponto fixo estável $\rightarrow$ ciclo limite $\rightarrow$ órbita homoclínica $\rightarrow$ atrator estranho.
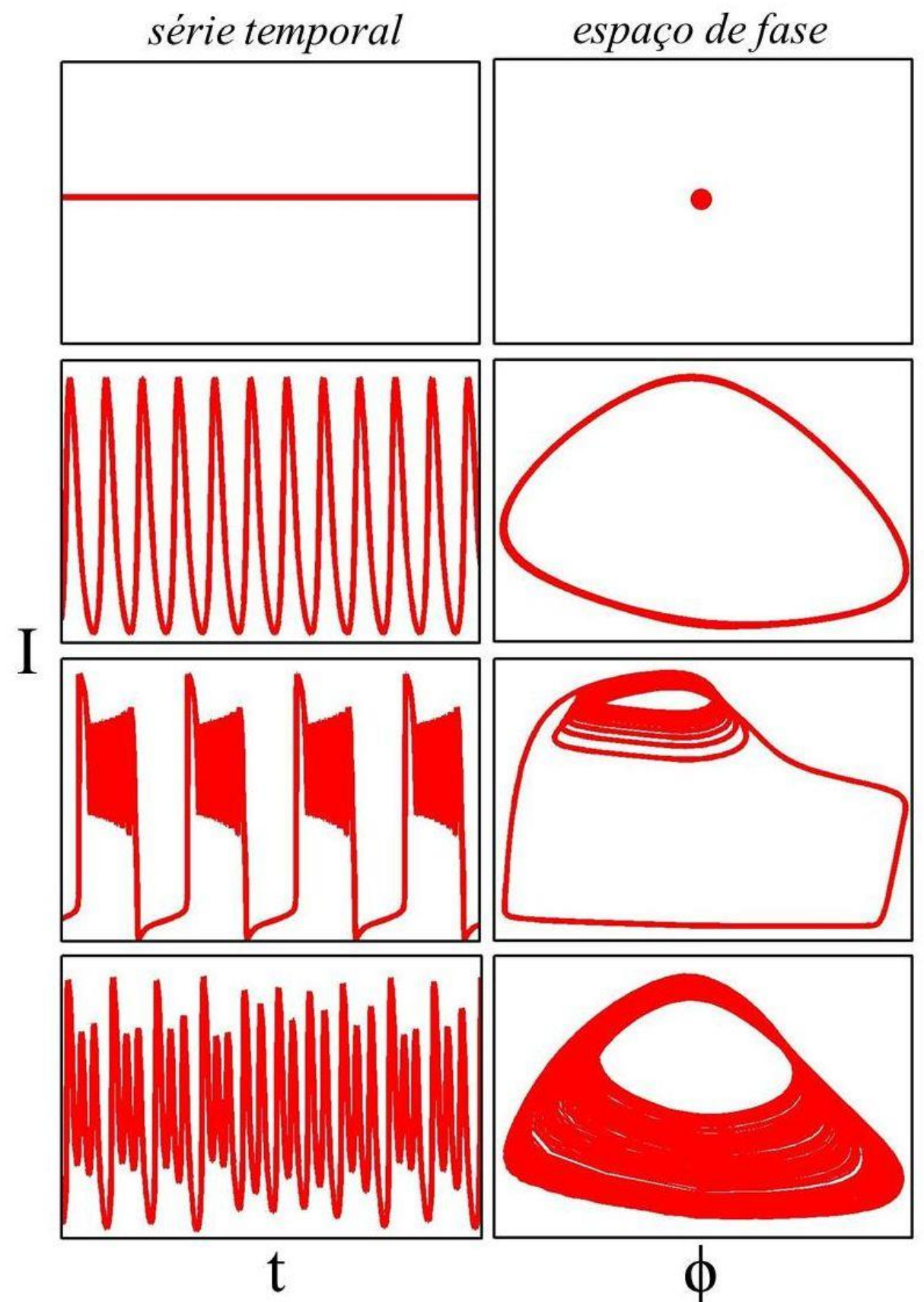

\section{$\theta$}

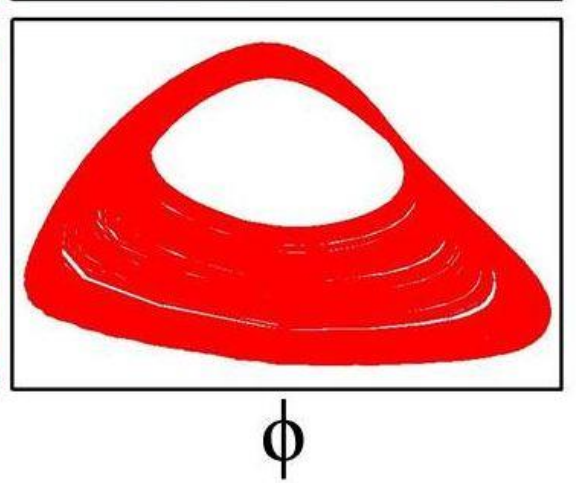

modo misto $\mathrm{L}^{\mathrm{S}}$, caracterizadas pela intercalação entre grandes (L) e pequenas (S) amplitudes, estão associadas a um cenário homoclínico. De acordo com Wiggins [100] existem duas formas de se obter um comportamento homoclínico associado a três autovalores: o ciclo limite atinge domínios de um ponto de sela-nó ou sela-foco em um valor crítico do parâmetro de controle. Sabendo-se que a equação característica resulta em um polinômio de grau três, a solução do sistema pode ser expressa em um plano em forma de "S" (slow manifold). Caso 
essa contração seja intensa, o sistema esta sujeito ao processo conhecido como reinjeção, vide Figura 2.5. Ao se aproximarem do ponto de sela-nó (ou sela-foco), as trajetórias do ciclo limite são atraídas substancialmente para este estado, porém são repulsionadas perpendicularmente à direção de atração, gerando um movimento circular espiralado com o aumento gradual da amplitude. Neste ponto, as trajetórias são reinjetadas na porção superior do plano, iniciando-se novamente o ciclo. As transições entre oscilações de grandes e pequenas amplitudes seguem uma sequência numérica bem definida denominada árvore de Farey, [101] ou de forma mais geral Stern-Brocot. [102] Esta sequência composta por números racionais é capaz de predizer qual o padrão temporal seguinte mediante o conhecimento de um ou mais estados presentes na sequência. De fato, o cenário homoclínico tem sido utilizado na descrição de oscilações de modo misto e caos, [103-105] sendo algumas destas referentes ao sistema eletroquímico. [101, 106, 107]

Caos também pode emergir na presença de pelo menos três graus de liberdade. É definido como um comportamento dinâmico aperiódico em longo prazo observado em um sistema determinístico que exibe alta sensibilidade das condições iniciais. [108] A representação desta série temporal no espaço de fase é conhecida como um atrator estranho. As trajetórias nunca cruzam entre si, formando uma estrutura fractal com dimensão fracionária. Um sumário das séries temporais observadas nessa tese de doutorado e suas respectivas projeções no espaço de fase podem ser visualizados na Figura 2.6.

Por questões de praticidade, diversos tipos de bifurcações, comportamentos dinâmicos e definições formais foram omitidos na presente descrição. Para uma análise mais detalhada que foge do escopo desta tese, recomendam-se as referências [96, 97].

\subsection{Osciladores Eletroquímicos do Tipo HN-NDR}

A maioria dos processos que ocorrem na interface sólido/líquido podem apresentar instabilidades dinâmicas em determinada faixa de parâmetros experimentais. [32-34] Cinética complexa em sistemas eletroquímicos está relacionada à presença de autocatálise no potencial do eletrodo expressa na forma de uma resistência diferencial negativa (Negative Differential Resistance, NDR) na curva estacionária corrente/potencial. [64] Neste sentido, reações eletrocatalíticas são susceptíveis a instabilidades dinâmicas graças à competição por sítios superficiais entre diferentes intermediários de reação e consequente dependência das respectivas isotermas de adsorção em relação ao potencial. [34] 
$\mathrm{Na}$ ausência de outros ciclos de retroalimentação, autocatálise no potencial do eletrodo pode resultar em biestabilidade (i.e. presença de dois estados estáveis para um mesmo conjunto de parâmetros). No entanto, a adição de um ciclo de retroalimentação negativo pode ocasionar o surgimento de oscilações periódicas. Oscilações mistas e caos surgem da criação de um grau de liberdade adicional e, portanto, um aumento da dimensão no espaço de fase. $[96,97]$

A ocorrência espontânea da dinâmica oscilatória em sistemas eletroquímicos pode ser explicada pela facilidade com que uma NDR é formada. A origem deste comportamento temporal foi discutida detalhadamente por Koper. [109] Em sistemas eletroquímicos, instabilidades dinâmicas resultam da interação entre as características na interface eletrodo/solução (impedância faradaica) com adicionais elementos externos do circuito elétrico (capacitância do eletrodo e resistência do eletrólito) e parâmetros de controle (potencial e corrente). O circuito equivalente da célula eletroquímica é mostrado na Figura 2.7 .

Figura 2.7 - Circuito elétrico equivalente de uma interface eletrificada sob controle potenciostático.

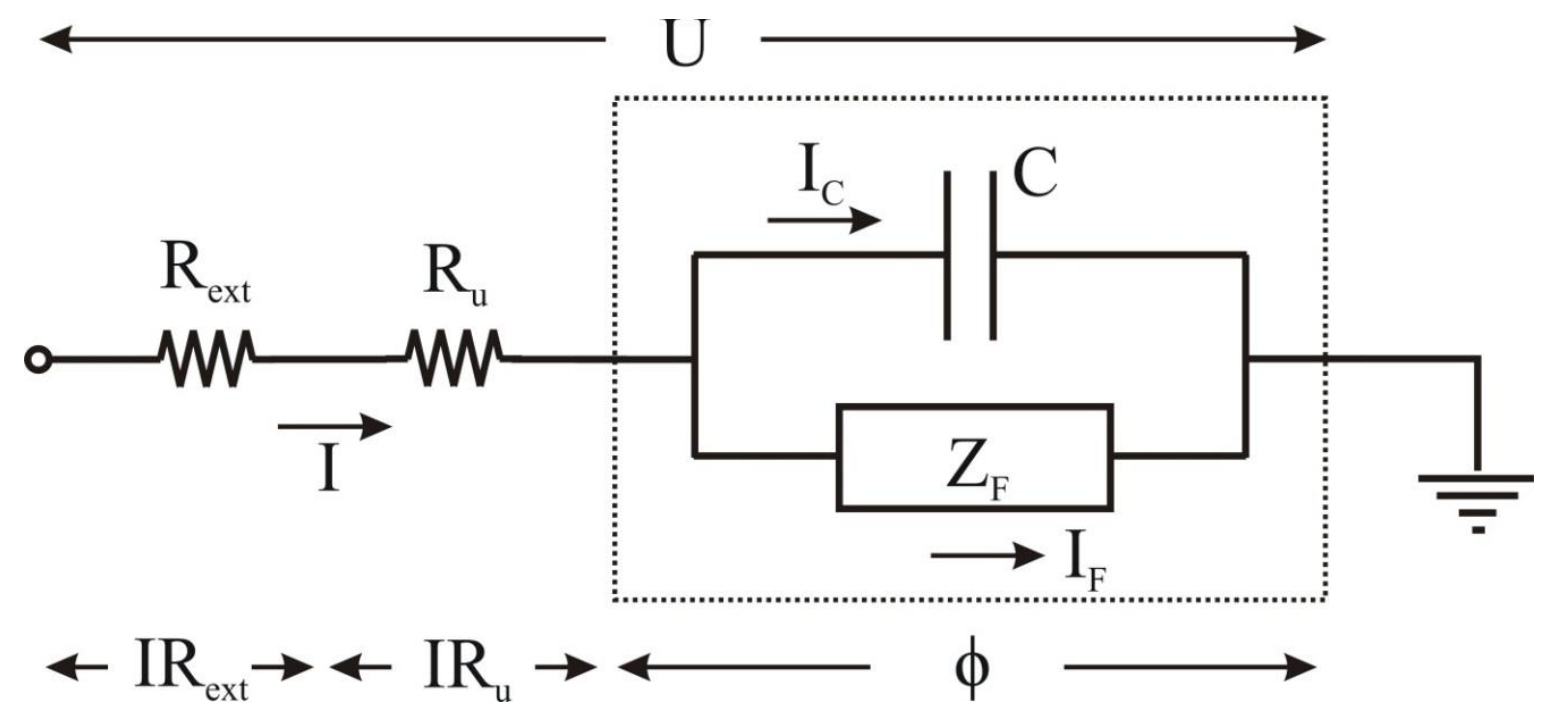

Nesta representação, U é o potencial aplicado, $\phi$ potencial da dupla camada, C capacitância da dupla camada, $Z_{F}$ impedância faradaica, $R_{\text {ext }}$ resistência externa inserida entre o eletrodo de trabalho e o potenciostato, $R_{u}$ resistência não compensada ou queda ôhmica, $I_{c}$ corrente capacitiva, $I_{F}$ corrente faradaica e I corrente total. Aplicando a primeira lei de 
Kirchhoff ou a conservação das cargas no circuito equivalente dado na Figura 2.7, obtém-se que $\mathrm{I}=\mathrm{I}_{\mathrm{c}}+\mathrm{I}_{\mathrm{F}}$, logo:

$\mathrm{CA} \frac{\mathrm{d} \phi}{\mathrm{dt}}=-\mathrm{I}_{\mathrm{F}}(\phi)+\frac{\mathrm{U}-\phi}{\mathrm{R}_{\mathrm{T}}}$

em que $R_{T}$ representa a soma entre $R_{e x t}$ e $R_{u}$.

Na Equação 2.16 observa-se que $\phi$ comporta-se como uma variável em função do tempo. A análise de estabilidade linear referente à evolução do potencial da dupla camada fornece informações importantes no seu comportamento dinâmico e, portanto, do nascimento da NDR. Sob regime de potencial fixo aplicado, o circuito elétrico no estado estacionário é dado por,

$\mathrm{I}_{\mathrm{F}}\left(\phi_{e e}\right)=\frac{\mathrm{U}-\phi_{e e}}{\mathrm{R}_{\mathrm{T}}}$

uma vez que $\mathrm{d} \phi_{e e} / \mathrm{dt}=0$. Assim a análise de estabilidade no estado estacionário $\phi_{e e}$ pode ser obtida através de uma pequena perturbação $\delta \phi$,

$\phi=\phi_{e e}+\delta \phi$

se a perturbação for pequena, a corrente faradaica responde de modo linear de acordo com,

$\mathrm{I}_{\mathrm{F}}(\phi)=\mathrm{I}_{\mathrm{F}}\left(\phi_{e e}+\delta \phi\right)=\mathrm{I}_{\mathrm{F}}\left(\phi_{e e}\right)+\left[\frac{\mathrm{dI}_{\mathrm{F}}(\phi)}{\mathrm{d} \phi}\right]_{\phi=\phi_{e e}} \delta \phi$

Substituindo-se as Equações 2.17, 2.18 e 2.19 em 2.16, é obtida a evolução,

$\mathrm{CA} \frac{\mathrm{d} \delta \phi}{\mathrm{dt}}=-\left(\frac{1}{\mathrm{Z}_{\mathrm{F}}}+\frac{1}{\mathrm{R}_{\mathrm{T}}}\right) \delta \phi$ 
assim, a pequena flutuação aumentará de maneira autocatalítica se $\left(\mathrm{Z}_{\mathrm{F}}^{-1}+\mathrm{R}_{\mathrm{T}}^{-1}\right)<0$. Neste caso, a perda de estabilidade do ponto fixo apenas acontecerá se as duas condições nas Inequações 2.21 são satisfeitas simultaneamente,

$Z_{F}<0 \quad$ e $R_{T}>\left|Z_{F}\right|$

Nota-se claramente a importância da impedância faradaica negativa e a resistência externa conectada em série com o eletrodo de trabalho em regime potenciostático. A interpretação para este resultado é que oscilações de corrente necessitam de uma $\mathrm{R}_{\text {ext }}$, funcionando como um parâmetro de bifurcação. Ademais, para o caso limite,

$I=\lim _{\substack{R_{T} \rightarrow \infty \\ U \rightarrow \infty}} \frac{U-\phi}{R_{T}}$

ou seja, em modo de operação galvanostático as condições estabelecidas pelas Inequações 2.21 são equivalentes.

A origem química para o aparecimento da $\mathrm{Z}_{\mathrm{F}}<0$ está intimamente relacionada com a contribuição faradaica no balanço de carga do circuito equivalente. Considerando a expressão geral de $\mathrm{I}_{\mathrm{F}}$,

$\mathrm{I}_{\mathrm{F}}(\phi)=\operatorname{nFA}(\phi) \mathrm{k}(\phi) \mathrm{c}(\phi)$

neste caso, a impedância faradaica é dada por,

$\mathrm{Z}_{\mathrm{F}}^{-1}=\frac{\mathrm{dI}_{\mathrm{F}}(\phi)}{\mathrm{d} \phi}=\mathrm{nF}\left[\mathrm{kc} \frac{\mathrm{dA}(\phi)}{\mathrm{d} \phi}+\mathrm{Ac} \frac{\mathrm{dk}(\phi)}{\mathrm{d} \phi}+\mathrm{Ak} \frac{\mathrm{dc}(\phi)}{\mathrm{d} \phi}\right]$

onde $\mathrm{n}$ é o número de $e^{-}$transferidos, F constante de Faraday, A área do eletrodo, k constante de velocidade, c concentração superficial do reagente. Pela Equação 2.24, observa-se que a impedância negativa é originada quando pelo menos um item seja satisfeito: (a) $\mathrm{dA}(\phi) / \mathrm{d} \phi<0$, (b) $\mathrm{dk}(\phi) / \mathrm{d} \phi<0$ ou (c) $\mathrm{dc}(\phi) / \mathrm{d} \phi<0$. Exemplos eletroquímicos atendendo os três casos são relatados na literatura. [32-34] 
Em sistemas eletroquímicos a NDR pode se manifestar na curva estacionária de corrente/potencial na forma de "N" ou "S", [64] sendo $\phi$ a variável autocatalítica no primeiro caso e inibidora no último. Em termos de nomenclatura são classificados como sistemas do tipo N-NDR e S-NDR. A partir das similaridades mecanísticas entre as reações de eletrooxidação moléculas orgânicas pequenas, postula-se usualmente que as instabilidades dinâmicas resultantes nesses sistemas pertencem à classe dos osciladores eletroquímicos do tipo HN-NDR. [64] A nomenclatura deve-se à presença de uma NDR em uma curva de polarização em forma de "N" parcialmente escondida (hidden, H) em condições voltamétricas. O termo hidden aparece devido à adsorção de espécies eletroativas em baixos potenciais que bloqueiam o processo reacional, escondendo a NDR. Uma visão geral do comportamento descrito é evidenciada na Figura 2.8 obtido a partir de um modelo genérico para um oscilador eletroquímico do tipo HN-NDR.

Na Figura 2.8 observa-se em (a) a curva estacionária em forma de "N", originando a NDR, (b) a isoterma de adsorção da espécie bloqueante e (c) a curva estacionária resultante em azul da interação entre as curvas em vermelho e preto. Note que experimentalmente em condições estacionárias a região da resistência diferencial negativa aparece com uma inclinação positiva no sistema do tipo HN-NDR, devido ao bloqueio superficial em baixos potenciais.

Considerando as condições necessárias para a perda de estabilidade autocatalítica do estado estacionário por meio da NDR em regime potenciostático e galvanostático, a emergência das oscilações por meio de um oscilador eletroquímico do tipo HN-NDR apenas é alcançada com a inserção de um ciclo de retroalimentação negativo. Este ciclo inclui uma variável inibidora no modelo genérico o que corresponde a inserir um grau de liberdade adicional ao sistema. Neste caso, com no mínimo duas variáveis, a condição de Hopf (i.e. o nascimento de um ciclo limite estável) pode ser alcançada. [96] Na Figura 2.9 é mostrado um esquema generalizado da interação entre os ciclos de retroalimentação positivo e negativo responsáveis pelo nascimento das oscilações durante a eletro-oxidação de moléculas orgânicas pequenas.

Mecanisticamente, os ciclos de retroalimentação envolvidos na dinâmica oscilatória estão relacionados à interação entre as isotermas de adsorção dependentes do potencial das espécies bloqueantes como $\mathrm{CO}_{\mathrm{ad}}$ e $\mathrm{OH}_{\mathrm{ad}}$ que envenenam a reação de fundo. Considere inicialmente que o sistema se encontra sob controle galvanostático e que o potencial do eletrodo $\phi$, sofra uma pequena flutuação para valores ligeiramente positivos. Em resposta a 
Figura 2.8 - Perfis estacionários obtidos a partir do modelo genérico para oscilador eletroquímico do tipo HN-NDR. [33] (a) curva em forma de "N" relativo aos processos faradaicos, (b) isoterma de adsorção da espécie bloqueante e (c) processo global, em azul, resultante da combinação das curvas em vermelho e preto.
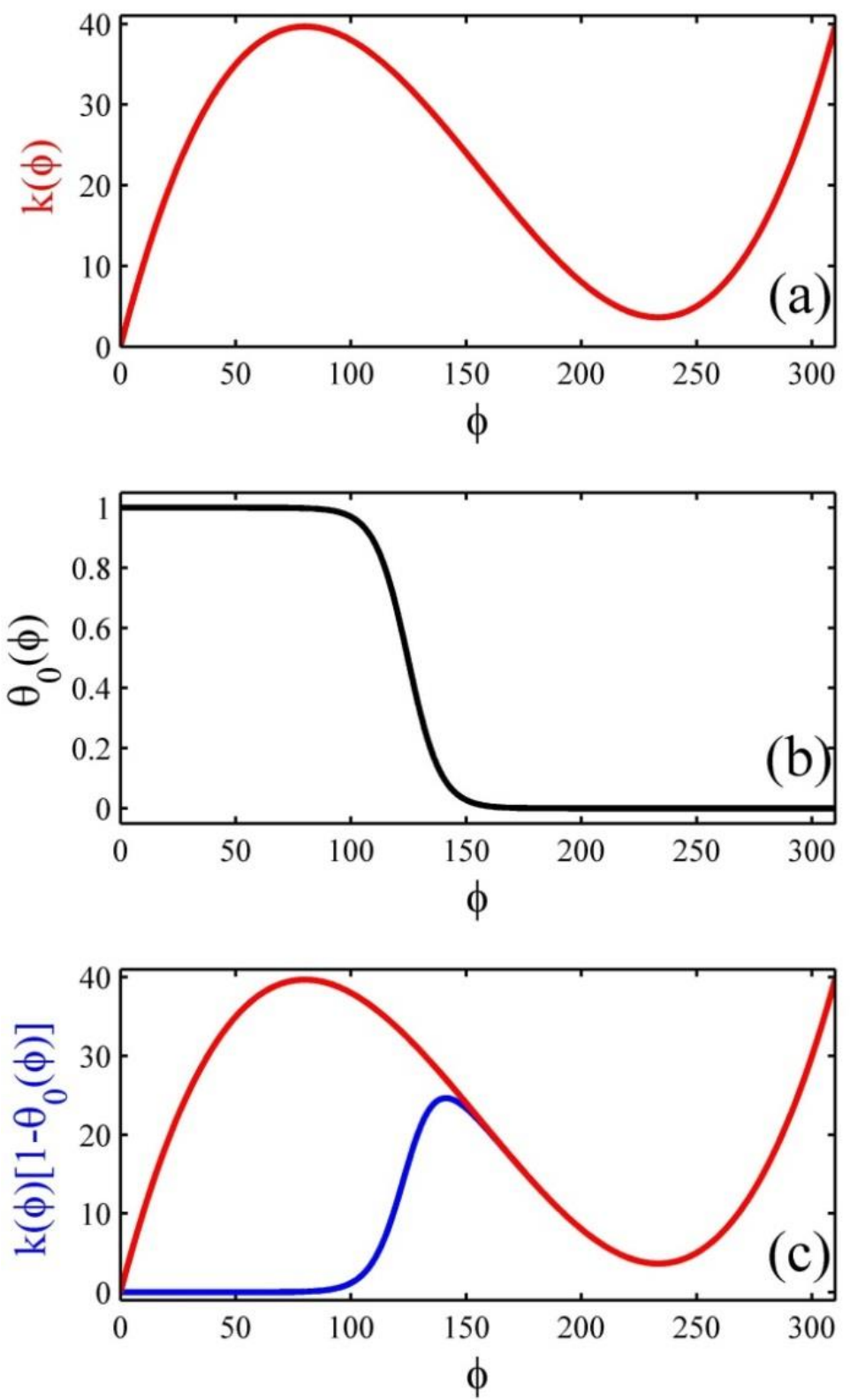

essa flutuação de $\phi$ a cobertura de $\mathrm{OH}_{a d}$ aumenta de maneira autocatalítica, acarretando na diminuição de $\mathrm{I}_{\mathrm{F}}$. Uma vez que a corrente total aplicada é constante, vide Equação 2.16, necessariamente temos que $\mathrm{d} \phi / \mathrm{dt}>0$ e, portanto $U$ deve aumentar (ciclo de retroalimentação positivo). Adotando certo atraso, a variável inibidora $\mathrm{CO}_{\mathrm{ad}}$ reage com $\mathrm{OH}_{\mathrm{ad}}$ via o mecanismo de Langmuir-Hinshelwood de forma a promover o processo de reativação superficial, disponibilizando novamente sítios livres para a etapa autocatalítica o que favorece o aumentode $\mathrm{I}_{\mathrm{F}}$, que por sua vez induz $\mathrm{d} \phi / \mathrm{dt}<0$ e assim uma diminuição dos valores de $\mathrm{U}$ 
(ciclo de retroalimentação negativo). Uma importante característica dos osciladores classificados como HN-NDR é que oscilam tanto em modo galvanostático quanto em modo potenciostático. [64]

Figura 2.9 - Esquema genérico da interação entre os ciclos de retroalimentação positivo e negativo responsáveis pelas oscilações observadas na reação de eletro-oxidação de moléculas orgânicas pequenas.

$$
\begin{gathered}
\text { retroalimentação } \\
\text { positiva }
\end{gathered}
$$
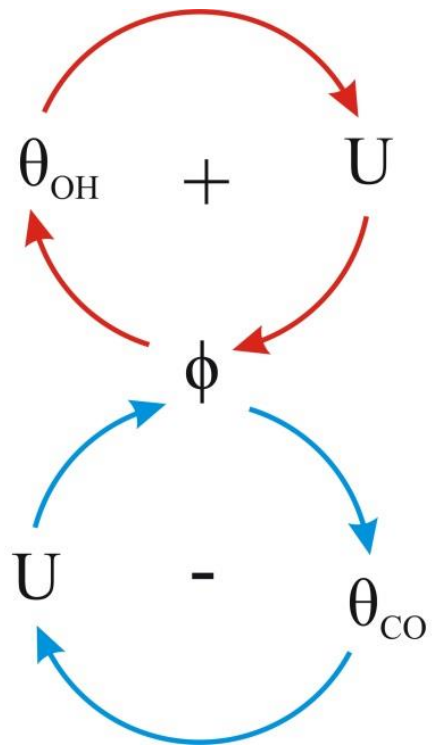

retroalimentação negativa 



\section{Capítulo 3}

\section{PROCEDIMENTO EXPERIMENTAL}

Neste capítulo é abordado o procedimento e todo aparato utilizado nos experimentos envolvidos nessa tese de doutorado. Informações mais detalhadas do setup experimental podem ser encontradas em livros texto apropriados. [110, 111] 



\subsection{Sistema Eletroquímico}

A configuração convencional de três eletrodos em uma célula eletroquímica foi utilizada em nossos experimentos. Para as medidas de controle do drift (Capítulo 5) foi utilizado como eletrodo de trabalho (ET) uma placa de platina policristalina com área real $\mathrm{A}_{\mathrm{R}}=0,3 \mathrm{~cm}^{2}$ e fator de rugosidade em torno de 1,1 estimado em termos da carga de oxidação de uma monocamada de hidrogênio, $210 \mu \mathrm{C} \mathrm{cm}^{-2}$. [112] No caso dos experimentos eletroquímicos acoplados ao espectrômetro de massas (Capítulo 6), o ET foi um depósito de platina sob uma membrana de Teflon (Gore-Tex, PTFE) com espessura por volta de $50 \mathrm{~nm}$, com área real de $A_{R}=3,5 \pm 0,3 \mathrm{~cm}^{2}$ e rugosidade de $8,8 \pm 0,8$ calculada por meio da carga oxidação de uma monocamada de $\mathrm{CO}$ previamente adsorvido, $420 \mu \mathrm{C} \mathrm{cm}^{-2}$. [113] Uma tela de platina platinizada com grande área superficial foi utilizada como contra-eletrodo (CE) com a finalidade de não limitar o fluxo de elétrons no circuito eletroquímico. O eletrodo de reversível de hidrogênio (ERH) preparado como a mesma composição e concentração do eletrólito de suporte foi usado como eletrodo de referência (ER). O esquema genérico do sistema eletroquímico pode ser visualizado na Figura 3.1.

O potencial aplicado pelo potenciostato, $U$ entre o ET e o ER resulta em uma corrente faradaica I que é medida pelo fluxo de carga no CE. Portanto, $\mathrm{U}\left(=\phi+\mathrm{IR}_{\mathrm{u}}\right)$ refere-se à soma entre o potencial da dupla camada $\phi$ mais a queda ôhmica presente na solução $I_{u}$, onde $R_{u}$ é a resistência não-compensada e $R_{c}$ a resistência compensada pelo ER. Todas as soluções foram preparadas com água de alta pureza (sistema Millipore Milli-Q, $18 \mathrm{M} \Omega \mathrm{cm}$ ), $\mathrm{HClO}_{4}$ (Sigma-Aldrich, 70-72\%), $\mathrm{H}_{2} \mathrm{SO}_{4}$ (Merck, 98\%) e $\mathrm{H}_{3} \mathrm{COH}$ (J.T. Baker, grade cromatográfica 99,9\%). As vidrarias e eletrodos foram submetidos a um procedimento de limpeza química: banho em solução alcalina de $\mathrm{KMnO}_{4}$ por 12 horas seguido de um banho de $\mathrm{H}_{2} \mathrm{O}_{2} 30 \%$ em meio ácido por 30 minutos e, por fim, aquecimento até ebulição e enxague consecutivos com água de alta pureza. O eletrólito foi previamente deaerado com $\operatorname{Ar}$ (White Martins $5 \mathrm{~N}$ ) por pelo menos 20 minutos e mantido sobre atmosfera inerte durante todos os experimentos eletroquímicos para evitar a presença de oxigênio molecular dissolvido. O eletrodo de trabalho foi limpo por aquecimento em chama de butano/ar (flame-annealing) e resfriado em atmosfera de argônio, exceto para o depósito de platina em Teflon. Após este procedimento, o eletrodo foi imerso na solução eletrolítica e ciclado entre 0,05 e $1,50 \mathrm{~V} \mathrm{a} 1,00 \mathrm{~V} \mathrm{~s}^{-1}$ até atingir uma estrutura superficial independente do tempo (eletrochemical-annealing). 
Figura 3.1 - Esquema genérico do circuito eletroquímico utilizado. Imagem cortesia de H. Varela.
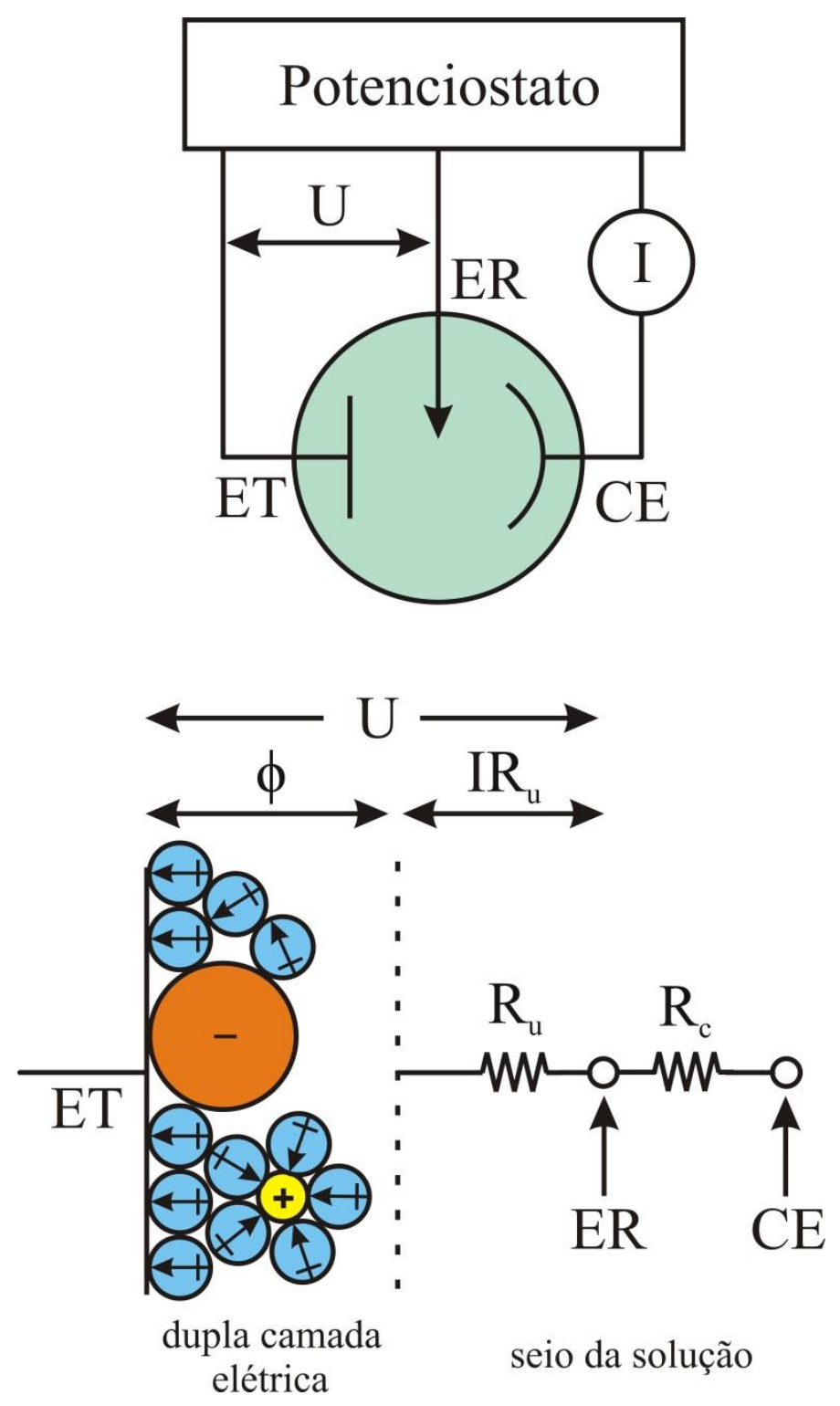

Experimentos galvanodinâmicos lentos foram conduzidos para localizar a região oscilatória (i.e. intervalo de corrente em que aparecem oscilações estáveis de potencial). A densidade de corrente aplicada $\mathrm{j}$ é definida como $\mathrm{I} / \mathrm{A}_{\mathrm{R}}$, no qual I representa a corrente aplicada. Experimentos galvanostáticos foram realizados sob uma frequência de aquisição de $10 \mathrm{~Hz}$. Antes de cada experimento eletroquímico 10 ciclos entre 0,05 e $1,50 \mathrm{~V}$ a $0,10 \mathrm{~V} \mathrm{~s}^{-1}$ foram conduzidos como pré-tratamento para assegurar a reprodutibilidade.

As medidas do Capítulo 5 foram realizadas em temperatura ambiente, $\mathrm{T}=25 \pm 1{ }^{\circ} \mathrm{C} \mathrm{e}$ concentrações: $\left[\mathrm{HClO}_{4}\right]=0,1 \mathrm{~mol} \mathrm{~L}^{-1} \mathrm{e}\left[\mathrm{H}_{3} \mathrm{COH}\right]=0,5 \mathrm{~mol} \mathrm{~L}^{-1}$ enquanto que para as medidas eletroquímicas realizadas no Capítulo 6, utilizou-se um controle de temperatura à $T=20,0 \pm$ 
$0,1{ }^{\circ} \mathrm{C}$ via um termostato (Cole-Parmer Polystat) e concentrações: $\left[\mathrm{HClO}_{4}\right]=\left[\mathrm{H}_{2} \mathrm{SO}_{4}\right]=0,5$ mol L $\mathrm{L}^{-1}$ e $\left[\mathrm{H}_{3} \mathrm{COH}\right]=0,5$ e $2,0 \mathrm{~mol} \mathrm{~L}^{-1}$. O controle eletroquímico foi realizado pelo potentiostato/galvanostato (Autolab/Eco-Chemie, PGSTAT3002) equipado com o módulo SCANGEN, ou gerador analógico da rampa de potencial. Padrões oscilatórios também foram visualmente monitorados pelo osciloscópio (Minipa, MO-1225 20 MHz).

\subsection{Sistema Eletroquímico Acoplado ao Espectrômetro de Massas}

Os produtos voláteis formados durante a eletro-oxidação de metanol foram monitorados por espectrometria de massas eletroquímica diferencial (Differential Electrochemical Mass Spectrometry, DEMS) on line, [114] como mostrado na Figura 3.2.

Figura 3.2 - Representação esquemática da célula espectro-eletroquímica: (1) eletrodo de trabalho (ET), (2) contato de Au do ET, (3) contra eletrodo (CE), (4) eletrodo de referência (ER), (5) fluxo de gás (entrada e saída); e do aparato de DEMS on line: (a) controle eletrônico do espectrômetro de massas, (b) quadrupolo e detector, (c1 e c2) câmara principal e précâmara, (d1 e d2) bomba turbo molecular, (e) bomba mecânica, e (f) conector e válvula do sistema de vácuo. Imagem cortesia de D. A. Cantane [115].

(4)

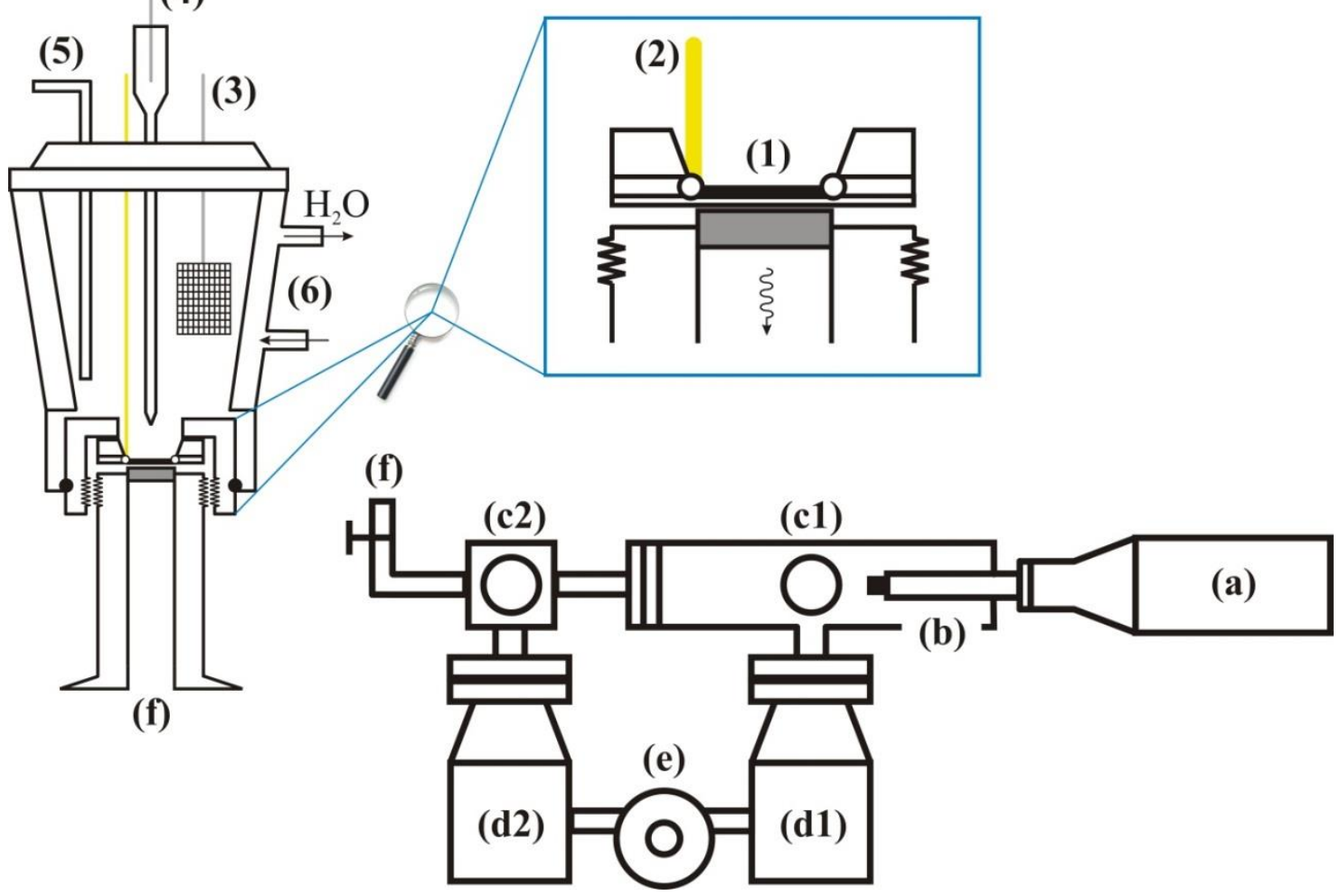


O equipamento de DEMS foi adaptado à célula eletroquímica (interface vácuo/eletrólito separado pela membrana de Teflon) por meio de dois sistemas de câmaras (Vacum, Pfeiffer) com a finalidade de obter uma rápida resolução temporal on line. $\mathrm{O}$ alto vácuo na pré-câmara $\left(4,210^{-5} \mathrm{mbar}\right)$ e a câmara principal $\left(5,510^{-7} \mathrm{mbar}\right)$ foi gerado por duas bombas moleculares do tipo turbo-drag (60000 rpm, Pfeiffer) com uma diferença de pressão de aproximadamente 100 vezes entre ambas. Na câmara principal encontra-se o espectrômetro de massas com um quadrupolo (QMA 200, Pfeiffer) equipado com detector do tipo copo de Faraday e uma multiplicadora de elétrons. Este conjunto foi utilizado como detector e analisador das razões massa/carga $(\mathrm{m} / \mathrm{z}) 44$ para dióxido de carbono e 60 para metilformiato com uma frequência de aquisição de $5,7 \mathrm{~Hz}$.

As correntes iônicas de massa foram normalizadas pelo sinal de massa de $\left[\mathrm{CO}_{2}\right]^{+}$no stripping de CO. Com a finalidade de estimar o tempo de resposta do DEMS, foi utilizado o método proposto por Wolter e Heitbaum. [114] O eletrodo de trabalho foi submetido a um salto de potencial de 0,4 até $-0,1 \mathrm{~V}$ vs. ERH e então novamente para $0,4 \mathrm{~V}$ depois de $30 \mathrm{~s}$, enquanto que o sinal $\mathrm{m} / \mathrm{z}=2\left(\mathrm{H}_{2}\right)$ foi simultaneamente medido. Com o salto para $-0,1 \mathrm{~V}$, hidrogênio molecular é formado e o sinal $\mathrm{m} / \mathrm{z}=2$ acompanha a corrente catódica. O software foi ajustado para ler o sinal de $\mathrm{H}_{2}$ a cada $2 \mathrm{~ms}$. Depois de considerar o atraso da resposta do potenciostato $(0,04 \mathrm{~s})$, os resultados obtidos mostraram um tempo de resposta do sinal $\mathrm{m} / \mathrm{z}$ em torno de 0,03 - 0,05 s. Assim, é seguramente possível aferir que os fragmentos de massas monitorados aqui são detectados $0,10 \mathrm{~s}$ após o sinal eletroquímico. Como o período oscilatório durante a eletro- oxidação de metanol está em torno de 4 - 5 segundos, podemos considerar que a evolução do sinal de massas esta praticamente sincronizada com o sinal eletroquímico.

Após cada experimento galvanostático, o sistema foi deixado em repouso no potencial de circuito aberto (i.e. $\sim 0,33 \mathrm{~V}$ ) durante 1 minuto, tempo suficiente para obtenção de uma boa linha de base da corrente iônica. Ambos os sinais de massa foram monitorados simultaneamente ao longo da medida eletroquímica. O seguinte protocolo foi aplicado antes dos experimentos galvanostáticos: 10 ciclos entre 0,05 e $1,5 \mathrm{~V}$ a $0,10 \mathrm{~V} \mathrm{~s}^{-1}$ (terminando em $0,05 \mathrm{~V}$ ) seguido pelo um salto de corrente para o valor desejado, e após o término da medida, o sistema foi mantido em circuito aberto por 1 minuto. Este procedimento garantiu uma excelente reprodutibilidade e permitiu utilizar uma linha de base para o critério de normalização dos sinais de massa; um procedimento similar foi adotado por Seidel et al. [116] 
Os resultados dos experimentos de DEMS foram obtidos com aproximadamente os mesmos valores de área real, rugosidade e condições experimentais idênticas, com a finalidade de garantir uma discussão semi-quantitativa da detecção dos produtos gasosos. No entanto, o comportamento dinâmico observado foi reproduzido em diferentes eletrodos depositados e também para parâmetros experimentais ligeiramente diferentes. 



\section{CAPÍtulo 4}

\section{MODELAGEM E SIMULAÇÕES NuMÉRICAS}

Neste capítulo é abordado o tratamento teórico utilizado. Cada tópico apresenta o processo de modelagem do sistema e o método de cálculo para as simulações numéricas referentes ao problema em questão. Foi utilizado um computador pessoal Dell Studio 1458 com sistema operacional Windows 7, processador Intel Core i5 - $450 \mathrm{M}$ de $2.50 \mathrm{GHz}$, cache $2 \mathrm{MB}$, memória RAM 6 GB e DDR3 com capacidade de armazenamento de 500 GB. Quando necessário, o cálculo foi paralelizado em quatro núcleos com a finalidade de utilizar a capacidade máxima do processador. As rotinas escritas em ambiente Matlab e Mathematica encontram-se nos Anexos. 



\subsection{Implementação do Drift nas Séries Temporais Eletroquímicas}

Nesta seção será mostrado o modelo utilizado para osciladores eletroquímicos e a respectiva modificação pela inserção de uma deriva (do inglês, drift) como o acúmulo superficial de uma espécie inerte por meio de uma adsorção irreversível. Este tratamento complementa os resultados experimentais apresentados no Capítulo 5. O oscilador genérico eletroquímico do tipo HN-NDR proposto por Krischer, [33] com base em modelos previamente apresentados por Koper e Sluyters, [117] foi utilizado para a realização das simulações numéricas. Basicamente o modelo completo consiste em três equações diferenciais ordinárias (EDO) referentes ao balanço de carga e massa do sistema eletroquímico, vide Equações 4.1 à 4.3.

$$
\begin{aligned}
& \mathrm{C} \frac{\mathrm{d} \phi}{\mathrm{dt}}=-\operatorname{nFck}(\phi)(1-\theta)+\frac{\mathrm{U}-\phi}{\mathrm{AR}_{\mathrm{T}}} \\
& \frac{\mathrm{dc}}{\mathrm{dt}}=-\frac{2}{\delta} \operatorname{ck}(\phi)+\frac{2 \mathrm{D}}{\delta^{2}}\left(\mathrm{c}^{\mathrm{b}}-\mathrm{c}\right) \\
& \frac{\mathrm{d} \theta}{\mathrm{dt}}=\mathrm{k}_{\mathrm{p}}\left[\theta_{0}(\phi)-\theta\right]
\end{aligned}
$$

O modelo descreve a evolução temporal do potencial da dupla camada $\phi$, concentração c e recobrimento superficial $\theta$ da espécie eletroativa. Assume-se um gradiente de concentração superficial linear e uma reação de oxirredução de uma espécie genérica $\mathrm{P}$ com caráter inibidor e isoterma de adsorção $\theta_{0}$ dependente do potencial aplicado. $\mathrm{k}_{\mathrm{p}}$ corresponde $\mathrm{a}$ uma constante de relaxação do recobrimento ao equilíbrio, D coeficiente de difusão, $\delta$ camada difusional de Nernst, $\mathrm{c}^{\mathrm{b}}$ concentração da espécie eletroativa no seio da solução. Utilizando as relações abaixo,

$$
\begin{gathered}
\frac{\mathrm{nF}}{\mathrm{RT}} \phi \rightarrow \phi, \frac{\mathrm{nF}}{\mathrm{RT}} \mathrm{U} \rightarrow \mathrm{U}, \frac{\mathrm{c}}{\mathrm{c}^{\mathrm{b}}} \rightarrow \mathrm{c}, \frac{\delta}{\mathrm{D}} \mathrm{k}(\phi) \rightarrow \mathrm{k}(\phi), \mathrm{k}_{\mathrm{p}} \mathrm{t} \rightarrow \mathrm{t} \\
\varepsilon=\mathrm{k}_{\mathrm{p}} \frac{\mathrm{CRT} \delta}{\mathrm{c}^{\mathrm{b}} \mathrm{n}^{2} \mathrm{~F}^{2} \mathrm{D}}, \mu=\mathrm{k}_{\mathrm{p}} \frac{\delta^{2}}{2 \mathrm{D}}, \rho=\mathrm{R}_{\mathrm{T}} \frac{\mathrm{Ac}^{\mathrm{b}} \mathrm{Dn}^{2} \mathrm{~F}^{2}}{\delta \mathrm{RT}}
\end{gathered}
$$

Krischer [33] obteve o modelo genérico do tipo HN-NDR adimensionalizado sob controle potenciostático, Equações 4.4 à 4.6, 
$\varepsilon \frac{\mathrm{d} \phi}{\mathrm{dt}}=-\operatorname{ck}(\phi)(1-\theta)+\frac{\mathrm{U}-\phi}{\rho}$

$\mu \frac{\mathrm{dc}}{\mathrm{dt}}=-\operatorname{ck}(\phi)(1-\theta)-\mathrm{c}+1$

$\frac{\mathrm{d} \theta}{\mathrm{dt}}=\theta_{0}(\phi)-\theta$

em que

$\mathrm{k}(\phi)=0,00002 \phi^{3}-0,0094 \phi^{2}+1,12 \phi$

$\theta_{0}(\phi)=\frac{1}{\left[1+\exp \left(\frac{\phi-\phi_{0}}{\mathrm{~b}}\right)\right]}$

A Equação 4.8, sugerida por Koper e Sluyters, [117] é derivada de uma isoterma de Langmuir. No entanto, diferentes expressões que imitam o perfil da isoterma podem ser utilizadas. $\mathrm{O}$ conjunto de Equações de 4.4 à 4.8 corresponde aos ciclos de retroalimentação (sistema rápido). A implementação do drift (sistema lento) e da varredura galvanodinâmica negativa (VGN) são dados pelas Equações 4.9 e 4.10, respectivamente,

$f=\exp (-\alpha t)$

$\mathrm{I}=\mathrm{I}_{0}-\beta \mathrm{t}$

em que $\alpha$ corresponde à taxa de decaimento da função $\mathrm{f}$. Neste sentido, o drift representa uma dependência exponencial de decaimento da quantidade de sítios superficiais disponíveis no processo faradaico. A compensação do transiente pela VGN pode ser dada por uma equação de reta onde $\beta$ é o coeficiente angular e $\mathrm{I}_{0}$ a corrente inicial aplicada como o coeficiente linear. A incorporação das Equações 4.9 e 4.10 no modelo genérico sob controle galvanostático resulta em,

$\varepsilon \frac{\mathrm{d} \phi}{\mathrm{dt}}=-\operatorname{ck}(\phi)(\mathrm{f}-\theta)+\mathrm{I}$ 
$\mu \frac{\mathrm{dc}}{\mathrm{dt}}=-\operatorname{ck}(\phi)(\mathrm{f}-\theta)-\mathrm{c}+1$

$\frac{\mathrm{d} \theta}{\mathrm{dt}}=\theta_{0}(\phi)-\theta$

em que

$\theta_{0}(\phi)=\frac{\mathrm{f}}{\left[1+\exp \left(\frac{\phi-\phi_{0}}{\mathrm{~b}}\right)\right]}$

Na Tabela 4.1 são dados os parâmetros e condições iniciais para a integração numérica.

Tabela 4.1 - Parâmetros e condições iniciais para a integração numérica do modelo cinético HN-NDR modificado.

\begin{tabular}{cc}
\hline parâmetros & valores \\
\hline$\varepsilon$ & 0,001 \\
$\mu$ & 50 \\
$\mathrm{~b}$ & 7,12 \\
$\phi_{0}$ & 200 \\
$\mathrm{I}_{0}$ & 0,5 \\
\hline condições iniciais & valores \\
\hline$\phi_{\mathrm{i}}$ & 50 \\
$\mathrm{c}_{\mathrm{i}}$ & 0,2 \\
$\theta_{\mathrm{i}}$ & 0,4
\end{tabular}

O sistema foi integrado numericamente pelo método Runge-Kutta de $4^{\mathrm{a}}$ ordem com passo fixo de 0,01 no software comercialmente disponível Matlab. 


\subsection{Modelagem Mecanística para a Eletro-oxidação de Metanol}

Com o intuito de investigar os caminhos paralelos presentes durante a eletro-oxidação de metanol sobre platina policristalina, um modelo reacional foi proposto. As simulações numéricas utilizando este modelo são apresentadas no Capítulo 6. Figura 4.1 sumariza os principais aspectos, atualmente aceitos, dos caminhos paralelos para a eletro-oxidação de metanol sobre platina. Depois de uma adsorção inicial e desidrogenação parcial, [118, 119] resíduos de metanol adsorvidos podem ser oxidados em rotas paralelas, i.e. vias direta e indireta. [120]

Figura 4.1 - Esquema das etapas reacionais para a eletro-oxidação de metanol utilizadas no modelo. As séries temporais experimentais e calculadas no Capítulo 6 seguem o padrão de cores adotado neste esquema reacional, vermelho: $\mathrm{CO}_{2}$, azul: $\mathrm{HCOOCH}_{3}$ e verde: $\mathrm{HCO}_{\mathrm{ad}}$.

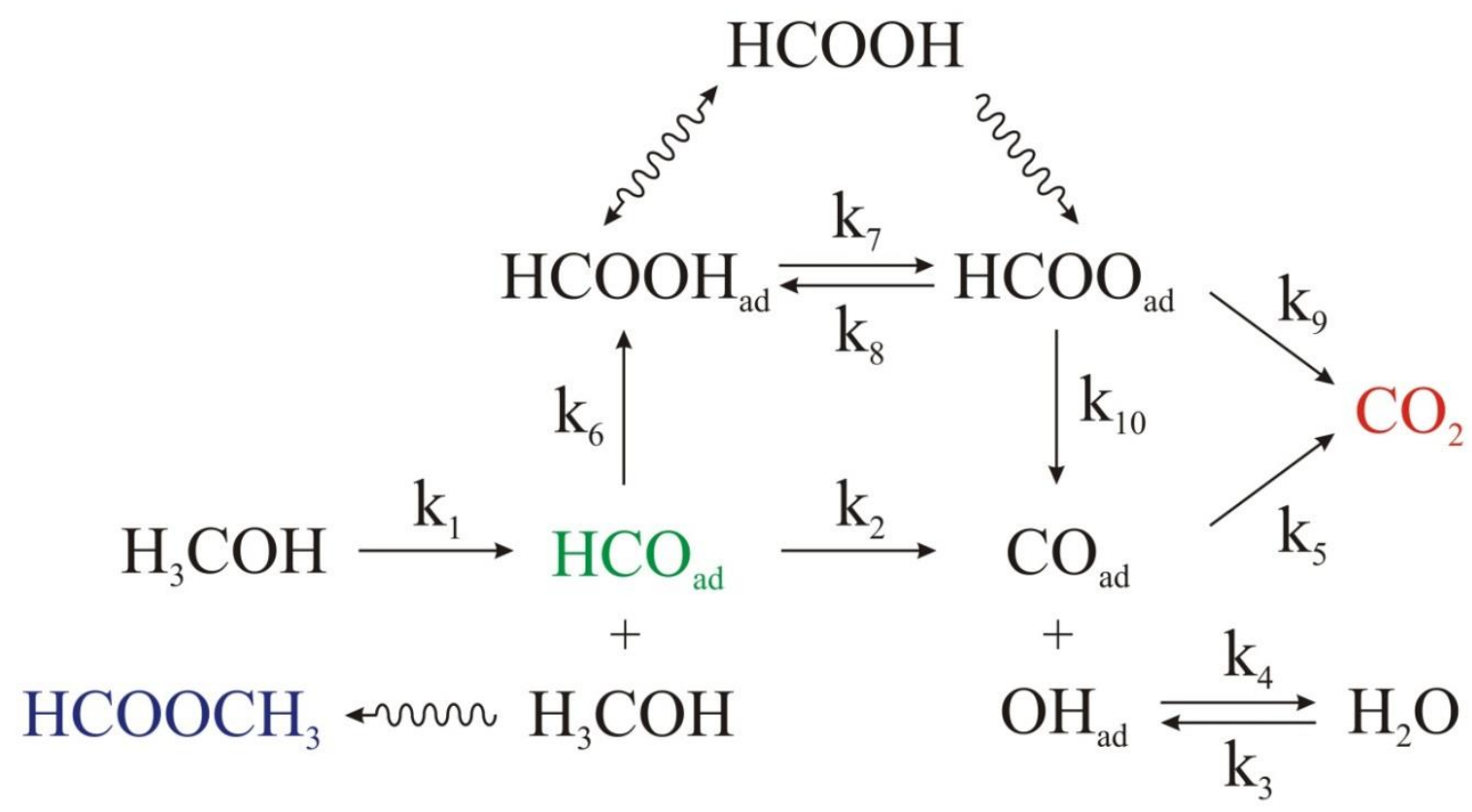

Ácido fórmico adsorvido pode agir como um precursor na formação de formiato adsorvido, um intermediário ativo no caminho direto [85-88] ou pode se dessorver da superfície. $\mathrm{HCOOH}$ dissolvido pode se adsorver novamente gerando formiato em um rápido equilíbrio. Em vez de ser formado em uma reação homogênea entre ácido fórmico e metanol, $[121,122]$ acredita-se que metilformiato é produzido por meio de um ataque nucleofílico da molécula de metanol em um intermediário adsorvido, [123] $\mathrm{HCO}_{\mathrm{ad}}$ na Figura 4.1. Formiato adsorvido em configuração de ponte pode se decompor a $\mathrm{CO}_{2}$ ou a $\mathrm{CO}_{\mathrm{ad}}$ por uma etapa de redução, [124] ambos requerendo um sítio ativo adicional para a quebra da ligação C-H. 
Monóxido de carbono adsorvido é oxidado pela reação com espécies oxigenadas, $(\mathrm{H})_{\mathrm{x}} \mathrm{O}$ onde $\mathrm{x}=0,1$ ou 2 e representa a natureza da espécie oxigenada adsorvida, em altos potenciais via o mecanismo de Langmuir-Hinshelwood (LH). [125]

As etapas que resumem a Figura 4.1 são detalhadas nas reações r1 à r10 como segue:

$$
\begin{aligned}
& \mathrm{H}_{3} \mathrm{COH}+3 * \stackrel{\mathrm{k}_{1}}{\rightarrow} \mathrm{HCO}_{\mathrm{ad}}+3 \mathrm{H}^{+}+3 \mathrm{e}^{-} \\
& \mathrm{HCO}_{\mathrm{ad}} \stackrel{\mathrm{k}_{2}}{\rightarrow} \mathrm{CO}_{\mathrm{ad}}+\mathrm{H}^{+}+\mathrm{e}^{-}+2^{*} \\
& \mathrm{H}_{2} \mathrm{O}+* \stackrel{\mathrm{k}_{3}}{\rightarrow} \mathrm{OH}_{\mathrm{ad}}+\mathrm{H}^{+}+\mathrm{e}^{-} \\
& \mathrm{OH}_{\mathrm{ad}}+\mathrm{H}^{+}+\mathrm{e}^{-} \stackrel{\mathrm{k}_{4}}{\rightarrow} \mathrm{H}_{2} \mathrm{O}+* \\
& \mathrm{CO}_{\mathrm{ad}}+\mathrm{OH}_{\mathrm{ad}} \stackrel{\mathrm{k}_{5}}{\rightarrow} \mathrm{CO}_{2}+\mathrm{H}^{+}+\mathrm{e}^{-}+2^{*} \\
& \mathrm{HCO}_{\mathrm{ad}}+*+\mathrm{H}_{2} \mathrm{O} \stackrel{\mathrm{k}_{6}}{\rightarrow} \mathrm{HCOOH}_{\mathrm{ad}}+\mathrm{H}^{+}+\mathrm{e}^{-}+2^{*} \\
& \mathrm{HCOOH}_{\mathrm{ad}} \stackrel{\mathrm{k}_{7}}{\rightarrow} \mathrm{HCOO}_{\mathrm{ad}}+\mathrm{H}^{+}+\mathrm{e}^{-} \\
& \mathrm{HCOO}_{\mathrm{ad}}+\mathrm{H}^{+}+\mathrm{e}^{-} \stackrel{\mathrm{k}_{8}}{\rightarrow} \mathrm{HCOOH}_{\mathrm{ad}} \\
& \mathrm{HCOO}_{\mathrm{ad}}+* \stackrel{\mathrm{k}_{9}}{\rightarrow} \mathrm{CO}_{2}+\mathrm{H}^{+}+\mathrm{e}^{-}+3^{*} \\
& \mathrm{HCOO}_{\mathrm{ad}}+*+\mathrm{H}^{+}+\mathrm{e}^{-} \stackrel{\mathrm{k}_{10}}{\rightarrow} \mathrm{CO}_{\mathrm{ad}}+\mathrm{H}_{2} \mathrm{O}+2^{*}
\end{aligned}
$$

As etapas elementares foram traduzidas em um modelo matemático consistindo em seis equações diferenciais ordinárias levando em conta a evolução temporal de $\mathrm{HCO}_{\mathrm{ad}}, \mathrm{OH}_{\mathrm{ad}}$, $\mathrm{CO}_{\mathrm{ad}}, \mathrm{HCOOH}_{\mathrm{ad}}, \mathrm{HCOO}_{\mathrm{ad}}$, e o potencial da dupla camada $\phi$. As variáveis foram escritas como $x_{\mathrm{n}}$ de acordo com: $x_{2}=\theta_{\mathrm{HCO}}, x_{3}=\theta_{\mathrm{OH}}, x_{4}=\theta_{\mathrm{CO}}, x_{5}=\theta_{\mathrm{HCOOH}}$, e $x_{6}=\theta_{\mathrm{HCOO}}$. O termo $\mathrm{j}$ representa a corrente total aplicada, $x_{\mathrm{e}}=\exp (\omega \phi)$ a componente elétrica para as reações faradaicas e $\omega$ o coeficiente de transferência. Os sítios livres superficiais são denotados como $x_{1}=1-3 x_{2}-x_{3}-x_{4}-2 x_{5}-2 x_{6}$. As velocidades das reações são:

$$
\begin{aligned}
& v_{1}=\mathrm{k}_{1} x_{1}^{2} x_{\mathrm{e}} \\
& v_{2}=\mathrm{k}_{2} x_{2} x_{\mathrm{e}} \\
& v_{3}=\mathrm{k}_{3} x_{1} x_{\mathrm{e}} \\
& v_{4}=\mathrm{k}_{4} x_{3} x_{\mathrm{e}}^{-1} \\
& v_{5}=\mathrm{k}_{5} x_{3} x_{4} x_{\mathrm{e}}
\end{aligned}
$$




$$
\begin{aligned}
& v_{6}=\mathrm{k}_{6} x_{1} x_{2} x_{\mathrm{e}} \\
& v_{7}=\mathrm{k}_{7} x_{5} x_{\mathrm{e}} \\
& v_{8}=\mathrm{k}_{8} x_{6} x_{\mathrm{e}}^{-1} \\
& v_{9}=\mathrm{k}_{9} x_{1} x_{6} x_{\mathrm{e}} \\
& v_{10}=\mathrm{k}_{10} x_{1} x_{6} x_{\mathrm{e}}^{-1}
\end{aligned}
$$

O uso de dois sítios livres de platina na Equação 4.15 segue a aproximação adotada na referência. [126] Com a finalidade de simplificar o modelo, também foi mantido $x_{\mathrm{e}}$ como uma função independente do número de elétrons produzidos em cada etapa elementar. O conjunto de EDO adimensionalizado utilizado nas simulações é dado nas Equações 4.25 à 4.30,

$$
\begin{aligned}
& \frac{\mathrm{d} x_{2}}{\mathrm{dt}}=v_{1}-v_{2}-v_{6} \\
& \frac{\mathrm{d} x_{3}}{\mathrm{dt}}=v_{3}-v_{4}-v_{5} \\
& \frac{\mathrm{d} x_{4}}{\mathrm{dt}}=v_{2}-v_{5}+v_{10} \\
& \frac{\mathrm{d} x_{5}}{\mathrm{dt}}=v_{6}-v_{7}+v_{8} \\
& \frac{\mathrm{d} x_{6}}{\mathrm{dt}}=v_{7}-v_{8}-v_{9}-v_{10} \\
& \frac{\mathrm{d} \phi}{\mathrm{dt}}=\mathrm{j}-v_{\mathrm{F}}
\end{aligned}
$$

com:

$$
v_{\mathrm{F}}=3 v_{1}+v_{2}+v_{3}-v_{4}+v_{5}+v_{6}+v_{7}-v_{8}+v_{9}-v_{10}
$$

As seis equações diferenciais ordinárias não-lineares acopladas foram integradas numericamente utilizando a ferramenta NDSolve do software Mathematica. Esta ferramenta utiliza-se de um conjunto de métodos de integração numérica com passo variável. Na Tabela 4.2 são dados os parâmetros e condições iniciais para o cálculo. 
Tabela 4.2 - Parâmetros e condições iniciais para a integração numérica do modelo cinético da eletro-oxidação de metanol.

\begin{tabular}{cc}
\hline parâmetros & valores \\
\hline $\mathrm{k}_{1}$ & 6 \\
$\mathrm{k}_{2}$ & 5 \\
$\mathrm{k}_{3}$ & 1 \\
$\mathrm{k}_{4}$ & 4 \\
$\mathrm{k}_{5}$ & 0,079 \\
$\mathrm{k}_{6}$ & 50 \\
$\mathrm{k}_{7}$ & 600 \\
$\mathrm{k}_{8}$ & 30 \\
$\mathrm{k}_{9}$ & 300 \\
$\mathrm{k}_{10}$ & 0,1 \\
$\omega$ & 15 \\
$\mathrm{j}$ & 1 \\
\hline condiçôes iniciais & valores \\
\hline$x_{r, \mathrm{i}}$ com $r=1, \ldots, 6$ & 0 \\
$\phi_{\mathrm{i}}$ & 0 \\
\hline &
\end{tabular}





\title{
CAPÍtulo 5
}

\section{ESTABILIZAÇÃO DE SÉRIES TEMPORAIS TRANSIENTES ELETROQUÍMICAS}

\begin{abstract}
Neste capítulo é investigada a identificação da natureza e efeito do drift em séries temporais não-estacionárias observadas experimentalmente em ambiente eletroquímico. Uma abordagem mecanística de caráter universal foi proposta para o acoplamento entre os sistemas de escalas de tempo lento e rápido na eletro-oxidação de moléculas orgânicas pequenas e também implementada em um modelo genérico. Os resultados experimentais foram publicados nos seguintes periódicos: R. Nagao et al. J. Phys. Chem. C 2010, 114, 22262 22268 e M. F. Cabral et al. Phys. Chem. Chem. Phys. 2013, 15, 1437 - 1442.
\end{abstract}





\subsection{Introdução}

Comportamento oscilatório em reatores químicos operados em batelada é caracterizado por uma dinâmica transiente, a qual reflete a diminuição da energia livre global pelo consumo de reagentes, direcionando o sistema para o equilíbrio termodinâmico, o atrator final em sistemas fechados. [127] Em sistemas abertos, o estado estacionário é mantido com alimentação contínua de reagentes no reservatório reacional e os produtos da reação são constantemente removidos de tal forma que o volume do reator permaneça constante. Sob estas condições, a entropia produzida devido aos processos irreversíveis das reações é exportada, permitindo a emergência espontânea de padrões temporais complexos. Tais estudos são usualmente conduzidos em um reator tanque perfeitamente agitado. [128-131]

Esta descrição qualitativa é também aplicada em reações químicas que ocorrem na interface sólido/líquido eletrificada. Sistemas eletroquímicos são considerados sistemas abertos no qual o volume de controle em torno da interface sólido/líquido é conectado com reservatórios inesgotáveis de reagente. Do lado do eletrodo, o sistema é aberto ao fluxo de elétrons, enquanto que do outro lado o mesmo está em contato com o seio da solução o qual permanece aproximadamente inalterado frente ao consumo de reagentes e formação de produtos. [132, 133] Ambos os modos de operação, potenciostático e galvanostático podem manter a emergência de oscilações do tipo harmônicas, relaxação, modo misto e caos. [56, 83, 89, 101, 134-143]

Um problema importante quando se trata das séries temporais experimentais é o fato que ela evolui com o tempo, apesar de todos os parâmetros controláveis serem mantidos constantes. Estes sistemas podem ser descritos como consistindo de dois ritmos acoplados: o central com escala de tempo rápida, referente às oscilações observadas e um termo de evolução lenta de longo prazo ou drift [144] que conduz o sistema central através de diferentes regiões de parâmetros. Como consequência da componente de variação lenta, a análise do comportamento dinâmico é restrita a janelas temporais consideravelmente pequenas.

Apesar da vasta literatura sobre o controle da dinâmica caótica [145-148] e estabilização de pontos fixos instáveis por meio de técnicas de controle de retroalimentação, [149-151] o estudo da compensação da variação em longo prazo na estabilização de séries temporais experimentais iniciou-se apenas recentemente. [152, 153] Neste capítulo, é discutida a introdução de um procedimento empírico de estabilização de séries temporais 
oscilatórias não-estacionárias em um experimento eletroquímico e a respectiva correlação com o drift. Oscilações foram conduzidas em controle galvanostático e os padrões temporais periódicos (simples e de modo misto) foram estabilizados individualmente por meio de uma varredura galvanodinâmica negativa (VGN). O procedimento é exemplificado para a eletrooxidação de metanol sobre platina, mas a estratégia é sugerida para ser de natureza geral e facilmente estendida para outros sistemas comparáveis.

\subsection{Objetivos}

Considerando a problemática do efeito do drift nas séries temporais experimentais, os objetivos específicos deste capítulo foram definidos como:

- Identificação do efeito e natureza química do drift durante as oscilações de potencial sob controle galvanostático;

- Introdução da varredura galvanodinâmica negativa na estabilização da série temporal transiente;

- Validação do método empírico proposto utilizando um modelo cinético genérico do tipo HN-NDR;

As séries temporais transientes serão estudadas durante a eletro-oxidação de metanol em platina policristalina. O drift será monitorado pela evolução temporal do potencial médio e a estabilização das oscilações controlada pela aplicação de diferentes taxas da VGN. Um modelo genérico do tipo HN-NDR com a inserção do sistema lento será utilizado para reproduzir o efeito do método empírico de estabilização. A ideia central consiste em compreender o fenômeno do drift usualmente encontrado em séries temporais experimentais.

\subsection{Resultados}

\subsubsection{Resultados Experimentais}

Figura 5.1 mostra uma visão geral do sistema experimental: curvas em preto representam voltametrias cíclicas conduzidas a dU/dt $=0,05 \mathrm{~V} \mathrm{~s}^{-1}$ entre 0,05 até $1,50 \mathrm{~V}$ em (a) 
solução aquosa de ácido perclórico $0,1 \mathrm{~mol} \mathrm{~L}^{-1}$ e (b) depois da adição de metanol com concentração final de $0,5 \mathrm{~mol} \mathrm{~L}^{-1}$. Em ambos os casos, os perfis voltamétricos revelam a qualidade da superfície e do setup experimental, tão bem quanto a limpeza do sistema. Detalhes dos perfis voltamétricos para platina policristalina em ácido perclórico [154] e na presença de metanol $[155,156]$ são descritos na literatura. O sistema $\mathrm{Pt} \mid \mathrm{HClO}_{4}, \mathrm{H}_{3} \mathrm{COH}$ foi selecionado porque exibe diferentes padrões temporais como oscilações quasi-harmônicas e de modo misto na mesma série temporal.

Figura 5.1 - (a) Voltametria cíclica conduzida a dU/dt $=0,05 \mathrm{~V} \mathrm{~s}^{-1}$ (linha preta) para platina policristalina em $\left[\mathrm{HClO}_{4}\right]=0,1 \mathrm{~mol} \mathrm{~L}^{-1}$ como eletrólito de suporte e (b) contendo $0,5 \mathrm{~mol} \mathrm{~L}{ }^{-1}$ de $\mathrm{H}_{3} \mathrm{COH}$. Varredura galvanodinâmica a $\mathrm{dj} / \mathrm{dt}=3,32 \mu \mathrm{A} \mathrm{cm} \mathrm{cm}^{-2} \mathrm{~s}^{-1}$ (linha vermelha) e sua região expandida para a mesma composição dada em (b).

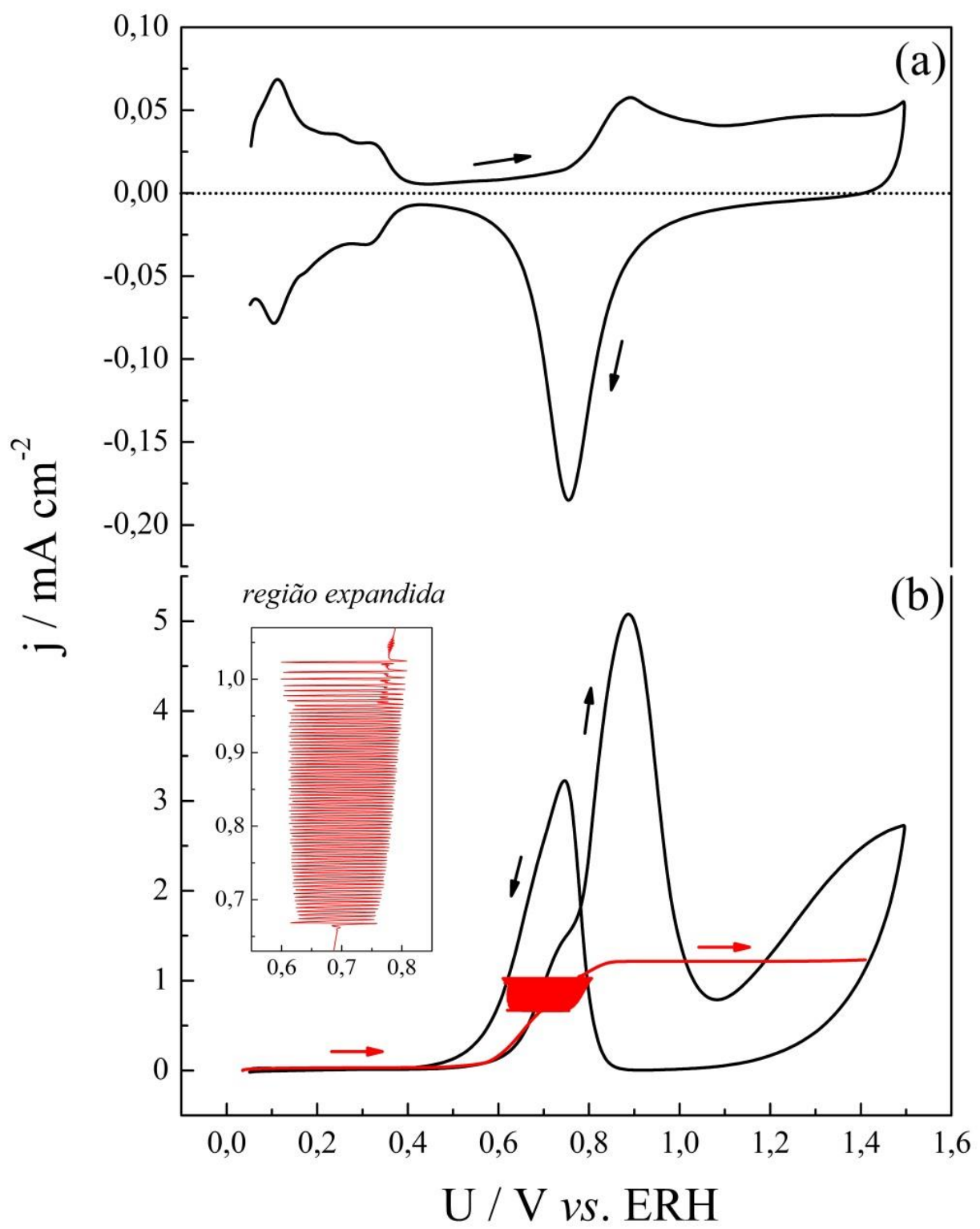


Com o intuito de investigar a região de instabilidade em que oscilações de potencial emergem, uma varredura galvanodinâmica lenta a $\mathrm{dj} / \mathrm{dt}=3,32 \mu \mathrm{A} \mathrm{cm}{ }^{-2}$ foi realizada sob condições idênticas ao apresentadas para o voltamograma cíclico na presença de metanol; resultados são mostrados na curva em vermelho, Figura 5.1(b). Note que em baixos potenciais, a curva galvanodinâmica coincide aproximadamente com a curva voltamétrica até cerca de $0,70 \mathrm{~V}$, onde o estado estacionário perde sua estabilidade via uma bifurcação de Hopf subcrítica, equivalente ao nascimento abrupto das oscilações.

Seguindo o aumento da corrente, oscilações tornam-se menos harmônicas e com maior amplitude, terminando com oscilações de modo misto no limite superior da região oscilatória. Em correntes maiores, o ciclo limite colide com um ponto de sela-nó referente ao ramo de desprendimento de oxigênio, e por fim, as oscilações são extintas. Na Figura 5.1(b) esta transição é dada pela uma descontinuidade de um salto abrupto para altos potenciais. A Figura 5.2 mostra um exemplo de uma série temporal oscilatória do potencial obtida sob condições galvanostáticas a $\mathrm{j}=1,00 \mathrm{~mA} \mathrm{~cm}^{-2}$.

Figura 5.2 - Série temporal obtida durante a eletro-oxidação de metanol a j=1,00 mA cm${ }^{-2}$. A seguinte sequência espontaneamente se desenvolve: nascimento das oscilações harmônicas por meio de um estado estacionário (ee), transição para oscilações de modo misto, e a morte das oscilações em torno de 371 segundos. Eletrólito: $\left[\mathrm{HClO}_{4}\right]=0,1 \mathrm{~mol} \mathrm{~L}^{-1}$ e $\left[\mathrm{H}_{3} \mathrm{COH}\right]=0,5$ $\mathrm{mol} \mathrm{L}{ }^{-1} . \mathrm{T}=25 \pm 1^{\circ} \mathrm{C}$.

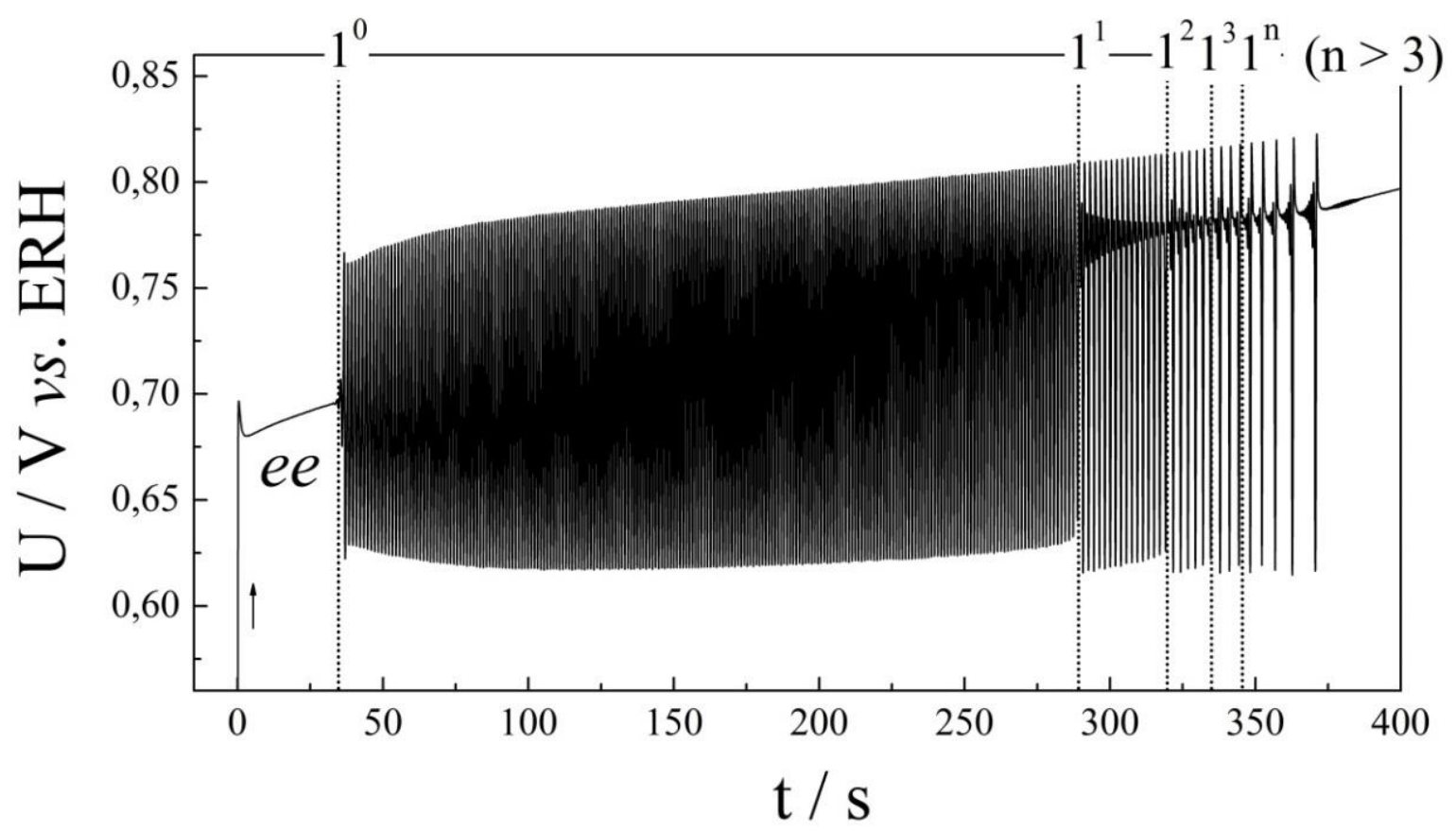


Oscilações quasi-harmônicas de altas amplitudes nascem após um período de indução e permanecem estáveis até aproximadamente 290 segundos. Uma transição homoclínica espontânea para oscilações de modo misto é então observada. Estas oscilações são caracterizadas pela intercalação entre grandes (L) e pequenas (S) amplitudes e espontaneamente evoluem na seguinte sequência $\mathrm{L}^{\mathrm{S}}: 1^{0} \rightarrow 1^{1} \rightarrow 1^{2} \rightarrow 1^{3} \rightarrow 1^{\mathrm{n}}$ com $\mathrm{n}>3$. De modo geral, esta sequência é bastante semelhante ao observado ao longo da varredura galvanodinâmica na Figura 5.1(b), refletindo uma natureza quasi-estacionária dos experimentos galvanodinâmicos. Entretanto, em contraste com as transições induzidas pela variação da corrente aplicada apresentadas nos experimentos galvanodinâmicos, as transições observadas na Figura 5.2 são espontâneas e, portanto, ocorrem apesar do fato de que todos os parâmetros experimentalmente controláveis são mantidos constantes.

Comparando os experimentos dinâmicos e estáticos nas Figura 5.1(b) e Figura 5.2, respectivamente, torna-se claro que o drift observado nas medidas galvanostáticas é equivalente ao causado pelo aumento deliberado da corrente aplicada nos experimentos galvanodinâmicos. Portanto, essa variação espontânea tem um papel de um parâmetro de bifurcação dependente do tempo cuja dinâmica é consideravelmente mais lenta do que as oscilações de potencial e pela qual, de alguma forma, é conectada com o aumento da corrente aplicada. Informações mecanísticas sobre a natureza do drift podem ser obtidas pela análise das regiões de potencial visitadas pelas oscilações. Neste aspecto, o aumento do potencial médio em cada ciclo é claramente discernível em um aumento monotônico no limite superior do potencial do eletrodo e também no tempo gasto em altos potenciais nos estados de modo misto. Em termos quantitativos, foi estimada a evolução do potencial médio do eletrodo, $\mathrm{U}_{\mathrm{m}}$, em cada ciclo oscilatório pela Equação 5.1,

$U_{m}=\frac{1}{t_{2}-t_{1}} \int_{t_{1}}^{t_{2}} U(t) d t$

$\mathrm{U}_{\mathrm{m}}$ é dado pelo teorema do valor médio para integrais definidas e a taxa $\mathrm{dU} / \mathrm{dt}$, foi então obtida via regressão linear uma vez que o sistema evolui vagarosamente. As seguintes taxas foram estimadas, para o período de indução: $0,519 \mathrm{mV} \mathrm{s}^{-1}$ e para os estados oscilatórios $1^{0}$ : $0,192 \mathrm{mV} \mathrm{s}^{-1}, 1^{1}: 0,264 \mathrm{mV} \mathrm{s}^{-1}, 1^{2}: 0,177 \mathrm{mV} \mathrm{s}^{-1}$ e $1^{3}: 0,145 \mathrm{mV} \mathrm{s}^{-1}$.

O potencial médio do eletrodo informa o recobrimento superficial presente. Durante um ciclo oscilatório, os valores de potencial visitados refletem as oscilações observadas no 
recobrimento de algumas espécies intermediárias. [126] Idealmente, a composição superficial seria reestabelecida depois de um ciclo inteiro, de tal forma que a população de espécies adsorvidas seria idêntica antes e depois de um ciclo, assim o sistema permaneceria essencialmente na mesma posição do espaço de fase. Como na maioria dos casos experimentais, a situação observada aqui é diferente e o potencial aumenta gradativamente a cada ciclo. Sendo o aumento no potencial do eletrodo e a sequência de padrões temporais observada é equivalente ao aumento da corrente aplicada, é intuitivo tentar compensar este drift ou variação espontânea pelo decréscimo gradual da corrente aplicada. O seguinte procedimento foi adotado com intuito de atingir este objetivo: um experimento estacionário foi iniciado a uma densidade de corrente constante até a observação de um padrão temporal previamente escolhido para a estabilização, dentro da sequência de padrões dada na Figura 5.2, e então uma varredura galvanodinâmica negativa (VGN) era aplicada.

Padrões temporais estabilizados são exemplificados na Figura 5.3. VGN foram aplicadas em diferentes taxas para a densidade de corrente inicial $\mathrm{j}=1,00 \mathrm{~mA} \mathrm{~cm}{ }^{-2}$. Comparando as Figura 5.2 e Figura 5.3, torna-se aparente que período-1 e estados de modo misto $\mathrm{L}^{\mathrm{S}}$ são satisfatoriamente estabilizados quando a VGN é aplicada. Adicionalmente, foi encontrada uma sequência de Farey incompleta com a concatenação de dois outros estados, designados como $1^{0} 1^{1}$ e $2^{0} 1^{1}$, entre a transição de $1^{1}$ para $1^{0}$, previstos pelos firing numbers. [135]

O efeito de estabilização pode ser melhor visualizado pela reconstrução dos atratores das séries temporais, vide Figura 5.4. A reconstrução dos atratores foi baseada no método do atraso $[157,158]$ nas séries temporais da Figura 5.3. Os respectivos $\tau$ 's foram escolhidos de forma arbitrária com o intuito de encontrar a melhor exposição visual dos atratores no espaço de fase, uma vez que qualquer informação topológica foi descartada. As projeções bidimensionais dos atratores reconstruídos sobre coordenadas de potencial evidenciam trajetórias no espaço de fase que se sobrepõem. Este comportamento dinâmico indica que o estado do sistema é completamente regenerado após um ciclo completo de potencial, realçando o efeito da VGN na eliminação da resposta transiente.

A região expandida dos atratores reconstruídos na parte inferior para cada item na Figura 5.4 representa uma órbita homoclínica. Neste cenário, as trajetórias assumem um movimento circular espiralado devido ao processo de repulsão ao se aproximar do ponto de sela-nó referente ao estado de desprendimento de oxigênio. Note que, para o item (d) na Figura 5.4, as trajetórias são ligeiramente divergentes devido à rápida transição do período $1^{3}$ 
para $1^{\mathrm{n}} \operatorname{com} \mathrm{n}>3$, o qual torna a estabilização deste padrão uma tarefa experimental não trivial.

Figura 5.3 - Período-1 e oscilações de modo misto estabilizadas por meio da VGN em diferentes taxas para a densidade de corrente inicial $\mathrm{j}=1,00 \mathrm{~mA} \mathrm{~cm}{ }^{-2}$. (a) $-2,39 \mu \mathrm{A} \mathrm{s}^{-1} \mathrm{~cm}^{-2}$, (b) $-1,00 \mu \mathrm{A} \mathrm{s}^{-1} \mathrm{~cm}^{-2}$, (c) $-1,33 \mu \mathrm{A} \mathrm{s}^{-1} \mathrm{~cm}^{-2} \mathrm{e}(\mathrm{d})-0,58 \mu \mathrm{A} \mathrm{s}^{-1} \mathrm{~cm}^{-2}$. Eletrólito: [HClO 4$]=$ $0,1 \mathrm{~mol} \mathrm{~L}{ }^{-1} \mathrm{e}\left[\mathrm{H}_{3} \mathrm{COH}\right]=0,5 \mathrm{~mol} \mathrm{~L}^{-1} . \mathrm{T}=25 \pm 1^{\circ} \mathrm{C}$.

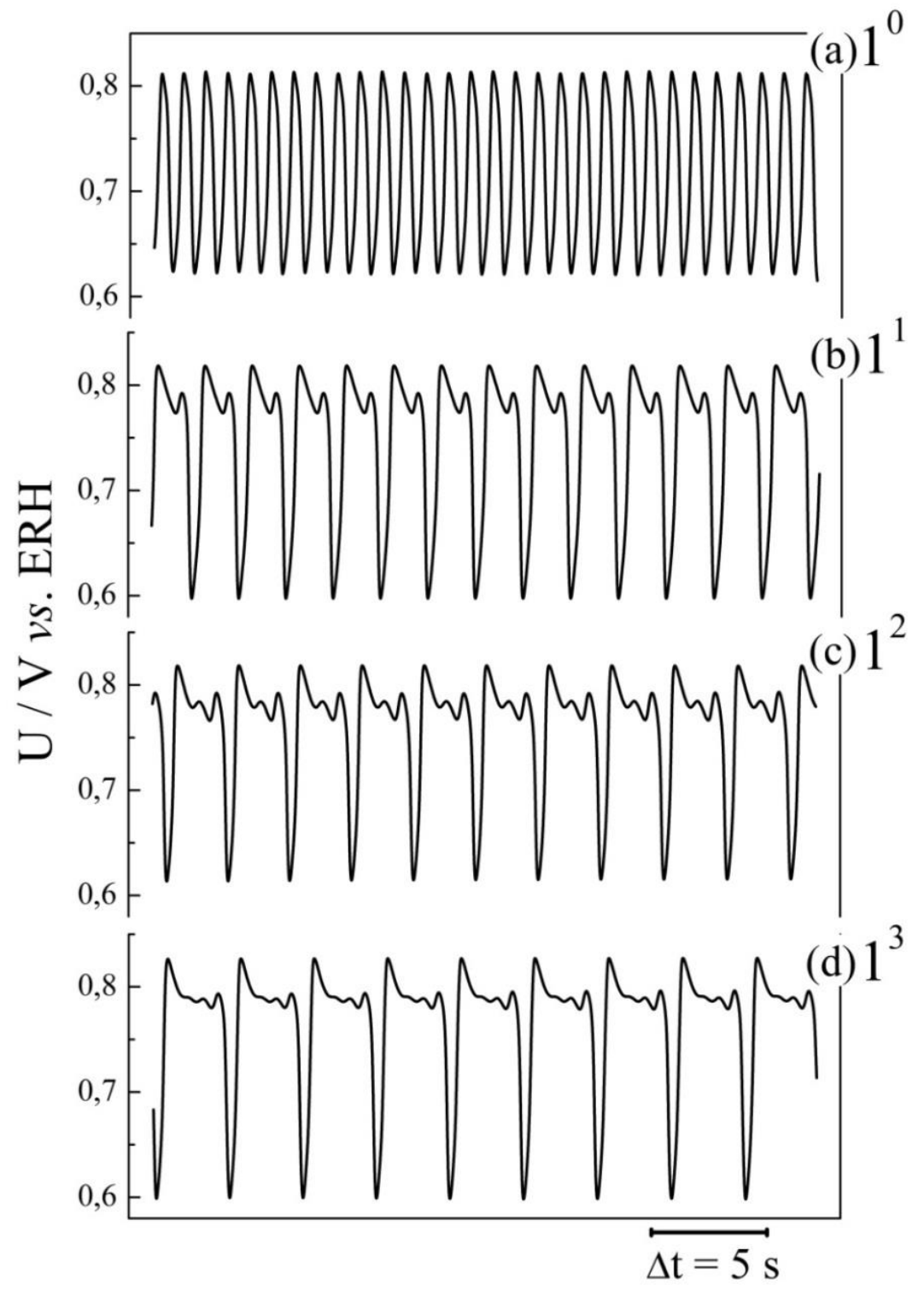

Como já mencionado, o aumento espontâneo e gradual do potencial médio em regime oscilatório é associado com as transformações no recobrimento superficial das espécies adsorvidas. Para verificar a eficiência do procedimento de estabilização, o número de ciclos foi monitorado em função de diferentes taxas da VGN em cada padrão temporal observado. 
Resultados são compilados na Tabela 5.1. O número de ciclos para os casos não estabilizados são dados pela varredura com magnitude zero na primeira linha. A imposição do decréscimo da corrente aplicada de forma linear resultou no aumento do número de ciclos.

Figura 5.4 - Projeção bidimensional dos atratores reconstruídos em coordenadas de potencial pela Figura 5.3, utilizando o método do atraso em (a) $\tau=0,203 \mathrm{~s}$, (b) $\tau=0,203 \mathrm{~s}$, (c) $\tau=0,190$ s e (d) $\tau=0,174 \mathrm{~s}$.

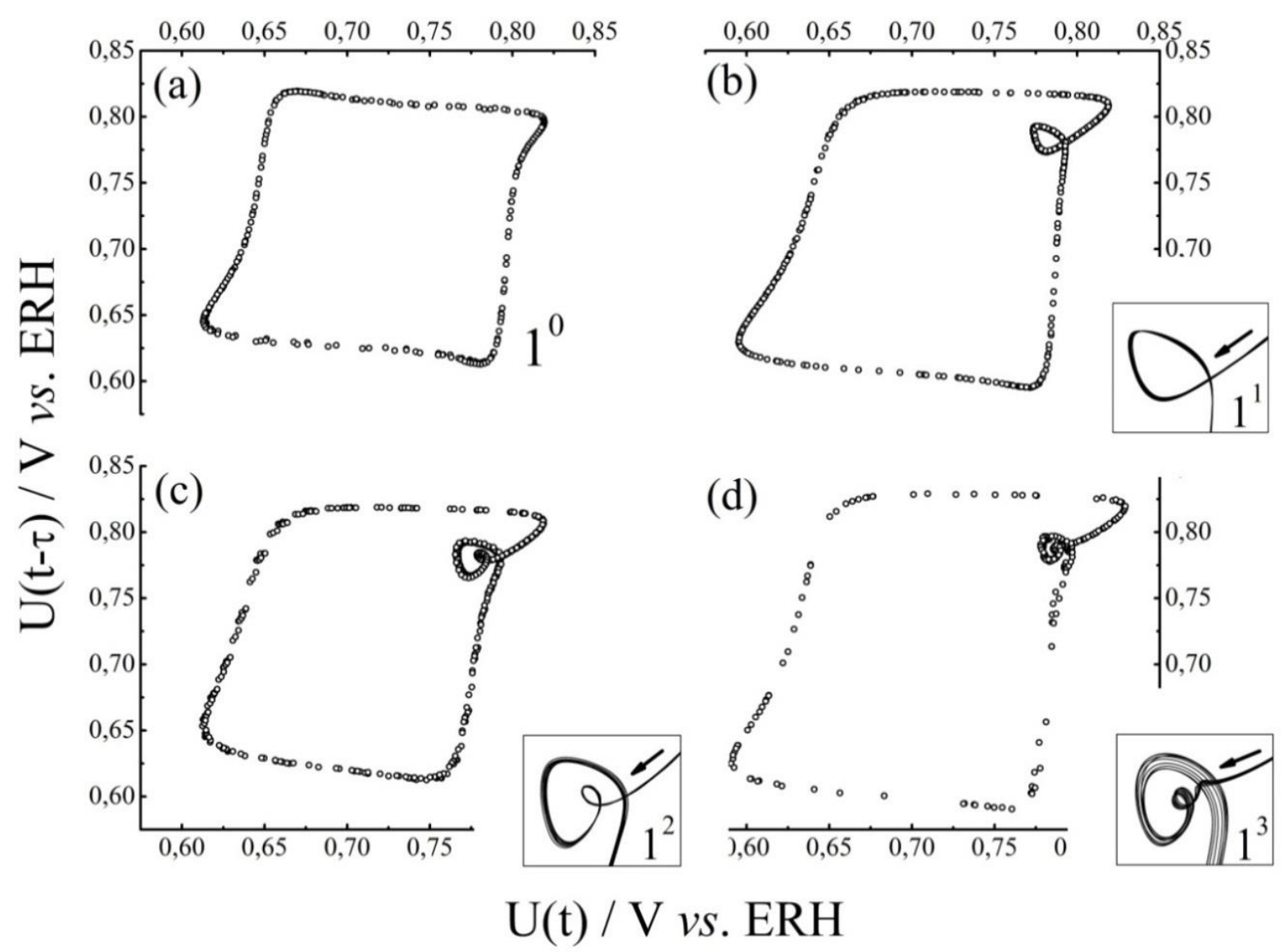

Na Tabela 5.1, a densidade de corrente $\mathrm{j}=1,59 \mathrm{~mA} \mathrm{~cm}^{-2}$ foi utilizada para a medida dos ciclos para o padrão $1^{0}$ e $\mathrm{j}=1,00 \mathrm{~mA} \mathrm{~cm} \mathrm{~cm}^{-2}$ para os casos $1^{1}, 1^{2}$ e $1^{3}$. De qualquer forma, a eficiência da estabilização (i.e. aumento no número de ciclos) aumenta com a taxa da varredura até um máximo, e então, decai. No valor ótimo da VGN um aumento pronunciado na série temporal é observado. Estabilização de 5 até mais de 20 vezes foram observadas no número de ciclos para os padrões $1^{3}$ e $1^{0}$, respectivamente. A taxa de estabilização ótima pode, entretanto, ser única no sentido de que esta reflete a taxa na qual as transformações superficiais acontecem para um dado padrão temporal. 
Tabela 5.1 - Número de ciclos oscilatórios em função de diferentes taxas da VGN em $\mu \mathrm{A} \mathrm{s}{ }^{-1}$ $\mathrm{cm}^{-2}$.

\begin{tabular}{|c|c|c|c|c|c|c|c|}
\hline \multicolumn{2}{|c|}{$1^{0}$} & \multicolumn{2}{|c|}{$1^{1}$} & \multicolumn{2}{|c|}{$1^{2}$} & \multicolumn{2}{|c|}{$1^{3}$} \\
\hline - $d j / d t$ & ciclos & - $d j / d t$ & ciclos & $-d j / d t$ & ciclos & $-d j / d t$ & ciclos \\
\hline 0 & 18 & 0 & 15 & 0 & 6 & 0 & 7 \\
\hline 0,78 & 125 & 0,33 & 19 & 0,33 & 7 & 0,17 & 9 \\
\hline 1,59 & 165 & 0,50 & 23 & 0,66 & 10 & 0,33 & 24 \\
\hline 2,39 & 382 & 0,66 & 25 & 1,00 & 17 & 0,41 & 25 \\
\hline 3,18 & 271 & 0,83 & 50 & 1,16 & 21 & 0,50 & 31 \\
\hline 4,78 & 172 & 1,00 & 87 & 1,33 & 54 & 0,58 & 35 \\
\hline 6,37 & 124 & 1,16 & 37 & 1,49 & 24 & 0,60 & 16 \\
\hline 7,96 & 81 & 1,33 & 12 & 1,66 & 6 & 0,66 & 10 \\
\hline
\end{tabular}

\subsubsection{Resultados Numéricos}

A desativação superficial pelo acúmulo gradual e irreversível de uma espécie inerte foi implementada pela diminuição exponencial de sítios superficiais, vide Equação 4.9. O efeito da acumulação dessa espécie pode ser evidenciado na Figura 5.5. Séries de potencial (linha preta) acompanhadas do potencial médio (linha vermelha) foram simuladas em diferentes valores de $\mathrm{f}$.

De maneira geral a diminuição da área livre resultou no aumento do período oscilatório uma vez que o sistema permanece por mais tempo em regiões de altos potenciais. Os resultados numéricos estão de acordo com o efeito de uma espécie bloqueante em um oscilador eletroquímico. [159] O acúmulo da espécie inerte retarda o processo de reativação superficial o que favorece o aumento do potencial médio (linha vermelha) acompanhado também de um sutil aumento da amplitude. A relação diretamente proporcional entre o aumento do período e amplitude oscilatória é observada experimentalmente. [49] Este tipo de comportamento dinâmico também foi observado para a eletro-oxidação de metanol na série temporal de período-1, Figura 5.2. 
Figura 5.5 - Séries temporais de potencial (linha preta) em diferentes valores de sítios superficiais f e potencial médio $\phi_{\mathrm{m}}$ calculado (linha vermelha) $\operatorname{com} \beta=0$, respectivamente. (a) $\mathrm{f}=1$ e $\phi_{\mathrm{m}}=59,9$, (b) $\mathrm{f}=0,65$ e $\phi_{\mathrm{m}}=74,4$, (c) $\mathrm{f}=0,30$ e $\phi_{\mathrm{m}}=142,9$.

(a)

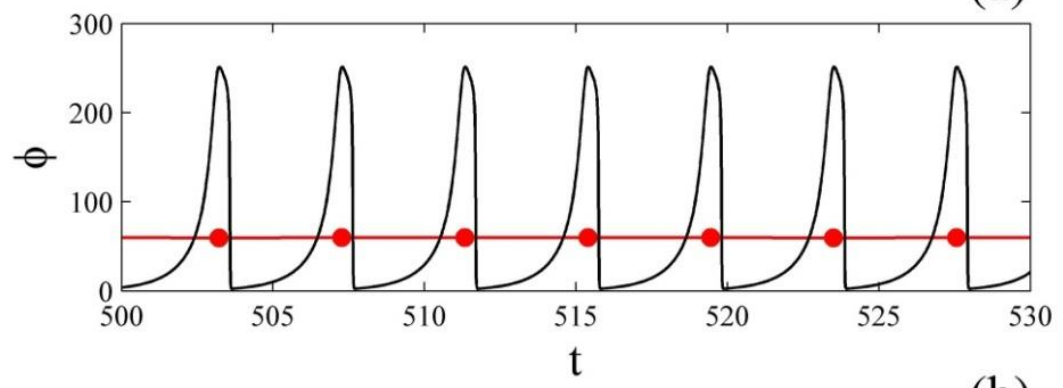

(b)

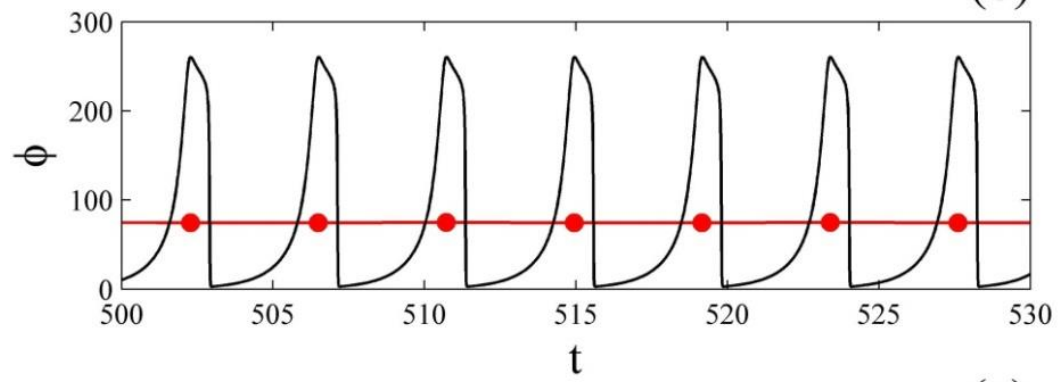

(c)

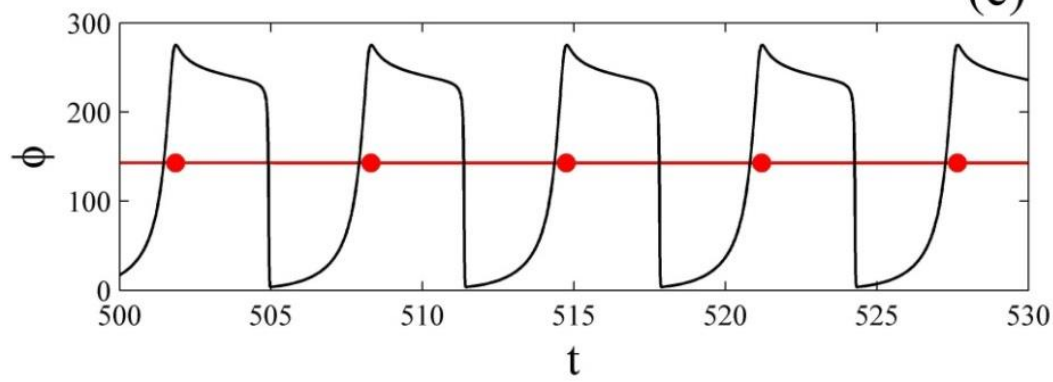

A compensação das séries temporais transientes é obtida pela aplicação da VGN. O procedimento de estabilização visa a compensar a variação da composição superficial pela diminuição da corrente aplicada a uma taxa linear. Na Figura 5.6, observa-se como a taxa de compensação $\beta$ da Equação 4.10 altera o número de ciclos numa dada série temporal. Em condições em que não há compensação, Figura 5.6(a), o drift conduz o sistema oscilatório para fora da região de Hopf, seguindo um aumento gradual do potencial médio (linha vermelha). O perfil transiente é qualitativamente similar ao da Figura 5.2, exceto pela transição de períodos observada experimentalmente. Na Figura 5.6(b) é possível notar que a aplicação da VGN estabiliza satisfatoriamente a série temporal aumentando 2,5 vezes o número de ciclos. $\mathrm{O}$ efeito do drift é minimizado, sobretudo no início da série temporal onde o recobrimento da espécie inerte ainda é pequena, neste caso $\mathrm{d} \phi_{\mathrm{m}} / \mathrm{dt} \approx 0$. No entanto, quando 
a taxa de compensação possui altos valores, rapidamente o sistema é conduzido para o estado estacionário, Figura 5.6(c). O método de compensação utilizado reproduz o perfil de estabilização encontrado experimentalmente dado na Tabela 5.1. Além de validar o método experimental de estabilização, as simulações numéricas também indicam um comportamento puramente superficial do drift.

Figura 5.6 - Séries temporais de potencial (linha preta) e potencial médio $\phi_{\mathrm{m}}$ (linha vermelha) calculados para $\alpha=1,0.10^{-4}$ e (a) $\beta=0$, (b) $\beta=0,125 \cdot 10^{-4}$, (c) $\beta=1,0.10^{-4}$.

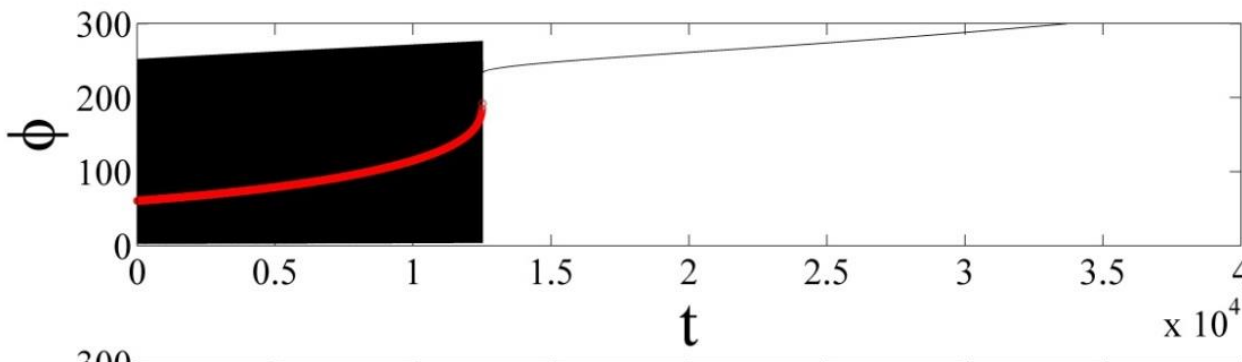

(a)

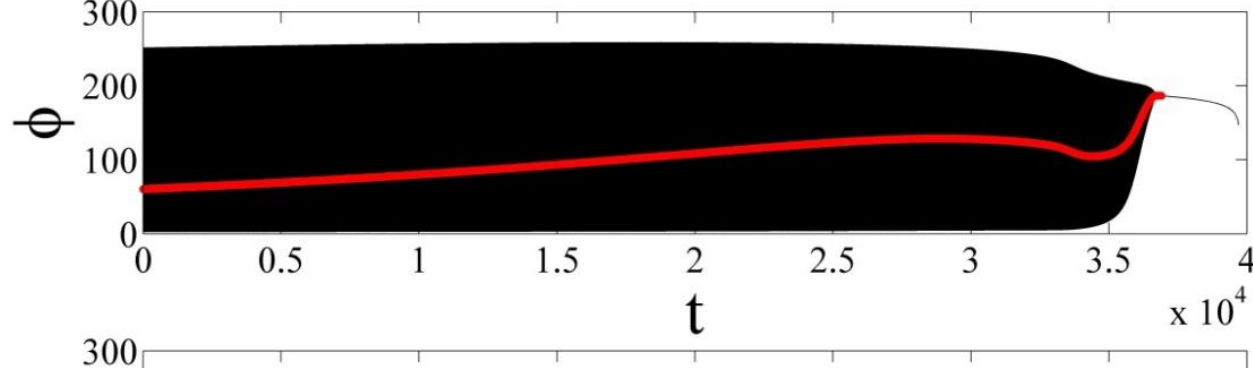

(b)

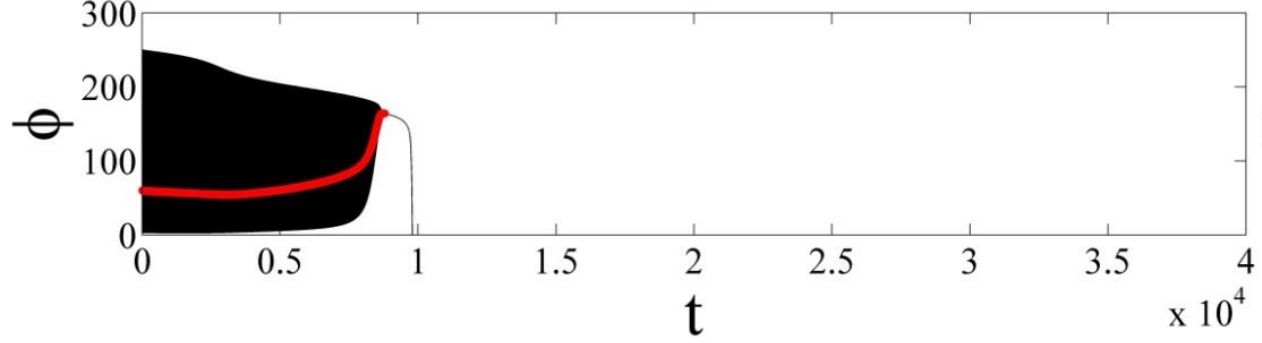

(c)

A localização do ponto ótimo de estabilização do número de ciclos pode fornecer informações importantes nas escalas de tempo do drift e da VGN. Na Figura 5.7, o número de ciclos foi contabilizado em função dos parâmetros $\alpha$ e $\beta$. Dada a evolução temporal exponencial do decaimento da área livre, a eficiência máxima de estabilização acontece principalmente em regiões onde $\alpha$ é relativamente pequeno. Novamente, as oscilações de potencial são rapidamente suprimidas em condições extremas, tanto de $\alpha$ quando de $\beta$. No entanto, um valor máximo de estabilização é obtido e percorre todo o plano $\alpha / \beta$ com uma tendência linear de proporcionalidade. Isto indica que para cada valor de $\alpha$ existe um $\beta$ único correspondente que resulta na máxima estabilização. 
Figura 5.7 - Mapeamento do número de ciclos para oscilações de potencial de período-1 em função dos parâmetros $\alpha$ e $\beta$. Cada elemento da malha $(200$ x 200) representa uma série temporal.

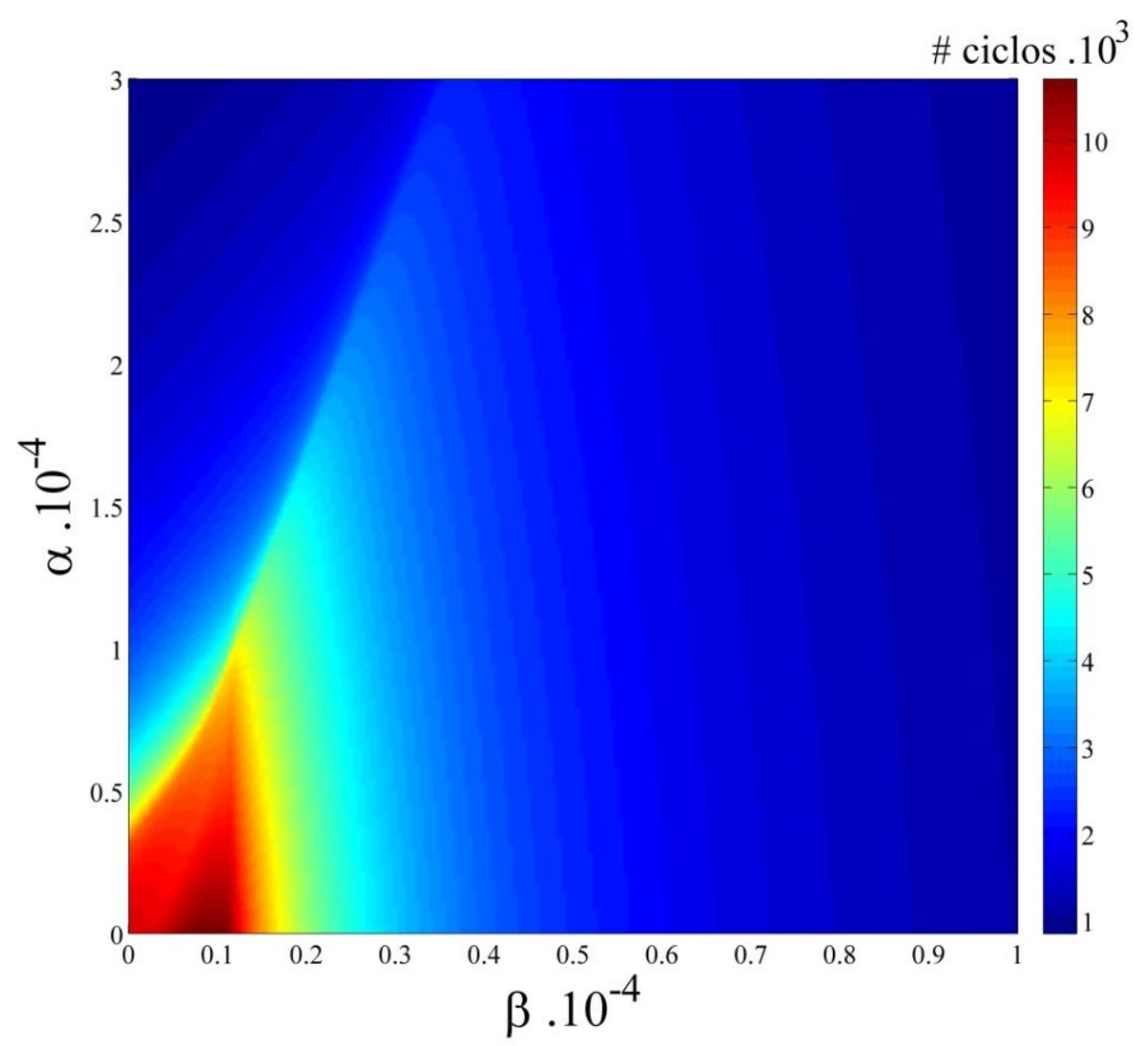

O valor ótimo da VGN reflete a taxa de variação da composição superficial dos intermediários envolvidos na reação em longo prazo. Considerando que neste ponto as escalas de tempo da VGN e do drift estão correlacionadas, a tentativa de extrair experimentalmente a taxa de variação do drift torna-se um objetivo importante na caracterização da evolução temporal. Dado o balanço de carga do circuito elétrico equivalente,

$\mathrm{I}=\mathrm{CA}_{\mathrm{F}} \frac{\mathrm{d} \phi}{\mathrm{dt}}+\mathrm{nFA}_{\mathrm{F}} \sum v_{\mathrm{i}}$

A análise do processo lento pode ser baseada na evolução temporal das variáveis médias (índice $m$ ). Considerando o caso particular em que a velocidade de reação de uma etapa elementar é muito superior em relação às outras: $v_{i} \gg \gg v_{i+1}, v_{i+2}, \ldots, v_{n}$. onde $i=1,2,3, \ldots, n$ 
$\mathrm{I}=\mathrm{CA}_{\mathrm{F}} \frac{\mathrm{d} \phi_{\mathrm{m}}}{\mathrm{dt}}+\mathrm{nFA}_{\mathrm{F}} \mathrm{k}_{\mathrm{m}} \mathrm{c}_{\mathrm{m}}\left(1-\theta_{\mathrm{T}}\right)$

Sabendo-se que no ponto ótimo de estabilização $\mathrm{d} \phi_{\mathrm{m}} / \mathrm{dt}=0$ e aplicando a derivada na Equação 5.3,

$\frac{\mathrm{dI}}{\mathrm{dt}}=\mathrm{nFk}_{\mathrm{m}} \mathrm{c}_{\mathrm{m}} \frac{\mathrm{d}}{\mathrm{dt}}\left[\mathrm{A}_{\mathrm{F}}\left(1-\theta_{\mathrm{T}}\right)\right]$

utilizando a relação linear da $\mathrm{VGN}, \mathrm{dI} / \mathrm{dt}=-\beta$, obtém-se

$-\beta=\mathrm{nFk}_{\mathrm{m}} \mathrm{c}_{\mathrm{m}}\left[\left(1-\theta_{\mathrm{T}}\right) \frac{\mathrm{dA_{F }}}{\mathrm{dt}}+\mathrm{A}_{\mathrm{F}} \frac{\mathrm{d}}{\mathrm{dt}}\left(1-\theta_{\mathrm{T}}\right)\right]$

$\log 0$

$-\beta=\mathrm{nFk}_{\mathrm{m}} \mathrm{c}_{\mathrm{m}}\left[\left(1-\theta_{\mathrm{T}}\right) \frac{\mathrm{dA}}{\mathrm{dt}}-\mathrm{A}_{\mathrm{F}} \frac{\mathrm{d} \theta_{\mathrm{T}}}{\mathrm{dt}}\right]$

considerando que a área livre $A_{F}$ diferencia-se da área real $A_{R}$ pela relação,

$A_{F}=A_{R}\left(1-\theta_{T}\right)$

obtemos a seguinte equação,

$-\beta=\mathrm{nFk}_{\mathrm{m}} \mathrm{c}_{\mathrm{m}}\left[-\mathrm{A}_{\mathrm{R}}\left(1-\theta_{\mathrm{T}}\right) \frac{\mathrm{d} \theta_{\mathrm{T}}}{\mathrm{dt}}-\mathrm{A}_{\mathrm{R}}\left(1-\theta_{\mathrm{T}}\right) \frac{\mathrm{d} \theta_{\mathrm{T}}}{\mathrm{dt}}\right]$

portanto,

$\frac{\mathrm{d} \theta_{\mathrm{T}}}{\mathrm{dt}}=\frac{\beta}{2 \mathrm{nFA}_{\mathrm{R}} \mathrm{k}_{\mathrm{m}} \mathrm{c}_{\mathrm{m}}\left(1-\theta_{\mathrm{T}}\right)}$ 
expandindo o recobrimento total $\theta_{\mathrm{T}}$ como uma combinação linear dos recobrimentos dos intermediários reacionais $\theta_{\mathrm{I}}$ mais o recobrimento associado ao drift (i.e. acúmulo de uma espécie superficial) $\theta_{\mathrm{d}}$,

$\frac{\mathrm{d} \theta_{\mathrm{I}}}{\mathrm{dt}}+\frac{\mathrm{d} \theta_{\mathrm{d}}}{\mathrm{dt}}=\frac{\beta}{2 \mathrm{nFA}_{\mathrm{R}} \mathrm{k}_{\mathrm{m}} \mathrm{c}_{\mathrm{m}}\left(1-\theta_{\mathrm{I}}-\theta_{\mathrm{d}}\right)}$

Considerando o início da VGN onde não foi possível acumular de forma significativa $\theta_{\mathrm{d}}$, o cálculo da evolução temporal do drift pode ser extraído pela Equação 5.11.

$\frac{\mathrm{d} \theta_{\mathrm{d}}}{\mathrm{dt}}=\frac{\beta}{2 \mathrm{nFA}_{\mathrm{R}} \mathrm{k}_{\mathrm{m}} \mathrm{c}_{\mathrm{m}}\left(1-\theta_{\mathrm{I}}\right)}-\frac{\mathrm{d} \theta_{\mathrm{I}}}{\mathrm{dt}}$

De forma simplificada a Equação 5.11 mostra que a relação entre o drift e a taxa de variação dos intermediários adsorvidos no ponto de estabilização ótimo depende da taxa de compensação da VGN e a corrente faradaica média,

$\frac{\mathrm{d} \theta_{\mathrm{d}}}{\mathrm{dt}}=\frac{\beta}{2 \mathrm{I}_{\mathrm{F}, \mathrm{m}}}-\frac{\mathrm{d} \theta_{\mathrm{I}}}{\mathrm{dt}}$

todos os parâmetros na Equação 5.12 são experimentalmente acessíveis.

\subsection{Discussão}

O problema apresentado ao longo deste capítulo consiste na variação lenta observada na série temporal de potencial registrada durante a eletro-oxidação de metanol sobre platina. Este drift é frequentemente observado em sistemas eletroquímicos, e para o caso do metanol, tem sido associado à mudança no recobrimento médio de espécies adsorvidas no decorrer das oscilações. [138] Estas mudanças resultam nas oscilações não-compensadas, ao longo das quais os recobrimentos originais de algumas espécies adsorvidas não são reestabelecidos depois de um ciclo (i.e. há a acumulação ou diminuição de espécies adsorvidas durante as oscilações). Inicialmente, serão discutidos nesta seção os principais processos superficiais que levam a este fenômeno. Em seguida, sugere-se um mecanismo reacional associado à dinâmica 
de curto e longo prazo. Finalmente, os resultados são discutidos em conexão com o problema da série temporal não estacionária em termos mais gerais.

\subsubsection{Reações Superficiais}

A eletro-oxidação de metanol em platina e superfícies de platina modificadas tem sido extensivamente investigada por meio de diferentes técnicas. A eletro-oxidação de metanol é comumente discutida em termos do mecanismo conhecido como dual [120] no qual vias reacionais paralelas ocorrem simultaneamente. Monóxido de carbono é conhecido como um intermediário de reação que bloqueia a superfície do eletrodo em baixos potenciais. Acreditase que este adsorbato é formado por meio de três etapas de desidrogenação. [160] O primeiro processo envolve a adsorção de metanol pelo átomo de carbono na superfície, requerendo ao menos três sítios superficiais ativos e disponíveis para a quebra da ligação C-H. [118, 119] Na via indireta, monóxido de carbono adsorvido é oxidado pela reação com espécies oxigenadas, $(\mathrm{H})_{\mathrm{x}} \mathrm{O}$ onde $\mathrm{x}=0,1$ ou 2 e representa a natureza da espécie oxigenada adsorvida, em altos potenciais via o mecanismo de Langmuir-Hinshelwood (LH) na reação de Ertl. [125]

$\mathrm{Na}$ via direta, moléculas de metanol se adsorvem pelo átomo de oxigênio, promovendo as espécies metóxi, [122] as quais geram formaldeído $\mathrm{H}_{2} \mathrm{CO}$, que dessorve da superfície e existe majoritariamente na sua forma hidratada: metileno glicol, $\mathrm{H}_{2} \mathrm{C}(\mathrm{OH})_{2}$. [161] Este, por sua vez, pode perder dois átomos de hidrogênio e formar $\mathrm{HCOOH}$. Ácido fórmico gera monóxido de carbono o qual é oxidado via mecanismo LH e também pode gerar formiato adsorvido $\mathrm{HCOO}_{\mathrm{ad}}$ considerado como intermediário ativo na decomposição oxidativa à $\mathrm{CO}_{2}$. [82-88] Finalmente, moléculas de metanol em solução reagem com $\mathrm{HCO}_{\mathrm{ad}}$, resultando em metilformiato, $\mathrm{HCOOCH}_{3}$. [123] Este mecanismo complexo é fortemente dependente de uma gama de variáveis experimentais, incluindo composição do eletrólito de suporte, concentração, temperatura, estrutura cristalina superficial e etc.

Em determinadas circunstâncias, o estado estacionário de distribuição de intermediários adsorvidos pode tornar-se instável de tal forma que a eletro-oxidação de metanol passa a exibir oscilações de corrente ou potencial. Em resumo, o regime oscilatório em sistemas reacionais eletrocatalíticos é mecanisticamente descrito pela competição entre isotermas de adsorção dependentes do potencial de espécies carbonáceas e oxigenadas. [34] 


\subsubsection{Dinâmicas de Curto e Longo Prazo}

Em termos das reações superficiais, o fenômeno relatado aqui consiste em dois processos com distintas escalas de tempo. A dinâmica central é mais rápida e está associada às oscilações de potencial com frequência na faixa entre 0,2 e $1 \mathrm{~Hz}$. Por sua vez, a dinâmica secundária é lenta e está associada à variação na cobertura média de algumas espécies adsorvidas responsáveis pelo drift espontâneo que move o sistema por diferentes regiões de parâmetros, resultando em distintos padrões temporais. Interessantes transições entre diferentes estados oscilatórios têm sido relatadas para a eletro-oxidação de formaldeído e metanol sobre platina policristalina. [139-141] Recentemente, transições comparáveis entre estados periódicos e caóticos foram observadas durante a eletro-oxidação de etileno glicol [92] e glicerol [162] em meio alcalino. O aumento no potencial do eletrodo é comumente observado nestes sistemas e tem sido reconhecido como um processo de desativação superficial. [139-141] Nestes trabalhos os autores descreveram o drift como uma sequência de uma série de estados dinâmicos, de forma que o tempo englobaria um ou mais parâmetros. Finalmente, ainda foi sugerido que o drift é causado por um processo superficial em vez de um processo de transporte de massa. A primeira evidência do bloqueio superficial gradativo que induzia o aumento da densidade de corrente foi observada por Neher et al. [163] durante a eletro-redução de $\mathrm{H}_{2} \mathrm{O}_{2}$ em semicondutores p-CuInSe 2 .

Boscheto et al. [138] utilizaram espectroscopia de infravermelho in situ na configuração de reflexão total atenuada (Surface Enhanced Infrared Absorption Spectroscopy in Attenuated Total Reflection, ATR-SEIRAS) com a finalidade de monitorar as mudanças na composição superficial durante a eletro-oxidação de metanol sobre um filme de platina em solução aquosa de ácido sulfúrico. Os autores encontraram na dinâmica de longo prazo um decréscimo contínuo no recobrimento de $\mathrm{CO}_{\mathrm{L}}$ com $-4,510^{-4}$ e $-0,910^{-4} \mathrm{~cm}^{-1} \mathrm{~s}^{-1}$ ao longo da transição do período de indução e para as oscilações no intervalo entre 0,34 e 0,2 monocamadas (monolayers, ML), enquanto que o recobrimento de $\mathrm{CO}_{\mathrm{B}}$ variou entre $0,06 \mathrm{e}$ 0,04 ML. A dinâmica principal foi caracterizada por pequenas oscilações na cobertura de CO, $\Delta \theta_{\mathrm{COL}} \sim 0,04-0,05 \mathrm{ML}$ e oscilações de potencial comparáveis às relatadas aqui. $\mathrm{A}$ intensidade de banda relativa à adsorção de formiato permaneceu pequena e sem variações detectáveis. Em pleno acordo com os resultados apresentados, eles encontraram taxas $\mathrm{dU}$ de $+0,066$ e $+0,011 \mathrm{mV} \mathrm{s}^{-1}$ durante o período de indução e oscilações de período-1, respectivamente. [138] Neste trabalho, a evolução do potencial médio do eletrodo de $+0,519$ 
$\mathrm{mV} \mathrm{s}^{-1}$ (período de indução), +0,192 $\mathrm{mV} \mathrm{s}^{-1}$ (padrão $1^{0}$ ), +0,264 $\mathrm{mV} \mathrm{s}^{-1}$ (padrão $1^{1}$ ), +0,177 $\mathrm{mV} \mathrm{s}^{-1}$ (padrão $1^{2}$ ), e $+0,145 \mathrm{mV} \mathrm{s}^{-1}$ (padrão $1^{3}$ ) foram observadas.

De acordo com o cenário mecanístico descrito, a cobertura superficial total $\theta_{\mathrm{T}}$ durante a eletro-oxidação de metanol sobre platina pode ser escrita em geral como,

$\theta_{\mathrm{T}}=\left(\theta_{\mathrm{C}-\mathrm{H}}+\theta_{\mathrm{O}-\mathrm{C}}+\theta_{\mathrm{CO}}+2 \theta_{\mathrm{HCOO}}+\theta_{(\mathrm{H})_{\mathrm{x}} \mathrm{O}}+\theta_{\mathrm{A}}\right)$

em que $\theta_{\mathrm{C}-\mathrm{H}}$ e $\theta_{\mathrm{O}-\mathrm{C}}$ representam as coberturas de diferentes resíduos de metanol adsorvidos. $\theta_{\mathrm{CO}}$ representa a cobertura de monóxido de carbono, $\theta_{\mathrm{HCOO}}$ a cobertura de formiato adsorvido em forma de ponte, $\theta_{(\mathrm{H}) \times \mathrm{O}}$ a cobertura de espécies oxigenadas e $\theta_{\mathrm{A}}$ os ânions adsorvidos. $\mathrm{Na}$ faixa de potencial em que as oscilações em modo galvanostático emergem, entre c.a. 0,60 e $0,85 \mathrm{~V}$, a principal contribuição à reação de eletro-oxidação pode ser reduzida à,

$\theta_{\mathrm{T}}=\left(\theta_{\mathrm{CO}}+2 \theta_{\mathrm{HCOO}}+\theta_{(\mathrm{H})_{\mathrm{x}} \mathrm{O}}\right)$

A simplificação da Equação 5.13 para 5.14 é justificada pelos seguintes argumentos: (a) a oxidação de monóxido de carbono, pela via indireta, é a etapa determinante na faixa de potencial onde ocorrem as oscilações de potencial, [119, 164-166] (b) resultados experimentais sugerem formiato como uma espécie adsorvida durante a eletro-oxidação de metanol sobre platina, sendo normalmente associado como intermediário ativo na formação de $\mathrm{CO}_{2}$; [85-88] (c) a interação entre moléculas de água e a superfície aumenta com o aumento do potencial. [167] Moléculas de água competem com o substrato orgânico por sítios superficiais e têm um papel central na reação global, [168] atuando na doação de oxigênio para a formação de $\mathrm{CO}_{2}$; [169] (d) entre os ânions mais utilizados em eletrólitos, o perclorato é o que se adsorve mais fracamente sobre platina, [170] de forma que sua cobertura pode ser desprezada.

A adsorção de espécies no eletrodo contribui para a diminuição da área superficial ativa, mudando, portanto, a densidade de corrente local $\mathrm{J}$ definida como a razão entre a corrente aplicada e a área livre $A_{F}$. A densidade de corrente definida pela razão entre a corrente aplicada e a área real, obtida usualmente pela região de hidrogênio, $\mathrm{j}=\mathrm{I} / \mathrm{A}_{\mathrm{R}}$ é diferente de $\mathrm{J}=\mathrm{I} / \mathrm{A}_{\mathrm{F}}$, uma vez que, 
$A_{F}=A_{R}\left(1-\theta_{\mathrm{CO}}-2 \theta_{\mathrm{HCOO}}-\theta_{(\mathrm{H})_{\mathrm{x}} \mathrm{O}}\right)$

Dessa forma, ainda que a área real $A_{R}$ permaneça constante (e igual a $0,3 \mathrm{~cm}^{2}$, ver Capítulo 3 - Seção 3.1) durante as oscilações, a área livre $A_{F}$ varia de forma líquida como evidenciado pela lenta variação da cobertura média de alguns intermediários. Portanto, a densidade de corrente local se torna uma função do tempo $J=J(t)$. Um esquema ilustrativo do processo em questão é dado na Figura 5.8.

Figura 5.8 - Esquema ilustrativo para a acumulação de uma espécie adsorvida e desconhecida $S$, durante três etapas (a) $t_{0}$, (b) $t_{1}$ e (c) $t_{2}$.

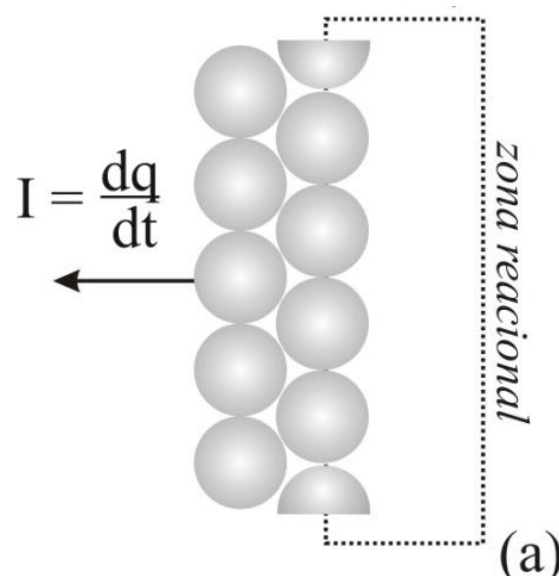

(a)

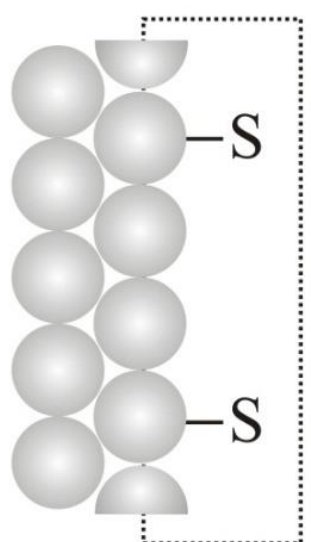

(b)

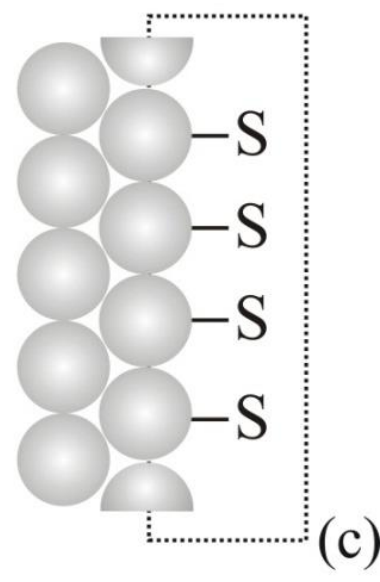

(c)

Com o passar do tempo, por exemplo de $\mathrm{t}_{0} \mathrm{a}_{2}$, a cobertura residual de espécies bloqueantes (representadas por $\mathrm{S}$ ) aumenta de forma que a área livre diminui: $\mathrm{A}_{\mathrm{F}, \mathrm{t} 0}>\mathrm{A}_{\mathrm{F}, \mathrm{t} 1}>\mathrm{A}_{\mathrm{F}, \mathrm{t} 2}$ e assim $\mathrm{J}_{\mathrm{t} 0}<\mathrm{J}_{\mathrm{t} 1}<\mathrm{J}_{\mathrm{t} 2}$. Note que em regime galvanostático é possível controlar de forma precisa a corrente aplicada $\mathrm{I}=\mathrm{dq} / \mathrm{dt}$ como o fluxo de elétrons através da interface sólido/líquido. Como a corrente aplicada é mantida constante, o produto $\mathrm{JA}_{\mathrm{F}}$ permanece constante, e a derivada deste produto resulta em,

$A_{F} \frac{d J}{d t}+J \frac{d A_{F}}{d t}=0$

$\mathrm{Ou}$ 
$\frac{\mathrm{dJ}}{\mathrm{dt}}=-\frac{\mathrm{J}}{\mathrm{A}_{\mathrm{F}}} \frac{\mathrm{dA}_{\mathrm{F}}}{\mathrm{dt}}$

Utilizando a derivada da Equação 5.15,

$\frac{d A_{F}}{d t}=-A_{R}\left(\frac{d \theta_{C O}}{d t}+2 \frac{d \theta_{H C O O}}{d t}+\frac{d \theta_{(H)_{x} \mathrm{O}}}{d t}\right)$

na Equação 5.17, resulta em

$\frac{\mathrm{dJ}}{\mathrm{dt}}=\mathrm{J} \frac{\mathrm{A}_{\mathrm{R}}}{\mathrm{A}_{\mathrm{F}}}\left(\frac{\mathrm{d} \theta_{\mathrm{CO}}}{\mathrm{dt}}+2 \frac{\mathrm{d} \theta_{\mathrm{HCOO}}}{\mathrm{dt}}+\frac{\mathrm{d} \theta_{(\mathrm{H})_{\mathrm{X}} \mathrm{O}}}{\mathrm{dt}}\right)$

escrevendo a densidade de corrente local $\mathrm{J}$ em função da densidade de corrente aplicada j

$\frac{\mathrm{dJ}}{\mathrm{dt}}=\frac{\mathrm{j}}{\left(1-\theta_{\mathrm{T}}\right)^{2}}\left(\frac{\mathrm{d} \theta_{\mathrm{CO}}}{\mathrm{dt}}+2 \frac{\mathrm{d} \theta_{\mathrm{HCOO}}}{\mathrm{dt}}+\frac{\mathrm{d} \theta_{(\mathrm{H})_{\mathrm{x}} \mathrm{O}}}{\mathrm{dt}}\right)$

reescrevendo,

$\frac{\mathrm{dJ}}{\mathrm{dt}}=\kappa\left(\frac{\mathrm{d} \theta_{\mathrm{CO}}}{\mathrm{dt}}+2 \frac{\mathrm{d} \theta_{\mathrm{HCOO}}}{\mathrm{dt}}+\frac{\mathrm{d} \theta_{(\mathrm{H})_{\mathrm{x}} \mathrm{O}}}{\mathrm{dt}}\right)$

no qual o termo $\kappa$ é sempre positivo. $\mathrm{O}$ decréscimo na área livre $\mathrm{A}_{\mathrm{F}}$, é refletido no aumento líquido da população de espécies adsorvidas na superfície se,

$\left(\frac{\mathrm{d} \theta_{\mathrm{CO}}}{\mathrm{dt}}+2 \frac{\mathrm{d} \theta_{\mathrm{HCOO}}}{\mathrm{dt}}+\frac{\mathrm{d} \theta_{(\mathrm{H})_{\mathrm{X}} \mathrm{O}}}{\mathrm{dt}}\right)>0$

De acordo com os resultados experimentais da dinâmica de longo prazo, foi observado que $\mathrm{d} \theta_{(\mathrm{H}) \mathrm{xO}} / \mathrm{dt}>0, \mathrm{~d} \theta_{\mathrm{CO}} / \mathrm{dt}<0$ e $\mathrm{d} \theta_{\mathrm{HCOO}} / \mathrm{dt} \rightarrow 0$. [138] Portanto, a condição na Inequação 5.22 é satisfeita e as oscilações não-compensadas resultam em um lento acúmulo de espécies oxigenadas $(\mathrm{H})_{\mathrm{x}} \mathrm{O}$ na superfície do eletrodo. Como já foi dito, este acúmulo ocorre de forma 
lenta e, portanto, não é discernível na simples inspeção de poucos ciclos oscilatórios. Apesar da corrente aplicada $\mathrm{j}$ ser mantida constante nos experimentos, a corrente local $\mathbf{J}$ que flui através da área não bloqueada aumenta. Este aumento espontâneo durante as oscilações, vide Inequação 5.22, conduz o sistema a diferentes estados como exemplificado na Figura 5.2. A varredura galvanodinâmica negativa compensa esta variação espontânea ou drift. Os resultados da Tabela 5.1 demonstram este aspecto e mostram como a velocidade de decréscimo da corrente aplicada influencia a estabilização de um dado padrão.

Aspectos mecanísticos referente à origem química do drift foram recentemente discutidos por Cabral et al. [153] para a eletro-oxidação de formaldeído em platina policristalina como mostrado na Figura 5.9. Em contraste ao observado neste trabalho, o potencial médio $U_{m}$ apresenta uma evolução temporal mais complexa e fortemente dependente do padrão temporal, vide Figura 5.9(a) e (b), respectivamente. Esta sequência de janelas temporais (item (c)-(h)) ilustra a transição contínua de diferentes padrões oscilatórios observados com a variação lenta da corrente.

O primeiro padrão, item (c), é caracterizado pelo aumento gradual, seguido por um decréscimo súbito e aumento subsequente do potencial médio. Estas oscilações repetem por sete ciclos e são as que possuem as menores amplitudes. As maiores amplitudes são encontradas no item (e) e são as mais estáveis dentre aquelas observadas experimentalmente. A transição entre os itens (c) e (e) é mediada por um padrão composto, (d). Estas estruturas complexas são instáveis e existem apenas por dois ciclos. O padrão dado no item (f) é similar ao observado no item (e), mas com uma pequena modulação em altos potenciais. A principal característica nas estruturas temporais observadas nos itens (g) e (h) é a ocorrência do aumento gradual do potencial médio dada pela grande excursão em regiões de altos potenciais como nos padrões (e) e (f). Quando comparadas aos padrões observados no item (c), a permanência mais longa em altos potenciais resulta em uma oxidação mais eficiente de traços orgânicos superficiais o que resulta em um decréscimo mais agudo do potencial.

A dinâmica transiente, portanto, não resulta apenas em um acúmulo irreversível de uma espécie superficial, o que favoreceria apenas um aumento inexorável de $\mathrm{U}_{\mathrm{m}}$. Os autores propõem que o aumento da população de espécies oxigenadas $(\mathrm{H})_{\mathrm{x}} \mathrm{O}$ resulta no processo conhecido como place exchange em que átomos de oxigênio são inseridos na estrutura cristalina da platina com a finalidade de acomodar uma maior quantidade de espécies oxigenadas. [171] 
Figura 5.9 - Evolução do (a) potencial médio e (b) potencial do eletrodo durante a eletrooxidação galvanodinâmica de formaldeído sobre platina policristalina. Detalhes das oscilações são mostradas nas janelas (c)-(h). Eletrólito: $\left[\mathrm{H}_{2} \mathrm{SO}_{4}\right]=0,5 \mathrm{~mol} \mathrm{~L}^{-1}$ e $[\mathrm{HCHO}]=$ $0,1 \mathrm{~mol} \mathrm{~L}^{-1}$.
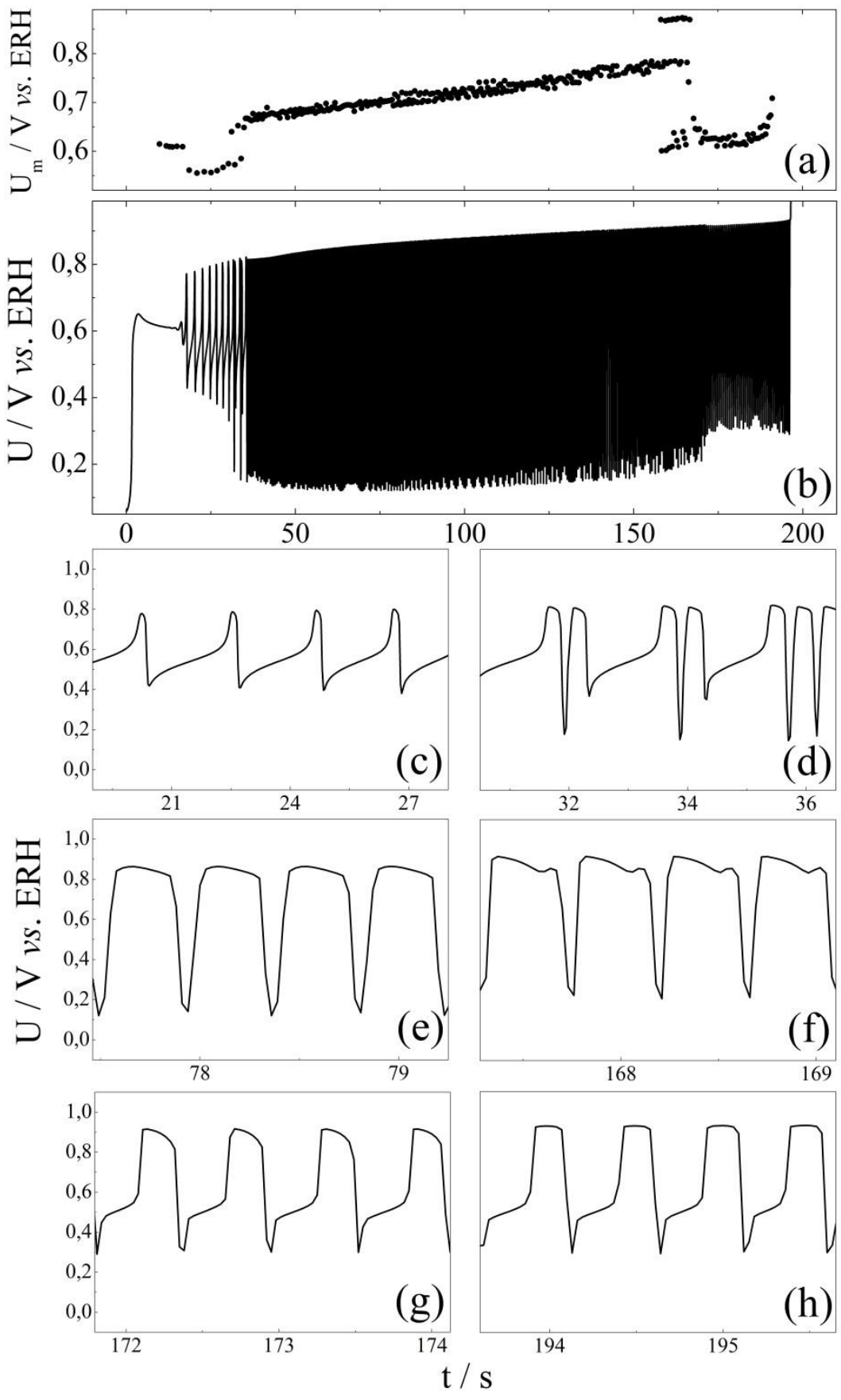

Oxigênio subsuperficial $\mathrm{O}_{\text {sub }}$ não participa da reação com monóxido de carbono segundo o mecanismo LH. Adicionalmente, o átomo de platina presente na ligação $\mathrm{O}_{\text {sub }} \mathrm{Pt}$ também não apresenta atividade frente uma reação faradaica, assim o aumento da formação de $\mathrm{O}_{\text {sub }}$ é equivalente à diminuição no número de sítios livres disponíveis, e 
consequentemente há o aumento da densidade da corrente local. Entretanto, no processo de place exchange, o oxigênio subsuperficial pode reemergir facilitando a reação com intermediários carbonáceos presente durante a eletro-oxidação de moléculas orgânicas. Desse modo, o consumo de espécies oxigenadas e a liberação de $\mathrm{O}_{\text {sub }}$ podem resultar no decaimento do potencial médio no decorrer da evolução da série temporal transiente. Mudanças do padrão temporal acompanhada pela variação na magnitude do potencial médio foram observadas durante a eletro-oxidação de formaldeído. [153]

Espécies aniônicas presentes no eletrólito de suporte também podem influenciar a evolução temporal do drift uma vez que o processo de adsorção é facilitado em altos potenciais como a formação de espécies oxigenadas. Ferreira et al. [172] estudaram o efeito do ânion trifluorometanosulfonato durante a eletro-oxidação de metanol em regime oscilatório. O aumento da concentração do ânion resultou na redução autocatalítica do número de ciclos pela diminuição da região oscilatória do oscilador central. Portanto, o aumento do recobrimento de uma espécie inerte intensificou a taxa na qual o drift ocorre. [172]

$\mathrm{O}$ esquema genérico do acoplamento entre os sistemas lento e rápido para o caso da eletro-oxidação de moléculas orgânicas pequenas é dado na Figura 5.10. O sistema lento (região em vermelho) acopla-se como o sistema rápido (região em azul) pela formação de espécies oxigenadas $(\mathrm{H})_{\mathrm{x}} \mathrm{O}$. Dois casos distintos, dependendo do sinal do ciclo no sistema lento aparecem. O primeiro (sinal positivo) é relacionado ao caso mais simples em que há apenas o aumento monotônico de $\mathrm{U}_{\mathrm{m}}$ pela formação de $(\mathrm{H})_{\mathrm{x}} \mathrm{O}$ e $\mathrm{O}_{\text {sub }} \mathrm{o}$ que promove o aumento da densidade de corrente local. Este comportamento está intimamente ligado á estreita faixa de potencial onde as oscilações ocorrem, prevenindo a emersão de $\mathrm{O}_{\text {sub }}$. No entanto, se o padrão temporal visitar regiões de baixos potenciais, eventualmente o ciclo do sistema lento pode trocar de sinal (sinal negativo). Isto acontece quando há um consumo pronunciado de $(\mathrm{H})_{\mathrm{x}} \mathrm{O}$ e emersão de $\mathrm{O}_{\text {sub }}$ o que favorece a diminuição de $\mathrm{U}_{\mathrm{m}}$.

Sabendo-se que as espécies $(\mathrm{H})_{\mathrm{x}} \mathrm{O}$ e $\mathrm{O}_{\text {sub }}$ são intermediários derivados da oxidação da água no meio reacional, é esperado que o drift tenha a mesma natureza independente da molécula orgânica em estudo. $O$ tratamento empírico apresentado assume uma evolução linear do drift o qual resultaria de uma evolução também linear da população de adsorbatos durante as oscilações não compensadas. Esta é uma aproximação questionável uma vez que foi observado experimentalmente que a evolução da cobertura de monóxido de carbono é nãolinear. [138] Além do mais, a simplificação do nosso tratamento se torna visível quando se nota que a VGN é menos eficiente em altos potenciais onde os padrões temporais observados 
são mais complicados. Em lugar de um tratamento sofisticado, a metodologia desenvolvida basicamente aplica conhecimentos prévios sobre as dinâmicas rápida e lenta. Ainda assim, o aumento do número de oscilações observado para um dado estado entre 5 e 20 vezes pode ser suficiente para caracterizar padrões temporais confinados a uma janela estreita de parâmetros. Discute-se a seguir como a compensação do drift pode fornecer informações sobre o mecanismo de envenenamento.

Figura 5.10 - Esquema genérico da interação entre os ciclos de retroalimentação (sistema rápido) com o drift (sistema lento) na geração de oscilações não-compensadas.

\section{sistema lento sistema rápido}

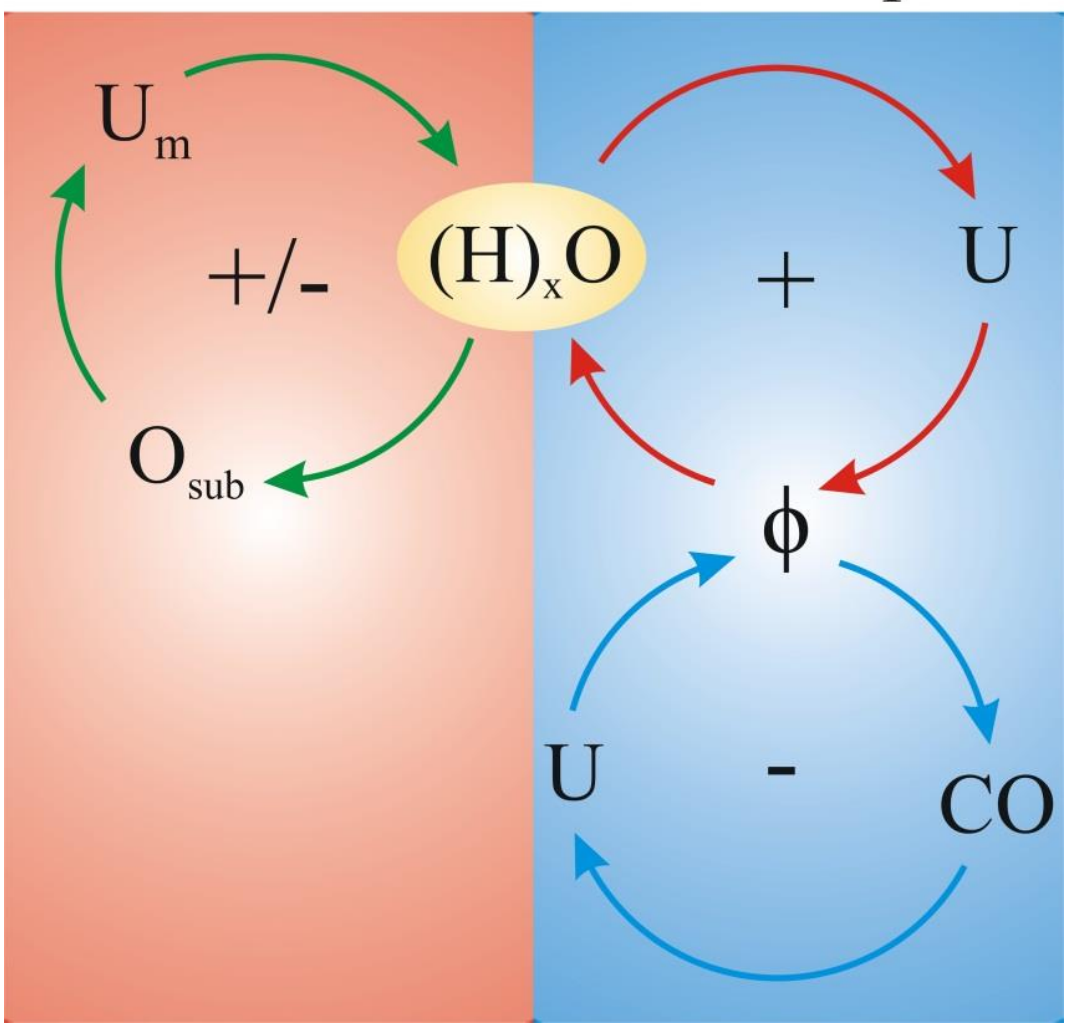

\subsubsection{O problema das Séries Não-Estacionárias}

O acoplamento entre diferentes escalas de tempo relativas a processos como transporte de massa, adsorção e reação presentes em sistemas eletroquímicos resulta em uma dinâmica bastante rica, incluindo uma variedade de padrões complexos. [56, 92, 101, 134-143, 162] A natureza não estacionária das séries temporais pode, a princípio, ser considerada uma 
característica indesejável quando o objetivo é a classificação dos padrões temporais, como a maioria dos casos. O método proposto aqui provou sua eficácia na estabilização das séries. No entanto, a característica não-estacionária não representa simplesmente uma imperfeição a ser evitada, ela pode também ser utilizada na obtenção de algumas informações sobre o mecanismo reacional.

A coexistência de diferentes escalas de tempo é um assunto importante e relativamente comum em dinâmica não-linear experimental, principalmente se considerarmos situações em que um processo lento associado a um parâmetro escondido conduz o sistema rápido por diferentes regiões. [173] A identificação deste processo lento é útil em distintas situações como a predição do efeito deletério do lento acúmulo de danos/fadiga em medidas (bio)mecânicas. Um método para seguir esta evolução, método de monitoração não-linear de danos (nonlinear damage tracking method) [173, 174] tem sido utilizado para acompanhar a evolução temporal de fadiga fisiológica e afins. [175-177] Este tipo de tratamento fornece a possibilidade de obter informações de processos biológicos aparentemente inacessíveis a partir de dados biomecânicos facilmente mensuráveis. A identificação prematura de doenças que evoluem lentamente por meio deste monitoramento abre interessantes perspectivas à solução de diferentes questões com motivações biológicas.

De fato, a ocorrência de ritmos acoplados é ubíqua na natureza e o entendimento de como diferentes ritmos se acoplam é essencial à exploração da riqueza por trás de séries temporais fisiológicas. Exemplos de problemas desta natureza relacionados à engenharia são a evolução de danos em estruturas e máquinas, predição de ruptura, processos de corrosão em estruturas, diminuição contínua de desempenho, e etc. [173-177] Em sistemas envolvendo reações químicas, este assunto permanece inexplorado e a dinâmica do sistema lento pode oferecer informações relevantes sobre a desativação de um processo catalítico, envolvendo enzimas ou, como no presente caso, uma superfície. Como observado nos exemplos citados, a identificação prematura pode ajudar a prevenir uma queda mais acentuada no desempenho do processo. Mais que algo a ser evitado, os aspectos não estacionários das séries temporais em sistemas químicos podem fornecer informações importantes se analisados de maneira apropriada. 


\subsection{Conclusões e Perspectivas}

Foi apresentado neste capítulo um tratamento empírico para estabilizar séries temporais experimentais. O método proposto foi aplicado para a eletro-oxidação de metanol sobre platina policristalina em solução aquosa de ácido perclórico. O sistema foi estudado em regime galvanostático e transições espontâneas entre padrões aproximadamente senoidais e de modo misto $\left(\mathrm{L}^{\mathrm{S}}: 1^{0} \rightarrow 1^{1} \rightarrow 1^{2} \rightarrow 1^{3} \rightarrow 1^{\mathrm{n}}\right.$, com $\mathrm{n}>3$ ) foram observadas numa faixa considerável de correntes aplicadas. Cada padrão temporal foi estabilizado por uma varredura galvanodinâmica negativa (VGN) em diferentes taxas, de forma que houve um aumento expressivo no número de ciclos oscilatórios, pelo menos 5 vezes para o padrão $1^{3}$ e mais de 20 vezes para o padrão $1^{0}$.

Simulações numéricas por meio de um oscilador eletroquímico do tipo HN-NDR genérico indicam um comportamento puramente superficial do drift. Qualitativamente, o modelo modificado reproduziu as características principais observadas experimentalmente o que valida o método empírico de estabilização. O parâmetro de bifurcação dependente do tempo atua como uma espécie que se adsorve irreversivelmente na superfície do eletrodo alterando a densidade de corrente local, sendo identificado como uma acumulação de espécies oxigenadas. No caso da eletro-oxidação de formaldeído, o potencial médio apresenta uma evolução mais complexa com transições agudas. É proposto que o acúmulo de espécies oxigenadas pode resultar no processo conhecido como place exchange que fornece espécies oxigenadas subsuperficiais para o consumo de intermediários orgânicos, intensificando a etapa de reativação, e portanto, gerando um comportamento não monotônico do aumento gradual do potencial médio.

Os resultados apresentados abrem uma interessante possibilidade para a investigação de padrões temporais confinados em regiões estreitas de parâmetros. Métodos experimentais para estabilizar séries temporais são importantes na tentativa de se construir diagramas de fase bidimensionais, numericamente antecipado para esta classe de oscilador. [63] O maior problema experimental na obtenção destes diagramas de alta resolução é a identificação de alguns padrões temporais confinados em uma região muito comprimida de parâmetros. $\mathrm{O}$ método discutido aqui é uma alternativa para ultrapassar esta limitação.

Além da estabilização em si, foi sugerido que alguns aspectos mecanísticos poderiam ser revelados a partir da análise do drift. Uma vez que o transiente em experimentos estacionários está relacionado ao envenenamento da superfície, a velocidade ótima de 
estabilização fornece informações sobre a velocidade de variação da cobertura de formação das espécies oxigenadas, vide Equação 5.12.

A estabilização de alguns padrões específicos pode ainda ter impacto no aumento da eficiência ou redução da dissipação de alguns sistemas operando em regime oscilatório. [178] Especificamente no contexto das células a combustível, foi mostrado recentemente que em regime oscilatório, o aumento do desempenho global do dispositivo depende fortemente da morfologia, período e amplitude das oscilações. [48-50] A estabilização de oscilações eletroquímicas de forma a maximizar o tempo em que o sistema permanece no estado de alta conversão é certamente um alvo relevante a ser explorado. 


\section{CAPÍtulo 6}

\section{DESACOPLAMENTO E EFEITO DE ÂNIONS NAS Vias PARALELAS DE PRODUÇÃO DE $\mathrm{CO}_{2}$ DURANTE A ElETRO-OXIDAÇÃO DE METANOL}

Neste capítulo é demonstrado por meio da combinação de experimentos, modelagem e simulações numéricas o desacoplamento das vias paralelas de produção de $\mathrm{CO}_{2}$ (i.e. via direta e indireta) durante a eletro-oxidação de metanol em regime oscilatório. O efeito dos ânions perclorato e sulfato foi estudado nos pesos relativos de produção de $\mathrm{CO}_{2}$ por meio da deconvolução dos picos da série temporal. Adicionalmente, a seletividade da corrente aplicada e a identificação dos precursores na formação de $\mathrm{CO}_{2}$ em diferentes picos foram abordadas. Os resultados foram publicados nos seguintes periódicos: R. Nagao et al. Phys. Chem. Chem. Phys. 2012, 14, 8294 - 8298 e R. Nagao et al. J. Phys. Chem. C 2013, 117, $15098-15105$. 



\subsection{Introdução}

Como discutido até o momento, as oscilações galvanostáticas durante a eletrooxidação de metanol foram estudadas por meio da monitoração da evolução do potencial. No entanto, esta variável representa uma medida global referente à distribuição da composição superficial das espécies adsorvidas no eletrodo e toda análise no mecanismo molecular é realizada indiretamente. $\mathrm{O}$ acesso às etapas elementares pode ser obtido pela modelagem e simulações numéricas e/ou pela monitoração de algum intermediário de reação via técnicas in situ ou on line acopladas ao sistema eletroquímico. De fato, a segunda abordagem tem sido utilizada no estudo da eletro-oxidação de metanol. [121, 122, 166, 179-181] Um esquema simplificado das rotas reacionais paralelas durante a eletro-oxidação de metanol é dado na Figura 6.1 (ver Capítulo 4 - Seção 4.2 para maiores detalhes).

Figura 6.1 - Esquema reacional simplificado para a eletro-oxidação de metanol.

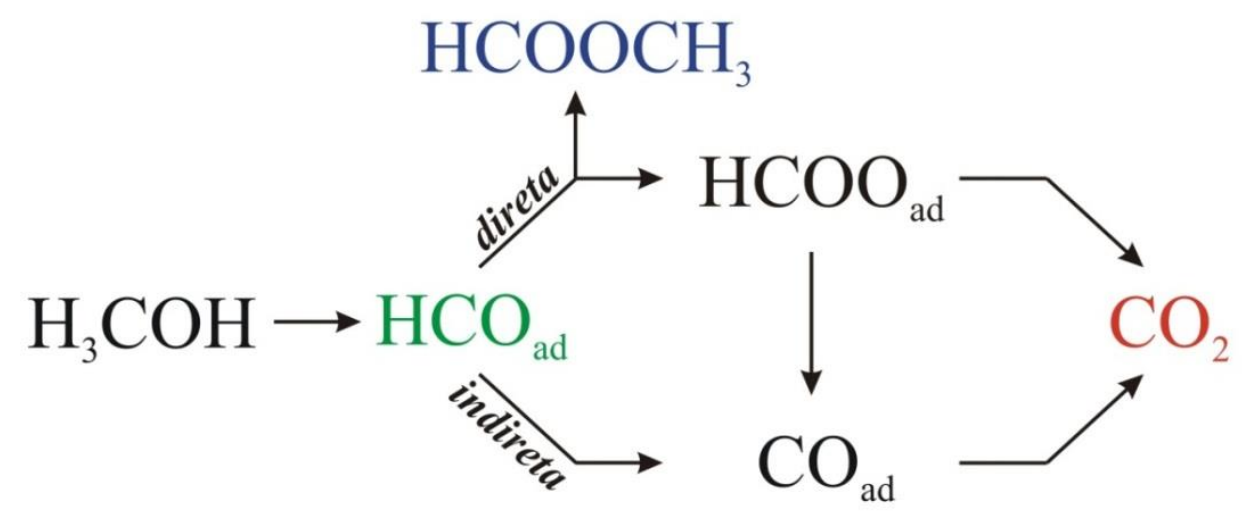

A via direta da reação acontece por meio da formação de intermediários reativos tais como formaldeído e ácido fórmico. Ambos podem atuar como precursores na formação de formiato adsorvido duplamente ligado pelos oxigênios $\left(\mathrm{HCOO}_{\mathrm{ad}}\right)$ o qual é considerado um intermediário ativo na produção de $\mathrm{CO}_{2}$ [82-88] e também na formação de $\mathrm{CO}_{\mathrm{ad}}$. [124] A via indireta ocorre em paralelo e procede pela formação de monóxido de carbono adsorvido $\left(\mathrm{CO}_{\mathrm{ad}}\right)$, o qual reage com espécies oxigenadas em altos potenciais via o mecanismo de Langmuir-Hinshelwood (LH). [125] Detectado por meio da técnica de espectrometria de massas eletroquímica diferencial (Differential Electrochemical Mass Spectrometry, DEMS) on line, [181] metilfomiato tem sido utilizado para inferir na cinética do caminho direto de reação. [182] Atualmente, acredita-se que a formação de metilformiato acontece por um ataque nucleofílico da molécula de metanol em um intermediário adsorvido $\mathrm{HCO}_{\mathrm{ad}}$ [123] em 
vez de uma reação homogênea entre ácido fórmico e metanol em solução. [122] No caso de um ataque nucleofílico de moléculas de $\mathrm{H}_{2} \mathrm{O}$ sob o intermediário adsorvido em vez de metanol, ácido fórmico é formado. [123]

Além das espécies carbonáceas ilustradas na Figura 6.1, a presença de espécies adsorvidas tais como oxigenadas e ânions presentes no eletrólito de suporte devem ser consideradas na descrição cinética durante a eletro-oxidação de metanol. A adsorção de tais espécies é conhecida por influenciar as taxas reacionais, seletividade, distribuição de produtos e etc. $[168-170,183,184]$ Tem sido postulado que a primeira etapa de adsorção da molécula de metanol é a que dita qual o caminho que a reação se procederá. [122] Se a adsorção acontece pelo átomo de carbono, uma rápida sequência de etapas de desidrogenação, requerendo pelo menos três sítios contíguos livres, [118, 119] irá gerar monóxido de carbono adsorvido levando à via indireta da reação. Por outro lado, se a adsorção proceder pelo átomo de oxigênio, espécies metóxi são formadas e a produção de formaldeído e ácido fórmico é favorecida, seguindo a via direta da reação. [122, 182]

Considerando que diferentes números de sítios reacionais são requeridos para cada caminho reacional, torna-se claro que a competição por sítios superficiais de espécies dissolvidas impactam fortemente na eficiência e na seletividade do processo como um todo. Apesar da vasta literatura da eletro-oxidação de metanol, a análise da cinética química pela medida de corrente juntamente com dados espectroscópicas e/ou espectrométricas tem sido embasada em evidências indiretas do mecanismo dual. [121, 122, 166, 179-182, 185] Apenas recentemente foi possível distinguir a contribuição das vias direta e indireta pela monitoração de um produto em comum as duas vias longe do equilíbrio termodinâmico. [61, 62]

Iwasita et al. [183, 184] investigaram o impacto da adsorção de ânions na distribuição de produtos ao longo da eletro-oxidação de metanol em platina por meio de medidas em cromatografia líquida de alta performance (High Performance Liquid Chromatography, HPLC). Eletrólises de $1000 \mathrm{~s}$ foram conduzidas à $0,6 \mathrm{~V} v s$ ERH o que evidenciaram o efeito inibitório dos ânions sulfato em comparação ao perclorato com respeito ao rendimento de produção de $\mathrm{CO}_{2}$ em superfícies de $\mathrm{Pt}(111)$. Em contraste, a produção de $\mathrm{HCHO}$ e $\mathrm{HCOOH}$ permaneceu praticamente inalterada frente a adsorção de ânions. Adicionalmente os autores também concluíram que embora sulfato adsorvido iniba a adsorção dissociativa de metanol, o ânion não altera de forma expressiva o processo de oxidação de $\mathrm{CO}_{\mathrm{ad}}$. A alta energia de adsorção específica dos ânions sulfato previne a formação de monóxido de carbono na superfície e diminui a corrente faradaica total. 
Altas taxas reacionais durante a eletro-oxidação de metanol em ácido perclórico também foi observado por Baltruchat et al. [185] utilizando uma célula de fluxo de camada fina acoplada ao DEMS on line. Entretanto, uma ligeira mudança foi verificada na eficiência de corrente de $\mathrm{CO}_{2}$ quando ácido perclórico foi trocado por sulfúrico. De modo geral, a quantidade de metilformiato foi de $10-13 \%$ maior em comparação à $\mathrm{CO}_{2}$ em baixos potenciais.

Neste capítulo, será inicialmente tratado o desacoplamento das vias paralelas de produção de $\mathrm{CO}_{2}$ na eletro-oxidação de metanol. A metodologia consiste na combinação integrada entre experimentos, modelagem e simulações numéricas. Uma vez identificada a contribuição de cada caminho reacional na distribuição de picos de $\mathrm{CO}_{2}$ observada na série temporal, diferentes ânions serão utilizados para perturbar o sistema. A influência da corrente aplicada e o efeito dos ânions na produção de $\mathrm{CO}_{2}$ foram analisados por meio da deconvolução dos picos observados nas séries temporais.

\subsection{Objetivos}

Sabendo-se da importância do conhecimento da cinética envolvida na produção de $\mathrm{CO}_{2}$ durante a eletro-oxidação de metanol, os objetivos desse trabalho foram definidos como:

- Análise do desacoplamento das vias reacionais paralelas direta e indireta pela combinação de experimentos, modelagem e simulações numéricas;

- Estudo do efeito da adsorção inibitória dos ânions perclorato e sulfato presentes no eletrólito de suporte nas vias paralelas de produção de $\mathrm{CO}_{2}$;

- Identificação dos precursores da produção de $\mathrm{CO}_{2}$ nos distintos picos presentes na série temporal;

O desacoplamento das vias paralelas de produção de $\mathrm{CO}_{2}$ é validado pelos experimentos de DEMS juntamente com um novo modelo proposto para a eletro-oxidação de metanol. A utilização de simulações numéricas permitiu a discriminação das etapas elementares envolvidas. Sabendo-se da natureza dos picos de $\mathrm{CO}_{2}$ presentes na série temporal, diferentes ânions como perclorato e sulfato foram utilizados para perturbar o 
sistema, o que favoreceu a classificação das espécies precursoras nos diferentes picos de produção de $\mathrm{CO}_{2}$.

\subsection{Resultados}

\subsubsection{O Desacoplamento das Vias Paralelas de Produção de $\mathrm{CO}_{2}$}

Figura 6.2 mostra a caracterização voltamétrica do sistema em termos da (a) densidade de corrente faradaica e variações nos fragmentos de massa (b) $\mathrm{m} / \mathrm{z}=44$ (dióxido de carbono) e (c) $\mathrm{m} / \mathrm{z}=60$ (metilformiato), obtidas em regime potenciodinâmico a dU/dt $=0,01 \mathrm{~V} \mathrm{~s}^{-1}$. Em geral, as características desses três perfis voltamétricos estão em concordância com os resultados experimentais relatados na literatura. [121, 166, 179, 181]

Figura 6.2 - (a) voltametria cíclica a dU/dt $=0,01 \mathrm{~V} \mathrm{~s}^{-1}$ e fragmentos de massa $\mathrm{m} / \mathrm{z}=$ (b) $44 \mathrm{e}$ (c) 60 monitorados simultaneamente durante a eletro-oxidação de metanol. $\left[\mathrm{H}_{3} \mathrm{COH}\right]=2,0$ mol L ${ }^{-1},\left[\mathrm{HClO}_{4}\right]=0,5 \mathrm{~mol} \mathrm{~L}^{-1}$ e T $=20^{\circ} \mathrm{C}$.

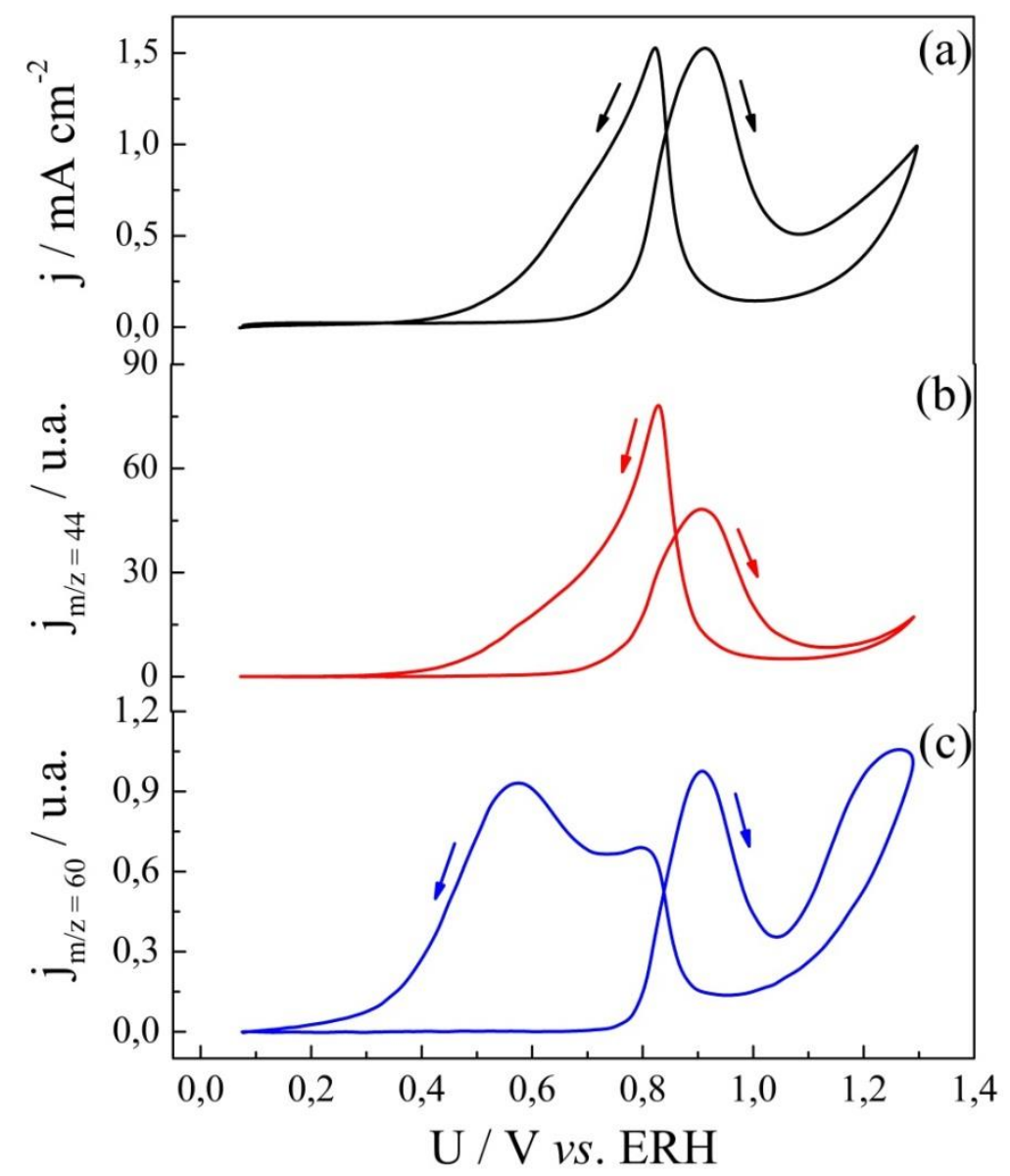


Como no caso de muitas moléculas orgânicas pequenas, [34] a eletro-oxidação de metanol é conhecida por apresentar oscilações de corrente e potencial em determinadas circunstâncias. [90, 91, 137-139, 143, 152] Figura 6.3 mostra séries temporais típicas registradas simultaneamente a $\mathrm{j}=0,35 \mathrm{~mA} \mathrm{~cm}^{-2}$ para (a) o potencial do eletrodo e fragmentos de massa $\mathrm{m} / \mathrm{z}=$ (b) 44 e (c) $60 . \mathrm{O}$ atraso máximo estimado pela detecção de massa $(<0,10$ s) é consideravelmente menor do que o período oscilatório (c.a. 4,3 s), de tal forma que as séries temporais podem ser consideradas sincronizadas para efeitos práticos.

Figura 6.3 - Série temporal a j = $0,35 \mathrm{~mA} \mathrm{~cm}^{-2}$ do (a) potencial do eletrodo durante a eletrooxidação de metanol acompanhadas pelos fragmentos de massa $\mathrm{m} / \mathrm{z}=$ (b) 44 e (c) 60 . $\left[\mathrm{H}_{3} \mathrm{COH}\right]=2,0 \mathrm{~mol} \mathrm{~L}^{-1},\left[\mathrm{HClO}_{4}\right]=0,5 \mathrm{~mol} \mathrm{~L}^{-1}$ e $\mathrm{T}=20^{\circ} \mathrm{C}$.

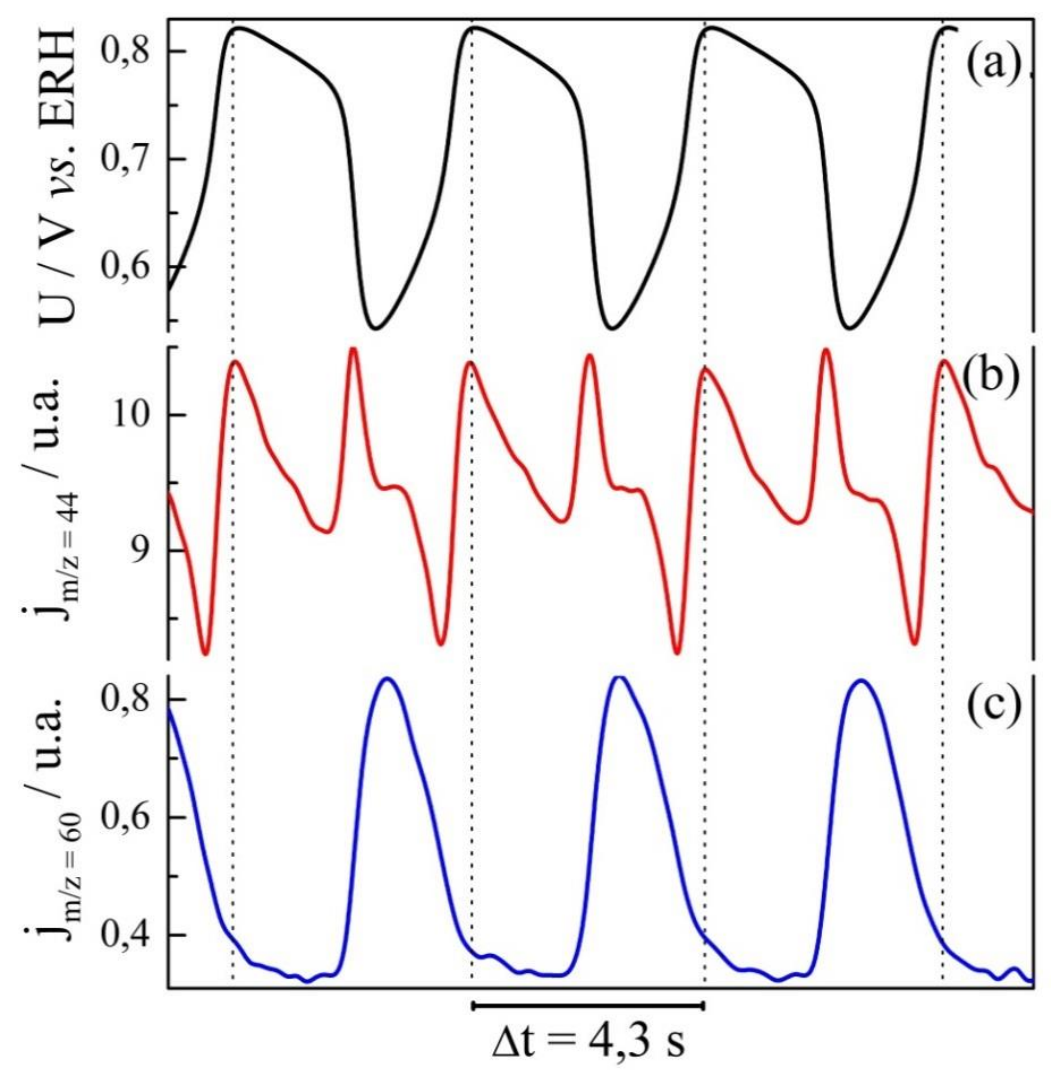

$\mathrm{O}$ aspecto principal a ser realçado na Figura 6.3 é a presença de picos adicionais na produção de $\mathrm{CO}_{2}$ para cada período da oscilação. Este, de certa forma, está em contraste também com as oscilações regulares de período-1 para o fragmento de massa do $\mathrm{HCOOCH}_{3}$. $\mathrm{O}$ fato de que o perfil oscilatório mais complexo para a produção de $\mathrm{CO}_{2}$ não se equipara com o período mais simples das oscilações de potencial do eletrodo e para a formação de metilformiato é uma dica de que este sinal na verdade representa uma combinação de mais de 
uma etapa elementar. Este é o aspecto principal discutido aqui e será desenvolvido a seguir. A conjectura que a produção de $\mathrm{CO}_{2}$ vem parcialmente da oxidação de $\mathrm{CO}_{\mathrm{ad}}$ está de acordo com os resultados publicados utilizando-se da espectroscopia de infravermelho in situ, [138] no sentido de que oscilações de período-1 foram encontradas para o recobrimento de $\mathrm{CO}_{\mathrm{ad}}$, e em condições similares para série temporal de potencial. A integração das Equações 4.25 até 4.30 resultaram em oscilações para diversas combinações de constantes de velocidades, séries temporais simuladas típicas são ilustradas na Figura 6.4.

Figura 6.4 - Series temporais simuladas usando as Equações 4.25 até 4.31 para: (a) $\phi$, potencial da dupla camada; (b) $v_{5}+v_{9}, \mathrm{CO}_{2}$ total; (c) $x_{2}$, recobrimento de $\mathrm{HCO}$; (d) $v_{5}, \mathrm{CO}_{2}$ da via indireta (e) $v_{9}, \mathrm{CO}_{2}$ da via direta. Ver Capítulo 4 - Seção 4.2 para maiores detalhes.

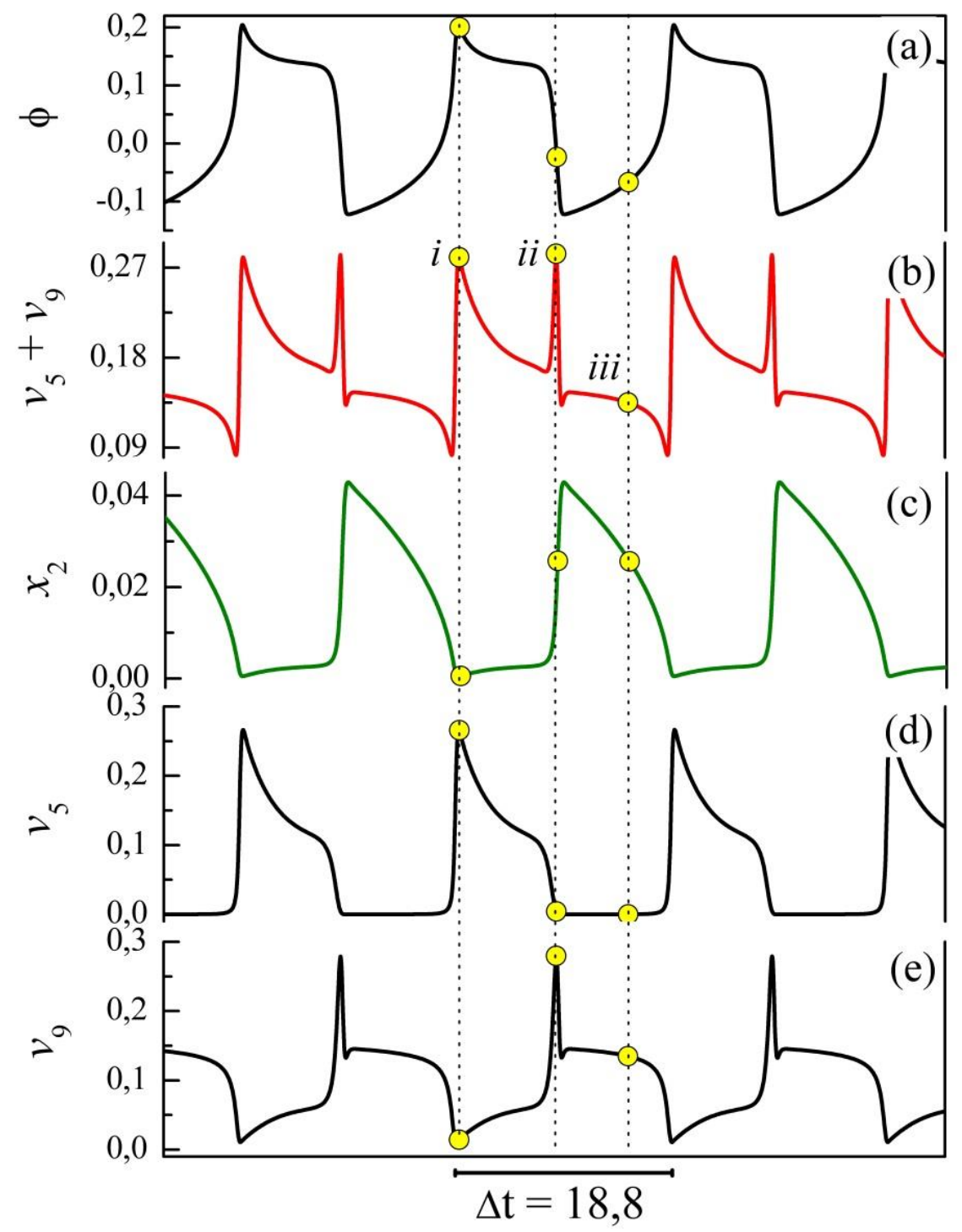


Os perfis simulados para (a) o potencial no plano reacional e (b) produção total de $\mathrm{CO}_{2}$ podem ser comparados ao observados experimentalmente e mostrados na Figura 6.3(a) e (b), respectivamente. Seguindo e esquema ilustrado nas Figura 4.1 e Figura 6.1, a concentração de $\mathrm{HCO}$ adsorvido pode ser interpretada como uma espécie proporcional à concentração de metilformiato dissolvido. Comparando as fases relativas das séries temporais simuladas para $\phi$ e $\mathrm{HCOOCH}_{3}$, Figura 6.4(a) e (c), e experimentos, Figura 6.3(a) e (c), evidenciam uma boa correspondência e em ambos os casos a produção de metilformiato permanece fora de fase com relação ao potencial. Focando agora na série temporal de produção de $\mathrm{CO}_{2}$, Figura 6.4(b), picos $i$ e ii possuem fases e amplitudes relativas comparáveis com respeito ao potencial do eletrodo ao observado experimentalmente, Figura 6.3(b). O pequeno ombro designado como iii aparece em pequenas amplitudes e um pouco mais separado do pico ii, quando comparado ao observado nos experimentos. Apesar dessa pequena discrepância, o valor mínimo da produção de $\mathrm{CO}_{2}$ em ambos, experimentos e simulações, coincide.

Dada a boa congruência entre experimentos e simulações, os resultados podem ser consistentemente interpretados. O ponto principal é que a produção complexa de $\mathrm{CO}_{2}$ resulta da soma de duas contribuições paralelas: a via indireta e a via direta, Figura 6.4(d) e (e), como evidenciado pela decomposição do sinal global, Figura 6.4(b). A produção de $\mathrm{CO}_{2}$ via $\mathrm{CO}_{\mathrm{ad}}$, Figura 6.4(d), oscila em fase com o potencial do eletrodo, coincidindo os pontos de máximos em ambos perfis. $\mathrm{Na}$ via direta, Figura 6.4(e), a maior produção de $\mathrm{CO}_{2}$ ocorre muito bruscamente durante o decréscimo do potencial do eletrodo e coincide com o aumento da produção de $\mathrm{HCO}_{\mathrm{ad}}$. Há uma concordância geral de que a eletro-oxidação de metanol sobre platina proceda via o mecanismo dual ou paralelo. Em baixos potenciais, $\mathrm{CO}_{\mathrm{ad}}$ é muito estável e a oxidação através da via direta é dominante. Em altos potenciais, onde $\mathrm{CO}_{\mathrm{ad}}$ é prontamente oxidado, ambos os caminhos reacionais tornam-se importantes e ocorrem em paralelo. Embora convincente, as evidências para este mecanismo são indiretos e apenas a produção total de $\mathrm{CO}_{2}$ tem sido monitorada até agora. [121, 122, 166, 179-182, 185] Trabalhando longe do estado de equilíbrio termodinâmico, especificamente em condições oscilatórias, foi possível desacoplar as contribuições paralelas, direta e indireta medindo um produto em comum de ambas as rotas (i.e. $\mathrm{CO}_{2}$ ). 


\subsubsection{A Influência da Adsorção Inibitória de Ânions nas Vias Paralelas}

O efeito do eletrólito de suporte foi estudado em duas concentrações de metanol. Figura 6.5 mostra os resultados para $\left[\mathrm{H}_{3} \mathrm{COH}\right]=0,50 \mathrm{~mol} \mathrm{~L}^{-1}$ (item (a)) e 2,0 mol L-1 (item (b)) em termos da corrente voltamétrica (índice 1), produção de dióxido de carbono $\left(\mathrm{CO}_{2}, \mathrm{~m} / \mathrm{z}\right.$ $=44$ e índice 2) e metilformiato $\left(\mathrm{HCOOCH}_{3}, \mathrm{~m} / \mathrm{z}=60\right.$ e índice 3). De maneira geral, o uso de $\mathrm{H}_{2} \mathrm{SO}_{4}$ (linha vermelha) em vez de $\mathrm{HClO}_{4}$ (linha preta) resulta em um decréscimo generalizado da corrente faradaica assim como na produção de $\mathrm{CO}_{2}$ e $\mathrm{HCOOCH}_{3}$. Os perfis voltamétricos e de fragmentos de massa são independentes da concentração de metanol e da natureza do eletrólito de suporte com uma produção dominante de dióxido de carbono sobre metilformiato em todo intervalo de potencial estudado. O pico principal de corrente ao longo da varredura positiva (negativa) foi descolado para valores mais positivos de potenciais de aproximadamente $80 \mathrm{mV}(60 \mathrm{mV})$ quando do aumento da concentração de metanol para 2,0 mol L'-1.

Figura 6.5 - Voltametrias cíclicas (índice 1) monitoradas simultaneamente com os fragmentos de massa $\mathrm{m} / \mathrm{z}=44$ (índice 2) e 60 (índice 3) durante a eletro-oxidação de metanol sob eletrodo de platina à $\left[\mathrm{H}_{3} \mathrm{COH}\right]=0,5 \mathrm{~mol} \mathrm{~L}^{-1}$ (item (a)) e 2,0 $\mathrm{mol} \mathrm{L}^{-1}$ (item (b)) em eletrólito aquoso de $\mathrm{HClO}_{4}$ (linha preta) e $\mathrm{H}_{2} \mathrm{SO}_{4}$ (linha vermelha). $\left[\mathrm{HClO}_{4}\right]=\left[\mathrm{H}_{2} \mathrm{SO}_{4}\right]=0,5 \mathrm{~mol} \mathrm{~L}^{-1}$. $\mathrm{dU} / \mathrm{dt}=0,01 \mathrm{~V} \mathrm{~s}^{-1}$ e $\mathrm{T}=20^{\circ} \mathrm{C}$.

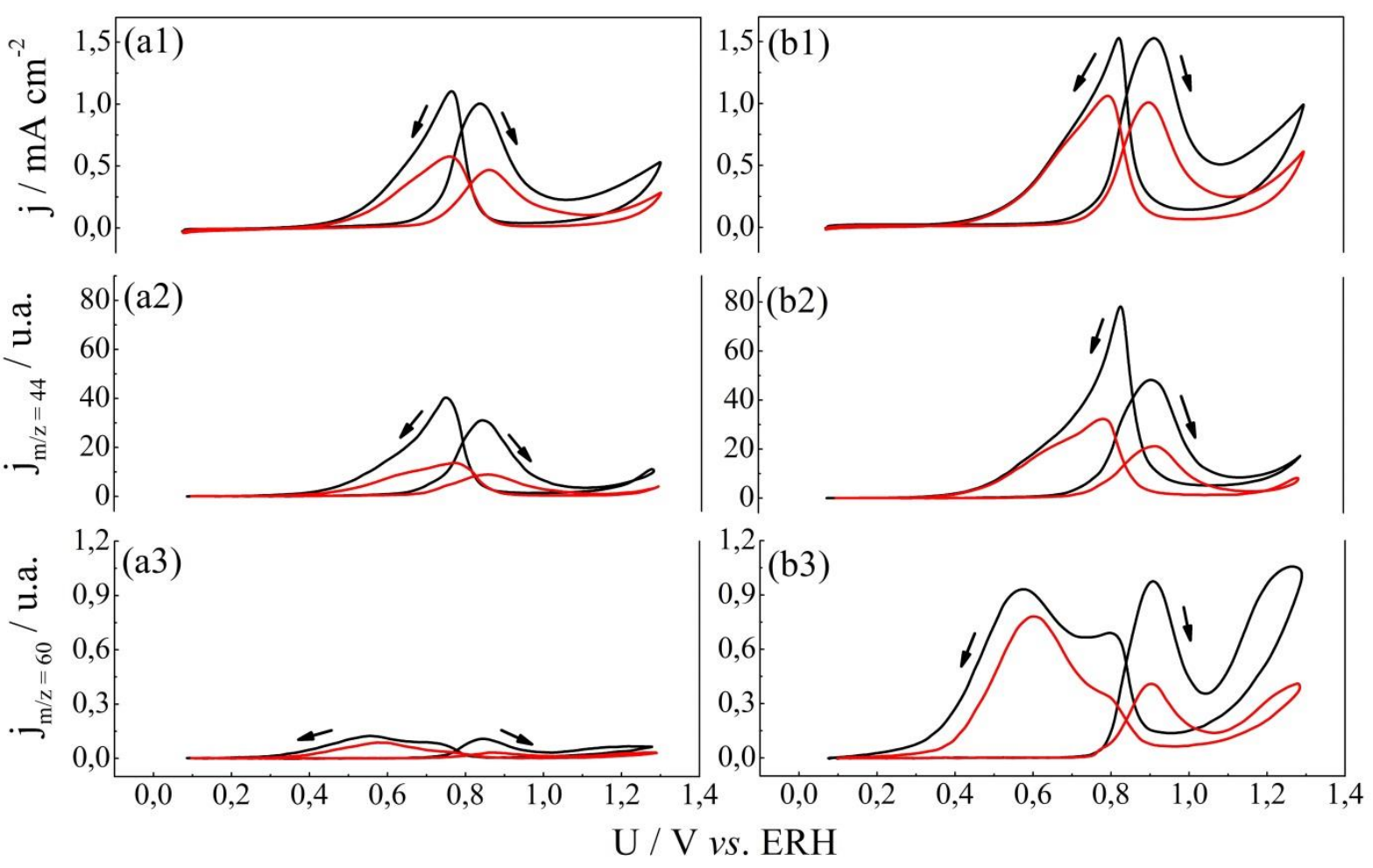


Em contraste com os aspectos relativamente bem conhecidos da adsorção de ânions e concentração de metanol em experimentos de voltametria cíclica, o efeito de tais parâmetros torna-se intricados em regime oscilatório. Como já relatado para este sistema, [91, 137, 138, 143, 152] oscilações de período-1 com grandes amplitudes emergem abruptamente em valores de correntes intermediárias. Exemplos de tais oscilações são dados na Figura 6.6 para $\left[\mathrm{H}_{3} \mathrm{COH}\right]=0,50 \mathrm{~mol} \mathrm{~L}^{-1}$ (item (a)) e 2,0 mol L-1 (item (b)) em solução aquosa de $\mathrm{HClO}_{4}$ (índice 1 até 3) e $\mathrm{H}_{2} \mathrm{SO}_{4}$ (índice 4 até 6).

Perfis oscilatórios do potencial do eletrodo (linha preta) e da produção de metilformiato (linha azul) possuem amplitude e morfologia similares em ambos os eletrólitos, mas o período oscilatório é em torno de $25 \%$ maior para o caso do ácido sulfúrico. Este aumento no período tem sido geralmente associado ao efeito inibitório causado pela adsorção de ânions. [159] A produção oscilatória de dióxido de carbono é muito mais susceptível à natureza do eletrólito de suporte, viz. adsorção de ânions. Como observado na Seção 6.3.1, as séries temporais experimentais do potencial do eletrodo e da evolução de $\mathrm{CO}_{2}$ e $\mathrm{HCOOCH}_{3}$ têm sido racionalizadas em termos da combinação integrada entre modelagem e simulações numéricas com experimentos de bancada. Em particular, focando-se na produção dos multipicos de $\mathrm{CO}_{2}$, observa-se que o pico $i$ resulta principalmente da via indireta enquanto que os picos ii e iii refletem a contribuição da via direta da reação. A mesma descrição pode ser utilizada para explicar o mecanismo associado aos picos $i$ ' a iii' em ácido sulfúrico. Uma observação importante é a ausência do pico iii e a supressão considerável dos picos ii' e iii' quando a concentração de metanol utilizada foi de 0,5 $\mathrm{mol} \mathrm{L}^{-1}$. Embora a ordem de magnitude de produção de $\mathrm{CO}_{2}$ seja basicamente a mesma em ambas as concentrações de metanol e composição de eletrólitos estudados, a produção de $\mathrm{HCOOCH}_{3}$ é consideravelmente afetada pela concentração de metanol em torno de 10 vezes maior para $\left[\mathrm{H}_{3} \mathrm{COH}\right]=2,0$ mol L $\mathrm{L}^{-1}$. Adicionalmente, a concentração de metanol praticamente não afetou de maneira significativa o período oscilatório em ambos os eletrólitos.

A densidade de corrente aplicada influência as intensidades dos picos na série temporal de $\mathrm{CO}_{2}$. Figura 6.7 mostra as séries temporais de $\mathrm{CO}_{2}$ em cinco diferentes densidades de corrente aplicadas em condições similares ao dado na Figura 6.6 em solução aquosa de (a) $\mathrm{HClO}_{4}$ e (b) $\mathrm{H}_{2} \mathrm{SO}_{4}$. A linha vertical tracejada indica a contribuição da via indireta da reação, i.e. pico $i$ ou $i$ '. Com o aumento da densidade de corrente, a produção de $\mathrm{CO}_{2}$ proveniente dessa via torna-se mais pronunciada e uma maior definição dos picos é 
observada quando ânions sulfato estão presentes no meio reacional. Salienta-se aqui a robustez do sistema pela estabilidade do ciclo limite.

Figura 6.6 - Séries temporais de período-1 (linha preta) durante a eletro-oxidação de metanol à $\left[\mathrm{H}_{3} \mathrm{COH}\right]=0,5 \mathrm{~mol} \mathrm{~L}^{-1}$ (item (a)) e 2,0 mol L-1 (item (b)) em solução aquosa de $\mathrm{HClO}_{4}$ (índice 1 à 3) e $\mathrm{H}_{2} \mathrm{SO}_{4}$ (índice 4 à 6 ) sob densidade de corrente aplicada $\mathrm{j}=0,30 \mathrm{~mA} \mathrm{~cm}^{-2}$ acompanhadas pelos fragmentos de massa $\mathrm{m} / \mathrm{z}=44$ (linha vermelha) e 60 (linha azul). Picos $i$ ou $i$ ' representam contribuições da via indireta e $i i$ ou $i i$ ' para a via direta. Detalhes adicionais na Figura 6.5.
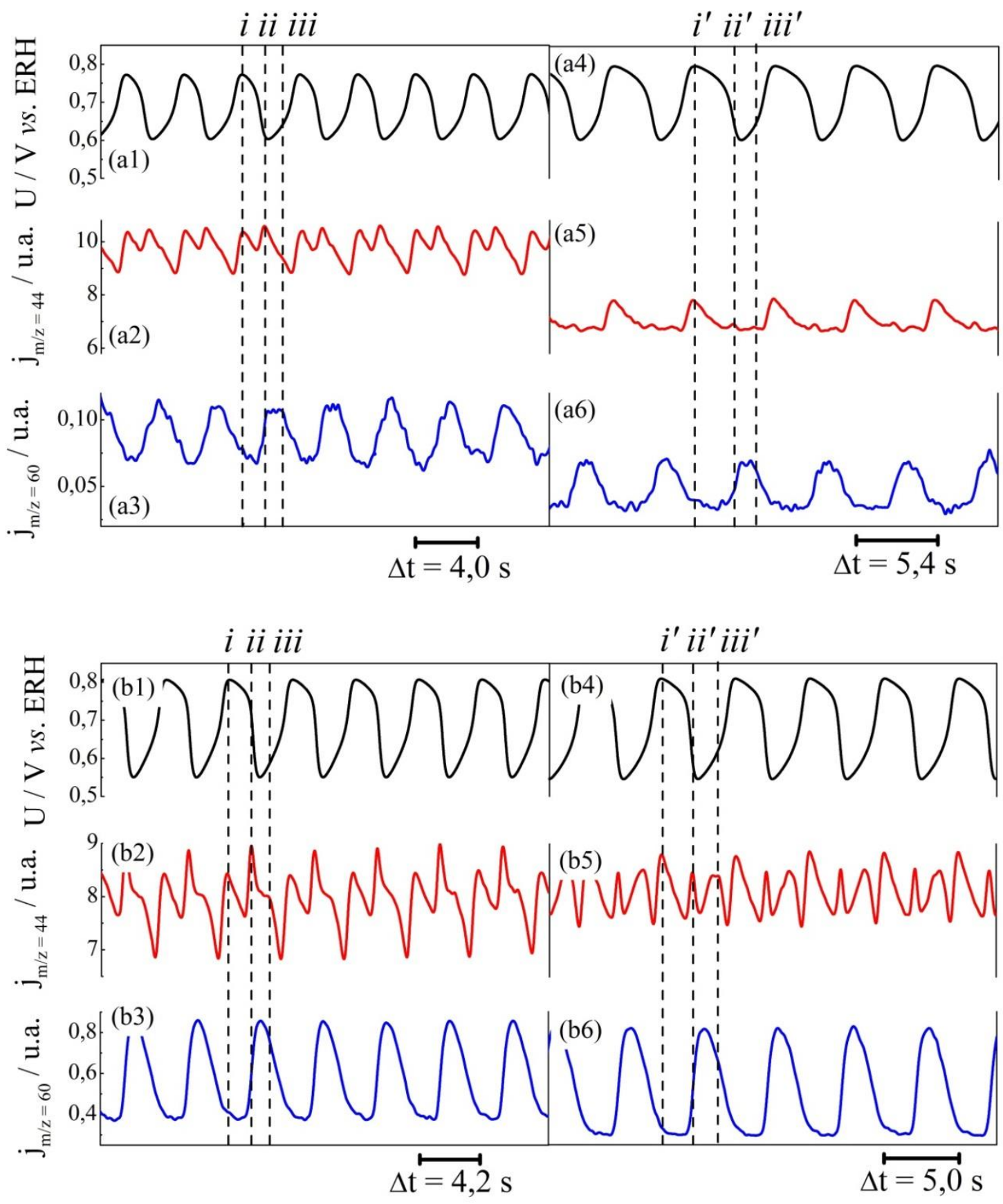
Figura 6.7 - Evolução temporal do fragmento de massa $\mathrm{m} / \mathrm{z}=44$ durante a eletro-oxidação de metanol em diferentes densidades de corrente aplicadas: $\mathrm{j}=0,20 \mathrm{~mA} \mathrm{~cm}^{-2}$ até $0,40 \mathrm{~mA} \mathrm{~cm}^{-2} \mathrm{e}$ $\left[\mathrm{H}_{3} \mathrm{COH}\right]=2,0 \mathrm{~mol} \mathrm{~L}{ }^{-1}$ em solução aquosa de (a) $\mathrm{HClO}_{4}$ e (b) $\mathrm{H}_{2} \mathrm{SO}_{4}$. A linha vertical tracejada indica o pico de $\mathrm{CO}_{2}$ proveniente da oxidação de monóxido de carbono (i.e. pico $i$ ou $\left.i^{\prime}\right)$. Detalhes adicionais na Figura 6.5.

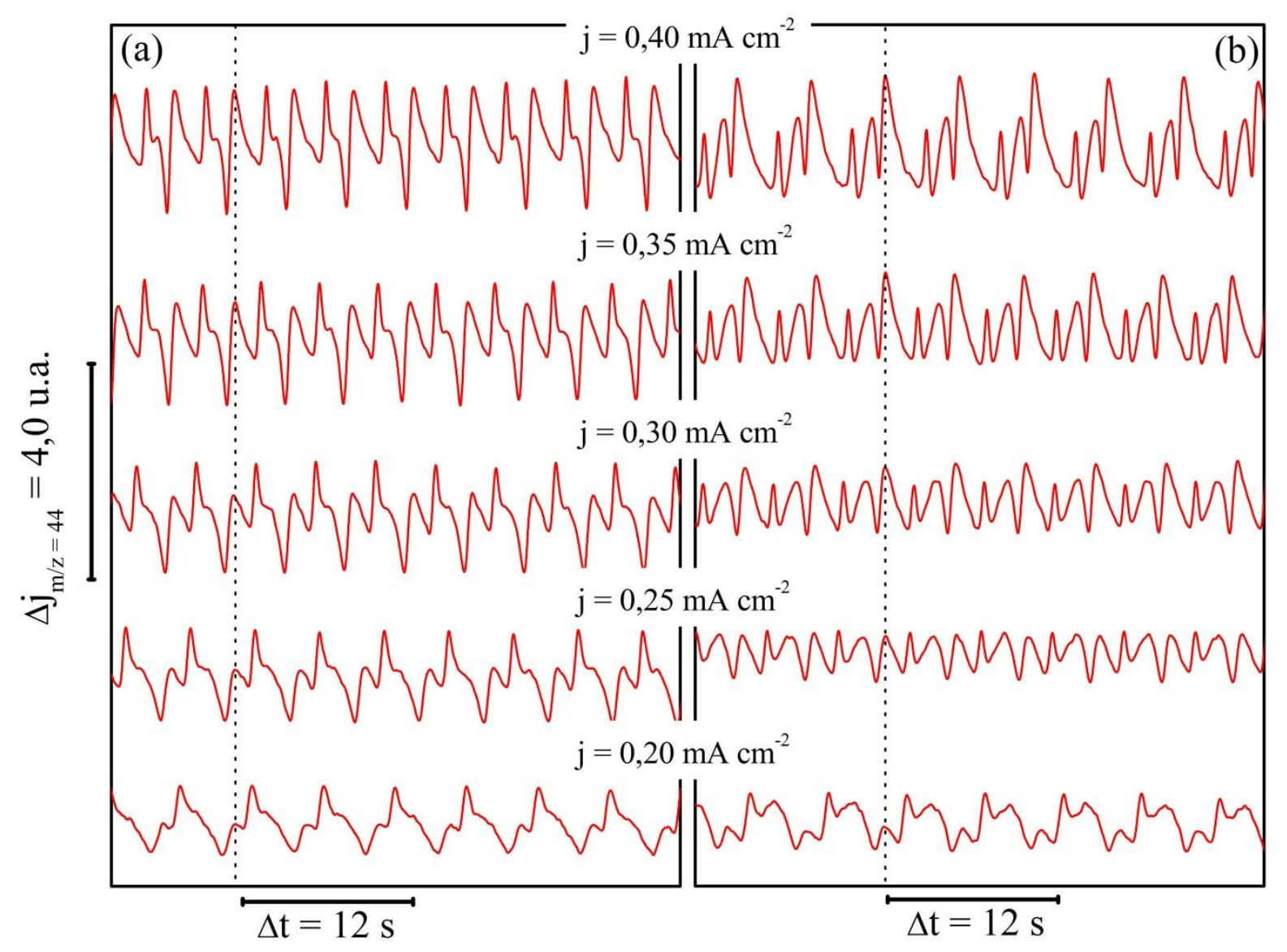

Os picos de $\mathrm{CO}_{2}$ apresentados na Figura 6.6 foram deconvoluídos (ver Anexos para o procedimento de deconvolução utilizado) e a contribuição da formação de $\mathrm{CO}_{2}$ avaliada para a via direta e indireta da reação, assumindo que a maior contribuição da via indireta provém do pico $i$ ( $i$ ') enquanto que a via direta está relacionada com os picos ii e iii (ii' e iii'). Os resultados obtidos são apresentados na Figura $6.8 \mathrm{com} \mathrm{j}=0,30 \mathrm{~mA} \mathrm{~cm}^{-2}$ em soluções aquosas de ácido perclórico e sulfúrico.

Quatro observações importantes podem ser extraídas da evolução em longo prazo das contribuições individuais nesta figura: (a) de modo geral, a produção relativa de $\mathrm{CO}_{2}$ é maior na presença de $\mathrm{HClO}_{4}$ em vez de $\mathrm{H}_{2} \mathrm{SO}_{4}$ em ambas as concentrações de metanol; (b) as contribuições dos caminhos paralelos de produção de $\mathrm{CO}_{2}$ possuem pesos similares em praticamente todos os casos; (c) existe um ligeiro aumento na produção temporal de $\mathrm{CO}_{2}$, uma 
vez que as oscilações evoluem no tempo tanto para via direta quanto para a indireta, exceto para o decréscimo inicial observado para a rota direta em $\left[\mathrm{H}_{3} \mathrm{COH}\right]=2,0 \mathrm{~mol} \mathrm{~L}^{-1}$; e (d) a inibição causada pela adsorção de ânions foi em geral mais pronunciada na via direta da reação. Em densidades de corrente consideravelmente mais altas, o padrão temporal de período-1 é substituído por oscilações de período-2. [152]

Figura 6.8 - Contribuição dos picos de $\mathrm{CO}_{2}$ da via: (a) indireta (pico $i$ ou $i$ ') e (b) direta (picos ii e iii ou ii' e iii') em função do tempo com $\mathrm{j}=0,30 \mathrm{~mA} \mathrm{~cm}^{-2}$. Experimentos realizados em solução aquosa de $\mathrm{HClO}_{4}$ (linha preta) e $\mathrm{H}_{2} \mathrm{SO}_{4}$ (linha vermelha) nas concentrações de metanol 0,5 mol L ${ }^{-1}$ (círculos preenchidos) e 2,0 $\mathrm{mol} \mathrm{L}^{-1}$ (círculos abertos). Dados obtidos pela deconvolução dos picos de $\mathrm{CO}_{2}$ apresentados na Figura 6.6.

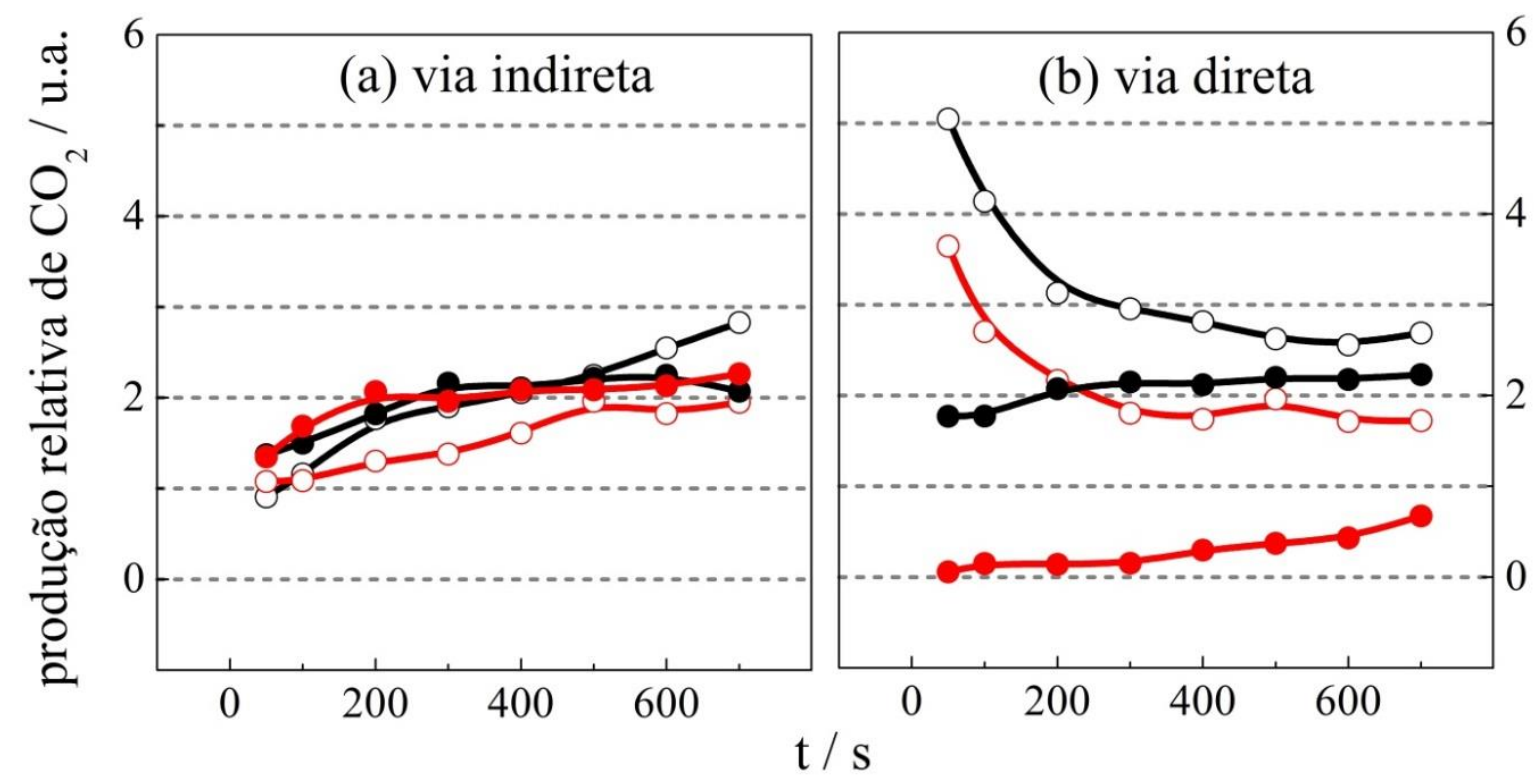

A Figura 6.9 ilustra as oscilações de período-2 no potencial do eletrodo, as quais são caracterizados por uma pequena modulação em altos potenciais em ambos os eletrólitos. A produção de metilformiato permanece muito similar ao encontrado para o período-1 e nenhum traço da modulação em altos potenciais é detectado na região quiescente. Como já evidenciado para o período-1, mudanças mais dramáticas foram detectadas para a série temporal de produção de $\mathrm{CO}_{2}$. 
Figura 6.9 - Séries temporais de período-2 (linha preta) durante a eletro-oxidação de metanol em $\left[\mathrm{H}_{3} \mathrm{COH}\right]=0,5 \mathrm{~mol} \mathrm{~L}^{-1}$ (item (a) com j $=0,35 \mathrm{~mA} \mathrm{~cm}^{-2}$ ) e $2,0 \mathrm{~mol} \mathrm{~L}^{-1}$ (item (b) com $\mathrm{j}=$ $0,40 \mathrm{~mA} \mathrm{~cm}^{-2}$ ) em solução aquosa de $\mathrm{HClO}_{4}$ (índice 1 à 3) e $\mathrm{H}_{2} \mathrm{SO}_{4}$ (índice 4 à 6) acompanhadas pelos fragmentos de massa $\mathrm{m} / \mathrm{z}=44$ (linha vermelha) e 60 (linha azul). Detalhes adicionais na Figura 6.5.
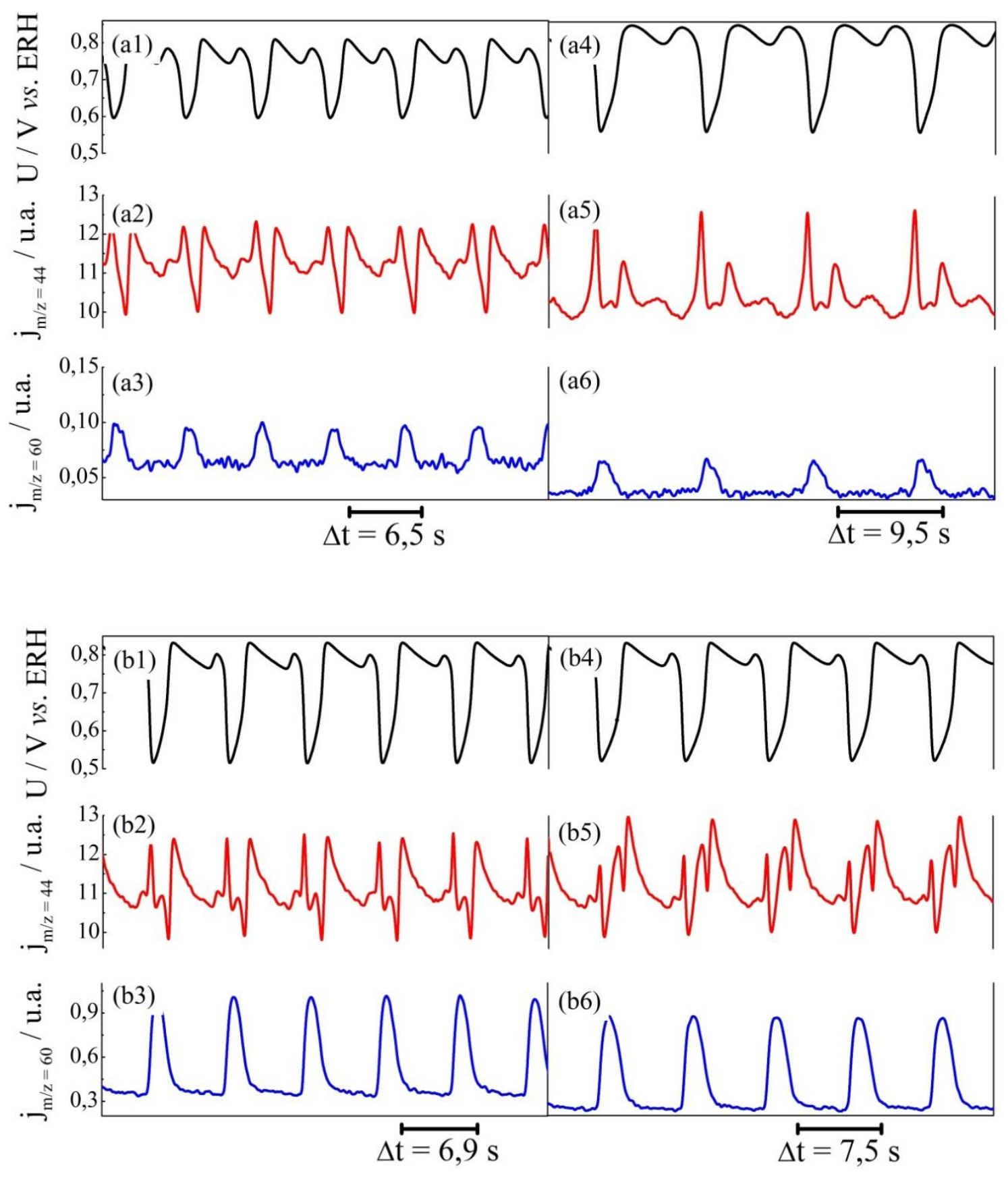


\subsection{Discussão}

A caracterização voltamétrica do sistema apresentada nas Figura 6.2 e Figura 6.5 atestam a sincronia entre a corrente faradaica e os sinais de fragmentos de massa, além da qualidade dos resultados em geral. As características gerais das voltametrias têm sido relatadas. [121, 166, 179, 181] A discussão desta seção será estruturada como segue. Primeiramente são examinados os aspectos da resposta oscilatória correspondente ao período1 e o efeito da adsorção dos ânions. A evolução em longo prazo da dinâmica do sistema e sua relação com a adsorção de ânions e produção de $\mathrm{CO}_{2}$ é brevemente discutida. Em seguida, foca-se nas estruturas de período-2 observadas em altas densidades de corrente. Por fim, é feita uma discussão com algumas considerações mecanísticas do papel do efeito do ânion na reação de eletro-oxidação longe e perto do equilíbrio termodinâmico.

\subsubsection{Oscilações de Potencial de Período-1}

Apesar das investigações anteriores sobre a eletro-oxidação oscilatória de ácido fórmico e formaldeído utilizando-se da técnica DEMS on line, [116, 186] os resultados relatados aqui para metanol podem ser classificados um tanto quanto que incomum. Em contraste com uma série temporal de estruturação de pico único para as oscilações de potencial e metilformiato, é encontrado uma estruturação de picos múltiplos para a evolução de $\mathrm{CO}_{2}$. O modelo proposto juntamente com as simulações numéricas reproduziram de forma satisfatória as observações experimentais de tal forma que a produção de picos múltiplos de $\mathrm{CO}_{2}$ na verdade permite o desacoplamento das vias paralelas de oxidação, direta e indireta. Espectrometria de massas tem sido utilizada para monitorar a produção de $\mathrm{CO}_{2}$ durante a eletro-oxidação oscilatória de monóxido de carbono na interface sólido/gás. [187, 188] Mas, à medida que a complexidade da molécula é considerada, a eletro-oxidação de metanol é aparentemente a única reação até o momento a apresentar a separação das vias paralelas de oxidação à $\mathrm{CO}_{2}$. [61]

A produção de $\mathrm{CO}_{2}$ pela via indireta acontece na porção da série de potencial correspondente a $\mathrm{U}>\sim 0,76 \mathrm{~V}$. A taxa de produção de $\mathrm{CO}_{2}$ através deste caminho reacional, i.e. reação entre $\mathrm{CO}_{\mathrm{ad}} \mathrm{e}(\mathrm{H})_{\mathrm{x}} \mathrm{O}_{\mathrm{ad}}(\mathrm{x}=0,1$ ou 2, dependendo da natureza da espécie oxigenada), aumenta de forma explosiva durante o aumento rápido de potencial e decai vagarosamente 
seguindo a diminuição do potencial e cai praticamente a zero quando $U$ torna-se menor que 0,76 V. Por outro lado, a produção de $\mathrm{CO}_{2}$ ao longo da via direta prevalece no intervalo de potencial $<0,76 \mathrm{~V}$, essencialmente onde o recobrimento de espécies oxigenadas é muito pequeno.

Baseado nessa descrição, torna-se possível discutir alguns aspectos mecanísticos da eletro-oxidação de metanol e sua relação com a adsorção de ânions. Como dado na Figura 6.6, a quantidade relativa de $\mathrm{CO}_{2}$ e $\mathrm{HCOOCH}_{3}$ produzidas em regime oscilatório é comparável em ambos os eletrólitos. Entretanto, as características da produção oscilatória de metilformiato são praticamente idênticas independentemente do eletrólito empregado na mesma concentração de metanol, o mesmo também acontece para oscilações mais complexas, c.f. Figura 6.9. De forma geral, a série temporal para a produção de metilformiato está fora de fase em relação às oscilações de potencial do eletrodo. Essa característica é também evidente nos perfis dos fragmentos de massas na Figura 6.2 e Figura 6.5.

Centrando agora nos detalhes da série temporal de produção de $\mathrm{CO}_{2}$, três picos para cada ciclo oscilatório são claramente discerníveis na Figura 6.6. O pico iii' previamente não observado para $\left[\mathrm{H}_{3} \mathrm{COH}\right]=2,0 \mathrm{~mol} \mathrm{~L} \mathrm{~L}^{-1}$ observado ao longo do aumento do potencial, relembra o ombro iii presente quando $\mathrm{HClO}_{4}$ é usado nas mesmas janelas de potencial, vide Figura 6.3. Como já discutido e de acordo com as simulações numéricas, o recobrimento de espécies oxigenadas nesta região de potencial é desprezível e a produção de $\mathrm{CO}_{2}$ vem predominantemente da via direta da reação. Ao contrário do pico bem definido iii', o ombro iii é seguido por um decréscimo agudo na produção de $\mathrm{CO}_{2}$ no caminho direto. Para baixas concentrações de metanol, há uma supressão significativa dos picos correspondentes à via direta seguido de um decréscimo do sinal de metilformiato. Portanto, pico iii e iii' podem ser associados com a re-oxidação parcial de produtos solúveis. Note que a subida do pico iii e iii ' coincide com a máxima produção de $\mathrm{HCOOCH}_{3}$.

\subsubsection{Dinâmica em Longo Prazo}

$\mathrm{O}$ efeito do eletrólito de suporte nas contribuições relativas da produção de $\mathrm{CO}_{2}$ foi analisado em toda a série temporal da Figura 6.6. De maneira geral, a produção de $\mathrm{CO}_{2}$ aumenta no tempo e comportamento similar também é observado em função da densidade de corrente aplicada (ver Anexos para maiores informações). O coeficiente angular para a curva 
de produção de $\mathrm{CO}_{2}$ vs. tempo em $\left[\mathrm{H}_{3} \mathrm{COH}\right]=0,5 \mathrm{~mol} \mathrm{~L}^{-1}$ é ligeiramente maior para o caso do ácido sulfúrico $\left(1,4510^{-3}\right.$ u.a. $\left.\mathrm{s}^{-1}\right)$ do que o observado para o ácido perclórico $\left(0,7310^{-3}\right.$ u.a. $\left.\mathrm{s}^{-1}\right)$. Essa observação está de acordo com o processo de envenenamento superficial causado pela adsorção de ânions na dinâmica em longo prazo. [172] Quando $\left[\mathrm{H}_{3} \mathrm{COH}\right]=2,0 \mathrm{~mol} \mathrm{~L}^{-1}$, há inicialmente um decréscimo seguido de um aumento da produção total de $\mathrm{CO}_{2}$. No entanto, para tempos longos, o aumento monotônico de $\mathrm{CO}_{2}$ é mais evidente e é dominante em altas densidades de corrente.

Como demonstrado no Capítulo 5, o drift espontâneo na série temporal tem sido racionalizado em termos de uma acumulação de espécies oxigenadas na superfície como o resultado do aumento da corrente local. Consequentemente, estas espécies oxigenadas adicionais podem reagir com $\mathrm{CO}_{\mathrm{ad}}$ por meio do mecanismo de Langmuir-Hinshelwood (LH) e a maior produção de $\mathrm{CO}_{2}$ proveniente da via indireta resulta no aumento do pico $i$ ou $i$ ' como observado quando há o aumento da densidade de corrente, Figura 6.7. Para a evolução em longo prazo, como o número de sítios livres está diminuindo em função do tempo, é esperado que o formiato adsorvido se acumulasse ligeiramente na superfície com o intuito de induzir a produção de $\mathrm{CO}_{2}$ da via direta. Entretanto, em altas concentrações de metanol, o decréscimo de $\mathrm{CO}_{2}$ é evidente. Neste caso, uma maior acumulação de espécies adsorvidas provenientes da adsorção dissociativa de metanol no eletrodo poderia resultar em um bloqueio na decomposição oxidativa de formiato, pela estabilização desta molécula e prevenção da quebra da ligação C-H. [82, 84]

\subsubsection{Oscilações de Potencial de Período-2}

Um aspecto adicional a ser discutido consiste na duplicação de período de potencial mostrado na Figura 6.9 depois da transição espontânea sofrida pelo sistema mediante a aplicação de uma corrente constante. A diferença principal entre oscilações de período-1 e período-2 é a presença de pequenas modulações observadas brevemente antes da queda de potencial para baixos valores. A Figura 6.10 mostra uma visão detalhada dessas séries temporais para ambos os eletrólitos a $\left[\mathrm{H}_{3} \mathrm{COH}\right]=2,0 \mathrm{~mol} \mathrm{~L}^{-1}$.

Como já foi mencionado, a produção de metilformiato permanece praticamente inalterada por esta pequena modulação na série temporal de potencial. Em contraste, a modulação de potencial é quase que espelhada no sinal de $\mathrm{CO}_{2}$ como observado pelo pequeno 
Figura 6.10 - Detalhes das oscilações de período-2 apresentadas na Figura 6.9 para soluções aquosas de (a) $\mathrm{HClO}_{4}$ e (b) $\mathrm{H}_{2} \mathrm{SO}_{4}$ em $\left[\mathrm{H}_{3} \mathrm{COH}\right]=2,0$ mol L ${ }^{-1}$.

(a) $\mathrm{HClO}_{4}$

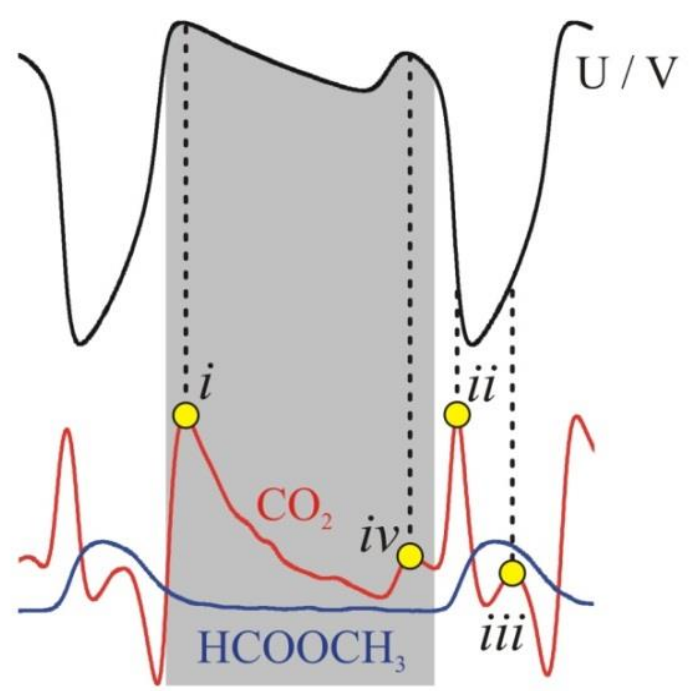

$\mathrm{H}_{2} \mathrm{SO}_{4}(\mathrm{~b})$

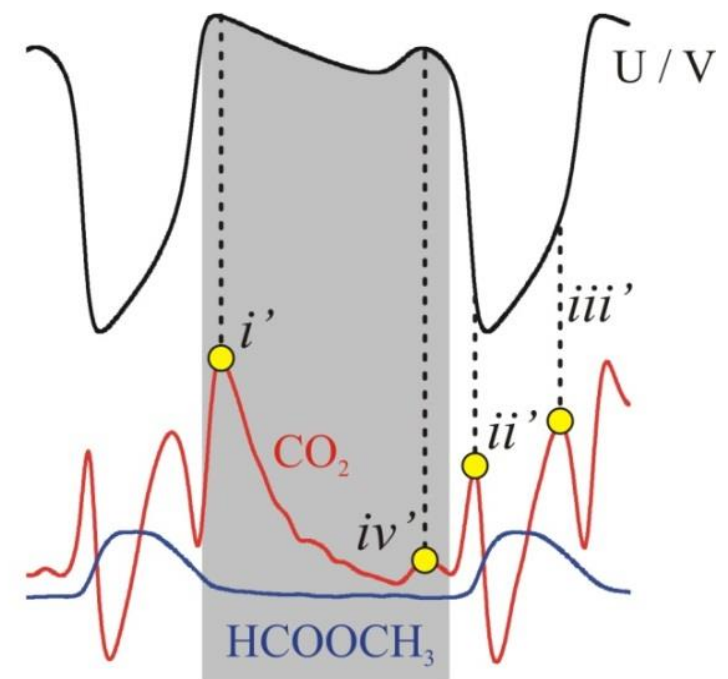

pico $i v$ ( $i v$ ' em ácido sulfúrico). As regiões em cinza delimitam a janela de potencial (i.e. $\mathrm{U} \geq$ $0,76 \mathrm{~V}$ ) na qual a adsorção de espécies oxigenadas ocorre. Neste sentido, é razoável assumir que a produção de $\mathrm{CO}_{2}$ em torno do pico iv ou $i v$ ' surge por meio da remoção oxidativa de $\mathrm{CO}_{\mathrm{ad}}$ via o mecanismo LH, i.e. via indireta da reação. Isto significa que o suboscilador para a oxidação de CO deve ser considerado na modelagem de oscilações de modo misto. De fato, esta pequena modulação em altos potenciais é usualmente observada durante a eletrooxidação de moléculas orgânicas pequenas, as quais possuem monóxido de carbono como um intermediário em comum. [92, 152, 153, 162]

Além dessa rota paralela, o caminho direto também apresenta dois picos diferentes associados à produção de $\mathrm{CO}_{2}$, denominados pico ii e iii, ou ii' e iii'. O pico ii ou ii', emerge quando o potencial do eletrodo decai abruptamente devido ao processo de reativação superficial que acontece junto com a formação de $\mathrm{HCOOCH}_{3}$. No entanto, quando o potencial aumenta novamente, este processo é suprimido e um subsequente inicia-se. O pico iii ou iii' surge quando metilformiato está perto do máximo de produção. Estas evidências indicam que, embora pertençam ao mesmo caminho reacional, pico $i i$ ( $\left.i i^{\prime}\right)$ é originado de uma rota diferente do pico iii ( $\left.i i i^{\prime}\right)$. Enquanto que o primeiro é induzido por um aumento explosivo no número de sítios livres, ou seja, um processo superficial, o último acontece quando a velocidade de formação de $\mathrm{HCOOCH}_{3}$ aumenta o que indica um processo de readsorção, por exemplo, de 
ácido fórmico que é produzido por um ataque nucleofílico da água no intermediário adsorvido, HCO.

\subsubsection{Considerações Mecanísticas}

A cinética química subjacente à produção de $\mathrm{CO}_{2}$ durante a eletro-oxidação de moléculas orgânicas pequenas é fortemente dependente da distribuição de sítios superficiais. A estratégia site-knockout desenvolvido por Cuesta [189] tem se mostrado um método poderoso em racionalizar efeitos de conjunto de átomos superficiais no mecanismo reacional. Resultados experimentais baseados em eletrodos de $\mathrm{Pt}(111)$ modificado com cianeto indicam que a formação de $\mathrm{CO}_{\mathrm{ad}}$ requer pelo menos três átomos de platina para a eletro-oxidação de metanol, enquanto que apenas dois sítios adjacentes são suficientes para promover a oxidação completa para $\mathrm{CO}_{2}$ através da via direta. [118, 119, 189] Estas evidências estão de acordo com o efeito de bloqueio dos ânions onde uma inibição mais intensa ocorreria no caminho reacional que necessitasse de um conjunto maior de átomos superficiais. Neste contexto, Iwasita et al. [183, 184] e Koper et al. [122] demonstraram que a formação de CO durante a eletro-oxidação de metanol é muito mais afetada por ânions sulfato do que perclorato, o que reflete na menor produção de $\mathrm{CO}_{2}$ em ácido sulfúrico.

A produção de $\mathrm{CO}_{2}$ proveniente da via indireta em regime oscilatório mostrou ser menos sensível à natureza dos ânions presentes no eletrólito em ambas às concentrações de metanol, vide Figura 6.8. Essa menor sensibilidade ao envenenamento superficial poderia ser explicado pelo consumo e reposição das mesmas quantidades de $\mathrm{CO}_{\mathrm{ad}}$ (i.e. similares $\Delta \theta_{\mathrm{CO}} \mathrm{em}$ um ciclo oscilatório) em ambos os eletrólitos, entretanto um menor recobrimento total de $\mathrm{CO}_{\mathrm{ad}}$ deve ser encontrado na presença de ácido sulfúrico. O comportamento é esperado uma vez que a adsorção de ânions não afeta de forma significativa a oxidação de monóxido de carbono. [184] Portanto, a produção de $\mathrm{CO}_{2}$ em regime oscilatório originado da via indireta é menos dependente do número de sítios superficiais, como evidenciado pela aparente e quase invariante morfologia, período e amplitude do pico $i$ ou $i$ ' quando perturbado com diferentes ânions.

O efeito da adsorção de ânions em condições oscilatórias é mais pronunciado na via direta da reação pela mudança mais significativa na produção de $\mathrm{CO}_{2}$, especialmente à $\left[\mathrm{H}_{3} \mathrm{COH}\right]=0,5 \mathrm{~mol} \mathrm{~L}^{-1}$, calculadas pela deconvolução dos picos ii (ii') e iii (iii'). Embora o 
número de sítios superficiais requeridos seja aparentemente menor para a via direta do que para a via indireta a adsorção de sulfato parece afetar mais fortemente essa rota. Adicionalmente, um decréscimo expressivo de aproximadamente 10 vezes de formação de metilformiato foi observado experimentalmente, o que é um indicativo da menor produção de intermediários reacionais dissolvidos que podem se readsorver na superfície. A diferença na produção de $\mathrm{CO}_{2}$ da via direta entre as duas concentrações de metanol pode estar relacionada com a diferença de produção do fragmento de massa $\mathrm{m} / \mathrm{z}=60$. Uma contribuição significativa da formação de $\mathrm{CO}_{2}$ aparenta ser originada do processo de re-adsorção de espécies solúveis. Como íons sulfato bloqueiam mais efetivamente sítios superficiais, a decomposição oxidativa de ácido fórmico e/ou formaldeído para $\mathrm{CO}_{2}$, os quais são produtos parcialmente oxidados e participam da via direta, são consequentemente afetados. As observações experimentais observadas neste capítulo estão de acordo com este cenário. Comparando a produção de $\mathrm{CO}_{2}$ em regime regular e oscilatório, torna-se claro que a adsorção de ânions inibe predominantemente a via direta da reação em ambas as concentrações de metanol.

\subsection{Conclusões e Perspectivas}

Neste capítulo foi estudado o desacoplamento das vias paralelas de produção de $\mathrm{CO}_{2}$ durante a eletro-oxidação de metanol e o efeito dos ânions perclorato e sulfato nos picos correspondentes às vias direta e indireta em regime oscilatório. Os experimentos foram conduzidos sob condições voltamétricas e, predominantemente em regime oscilatório, tendo a série temporal registrada concomitantemente à evolução da produção de $\mathrm{CO}_{2}$ e $\mathrm{HCOOCH}_{3}$ por meio da técnica DEMS on line. Os resultados são sumarizados a seguir.

Com base na combinação de experimentos, modelagem e simulações numéricas, as vias reacionais paralelas, direta e indireta responsáveis pela produção de $\mathrm{CO}_{2}$ foram desacopladas em regime oscilatório. $\mathrm{O}$ pico $i\left(i^{\prime}\right)$ corresponde à produção de $\mathrm{CO}_{2}$ proveniente da via indireta da reação enquanto que o pico ii ( $\left.i i^{\prime}\right)$ ou iii (iii') da via direta, vide Figura 6.10.

Em regime oscilatório, a inibição causada pela adsorção de ânions foi geralmente mais pronunciada na via direta da reação. Esta diferença esta ligada à baixa formação de intermediários solúveis como ácido fórmico e/ou formaldeído. Embora os picos ii (ii') e iii (iii') pertencem a via direta, foi observado que o pico ii ( $i i^{\prime}$ ) é originado de uma rota diferente ao comparado com o pico iii ( $\left.i i i^{\prime}\right)$. Enquanto que o primeiro tem uma dependência da 
produção autocatalítica de sítios superficiais, o último é referente a um processo de readsorção de intermediários solúveis.

Considerando as oscilações de período-2, foi encontrado um pico adicional $i v(i v$ ') em altos potenciais correspondentes à via indireta da reação. Esta conclusão adiciona informações mecanísticas na formação de estruturas temporais periódicas complexas durante a eletrooxidação de moléculas orgânicas pequenas.

Estudos como o apresentado aqui, podem inspirar esforços experimentais e teóricos e contribuir, por exemplo, na elucidação de aspectos mecanísticos de fenômenos químicos que acontecem na interface sólido/líquido. Os resultados descritos podem ser também vistos como uma metodologia precisa a ser empregada na identificação do papel de modificadores superficiais (e.g. segundo metal como $\mathrm{Ru}, \mathrm{Sn}, \mathrm{Bi}$ e etc.) no peso relativo de ambos os caminhos reacionais. Propriedades importantes como seletividade do catalisador e constantes de velocidade para etapas elementares em paralelo poderiam ser extraídas em tais experimentos. 


\section{Capítulo 7}

CONCLusões GeRAIS 

Esta tese de doutorado abordou dois casos distintos da elucidação do mecanismo reacional quando o sistema se encontrava longe do equilíbrio termodinâmico:

- O acúmulo de espécies oxigenadas ao longo da série temporal eletroquímica é o principal responsável pelo drift durante a eletro-oxidação oscilatória de moléculas orgânicas pequenas. De forma geral, este acúmulo superficial proporciona o aumento da densidade de corrente local, movendo o sistema para uma região de estado estacionário. A estabilização do padrão temporal oscilatório torna-se possível pela compensação da corrente aplicada por meio de uma varredura galvanodinâmica negativa.

- O desacoplamento das vias paralelas de produção de $\mathrm{CO}_{2}$ durante a eletrooxidação de metanol ocorre em regime oscilatório galvanostático. O desacoplamento tão bem como os pesos relativos da via direta e indireta na série temporal foi avaliado por meio da combinação entre experimentos, modelagem e simulações numéricas. Os ânions presentes no eletrólito de suporte afetam de forma significativa os caminhos reacionais. Íons sulfato bloqueiam mais fortemente a superfície, em relação aos íons perclorato, e previnem majoritariamente a produção de $\mathrm{CO}_{2}$ proveniente da via direta da reação.

Como demonstrado, algumas informações importantes sobre a cinética química não são acessíveis em condições próximas ao equilíbrio. Nesta situação, o sistema relaxa rapidamente para o estado estacionário e nenhum estado de coerência, tanto no tempo quanto no espaço, é observado. No entanto, quando o gradiente é grande o suficiente para levar o sistema para longe do equilíbrio termodinâmico, fenômenos não-lineares intrínsecos à cinética química do sistema são amplificados. Acompanhadas de uma dinâmica expressa comumente na forma de oscilações, o mecanismo molecular se apresenta de forma diferente e particularidades entre o acoplamento das etapas elementares de reação são evidenciadas. Essa interpretação mecanística adotada nessa tese de doutorado realça a possibilidade de ser utilizada como uma metodologia alternativa no estudo da eletrocatálise de reações químicas acopladas. A importância da exploração do comportamento complexo intrínseco na obtenção de informações do mecanismo molecular tem sido discutida por Tributsch [190] e van Saten. [191] De fato, esta abordagem pode trazer um passo adiante em comparação à análise tradicional. 
O trabalho pioneiro de Gerhard Ertl, laureado com o premio Nobel de Química de 2007, no estudo da oxidação de CO sobre superfícies monocristalinas em ultra-alto-vácuo pode ser citado como um exemplo típico de obtenção de informações do mecanismo reacional durante a formação de padrões espaço-temporais na interface sólido/gás. [192] Em homenagem a sua contribuição no entendimento dos processos químicos em superfícies sólidas, foi fundado recentemente o Ertl Center for Electrochemistry and Catalysis sediado na Coreia do Sul, tendo como objetivo central o estudo de problemas globais ligados à catálise, como a conversão de energia e controle de poluição. [193] Notavelmente, um dos três pilares que compõe o centro de pesquisa refere-se ao estudo da Dinâmica Química Não-linear.

Outro aspecto importante a ser destacado nesta tese é a combinação sinérgica entre modelagem, e simulações numéricas juntamente com experimentos de bancada na discussão e validação dos mecanismos reacionais propostos. [194] Diversas conjecturas baseadas em observações experimentais podem ser suportadas pela elaboração de um modelo matemático que reflete as condições estudadas. Embora não seja uma evidência direta do fenômeno, o qual só pode ser apenas obtido mediante observações experimentais, as simulações numéricas dão um forte indicativo ou direção do mecanismo reacional regente. Grande avanço no campo da dinâmica química não-linear tem sido obtido por esta combinação e, como observado, a grande maioria dos trabalhos publicados em periódicos indexados segue esta tendência. 


\section{Capítulo 8}

\section{Trabalhos FutURos - Sistema DE AQUISIÇÃO DE DADOS MULTICANAL}

Em paralelo aos trabalhos realizados nessa tese de doutorado, foi construído um setup experimental de um sistema de aquisição de dados multicanal com resolução espaçotemporal. Este aparato experimental permite o estudo da formação, seleção e evolução de padrões espaço-temporais em ambiente eletroquímico. Neste capítulo, é mostrado o procedimento de construção do eletrodo multicanal consistindo de 32 eletrodos de platina policristalina equidistantes sob uma configuração anular unidimensional. A interface de aquisição em Labview e um sistema de tratamento de sinal foram também implementados para a melhoria da relação sinal/ruído. A confecção do setup experimental foi dividida em três etapas: (a) verificação, (b) calibração e (c) validação. Para as primeiras medidas foi utilizada a eletro-oxidação de ácido fórmico como sistema modelo. 



\subsection{Motivação}

$\mathrm{O}$ entendimento de processos relacionados às propriedades emergentes em sistemas complexos é diretamente dependente da dinâmica temporal de cada elemento reacional e respectivas interações e acoplamento. Em determinado valores dos parâmetros de controle, a formação de padrões auto-organizados, acompanhadas de uma dinâmica temporal não-linear, pode surgir longe do equilíbrio termodinâmico. Exemplos em sistemas químicos e biológicos são frequentemente observados. [1-3] Neste sentido, osciladores eletroquímicos têm sido utilizados como sistemas modelos na mimetização do comportamento periódico em sistemas biológicos. [39] A dinâmica coletiva de sincronização de fase é um exemplo típico de uma resposta espaço-temporal encontrado sob um conjunto de osciladores eletroquímicos. [40-46]

Acredita-se que o comportamento em uníssono presente em sistemas nervosos (sincronia de neurônios acoplados) é um dos possíveis responsáveis para a realização de tarefas sofisticadas como cognição e memória associativa. [4] De fato, osciladores eletroquímicos têm sido considerados promissores no estudo do fenômeno de sincronização devido à facilidade de manipulação de estímulos externos como potencial, corrente e resistência, implementação de conjuntos de multi-eletrodos acoplados e lembrança fenomenológica com osciladores eletrofisiológicos. [195-199]

Os experimentos eletroquímicos mencionados nos Capítulos 5 e 6 levam em consideração a medida global de corrente e potencial, desse modo toda informação distribuída na interface sólido/líquido é desprezada. É adotado, portanto, uma análise pontual do sistema. Com intuito de analisar a distribuição de corrente na interface, houve a discretização do eletrodo de trabalho em 32 subunidades. Cada elemento é medido individualmente e o acoplamento é controlado pelo conjunto de resistências externas inseridas no sistema eletroquímico.

No contexto dos temas abordados nesta tese de doutorado, alguns tópicos mostram-se promissores, tais como: o efeito do drift sob o ponto de vista espaço-temporal; relação entre a estruturação superficial e a maximização de produção de $\mathrm{CO}_{2}$ durante a eletro-oxidação de moléculas orgânicas com potencial de uso em células a combustível; medida geométrica do alcance do acoplamento migratório pela desativação dos elementos individuais; ativação de um (ou mais) eletrodo individual pela eletrodeposição de um segundo metal e sua correlação com o início da estruturação espacial (marca-passos) e etc. 
Neste capítulo é mostrado o processo de confecção do aparato experimental. Primeiramente foi verificada a necessidade de construção do eletrodo de trabalho e célula eletroquímica multicanal além de um sistema de tratamento de dados para melhora da relação sinal/ruído. Após a montagem, criou-se um procedimento de calibração adotado em cada medida eletroquímica. Os resultados experimentais preliminares obtidos simultaneamente foram comparados entre medidas individuais de cada eletrodo e uma boa congruência foi alcançada, entretanto o procedimento de validação ainda encontra-se em fase de finalização.

\subsection{Resolução Espaço-Temporal}

Com a finalidade de se obter uma aquisição de dados com resolução espaço-temporal houve a necessidade da elaboração de uma célula eletroquímica que comportasse vários eletrodos pontuais. Tendo em mente que as condições de contorno como a geometria e a disposição dos eletrodos na célula possuem papel fundamental na emergência espontânea de padrões auto-organizados, [200] adotou-se a priori, uma configuração experimental unidimensional já conhecida no âmbito teórico [201-204] e experimental. [22-24, 58, 132, 205, 206] As principais características na formação de padrões espaço-temporais podem ser capturadas por essa geometria.

O comportamento coletivo em sistemas distribuídos ou espacialmente estendidos é descrito em termos de uma população formada por vários elementos individuais e resulta da interação entre a dinâmica intrínseca a cada célula e a forma na qual esses elementos pontuais trocam informação lateralmente, ou estão acoplados, entre si. O acoplamento espacial em sistemas eletroquímicos é basicamente governado pelo campo elétrico paralelo à superfície eletródica devido à distribuição de potencial no eletrólito de suporte.

A fim de manter a eletroneutralidade, qualquer flutuação no potencial da dupla camada de um eletrodo individual gera a redistribuição do potencial elétrico em toda célula eletroquímica por meio de uma corrente de migração. Sistemas deste tipo são classificados como reação-migração em contraste com os sistemas mais populares de reação-difusão. Diferentemente do acoplamento difusional ou de curto alcance, no entanto, interações via migração possuem sua localidade espacial não-local ou de longo alcance.

O acoplamento não-local é experimentalmente ajustável por meio da disposição dos eletrodos que compõe a célula. Christoph et al. [201] têm discutido o acoplamento espacial 
em sistemas eletroquímicos via a função de acoplamento, H. A distribuição de potencial no eletrólito é descrita em termos de uma função de Green onde $H_{B}\left(\left|x-x^{\prime}\right|\right)$ expressa o efeito que qualquer localização x' possui na dinâmica da posição x, vide Equação 8.1 e Figura 8.1. Neste caso, B representa a posição entre o eletrodo de trabalho: ET, contra-eletrodo: CE e eletrodo de referência: ER na célula eletroquímica.

$$
\mathrm{H}_{\mathrm{B}}\left(\left|\mathrm{x}-\mathrm{x}^{\prime}\right|\right)=\frac{\pi}{4 \mathrm{~B}^{2} \operatorname{senh}^{2}\left[\frac{\pi\left(\mathrm{x}-\mathrm{x}^{\prime}\right)}{2 \mathrm{~B}}\right]}+\frac{\delta\left(\left|\mathrm{x}-\mathrm{x}^{\prime}\right|\right)}{\mathrm{B}}
$$

Figura 8.1 - Função de acoplamento eletroquímica não-local, $\mathrm{H}_{\mathrm{B}}\left(\mid \mathrm{x}\right.$ - $\left.\mathrm{x}^{\prime} \mid\right)$ em função da coordenada angular $\mathrm{x}^{\prime}$ para a configuração de um eletrodo anular unidimensional sob diferentes valores de B. Figura adaptada de Christoph et al. [201]

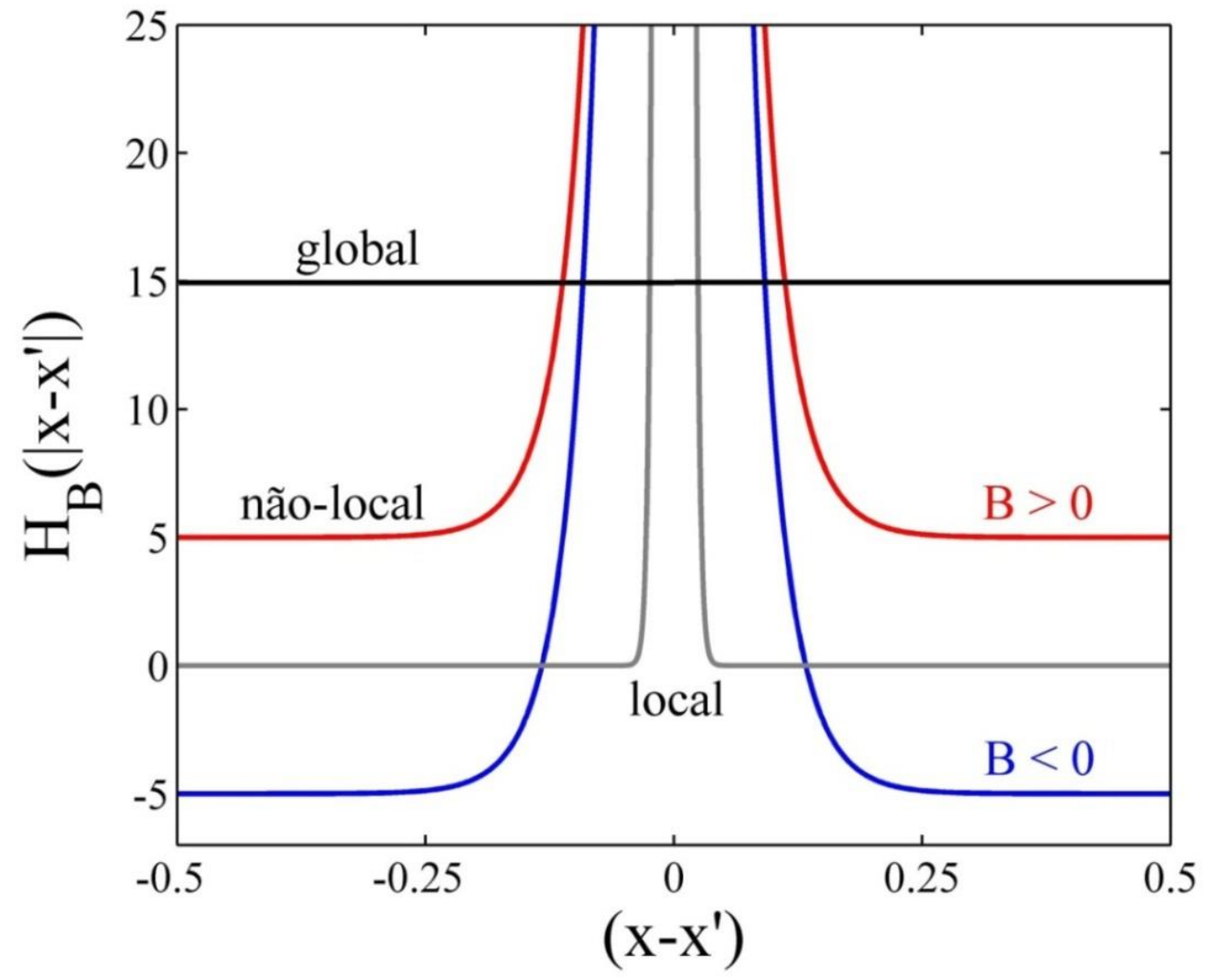

Note que valores onde B $>0$ (grande distância entre ET e ER) e no caso limite B $\rightarrow \infty$ (modo galvanostático) geram uma função de acoplamento sempre positiva que, necessariamente, remete a um comportamento em uníssono dos elementos individuais. No entanto, para $\mathrm{B}<0$ (RE posicionado entre o ET e CE) a função de acoplamento é parcialmente positiva em regiões adjacentes à $\mathrm{x}$, sendo majoritariamente negativa em toda a 
coordenada angular $\mathrm{x}$. Este tipo de acoplamento migratório negativo possui natureza dessincronizante o que intensifica as não-homogeneidades na distribuição do potencial elétrico, e portanto, facilita a formação de estruturas espaço-temporais. O acoplamento nãolocal pode se aproximar de um acoplamento local, quando o acoplamento é de curto alcance ou difusional.

Além do acoplamento migratório, existem meios adicionais de acoplamento entre os osciladores individuais por meio do modo de operação. $\mathrm{O}$ acoplamento é dito global quando a população de eletrodos sente de forma instantânea e igualitária a mudança do potencial da dupla camada de um elemento individual sob qualquer posição espacial do sistema. A interface está sujeita a um acoplamento global negativo (AGN) quando o controle é potenciostático uma vez que a compensação da queda ôhmica pode ser alcançada pela aproximação do ER em relação ao ET ou pela inserção de uma resistência externa com impedância negativa. Adicionalmente, o acoplamento global positivo (AGP) se faz presente quando um resistor externo é conectado entre o ET e o potenciostato ou, no caso limite, quando a interface é mantida sob controle galvanostático.

Krischer et al. [207] formularam a expressão geral para a evolução do potencial da dupla camada em termos dos acoplamentos espaciais, vide Equação 8.2 à 8.4.

$\mathrm{C} \frac{\partial \phi}{\partial \mathrm{t}}=-\mathrm{I}_{\mathrm{F}}+\frac{\mathrm{U}-\phi}{\mathrm{AR}_{\mathrm{u}}(1+\gamma)}-\left.\sigma\left(\frac{\partial \phi_{\mathrm{e}}}{\partial \mathrm{z}}-\phi_{\mathrm{e}}\right)\right|_{\mathrm{z}=\mathrm{ET}}+\frac{\gamma}{\mathrm{AR}_{\mathrm{u}}(1+\gamma)}(\langle\phi\rangle-\phi)$

$\mathrm{C}$ e $\phi$ correspondem à capacitância e potencial da dupla camada, respectivamente. $\mathrm{I}_{\mathrm{F}}$ é a corrente faradaica, $\mathrm{U}$ potencial aplicado, $\sigma$ condutividade, $\mathrm{A}$ área geométrica, $\mathrm{R}_{\mathrm{u}}$ resistência não compensada, $\phi_{\mathrm{e}}$ potencial elétrico no eletrólito, e $\mathrm{z}=\mathrm{ET}$ a posição no eletrólito normal ao eletrodo de trabalho. $\langle\phi\rangle$ representa a média do potencial da dupla camada sobre o espaço x,

$\langle\phi\rangle=\frac{1}{\mathrm{~A}} \int \phi \mathrm{dx}$

e $\gamma$ representa a razão entre a resistência compensada, $R_{c}$ e a não compensada, $R_{u}$

$\gamma=-\frac{\mathrm{R}_{\mathrm{c}}}{\mathrm{R}_{\mathrm{u}}}$ 
Os dois primeiros termos no lado direito da Equação 8.2 representam a dinâmica temporal não-linear, o terceiro descreve a corrente de migração e o último, o acoplamento global imposto pelo modo de operação. AGN é induzido no sistema sempre que alguma porção da resistência proveniente do eletrólito é compensada, $R_{c} \neq 0$. Como o ER está perto do ET, qualquer flutuação local no potencial do eletrodo de trabalho altera o potencial elétrico na posição do ER, gerando uma diferença de potencial local entre ET e ER diferente da distribuição de valores encontrados no espaço restante.

A fim de manter a mesma queda de potencial em toda a região do eletrodo o potenciostato altera o potencial de Galvani do ET ou, equivalentemente, do CE até que os valores sejam idênticos novamente. Entretanto, a mudança do potencial Galvani afeta a queda de potencial da dupla camada em toda interface sólido/líquido. Este tipo de acoplamento global pode ser induzido pela retroalimentação eletrônica em modo potenciostático, que tende a intensificar as diferenças entre $\phi$, favorecendo a quebra de simetria espacial e assim a formação de padrões espaço-temporais.

\subsection{Eletrodo de Trabalho e Célula Eletroquímica Multicanal}

Considerando a importância no alcance do acoplamento global negativo, foi adotado o seguinte esquema experimental mostrado na Figura 8.2. Nesses experimentos será utilizado um ET composto por 32 eletrodos pontuais de platina policristalina (diâmetro de 1,0 mm) espaçados de forma equidistantes por $0,5 \mathrm{~mm}$ e distribuídos em uma configuração anular quasi-unidimensional. O conjunto é globalmente controlado pelo potencio/galvanostato da Autolab/Eco-Chemie PGSTAT3002 e a corrente individual, $i_{\text {ind }}$ em cada eletrodo é monitorada por meio do Sistema de Aquisição de Dados (Data Acquisition System, DAS) pela queda de potencial presente em cada resistor individual, $\mathrm{R}_{\text {ind }}$ utilizado como shunt. A corrente coletiva, $i_{\text {coll }}$ representa a soma de todas das correntes individuais que flui através da década MDR-610, Minipa (ou resistência coletiva), $\mathrm{R}_{\text {coll }}$ conectada em série em relação ao eletrodo de trabalho, e portanto, responsável pelo acoplamento global. [208]

Utiliza-se o eletrodo reversível de hidrogênio como ER, preparado com composição e concentração igual ao utilizado no eletrólito de suporte. É posicionado de forma equidistante em relação a cada eletrodo pontual a fim de manter a mesma queda ôhmica, possuindo liberdade de movimentação vertical no eixo ortogonal ao plano do ET. Uma tela de platina 
policristalina platinizada com alto fator de rugosidade foi utilizada como CE. Este é posicionado atrás ou no mesmo plano equipotencial do ER com geometria e raio similares ao ET. O aparato experimental é retratado na Figura 8.3.

Figura 8.2 - Modelo esquemático representando a disposição dos eletrodos na célula eletroquímica multicanal. Eletrodo de trabalho: ET, contra-eletrodo: CE, eletrodo de referência: ER, potencial aplicado: $U$, corrente individual: $i_{\text {ind }}$, corrente coletiva: $i_{\text {coll }}$, resistência individual: $\mathrm{R}_{\text {ind }}$, resistência coletiva: $\mathrm{R}_{\text {coll }}$, raio do ET: $r$.

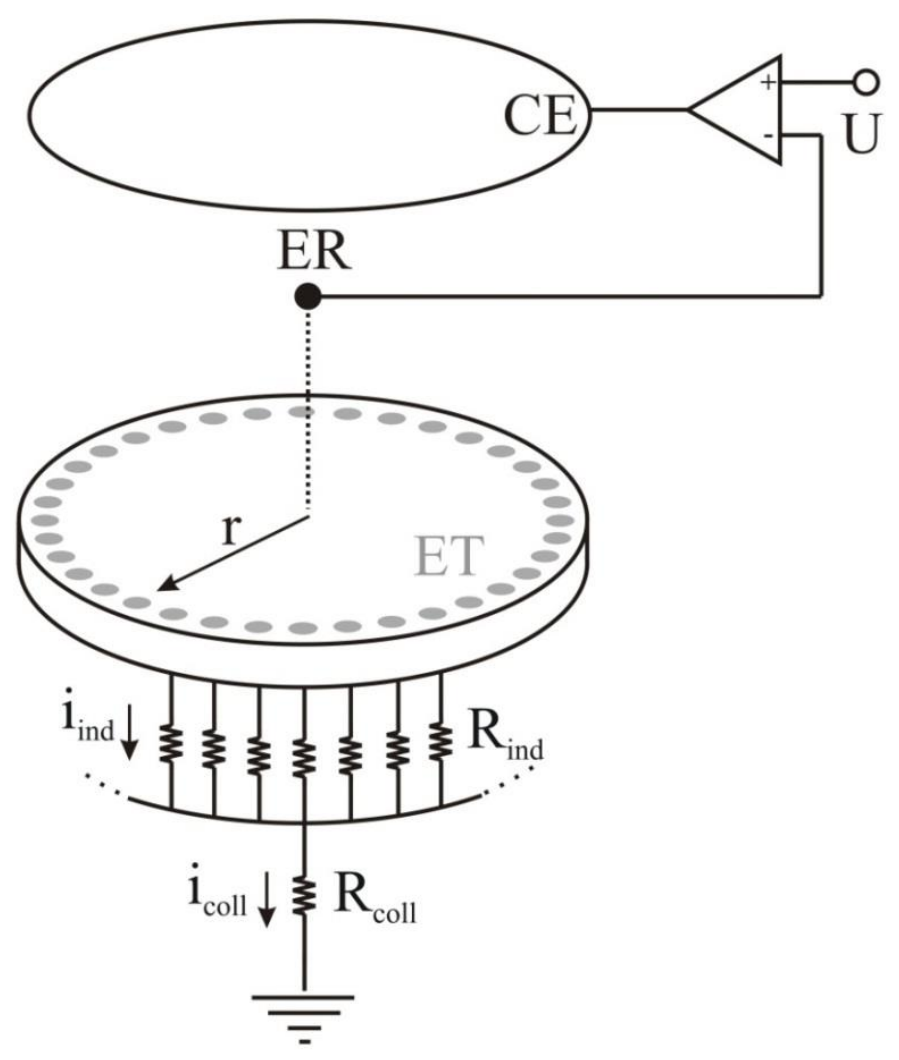

A célula eletroquímica é revestida por uma camisa térmica com possibilidade de controle de temperatura do meio reacional. O corpo cilíndrico é vazado nas duas extremidades onde as entradas superior/inferior são vedadas por tampas confeccionadas à base de Teflon, vide Figura 8.3(a). A entrada superior permite o encaixe do CE e ER além da purga de argônio, enquanto que a tampa inferior é responsável pelo aprisionamento do ET e respectivas conexões à célula eletroquímica como mostrado na Figura 8.3(b) e (c).

Os eletrodos pontuais foram confeccionados em uma matriz de resina Epoxi Araldite CY-248 BR Ren HY-956 da Maxepoxi. A escolha da resina foi baseada nas seguintes características: é um sistema líquido de baixa viscosidade ( $1500 \mathrm{mPa}$ s à $\left.25^{\circ} \mathrm{C}\right)$, baixo tempo 
de cura $\left(24 \mathrm{~h}\right.$ à $\left.25^{\circ} \mathrm{C}\right)$, transparente, isento de sais minerais (alta rigidez dielétrica, $19 \mathrm{kV}$ $\mathrm{mm}^{-1}$ ) e resistente à corrosão química na faixa de $\mathrm{pH}$ ácido ou alcalino comum ao eletrólito de suporte. Ademais, o embutimento realizado em resina é de excelente qualidade o que minimiza o efeito de queda ôhmica provocada por infiltrações laterais. O eletrodo de trabalho conecta-se a um suporte de Teflon que provê o cabeamento e as conexões necessárias para a discriminação dos eletrodos individuais, perfeitamente blindados com escoamento para o terra.

Figura 8.3 - (a) célula eletroquímica multicanal: (1), tampa rosqueada superior: (2) e inferior: (3), controle de altura para RE: (4), entrada: (5) e saída: (6) de Ar; (b) eletrodo de trabalho; (c) conexões e cabeamento para sistema de aquisição de dados multicanal.

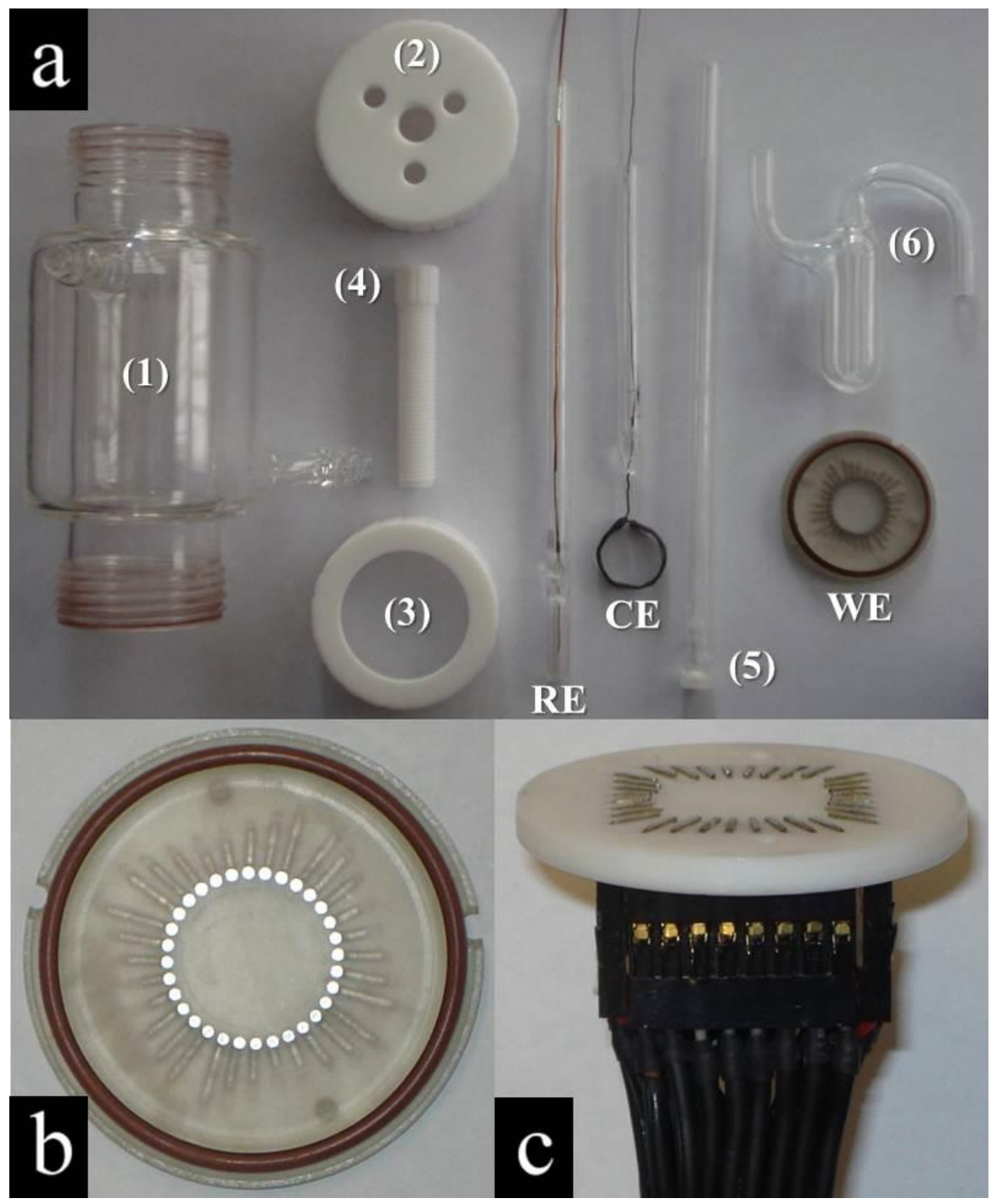




\subsection{Instrumentação e Aquisição de Dados}

Utilizou-se o sistema de aquisição de dados da National Instruments para as medidas eletroquímicas com resolução espaço-temporal. Os periféricos são listados abaixo:

PXIe-1062q

- Chassis com 8-Slot PXI Express de 3U.

- Largura de banda do backplane de $3 \mathrm{~GB} \mathrm{~s}^{-1} \mathrm{e}$ acima de $1 \mathrm{~GB} \mathrm{~s}^{-1}$ dedicado por slot.

- Fornecimento de energia até $354 \mathrm{~W}$ (0 à 55 $\left.{ }^{\circ} \mathrm{C}\right)$.

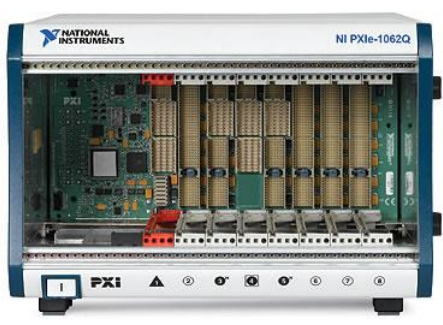

PXIe-8105

- $\quad 2.0 \mathrm{GHz}$ dual-core Intel Core Duo Processador $\mathrm{T} 2500$

- Largura de banda acima de $1 \mathrm{~GB} \mathrm{~s}^{-1}$ e $1 \mathrm{~GB} \mathrm{~s}^{-1}$ largura de banda por slot.

- 1024 GB (2 x 512 MB DIMM) dual-channel $667 \mathrm{MHz}$ DDR2 RAM standard, máximo 2 GB.

- Sistema operacional Windows com driver e softwares já instalados.

- Labview 8.2 como drives e módulos completos.

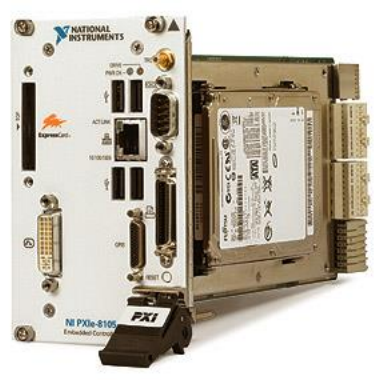

- ExpressCard/34 slot e 4 portas USB Hi-Speed.

- Hard drive integrado, GPIB, serial, e outros periféricos.

- 10/100/1000 BaseTX (Gigabit) Ethernet.

PXI-6225

- $250 \mathrm{kS} \mathrm{s}^{-1}$ (amostras por segundo).

- Duas saídas analógicas de 16-bit $\left(833 \mathrm{kS} \mathrm{s}^{-1}\right)$.

- 80 entradas analógicas DAQ (data acquisition) multifuncional.

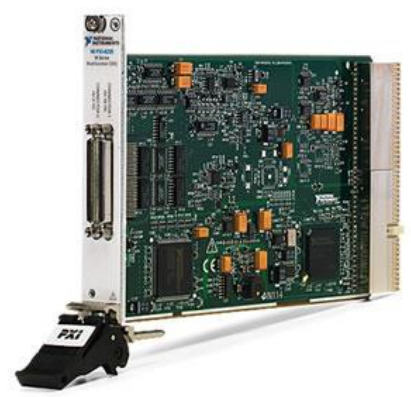


SCC-68

- Bloco de conectores de entrada e saída usados na serie X, M e E do NI-DAQmx.

- 68 terminais parafusados para conexões de $\mathrm{I} / \mathrm{O}$.

- 4 slots de expansão para módulos de SCC.

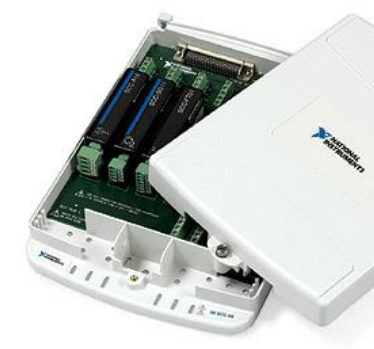

O programa de aquisição foi construído em linguagem Labview com preferência de utilização dos módulos pré-compilados. O diagrama de blocos pode ser visualizado na Figura 8.4 .

Figura 8.4 - Programação em diagrama de blocos construído em ambiente Labview para aquisição de dados.

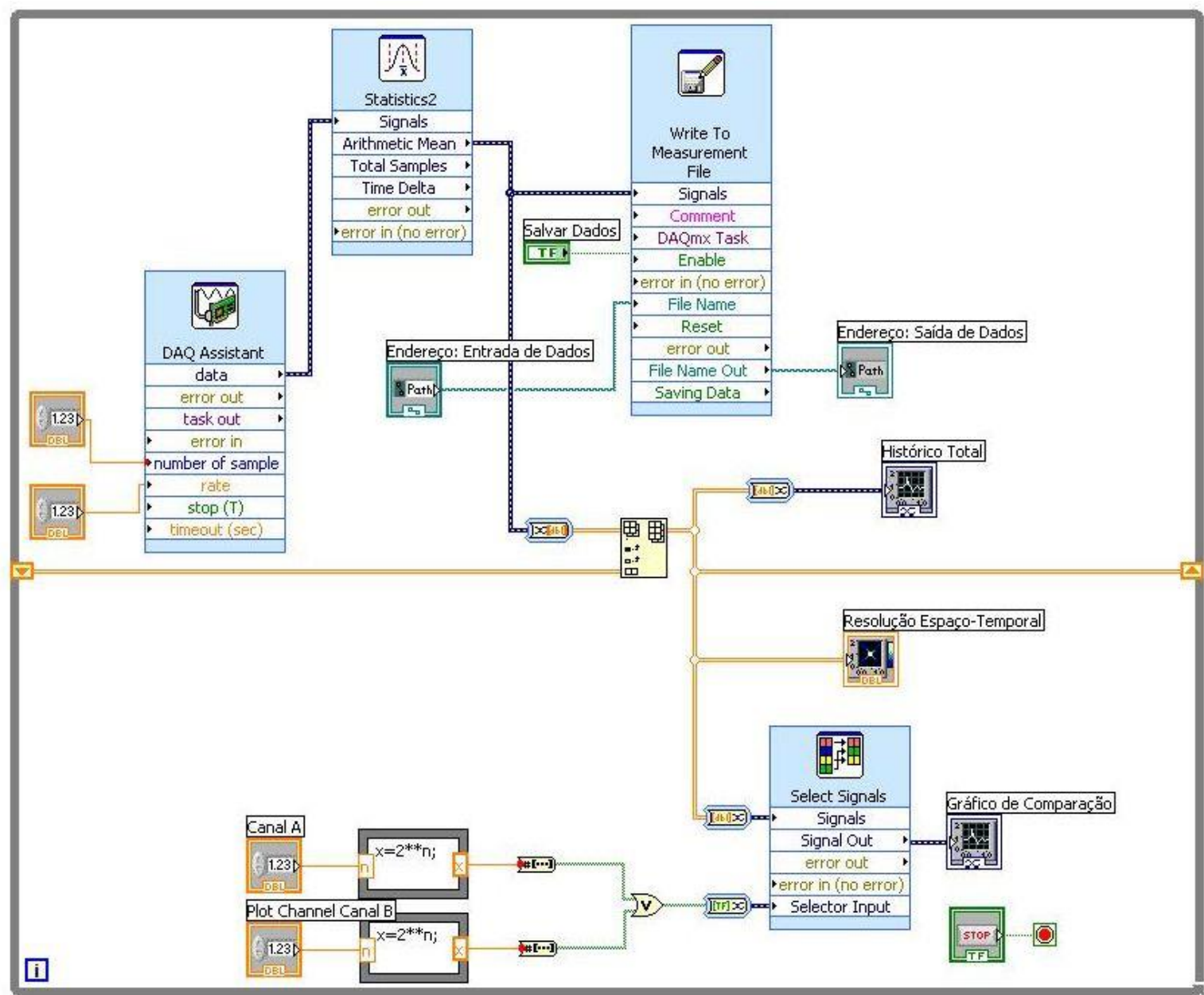


A cada loop do programa o módulo DAQ-Assistant retira os dados da placa de aquisição em configuração de terminal diferencial a uma taxa de amostragem pré-definida. A frequência de aquisição depende da frequência de varredura, do número de amostras coletadas e da quantidade de canais utilizados na medida. Considerando o valor máximo da frequência de varredura do conversor analógico-digital (A/D) PXI-6225 de $f_{\text {varr }}=250 \mathrm{kHz}$ e 32 canais como a quantidade total de eletrodos funcionando durante o experimento eletroquímico, a relação pode ser expressa pela Equação 8.5.

$\mathrm{f}_{\mathrm{aq}}=\frac{\mathrm{f}_{\mathrm{varr}}}{\left(\mathrm{n}^{\mathrm{o}} \text { amostras }\right)\left(\mathrm{n}^{\mathrm{o}} \text { canais }\right)}=7,81\left(\mathrm{n}^{\mathrm{o}} \text { amostras }\right)^{-1} \mathrm{kHz}$

Com base na Equação 8.5 foi possível estimar o número adequado de eletrodos pontuais de platina policristalina utilizados na confecção do ET. Foi utilizado a eletrooxidação de etileno glicol em meio básico como sistema referência por apresentar as oscilações mais rápidas dentre outros sistemas similares. [92] Trabalhando na aquisição máxima, a frequência oscilatória de $20 \mathrm{~Hz}$ pode ser monitorada nos 32 eletrodos individuais com aquisição de aproximadamente 100 pontos por ciclo oscilatório (com 4 amostras por ponto), o que fornece uma boa resolução experimental.

Na sequência, o sinal adquirido passa por uma série de tratamentos digitais, sendo o módulo Statistics o primeiro. Este tem a finalidade de concentrar toda a amostragem em um único ponto. A vantagem deste processamento é evitar que valores espúrios possivelmente não filtrados contaminem o sinal. Dentre uma vasta gama de cálculos oferecidos, o procedimento adotado foi uma média aritmética que tende a convergir o valor medido ao mais próximo do real. Neste sentido, é importante notar que quanto maior o $\mathrm{n}^{\mathrm{o}}$ de amostras maior será a precisão da medida. Portanto, o ideal é que o experimento seja realizado na quantidade máxima de amostras respeitando o valor para a frequência de aquisição, vide Equação 8.5.

Neste ponto, o sinal pode ser armazenado por meio do módulo Write to Measurement File. Os dados obtidos são salvos em disco no formato .lvm onde cada coluna corresponde a um canal (i.e. delimitação efetuada via tabulações). Uma vez salvos externamente, os dados podem ser importados e tratados no software comercialmente disponível Matlab. A graficação em tempo real é feita no painel frontal sob dois tipos de históricos temporais e um espaçotemporal. A apresentação de interface gráfica é mostrada na Figura 8.5. 
Figura 8.5 - Painel frontal utilizado como interface de usuário contendo: gráfico corrente/tempo com canais selecionáveis: Gráfico de Comparação; histórico temporal total: Histórico Total; gráfico bidimensional \#canal/tempo com resolução espaço-temporal: Resolução Espaço-Temporal; Armazenamento de dados: Entrada/Saída de Dados.

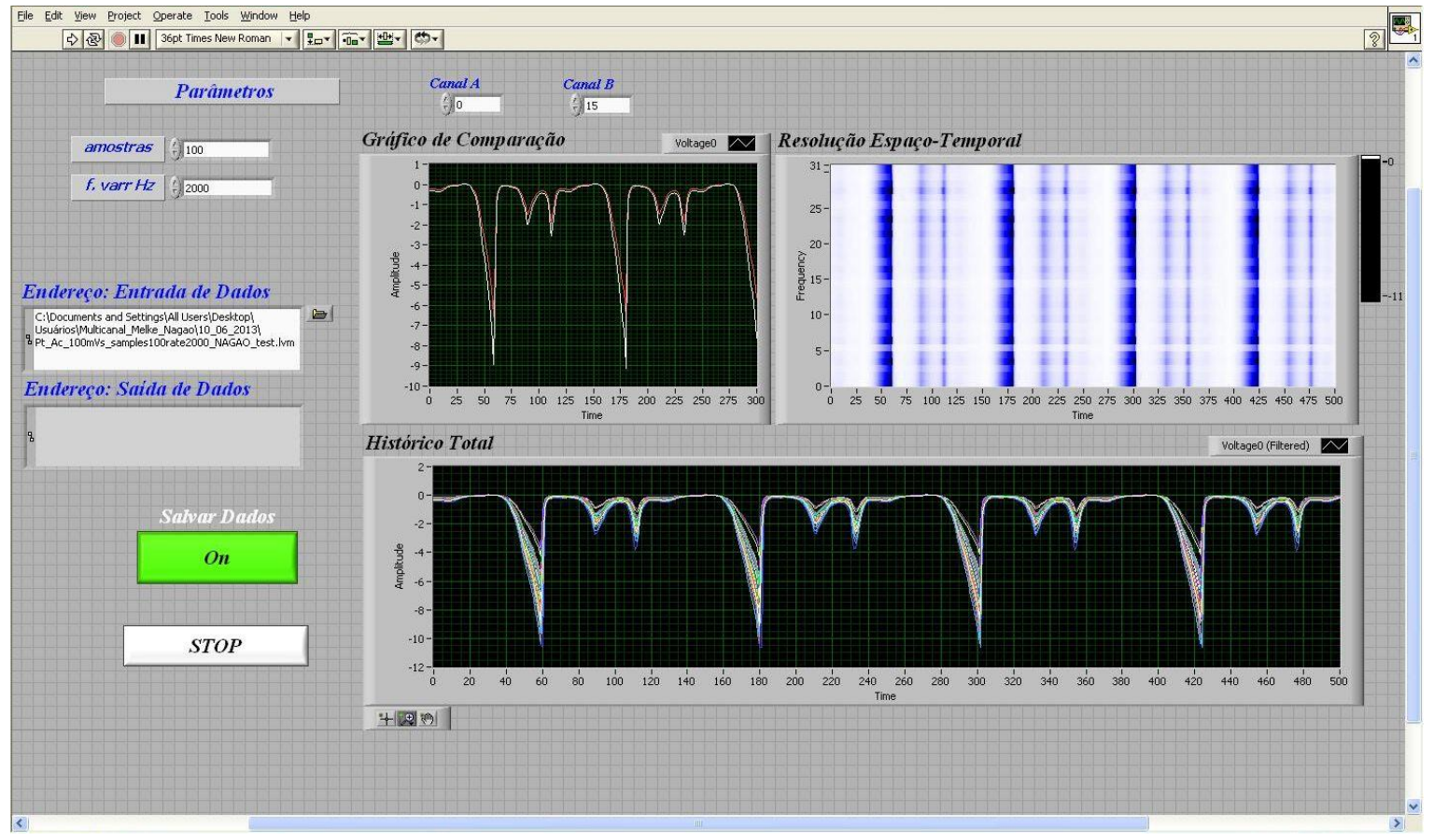

O Gráfico de Comparação fornece a visualização simultânea de até dois canais selecionáveis em função do tempo relativo. A escolha dos canais numerados P0 à P31 é realizada no seletor ressaltado pelo Canal A e B. O Histórico Total com os 32 canais não permiti a seleção de um canal individual. A frequência de aquisição pode ser controlada durante a medida pela variação da frequência de varredura e $n^{o}$ de amostras. Os resultados mais relevantes podem ser armazenados em disco rígido pelo endereço de usuário previamente fornecido, Entrada/Saída de Dados, apertando o botão ON/OFF ou STOP para iniciar a escrita ou finalizar a medida, respectivamente. Também é possível acompanhar em tempo real o gráfico bidimensional \#canal/tempo com Resolução Espaço-Temporal. Neste caso, a escala de cor representa a magnitude da corrente individual que flui pelo circuito eletroquímico.

De posse da instrumentação e interface gráfica necessária para a aquisição de dados multicanal, alguns experimentos foram realizados com um protótipo de cinco eletrodos individuais. Foi utilizado a eletro-oxidação de ácido fórmico em meio ácido por se constituir de um sistema com um dos maiores níveis de densidade de corrente em comparação à oxidação de outras moléculas orgânicas. $\mathrm{A} \mathrm{i}_{\text {ind }}$ foi monitorada pela queda de potencial por 
meio de um resistor shunt controlável, $\mathrm{R}_{\text {ind. }}$ A medida em configuração diferencial foi realizada pelo periférico SCC-68 e o sinal enviado diretamente ao conversor A/D. No entanto, o principal problema observado foi a presença de ruído durante as medidas oscilatórias em regime potenciostático. A escala de corrente foi menor que $10 \mu \mathrm{A}$ com amplitude oscilatória de $\mathrm{A}_{\text {osc }} \approx 0,3 \mu \mathrm{A}$ por eletrodo individual o qual está intimamente ligada à pequena área geométrica $\left(\mathrm{A}_{\mathrm{G}}=0,0078 \mathrm{~cm}^{2}\right)$ de cada eletrodo.

Com a finalidade de melhorar a relação sinal/ruído foi desenvolvido um dispositivo de tratamento de sinal (Signal Treatment Device, STD). O sistema foi confeccionado com componentes de alta precisão, alimentação externa e malha de terra, vide Anexos para maiores informações. Adaptado ao DAS pelo conector SHC68-68-EPM, o STD substitui o módulo SCC-68, possibilitando explorar os 80 canais analógicos presentes no PXI-6225. A quantidade de canais analógicos disponíveis permite posteriormente a confecção de um ET com geometria bidimensional. A necessidade da construção de um STD tem sido relatada em outros sistemas eletroquímicos de aquisição multicanal devido à baixa magnitude do sinal. [209-211]

De forma geral, a placa STD: (a) amplifica, (b) filtra e (c) controla a linha de base do sinal proveniente do experimento eletroquímico antes de ser enviado ao DAS. O sistema é dividido em 5 módulos alimentados externamente com 16 canais cada um. Na Figura 8.6 é mostrado a visão interna, frontal e superior do módulo 1.

Figura 8.6 - (a) STD com controle de amplificação, filtro passa-baixa e linha de base, (b) visão superior e (c) frontal. Potenciômetros shunt: (1)-(3), amplificação: (4) e linha de base: (5).

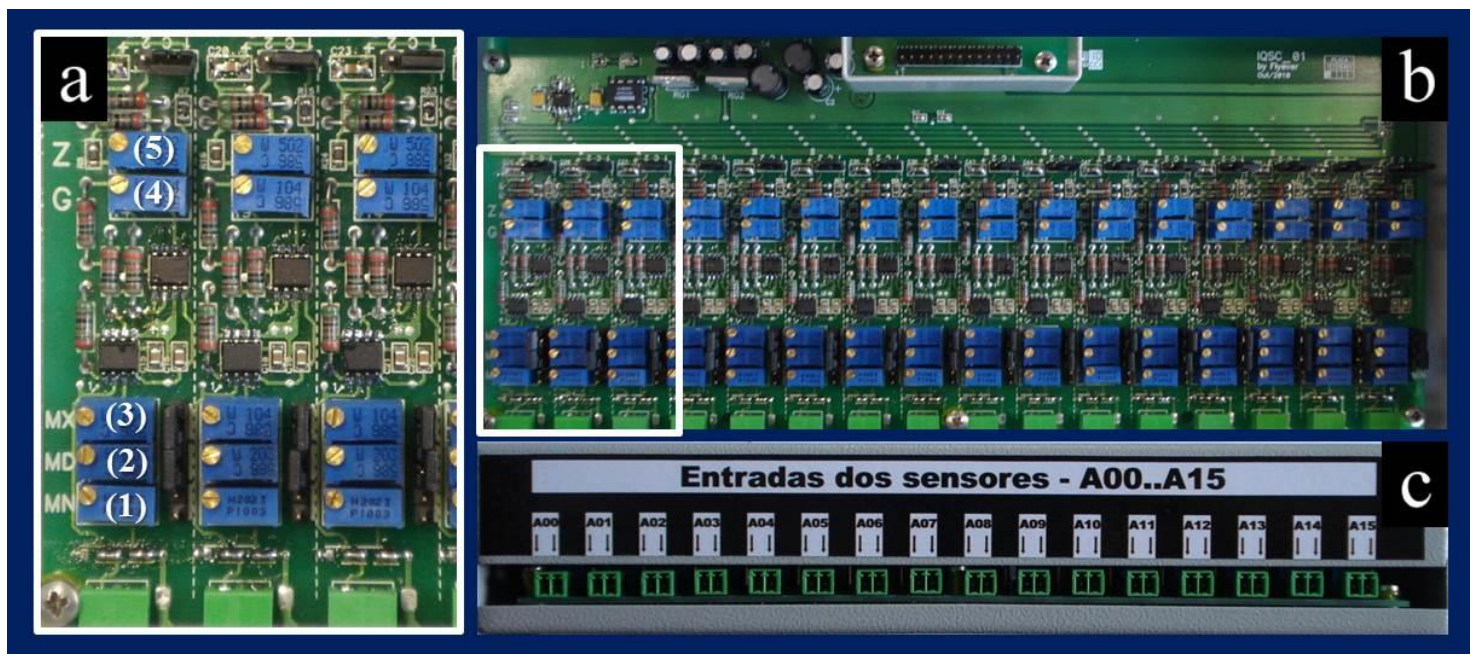


Utilizando a $\mathrm{R}_{\text {ind }}$ como uma sonda (i.e. potenciômetros shunt: (1)-(3)), é monitorada a queda de potencial associada ao fluxo de cada $i_{\text {ind. }}$. A magnitude do sinal pode ser manipulada variando-se a escala do potenciômetro (1) $2 \mathrm{k} \Omega$, (2) $20 \mathrm{k} \Omega$ e (3) $100 \mathrm{k} \Omega$. Além da amplificação, a grande faixa de resistência utilizada neste trabalho permite uma maior flexibilidade no alcance de oscilações potenciostáticas estacionárias uma vez que estes resistores influenciam a natureza do padrão espaço-temporal. [208] A amplificação é condicionada ao potenciômetro (4) $100 \mathrm{k} \Omega$ com ganho de $20 \mathrm{x}$ à $200 \mathrm{x}$ enquanto que a linha de base é controlada pelo potenciômetro (5) $5 \mathrm{k} \Omega$. Adicionalmente utilizou-se no STD um filtro passa-baixa de ordem 1 com frequência de corte fixa em $1 \mathrm{kHz}$. O valor utilizado é suficiente para filtrar e não atrasar o sinal, solicitando a média aritmética digital para frequências abaixo de $1 \mathrm{kHz}$. Tanto a amplificação como o filtro estão conectados ao amplificador operacional OP07C. A otimização e confecção do circuito impresso foi realizada pela empresa Flyever.

A fim de evitar a aquisição de resultados artificiais é realizado periodicamente um procedimento de calibração no STD (ver em Anexos a interface de calibração utilizada). Os potenciômetros de (1) a (3) são calibrados com um multímetro ET-2210, Minipa. A calibração da amplificação e linha de base consiste no ajuste dos valores dos potenciômetros (4) e (5) mediante aplicação de um sinal conhecido pela fonte de tensão MPL-3303 e/ou gerador de funções MFG-4204, seguido da monitoração na entrada/saída do canal pelo osciloscópio MO1225, todos da Minipa, e interface gráfica confeccionada exclusivamente para a calibração manual. Note que o gerador de função também pode ser utilizado nos experimentos eletroquímicos como uma perturbação periódica temporal conhecida em um ou mais eletrodos pontuais. O fluxograma geral que representa o setup experimental para a aquisição de dados multicanal pode ser representado na Figura 8.7.

\subsection{Resultados Experimentais Preliminares}

A limpeza da célula eletroquímica e eletrodos, exceto ao ET, foram conduzidos seguindo o procedimento descrito no Capítulo 3. O eletrodo de trabalho foi polido com pasta de diamante sob diferentes granulações, limpo com solução concentrada de acetona para a retirada de traços orgânicos e finalmente ciclado a dU/dt $=1 \mathrm{~V} \mathrm{~s}^{-1}$ entre 0,05 à $1,50 \mathrm{~V}$ durante 30 minutos antes de iniciar os experimentos oscilatórios. Utilizou-se a eletro-oxidação de 
ácido fórmico $\left(\right.$ Fluka, 98\%) com $[\mathrm{HCOOH}]=0,5 \mathrm{~mol} \mathrm{~L}^{-1}$ em eletrólito aquoso de $\left[\mathrm{H}_{2} \mathrm{SO}_{4}\right]=$ $0,1 \mathrm{~mol} \mathrm{~L}^{-1}$ como sistema modelo.

Figura 8.7 - Fluxograma referente ao setup experimental de aquisição de dados multicanal durante medidas eletroquímicas espacialmente resolvidas.

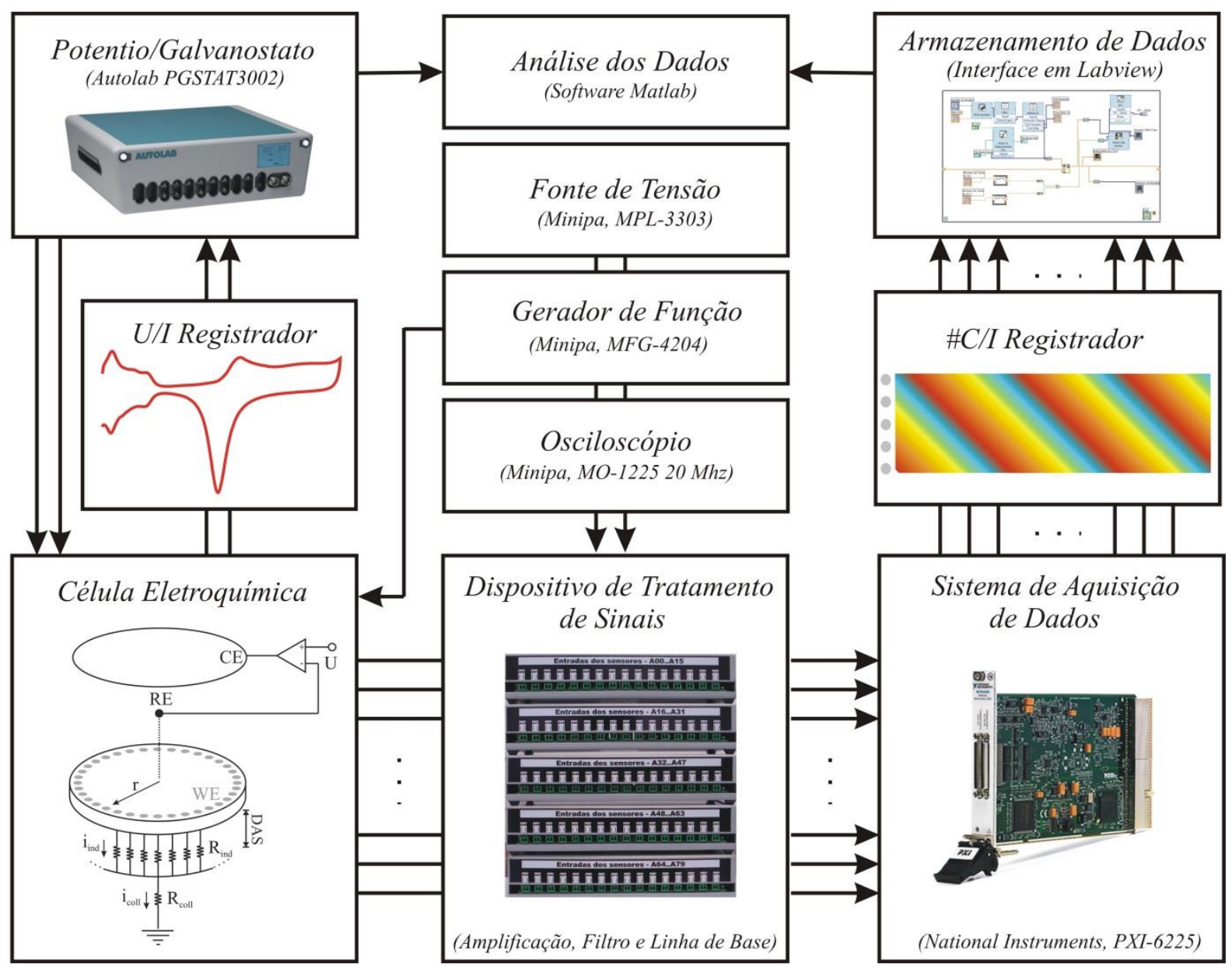

Mesmo com a calibração manual do STD pequenas divergências foram encontradas na resposta eletroquímica de cada canal. Com o intuito de validar o sinal e eliminar possíveis resultados artificiais, foi realizado adicionalmente um procedimento fino de calibração. No quesito amplificação, um fator de correção foi calculado pela relação entre as áreas ativas estimadas pela oxidação de uma monocamada de hidrogênio adsorvido nas voltametrias cíclicas medidas diretamente com o potenciostato e obtidas em paralelo pelo DAS. Este fator de correção ajustava as magnitudes dos sinais medidos simultaneamente pelo DAS em relação às medidas individuais do potenciostato, as quais eram utilizadas como referência. Note que possíveis variações no resistor shunt não afetam a amplificação do sinal uma vez que a 
calibração fina, baseada na comparação das áreas ativas, elimina este problema. Considerando a linha de base, o sistema era mantido em potencial de circuito aberto e uma aquisição de pontos pelo DAS foi efetuada durante 1 minuto. Uma distribuição gaussiana foi utilizada para descrever a dispersão entre as linhas de base e a média como critério de normalização. $\mathrm{Na}$ Figura 8.8 são mostrados resultados experimentais preliminares com resolução espaçotemporal durante a eletro-oxidação de ácido fórmico sobre platina policristalina. É importante salientar que em todos os experimentos a resistência da solução foi parcialmente compensada pelo posicionamento do ER perto do ET.

Figura 8.8 - Oscilações potenciostáticas sincronizadas (i.e. eletrodos fortemente acoplados) durante a eletro-oxidação de ácido fórmico em platina policristalina. (a) densidade de corrente total correspondente à soma das correntes individuais, (b) resolução espaço-temporal dos 32 eletrodos de trabalho. $[\mathrm{HCOOH}]=0,5 \mathrm{~mol} \mathrm{~L}^{-1}$ e $\left[\mathrm{H}_{2} \mathrm{SO}_{4}\right]=0,1 \mathrm{~mol} \mathrm{~L}^{-1}, \mathrm{R}_{\text {ind }}=1 \mathrm{k} \Omega, \mathrm{R}_{\text {coll }}=30$ $\mathrm{k} \Omega, \mathrm{U}=8 \mathrm{~V}, \xi=0,99$.

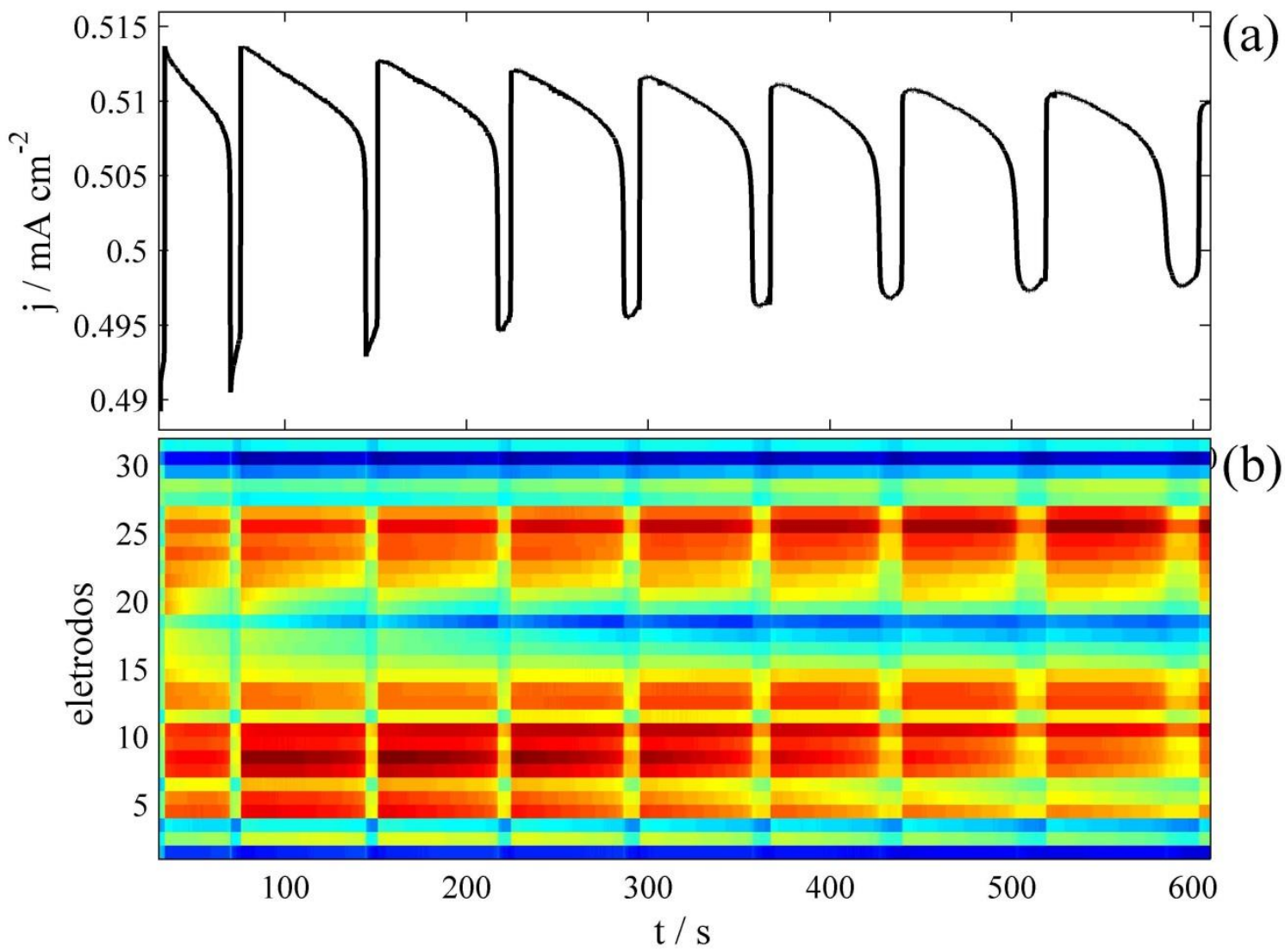

A soma das contribuições individuais de cada eletrodo pode ser expressa pela densidade de corrente total $\mathrm{j}$ dada na Figura 8.8(a). Oscilações potenciostáticas de período-1 foram observadas em uma grande faixa de resistências e potencial aplicado com uma 
excelente relação sinal/ruído. No entanto, a distribuição de corrente ao longo do ET não é uniforme, apresentando regiões com diferentes atividades catalíticas, Figura 8.8(b). Eletrodos identificados com $\mathrm{n}^{\circ} 5$ ao 14 e $\mathrm{n}^{\circ} 22$ ao 27 apresentam amplitude de oscilações maiores em comparação aos demais eletrodos. Uma característica importante observada no comportamento coletivo é a sincronização de fase entre os elementos individuais, expressa pelo fator de acoplamento, $\xi$. Este índice de sincronização varia no intervalo de $0 \leq \xi \leq 1$ e indica o grau de acoplamento entre os eletrodos; $\xi=0$ corresponde à uma fraca interação entre os eletrodos, apresentando uma série temporal completamente dessincronizada e $\xi=1$ um acoplamento intenso, promovendo a sincronização total de fase. $\xi$ está ligado ao acoplamento global e pode ser facilmente controlado pelo conjunto de resistências externas $\mathrm{R}_{\text {ind }}$ e $\mathrm{R}_{\text {coll. }}$. Na Figura 8.9 é exemplificada uma série temporal com um pequeno valor do fator de acoplamento.

Figura 8.9 - Oscilações potenciostáticas dessincronizadas (i.e. eletrodos fracamente acoplados) durante a eletro-oxidação de ácido fórmico em platina policristalina. (a) densidade de corrente total correspondente à soma das correntes individuais, (b) resolução espaçotemporal dos 32 eletrodos de trabalho. $[\mathrm{HCOOH}]=0,5 \mathrm{~mol} \mathrm{~L}^{-1}$ e $\left[\mathrm{H}_{2} \mathrm{SO}_{4}\right]=0,1 \mathrm{~mol} \mathrm{~L}^{-1}, \mathrm{R}_{\text {ind }}$ $=1 \mathrm{M} \Omega, \mathrm{R}_{\text {coll }}=5 \mathrm{k} \Omega, \mathrm{U}=10 \mathrm{~V}, \xi=0,14$.

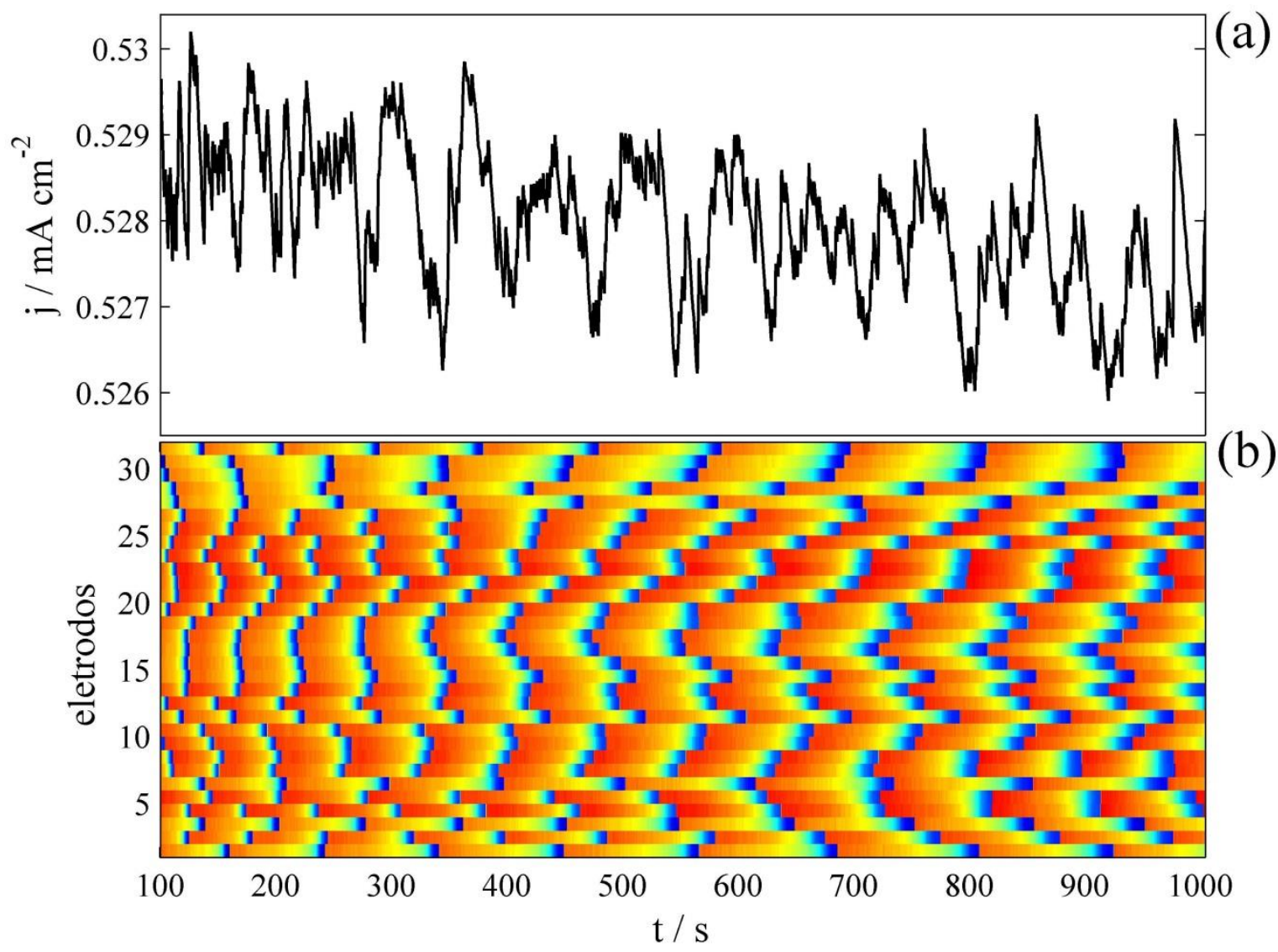


A resposta eletroquímica total dada na Figura 8.9(a) não apresenta uma periodicidade. Diferentemente ao observado na Figura 8.8, este comportamento dinâmico resulta da soma das correntes individuais, porém com os elementos fracamente acoplados, $\xi=0,14$. Na Figura 8.9(b) é mostrada essa estruturação superficial. Inicialmente os eletrodos encontram-se com fases relativas próximas e gradativamente vão se distanciando devido ao drift intrínseco à série temporal. Em torno de 300 a 800 s há a formação de um pulso que se propaga na superfície do ET e finalmente acima de $900 \mathrm{~s}$ essa estruturação perde coerência e uma distribuição mais homogênea surge no final da série temporal.

Os resultados experimentais apresentados nesta seção indicam a necessidade de utilizar o STD acoplado ao DAS o que promoveu uma relação sinal/ruído adequada em todos os experimentos realizados. A construção da célula eletroquímica e o eletrodo multicanal não apresentarem problemas com infiltrações laterais, queda ôhmica, ou problemas associados às conexões nos cabeamentos. O método de calibração gerou resultados com boa aproximação à medida real, porém alguns ajustes finais ainda estão em andamento. De forma geral, a construção do setup experimental espacialmente resolvido foi realizada com êxito e já se encontra disponível para o estudo de formação de padrões espaço-temporais em ambiente eletroquímico. 



\section{Capítulo 9}

REFERÊNCIAS BIBLIOGRÁFICAS 

1. GLANSDORFF, P.; PRIGOGINE, I. Thermodynamic theory of structure, stability and fluctuations. London: Wiley-Interscience, 1971.

2. NICOLIS, G.; PRIGOGINE, I. Self-organization in nonequilibrium systems: From dissipative structures to order through fluctuations. New York: Wiley, 1977.

3. WINFREE, A. T. The geometry of biological time. New York: Springer-Verlag, 2001.

4. BUZSAKI, G.; DRAGUHN, A. Neuronal oscillations in cortical networks. Science, v. 304, p. 1926-1929, 2004.

5. GLASS, L. Synchronization and rhythmic processes in physiology. Nature, v. 410, p. 277-284, 2001.

6. KONDEPUDI, D.; PRIGOGINE, I. Modern thermodynamics: From heat engines to dissipative structures. Chichester: John Wiley, 1998.

7. TURING, A. M. The Chemical Basis of Morphogenesis. Philosophical Transactions of the Royal Society of London Series B-Biological Sciences, v. 237, p. 37-72, 1952.

8. LENGYEL, I.; EPSTEIN, I. R. Modeling of Turing structures in the chlorite iodide malonic acid starch reaction system. Science, v. 251, p. 650-652, 1991.

9. WINFREE, A. T. On emerging coherence. Science, v. 298, p. 2336-2337, 2002.

10. EPSTEIN, I. R. Predicting complex biology with simple chemistry. Proceedings of the National Academy of Sciences of the United States of America, v. 103, p. 15727-15728, 2006.

11. ECONOMOU, A. D.; OHAZAMA, A.; PORNTAVEETUS, T.; SHARPE, P. T.; KONDO, S.; BASSON, M. A.; GRITLI-LINDE, A.; COBOURNE, M. T.; GREEN, J. B. A. Periodic stripe formation by a Turing mechanism operating at growth zones in the mammalian palate. Nature Genetics, v. 44, p. 348-351, 2012.

12. ZAIKIN, A. N.; ZHABOTINSKY, A. M. Concentration wave propagation in 2dimensional liquid-phase self-oscillating system. Nature, v. 225, p. 535-537, 1970.

13. VANAG, V. K.; EPSTEIN, I. R. Inwardly rotating spiral waves in a reaction-diffusion system. Science, v. 294, p. 835-837, 2001.

14. VANAG, V. K.; EPSTEIN, I. R. Pattern formation in a tunable medium: The BelousovZhabotinsky reaction in an aerosol OT microemulsion. Physical Review Letters, v. 87, p. 2001.

15. VANAG, V. K.; EPSTEIN, I. R. Segmented spiral waves in a reaction-diffusion system. Proceedings of the National Academy of Sciences of the United States of America, v. 100, p. 14635-14638, 2003. 
16. DE KEPPER, P.; EPSTEIN, I. R.; KUSTIN, K. A Systematically designed homogeneous oscillation reaction - The arsenite-iodate-chlorite system. Journal of the American Chemical Society, v. 103, p. 2133-2134, 1981.

17. LENGYEL, I.; RÁBAI, G.; EPSTEIN, I. R. Systematic design of chemical oscillators: Experimental and modeling study of oscillations in the chlorine dioxide iodine malonic acid reaction. Journal of the American Chemical Society, v. 112, p. 9104-9110, 1990.

18. KURIN-CSÖRGEI, K.; ZHABOTINSKY, A. M.; ORBÁN, M.; EPSTEIN, I. R. Bromate-1,4-cyclohexanedione-ferroin gas-free oscillating reaction .1. Basic features and crossing wave patterns in a reaction-diffusion system without gel. Journal of Physical Chemistry, v. 100, p. 5393-5397, 1996.

19. KURIN-CSÖRGEI, K.; EPSTEIN, I. R.; ORBÁN, M. Systematic design of chemical oscillators using complexation and precipitation equilibria. Nature, v. 433, p. 139-142, 2005.

20. POROS, E.; HORVÁTH, V.; KURIN-CSÖRGEI, K.; EPSTEIN, I. R.; ORBÁN, M. Generation of $\mathrm{pH}$-oscillations in closed chemical systems: Method and applications. Journal of the American Chemical Society, v. 133, p. 7174-7179, 2011.

21. LI, Y. J.; OSLONOVITCH, J.; MAZOUZ, N.; PLENGE, F.; KRISCHER, K.; ERTL, G. Turing-type patterns on electrode surfaces. Science, v. 291, p. 2395-2398, 2001.

22. KRISCHER, K.; MAZOUZ, N.; GRAUEL, P. Fronts, waves, and stationary patterns in electrochemical systems. Angewandte Chemie-International Edition, v. 40, p. 851-869, 2001.

23. VARELA, H.; BETA, C.; BONNEFONT, A.; KRISCHER, K. Transitions to electrochemical turbulence. Physical Review Letters, v. 94, p. 174104, 2005.

24. BONNEFONT, A.; VARELA, H.; KRISCHER, K. Stationary spatial patterns during bulk CO electrooxidation on platinum. Journal of Physical Chemistry B, v. 109, p. 3408$3415,2005$.

25. MORSCHL, R.; BOLTEN, J.; BONNEFONT, A.; KRISCHER, K. Pattern formation during $\mathrm{CO}$ electrooxidation on thin Pt films studied with spatially resolved infrared absorption spectroscopy. Journal of Physical Chemistry C, v. 112, p. 9548-9551, 2008.

26. MIETHE, I.; GARCIA-MORALES, V.; KRISCHER, K. Irregular subharmonic cluster patterns in an autonomous photoelectrochemical oscillator. Physical Review Letters, v. 102, p. 2009.

27. BAUER, P. R.; BONNEFONT, A.; KRISCHER, K. Spatially resolved ATR-FTIRS rtudy of the formation of macroscopic domains and microislands during $\mathrm{CO}$ electrooxidation on Pt. Chemphyschem, v. 11, p. 3002-3010, 2010.

28. BOCKRIS, J. O. M.; REDDY, A. K. N. Modern electrochemistry 1: Ionics. New York: Springer, 1998. 
29. BOCKRIS, J. O. M.; REDDY, A. K. N.; GAMBOA-ALDECO, M. E. Modern electrochemistry 2A: Fundamentals of electrodics. New York: Springer, 2001.

30. BOCKRIS, J. O. M.; REDDY, A. K. N. Modern electrochemistry 2B: Electrodics in chemistry, engineering, biology and environmental science. New York: Springer, 2001.

31. WOJTOWICZ, J. Oscillatory behaviour in electrochemical systems. In: CONWAY, B. E.; BOCKRIS, J. O.; WHITE, R. E. Modern aspects of electrochemistry. New York: Kluver Academic/Plenum Publishers, 1972. v. 8. p. 47-120.

32. KOPER, M. T. M. Oscillations and complex dynamical bifurcations in electrochemical systems. In: PRIGOGINE, I.; RICE, S. A. Advances in chemical physics. New York: Wiley, 1996. v. 92. p. $161-298$

33. KRISCHER, K. Principles of temporal and spatial pattern formation in electrochemical systems. In: CONWAY, B. E.; BOCKRIS, J. O.; WHITE, R. E. Modern aspects of electrochemistry. New York: Kluver Academic/Plenum Publishers, 1999. v. 32. p. 1-142.

34. KRISCHER, K.; VARELA, H. Oscillations and other dynamic instabilities. In: VIELSTICH, W.; LAMM, A.; GASTEIGER, H. A. Handbook of fuel cells: Fundamentals, technology and applications. Chichester: John Wiley, 2003. v. 2. p. 679-701.

35. MURRAY, J. D. Mathematical biology: I. An introduction. Berlin: Springer-Verlag, 2002.

36. MURRAY, J. D. Mathematical biology: II. Spatial models and biomedical applications. Berlin: Springer-Verlag, 2003.

37. RUOFF, P. Introducing temperature-compensation in any reaction kinetic oscillator model. Journal of Interdisciplinary Cycle Research, v. 23, p. 92-99, 1992.

38. RUOFF, P. Antagonist balance in the Oregonator - About the possibility of temperaturecompensation in the Belousov-Zhabotinsky reaction. Physica D, v. 84, p. 204-211, 1995.

39. NAGAO, R.; EPSTEIN, I. R.; GONZALEZ, E. R.; VARELA, H. Temperature (over) compensation in an oscillatory surface reaction. Journal of Physical Chemistry A, v. 112, p. 4617-4624, 2008.

40. KISS, I. Z.; ZHAI, Y.; HUDSON, J. L. Collective dynamics of chaotic chemical oscillators and the law of large numbers. Physical Review Letters, v. 88, p. 238301, 2002.

41. KISS, I. Z.; ZHAI, Y. M.; HUDSON, J. L. Emerging coherence in a population of chemical oscillators. Science, v. 296, p. 1676-1678, 2002.

42. KISS, I. Z.; RUSIN, C. G.; KORI, H.; HUDSON, J. L. Engineering complex dynamical structures: Sequential patterns and desynchronization. Science, v. 316, p. 1886-1889, 2007.

43. TAYLOR, A. F.; TINSLEY, M. R.; WANG, F.; HUANG, Z. Y.; SHOWALTER, K. Dynamical quorum sensing and synchronization in large populations of chemical oscillators. Science, v. 323, p. 614-617, 2009. 
44. TAYLOR, A. F.; TINSLEY, M. R.; WANG, F.; SHOWALTER, K. Phase clusters in large populations of chemical oscillators. Angewandte Chemie-International Edition, v. 50, p. 10161-10164, 2011.

45. TINSLEY, M. R.; NKOMO, S.; SHOWALTER, K. Chimera and phase-cluster states in populations of coupled chemical oscillators. Nature Physics, v. 8, p. 662-665, 2012.

46. NKOMO, S.; TINSLEY, M. R.; SHOWALTER, K. Chimera states in populations of nonlocally coupled chemical oscillators. Physical Review Letters, v. 110, p. 244102, 2013.

47. KURAMOTO, Y. Chemical oscillations, waves and turbulence. New York: SpringVerlag, 1984.

48. MOTA, A.; EISWIRTH, M.; GONZALEZ, E. R. Enhanced efficiency of CO-containing hydrogen electroxidation with autonomous oscillations. Journal of Physical Chemistry $\mathbf{C}$, v. 117, p. 12495-12501, 2013.

49. MOTA, A.; LOPES, P. P.; TICIANELLI, E. A.; GONZALEZ, E. R.; VARELA, H. Complex oscillatory response of a PEM fuel cell fed with $\mathrm{H}_{2} / \mathrm{CO}$ and oxygen. Journal of the Electrochemical Society, v. 157, p. B1301-B1304, 2010.

50. LOPES, P. P.; TICIANELLI, E. A.; VARELA, H. Potential oscillations in a proton exchange membrane fuel cell with a Pd-Pt/C anode. Journal of Power Sources, v. 196, p. 84-89, 2011.

51. HANKE-RAUSCHENBACH, R.; KIRSCH, S.; KELLING, R.; WEINZIERL, C.; SUNDMACHER, K. Oscillations and pattern formation in a PEM fuel cell with $\mathrm{Pt} / \mathrm{Ru}$ anode exposed to $\mathrm{H}_{2} / \mathrm{CO}$ mixtures. Journal of Electrochemical Society, v. 157, p. B1521-B1528, 2010.

52. HANKE-RAUSCHENBACH, R.; MANGOLD, M.; SUNDMACHER, K. Nonlinear dynamics of fuel cells: a review. Reviews in Chemical Engineering, v. 27, p. 23-52, 2011.

53. KIRSCH, S.; HANKE-RAUSCHENBACH, R.; SUNDMACHER, K. Analysis of spatiotemporal pattern formation in a PEM fuel cell with $\mathrm{Pt} / \mathrm{Ru}$ anode exposed to $\mathrm{H}_{2} / \mathrm{CO}$ mixtures. Journal of Electrochemical Society, v. 158, p. B44-B53, 2011.

54. KIRSCH, S.; HANKE-RAUSCHENBACH, R.; STEIN, B.; KRAUME, R.; SUNDMACHER, K. The Electro-oxidation of $\mathrm{H}_{2}, \mathrm{CO}$ in a model PEM fuel cell: Oscillations, chaos, pulses. Journal of the Electrochemical Society, v. 160, p. F436-F446, 2013.

55. SCHELL, M.; ALBAHADILY, F. N.; SAFAR, J.; XU, Y. H. Characterization of oscillatory states in the electrochemical oxidation of formaldehyde and formate formic acid. Journal of Physical Chemistry, v. 93, p. 4806-4810, 1989.

56. ALBAHADILY, F. N.; SCHELL, M. Observation of several different temporal patterns in the oxidation of formic acid at rotating platinum disk electrode in an acidic medium. Journal of Electroanalytical Chemistry, v. 308, p. 151-173, 1991. 
57. CHEN, S. L.; NOLES, T.; SCHELL, M. Differences in oscillations and sequences of dynamical states caused by anion adsorption in the electrochemical oxidation of formic acid. Journal of Physical Chemistry A, v. 104, p. 6791-6798, 2000.

58. CHRISTOPH, J.; STRASSER, P.; EISWIRTH, M.; ERTL, G. Remote triggering of waves in an electrochemical system. Science, v. 284, p. 291-293, 1999.

59. LEE, J. Y.; CHRISTOPH, J.; STRASSER, P.; EISWIRTH, M.; ERTL, G. Existence regions of spatiotemporal patterns in the electro-oxidation of formic acid. Physical Chemistry Chemical Physics, v. 5, p. 935-938, 2003.

60. CHRISTOPH, J.; NOH, T. G.; LEE, J.; STRASSER, P.; EISWIRTH, M. Spatiotemporal self-organization in the oscillatory $\mathrm{HCOOH}$ oxidation on a Pt ribbon electrode - Theory and experiments. Surface Science, v. 603, p. 1652-1661, 2009.

61. NAGAO, R.; CANTANE, D. A.; LIMA, F. H. B.; VARELA, H. The dual pathway in action: decoupling parallel routes for $\mathrm{CO}_{2}$ production during the oscillatory electro-oxidation of methanol. Physical Chemistry Chemical Physics, v. 14, p. 8294-8298, 2012.

62. NAGAO, R.; CANTANE, D. A.; LIMA, F. H. B.; VARELA, H. Influence of anion adsorption on the parallel reaction pathways in the oscillatory electro-oxidation of methanol. Journal of Physical Chemistry C, v. 117, p. 15098-15105, 2013.

63. NASCIMENTO, M. A.; GALLAS, J. A. C.; VARELA, H. Self-organized distribution of periodicity and chaos in an electrochemical oscillator. Physical Chemistry Chemical Physics, v. 13, p. 441-446, 2011.

64. STRASSER, P.; EISWIRTH, M.; KOPER, M. T. M. Mechanistic classification of electrochemical oscillators - operational experimental strategy. Journal of Electroanalytical Chemistry, v. 478, p. 50-66, 1999.

65. KIEDROWSKI, G.; OTTO, S.; HERDEWIJN, P. Welcome home, systems chemists! Journal of System Chemistry, v. 1, p. 1-6, 2010.

66. VARELA, H. Química de sistemas. Jornal da Ciência, 2010. Dísponível em: <http://www.jornaldaciencia.org.br/Detalhe.jsp?id=69818>. Acesso em: 13 out. 2013.

67. EISWIRTH, M.; FREUND, A.; ROSS, J. Mechanistic classification of chemical oscillators and the role of species. In: PRIGOGINE, I.; RICE, S. A. Advances in Chemical Physics. New York: Wiley, 1991. v. 80. p. 127-199.

68. PLASSON, R.; BRANDENBURG, A.; JULLIEN, L.; BERSINI, H. Autocatalyses. Journal of Physical Chemistry A, v. 115, p. 8073-8085, 2011.

69. SAGGIOMO, V.; HRISTOVA, Y. R.; LUDLOW, R. F.; OTTO, S. Systems chemistry: using thermodynamically controlled networks to assess molecular similarity. Journal of Systems Chemistry, v. 4, n. 2, p. 1-6, 2013.

70. EPSTEIN, I. R.; SHOWALTER, K. Nonlinear chemical dynamics: Oscillations, patterns, and chaos. Journal of Physical Chemistry, v. 100, p. 13132-13147, 1996. 
71. SAGUES, F.; EPSTEIN, I. R. Nonlinear chemical dynamics. Dalton Transactions, v. 7, p. 1201-1217, 2003.

72. FIELD, R. J.; NOYES, R. M.; KOROS, E. Oscillations in chemical systems. 2. Thorough analysis of temporal oscillation in bromate-cerium-malonic acid system. Journal of the American Chemical Society, v. 94, p. 8649-8664, 1972.

73. PRIGOGINE, I.; NICOLIS, G. On symmetry-breaking instabilities in dissipative systems .1. Journal of Chemical Physics, v. 46, p. 3542-3550, 1967.

74. PRIGOGINE, I.; LEFEVER, R. On symmetry-breaking instabilities in dissipative systems .2. Journal of Chemical Physics, v. 48, p. 1695-1700, 1968.

75. FIELD, R. J.; NOYES, R. M. Oscillations in chemical systems. 4. Limit cycle behavior in a model of a real chemical reaction. Journal of Chemical Physics, v. 60, p. 1877-1884, 1974.

76. CASTETS, V.; DULOS, E.; BOISSONADE, J.; DE KEPPER, P. Experimental evidence of a sustained standing Turing type nonequilibrium chemical pattern. Physical Review Letters, v. 64, p. 2953-2956, 1990.

77. EPSTEIN, I. R.; POJMAN, J. A. Introduction to nonlinear chemical dynamics. Oscillations, waves, patterns and chaos. New York: Oxford University, 1998.

78. HORVATH, J.; SZALAI, I.; DE KEPPER, P. An experimental design method leading to chemical Turing patterns. Science, v. 324, p. 772-775, 2009.

79. OKAMOTO, H.; TANAKA, N.; NAITO, M. Modelling temporal kinetic oscillations for electrochemical oxidation of formic acid on Pt. Chemical Physics Letters, v. 248, p. 289295, 1996.

80. STRASSER, P.; EISWIRTH, M.; ERTL, G. Oscillatory instabilities during formic acid oxidation on $\mathrm{Pt}(100), \operatorname{Pt}(110)$ and $\mathrm{Pt}(111)$ under potentiostatic control .2. Model calculations. Journal of Chemical Physics, v. 107, p. 991-1003, 1997.

81. MUKOUYAMA, Y.; KIKUCHI, M.; SAMJESKE, G.; OSAWA, M.; OKAMOTO, H. Potential oscillations in galvanostatic electrooxidation of formic acid on platinum: A mathematical modeling and simulation. Journal of Physical Chemistry B, v. 110, p. 11912 11917, 2006.

82. SAMJESKE, G.; OSAWA, M. Current oscillations during formic acid oxidation on a Pt electrode: Insight into the mechanism by time-resolved IR spectroscopy. Angewandte Chemie-International Edition, v. 44, p. 5694-5698, 2005.

83. SAMJESKE, G.; MIKI, A.; YE, S.; YAMAKATA, A.; MUKOUYAMA, Y.; OKAMOTO, H.; OSAWA, M. Potential oscillations in galvanostatic electrooxidation of formic acid on platinum: A time-resolved surface-enhanced infrared study. Journal of Physical Chemistry B, v. 109, p. 23509-23516, 2005. 
84. SAMJESKE, G.; MIKI, A.; YE, S.; OSAWA, M. Mechanistic study of electrocatalytic oxidation of formic acid at platinum in acidic solution by time-resolved surface-enhanced infrared absorption spectroscopy. Journal of Physical Chemistry B, v. 110, p. 16559-16566, 2006.

85. OSAWA, M.; KOMATSU, K.; SAMJESKE, G.; UCHIDA, T.; IKESHOJI, T.; CUESTA, A.; GUTIERREZ, C. The role of bridge-bonded adsorbed formate in the electrocatalytic oxidation of formic acid on platinum. Angewandte Chemie-International Edition, v. 50, p. 1159-1163, 2011.

86. CUESTA, A.; CABELLO, G.; OSAWA, M.; GUTIERREZ, C. Mechanism of the electrocatalytic oxidation of formic acid on metals. ACS Catalysis, v. 2, p. 728-738, 2012.

87. JOO, J.; UCHIDA, T.; CUESTA, A.; KOPER, M. T. M.; OSAWA, M. Importance of acid-base equilibrium in electrocatalytic oxidation of formic acid on platinum. Journal of the American Chemical Society, v. 135, p. 9991-9994, 2013.

88. CHEN, Y. X.; MIKI, A.; YE, S.; SAKAI, H.; OSAWA, M. Formate, an active intermediate for direct oxidation of methanol on Pt electrode. Journal of the American Chemical Society, v. 125, p. 3680-3681, 2003.

89. SAMJESKE, G.; MIKI, A.; OSAWA, M. Electrocatalytic oxidation of formaldehyde on platinum under galvanostatic and potential sweep conditions studied by time-resolved surface-enhanced infrared spectroscopy. Journal of Physical Chemistry C, v. 111, p. 1507415083, 2007.

90. HACHKAR, M.; BEDEN, B.; LAMY, C. Oscillating electrocatalytic systems. 1. Survey of systems involving the oxidation of organics and detailed electrochemical investigation of formaldehyde oxidation on rhodium electrodes. Journal of Electroanalytical Chemistry, v. 287, p. 81-98, 1990.

91. CARBONIO, E. A.; NAGAO, R.; GONZALEZ, E. R.; VARELA, H. Temperature effects on the oscillatory electro-oxidation of methanol on platinum. Physical Chemistry Chemical Physics, v. 11, p. 665-670, 2009.

92. SITTA, E.; NASCIMENTO, M. A.; VARELA, H. Complex kinetics, high frequency oscillations and temperature compensation in the electro-oxidation of ethylene glycol on platinum. Physical Chemistry Chemical Physics, v. 12, p. 15195-15206, 2010.

93. O termo drift, proveniente do inglês, é utilizado neste trabalho para descrever o transiente ou deriva observada nas séries temporais experimentais. Por definição drift é a variação de um parâmetro não controlável.

94. CALLEN, H. B. Thermodynamics and an introduction to thermostatistics. New York: Wiley, 1985.

95. HILL, T. L. An introduction to statistical thermodynamics. New York: Dover Publications, 1987. 
96. STROGATZ, S. H. Nonlinear dynamics and chaos: With applications to physics, biology, chemistry, and engineering. Cambridge: Addison-Wesley, 1994.

97. HILBORN, R. C. Chaos and nonlinear dynamics. New York: Oxford, 2000.

98. BOYCE, W. E.; DIPRIMA, R. C. Elementary differential equations. New York: John Wiley, 2001.

99. NASCIMENTO, M. A. Instabilidades cinéticas em sistemas eletroquímicos: Uma contribuição teórica. 2011. 112 f. Tese (Doutorado em Química) - Instituto de Química de São Carlos, Universidade de São Paulo, São Carlos, 2011.

100. WIGGINS, S. Introduction to applied nonlinear dynamical systems and chaos. New York: Springer, 2003.

101. ALBAHADILY, F. N.; RINGLAND, J.; SCHELL, M. Mixed mode oscillations in an electrochemical system. 1. A Farey sequence which does not occur on a torus. Journal of Chemical Physics, v. 90, p. 813-821, 1989.

102. FREIRE, J. G.; GALLAS, J. A. C. Stern-Brocot trees in the periodicity of mixed-mode oscillations. Physical Chemistry Chemical Physics, v. 13, p. 12191-12198, 2011.

103. GASPARD, P.; NICOLIS, G. What we can learn from homoclinic orbits in chaotic dynamics. Journal of Statistical Physics, v. 31, p. 499-518, 1983.

104. GASPARD, P.; KAPRAL, R.; NICOLIS, G. Bifurcation phenomena near homoclinic systems - A 2 parameter analysis. Journal of Statistical Physics, v. 35, p. 697-727, 1984.

105. GASPARD, P.; WANG, X. J. Homoclinic orbits and mixed-mode oscillations in far from equilibrium systems. Journal of Statistical Physics, v. 48, p. 151-199, 1987.

106. KOPER, M. T. M.; GASPARD, P.; SLUYTERS, J. H. Mixed-mode oscillations and incomplete homoclinic scenarios to a saddle focus in the indium/thiocyanate electrochemical oscillator. Journal of Chemical Physics, v. 97, p. 8250-8260, 1992.

107. KOPER, M. T. M.; GASPARD, P. The modeling of mixed-mode and chaotic oscillations in electrochemical systems. Journal of Chemical Physics, v. 96, p. 7797-7813, 1992.

108. LORENZ, E. N. Deterministic nonperiodic flow. Journal of the Atmospheric Sciences, v. 20, p. 130-141, 1963.

109. KOPER, M. T. M. The theory of electrochemical instabilities. Electrochimica Acta, v. 37, p. 1771-1778, 1992.

110. BARD, A. J.; FAULKNER, L. R. Electrochemical methods: Fundamentals and applications. New York: John Wiley, 1980.

111. HAMANN, C. H.; HAMNETT, A.; VIELSTICH, W. Electrochemistry. Weinheim: Wiley-VCH, 2007. 
112. TRASATTI, S.; PETRII, O. A. Real surface area measurements in electrochemistry. Pure and Applied Chemistry, v. 63, p. 711-734, 1991.

113. DE SOUZA, J. P. I.; IWASITA, T.; NART, F. C.; VIELSTICH, W. Performance evaluation of porous electrocatalysts via normalization of the active surface. Journal of Applied Electrochemistry, v. 30, p. 43-48, 2000.

114. WOLTER, O.; HEITBAUM, J. Differential electrochemical mass spectroscopy (DEMS) - A new method for study of electrode processes. Berichte Der BunsenGesellschaft-Physical Chemistry Chemical Physics, v. 88, p. 2-6, 1984.

115. CANTANE, D. A. Investigação da oxidação eletroquímica de etanol por espectrometria de massas on-line sobre nanoestruturas metálicas. 2013. 142 f. Tese (Doutorado em Química) - Instituto de Química de São Carlos, Universidade de São Paulo, São Carlos, 2013.

116. SEIDEL, Y. E.; JUSYS, Z.; LINDSTROM, R. W.; STENFELDT, M.; KASEMO, B.; KRISCHER, K. Oscillatory behaviour in galvanostatic formaldehyde oxidation on nanostructured Pt/glassy carbon model electrodes. Chemphyschem, v. 11, p. 1405-1415, 2010.

117. KOPER, M. T. M.; SLUYTERS, J. H. Electrochemical oscillators - Their description through a mathematical model. Journal of Electroanalytical Chemistry, v. 303, p. 73-94, 1991.

118. CUESTA, A. At least three contiguous atoms are necessary for $\mathrm{CO}$ formation during methanol electrooxidation on platinum. Journal of the American Chemical Society, v. 128, p. 13332-13333, 2006.

119. NEUROCK, M.; JANIK, M.; WIECKOWSKI, A. A first principles comparison of the mechanism and site requirements for the electrocatalytic oxidation of methanol and formic acid over Pt. Faraday Discussions, v. 140, p. 363-378, 2008.

120. PARSONS, R.; VANDERNOOT, T. The oxidation of small organic molecules - A survey of recent fuel-cell related research. Journal of Electroanalytical Chemistry, v. 257, p. 9-45, 1988.

121. JUSYS, Z.; KAISER, J.; BEHM, R. J. Methanol electrooxidation over Pt/C fuel cell catalysts: Dependence of product yields on catalyst loading. Langmuir, v. 19, p. 6759-6769, 2003.

122. HOUSMANS, T. H. M.; WONDERS, A. H.; KOPER, M. T. M. Structure sensitivity of methanol electrooxidation pathways on platinum: An on-line electrochemical mass spectrometry study. Journal of Physical Chemistry B, v. 110, p. 10021-10031, 2006.

123. ABD-EL-LATIF, A. A.; BALTRUSCHAT, H. Formation of methylformate during methanol oxidation revisited: The mechanism. Journal of Electroanalytical Chemistry, v. 662, p. 204-212, 2011. 
124. CUESTA, A.; CABELLO, G.; GUTIERREZ, C.; OSAWA, M. Adsorbed formate: the key intermediate in the oxidation of formic acid on platinum electrodes. Physical Chemistry Chemical Physics, v. 13, p. 20091-20095, 2011.

125. CAMPBELL, C. T.; ERTL, G.; KUIPERS, H.; SEGNER, J. A molecular beam study of the catalytic oxidation of $\mathrm{CO}$ on a $\mathrm{Pt}(111)$ surface. Journal of Chemical Physics, v. 73, p. 5862-5873, 1980.

126. SAUERBREI, S.; NASCIMENTO, M. A.; EISWIRTH, M.; VARELA, H. Mechanism and model of the oscillatory electro-oxidation of methanol. Journal of Chemical Physics, v. 132, p. 154901, 2010.

127. NOGUEIRA, P. A.; OLIVEIRA, H. C. L.; VARELA, H. Time evolution of the activation energy in a batch chemical oscillator. Journal of Physical Chemistry A, v. 112, p. 12412-12415, 2008.

128. MAREK, M.; SVOBODOVA, E. Nonlinear phenomena in oscillatory systems of homogeneous reactions - Experimental observations. Biophysical Chemistry, v. 3, p. 263$273,1975$.

129. ALAMGIR, M.; DE KEPPER, P.; ORBAN, M.; EPSTEIN, I. R. Systematic design of chemical oscillators.15. A new type of bromate oscillator - The bromate-iodide reaction in a stirred-flow reactor. Journal of the American Chemical Society, v. 105, p. 2641-2643, 1983.

130. FARIA, R. B. Introduction to oscillating chemical systems. Quimica Nova, v. 18, p. 281-294, 1995.

131. NOGUEIRA, P. A.; VARELA, H.; FARIA, R. B. The role of Ce(III) in BZ oscillating reactions. Chemical Physics Letters, v. 530, p. 137-139, 2012.

132. VARELA, H. Spatiotemporal pattern formation during electrochemical oxidation of hydrogen on platinum. 2003. 171 f. Tese (Doutorado em Ciências Naturais) - Fachbereich Biologie, Chemie, Pharmazie, Freien Universität Berlin, Berlim, 2003.

133. VARELA, H. Spatiotemporal pattern formation during electrochemical oxidation of hydrogen on platinum. ChemistryOpen, v. 1, p. 165-168, 2012.

134. BASSETT, M. R.; HUDSON, J. L. Shilnikov chaos during copper electrodissolution. Journal of Physical Chemistry, v. 92, p. 6963-6966, 1988.

135. ALBAHADILY, F. N.; SCHELL, M. An experimental investigation of periodic and chaotic electrochemical oscillations in the anodic dissolution of copper in phosphoric acid. Journal of Chemical Physics, v. 88, p. 4312-4319, 1988.

136. ORGAN, L.; KISS, I. Z.; HUDSON, J. L. Bursting oscillations during metal electrodissolution: Experiments and model. Journal of Physical Chemistry B, v. 107, p. 6648-6659, 2003. 
137. MARTINS, A. L.; BATISTA, B. C.; SITTA, E.; VARELA, H. Oscillatory instabilities during the electrocatalytic oxidation of methanol on platinum. Journal of the Brazilian Chemical Society, v. 19, p. 679-687, 2008.

138. BOSCHETO, E.; BATISTA, B. C.; LIMA, R. B.; VARELA, H. A surface-enhanced infrared absorption spectroscopic (SEIRAS) study of the oscillatory electro-oxidation of methanol on platinum. Journal of Electroanalytical Chemistry, v. 642, p. 17-21, 2010.

139. OKAMOTO, H.; TANAKA, N.; NAITO, M. Chaos in the oxidation of formaldehyde and/or methanol. Journal of Physical Chemistry A, v. 101, p. 8480-8488, 1997.

140. OKAMOTO, H.; TANAKA, N.; NAITO, M. Chaotic and periodic potential oscillations in formaldehyde oxidation. Journal of Physical Chemistry A, v. 102, p. 7343-7352, 1998.

141. OKAMOTO, H.; TANAKA, N.; NAITO, M. Intermittencies and related phenomena in the oxidation of formaldehyde at a constant current. Journal of Physical Chemistry A, v. 102, p. 7353-7361, 1998.

142. OKAMOTO, H.; KIKUCHI, M.; MUKOUYAMA, Y. Effect of chloride ions on potential oscillation generated by formic acid oxidation. Journal of Electroanalytical Chemistry, v. 622, p. 1-9, 2008.

143. KRAUSA, M.; VIELSTICH, W. Potential oscillations during methanol oxidation at Ptelectrodes.1. Experimental conditions. Journal of Electroanalytical Chemistry, v. 399, p. 7$12,1995$.

144. LIAUW, M. A.; KOBLITZ, K.; JAEGER, N. I.; PLATH, P. J. Periodic perturbation of a drifting heterogeneous catalytic system. Journal of Physical Chemistry, v. 97, p. 1172411730, 1993.

145. OTT, E.; GREBOGI, C.; YORKE, J. A. Controlling chaos. Physical Review Letters, v. 64, p. 1196-1199, 1990.

146. PYRAGAS, K. Continuous control of chaos by self-controlling feedback. Physics Letters A, v. 170, p. 421-428, 1992.

147. BIELAWSKI, S.; DEROZIER, D.; GLORIEUX, P. Experimental characterization of unstable periodic orbits by controlling chaos. Physical Review A, v. 47, p. R2492-R2495, 1993.

148. PETROV, V.; GASPAR, V.; MASERE, J.; SHOWALTER, K. Controlling chaos in the Belousov-Zhabotinsky reaction. Nature, v. 361, p. 240-243, 1993.

149. SCHELL, M.; ROSS, J. Effects of time delay in rate processes. Journal of Chemical Physics, v. 85, p. 6489-6503, 1986.

150. HJELMFELT, A.; ROSS, J. Experimental stabilization of unstable steady states in oscillatory and excitable reaction systems. Journal of Physical Chemistry, v. 98, p. 11761179, 1994. 
151. PARMANANDA, P.; EISWIRTH, M. Stabilizing unstable fixed points using derivative control. Journal of Physical Chemistry, v. 100, p. 16568-16570, 1996.

152. NAGAO, R.; SITTA, E.; VARELA, H. Stabilizing nonstationary electrochemical time series. Journal of Physical Chemistry C, v. 114, p. 22262-22268, 2010.

153. CABRAL, M. F.; NAGAO, R.; SITTA, E.; EISWIRTH, M.; VARELA, H. Mechanistic aspects of the linear stabilization of non-stationary electrochemical oscillations. Physical Chemistry Chemical Physics, v. 15, p. 1437-1442, 2013.

154. CHEN, Q. S.; SOLLA-GULLON, J.; SUN, S. G.; FELIU, J. M. The potential of zero total charge of Pt nanoparticles and polycrystalline electrodes with different surface structure The role of anion adsorption in fundamental electrocatalysis. Electrochimica Acta, v. 55, p. 7982-7994, 2010.

155. COHEN, J. L.; VOLPE, D. J.; ABRUNA, H. D. Electrochemical determination of activation energies for methanol oxidation on polycrystalline platinum in acidic and alkaline electrolytes. Physical Chemistry Chemical Physics, v. 9, p. 49-77, 2007.

156. SITTA, E.; SANTOS, A. L.; NAGAO, R.; VARELA, H. Nanogravimetric study of the complex voltammetric response in the electro-oxidation of methanol on platinum.

Electrochimica Acta, v. 55, p. 404-409, 2009.

157. TAKENS, F. Detecting strange attractors in turbulence. In: RAND, D. A.; YOUNG, L.S. Dynamical systems and turbulence. Lecture notes in mathematics. Warwick: Springer, 1981. v. 898. p. 366-381.

158. PACKARD, N. H.; CRUTCHFIELD, J. P.; FARMER, J. D.; SHAW, R. S. Geometry from a time-series. Physical Review Letters, v. 45, p. 712-716, 1980.

159. BATISTA, B. C.; FERREIRA, G. C. A.; VARELA, H. The effect of poisoning species on the oscillatory dynamics of an electrochemical reaction. Journal of Physics: Conference Series, v. 285, p. 012003, 2011.

160. BAGOTZKY, V. S.; VASSILIEV, Y. B.; KHAZOVA, O. A. Generalized scheme of chemisorption, electrooxidation and electroreduction of simple organic compounds on platinum group metals. Journal of Electroanalytical Chemistry, v. 81, p. 229-238, 1977.

161. BATISTA, E. A.; IWASITA, T. Adsorbed intermediates of formaldehyde oxidation and their role in the reaction mechanism. Langmuir, v. 22, p. 7912-7916, 2006.

162. OLIVEIRA, C. P.; LUSSARI, N. V.; SITTA, E.; VARELA, H. Oscillatory electrooxidation of glycerol on platinum. Electrochimica Acta, v. 85, p. 674-679, 2012.

163. NEHER, G.; POHLMANN, L.; TRIBUTSCH, H. Mixed-mode oscillations, selfsimilarity, and time-transient chaotic behavior in the (photo-) electrochemical system p$\mathrm{CuInSe}{ }_{2} / \mathrm{H}_{2} \mathrm{O}_{2}$. Journal of Physical Chemistry, v. 99, p. 17763-17771, 1995. 
164. GASTEIGER, H. A.; MARKOVIC, N.; ROSS, P. N.; CAIRNS, E. J. Methanol electrooxidation on well characterized Pt-Ru alloys. Journal of Physical Chemistry, v. 97, p. 12020-12029, 1993.

165. CHRISTENSEN, P. A.; HAMNETT, A.; TROUGHTON, G. L. The role of morphology in the methanol electrooxidation reaction. Journal of Electroanalytical Chemistry, v. 362, p. 207-218, 1993.

166. JUSYS, Z.; BEHM, R. J. Methanol oxidation on a carbon-supported Pt fuel cell catalyst - A kinetic and mechanistic study by differential electrochemical mass spectrometry. Journal of Physical Chemistry B, v. 105, p. 10874-10883, 2001.

167. IWASITA, T.; XIA, X. H. Adsorption of water at $\mathrm{Pt}(111)$ electrode in $\mathrm{HClO}_{4}$ solutions. The potential of zero charge. Journal of Electroanalytical Chemistry, v. 411, p. 95-102, 1996.

168. IWASITA, T.; XIA, X. H.; LIESS, H. D.; VIELSTICH, W. Electrocatalysis of organic oxidations: Influence of water adsorption on the rate of reaction. Journal of Physical Chemistry B, v. 101, p. 7542-7547, 1997.

169. KIM, H.; DE MORAES, I. R.; TREMILIOSI, G.; HAASCH, R.; WIECKOWSKI, A. Chemical state of ruthenium submonolayers on a Pt(111) electrode. Surface Science, v. 474, p. L203-L212, 2001.

170. SOBKOWSKI, J.; FRANASZCZUK, K.; DOBROWOLSKA, K. Effect of anions and $\mathrm{pH}$ on the adsorption and oxidation of methanol on a platinum electrode. Journal of Electroanalytical Chemistry, v. 330, p. 529-540, 1992.

171. ANGERSTE, H.; CONWAY, B., E.; SHARP, W. B. A. Real condition of electrochemically oxidized platinum surfaces. 1.Resolution of component processes. Journal of Electroanalytical Chemistry, v. 43, p. 9-36, 1973.

172. FERREIRA, G. C. A.; BATISTA, B. C.; VARELA, H. Experimental assessment of the sensitiveness of an electrochemical oscillator towards chemical perturbations. Plos One, v. 7, p. e50145, 2012.

173. CHELIDZE, D.; CUSUMANO, J. P.; CHATTERJEE, A. A dynamical systems approach to damage evolution tracking, part 1: Description and experimental application. Journal of Vibration and Acoustics-Transactions of the Asme, v. 124, p. 250-257, 2002.

174. CUSUMANO, J. P.; CHELIDZE, D.; CHATTERJEE, A. A dynamical systems approach to damage evolution tracking, part 2: Model-based validation and physical interpretation. Journal of Vibration and Acoustics-Transactions of the Asme, v. 124, p. 258-264, 2002.

175. DINGWELL, J. B.; NAPOLITANO, D. F.; CHELIDZE, D. A nonlinear approach to tracking slow-time-scale changes in movement kinematics. Journal of Biomechanics, v. 40, p. 1629-1634, 2007. 
176. SONG, M.; SEGALA, D. B.; DINGWELL, J. B.; CHELIDZE, D. Slow-time changes in human EMG muscle fatigue states are fully represented in movement kinematics. Journal of Biomechanical Engineering, v. 131, p. 021004, 2009.

177. KANG, H. G.; DINGWELL, J. B. Dynamics and stability of muscle activations during walking in healthy young and older adults. Journal of Biomechanics, v. 42, p. 2231-2237, 2009.

178. RICHTER, P. H.; ROSS, J. Concentration oscillations and efficiency - Glycoysis. Science, v. 211, p. 715-717, 1981.

179. JUSYS, Z.; KAISER, J.; BEHM, R. J. Composition and activity of high surface area PtRu catalysts towards adsorbed CO and methanol electrooxidation - A DEMS study.

Electrochimica Acta, v. 47, p. 3693-3706, 2002.

180. CHOJAK-HALSEID, M.; JUSYS, Z.; BEHM, R. J. Methanol oxidation over a Pt/C catalyst at high temperatures and pressure: An on line electrochemical mass spectrometry study. Journal of Physical Chemistry C, v. 114, p. 22573-22581, 2010.

181. IWASITA, T.; VIELSTICH, W. On line mass spectroscopy of volatile products during methanol oxidation at platinum in acid solutions. Journal of Electroanalytical Chemistry, v. 201, p. 403-408, 1986.

182. WANG, H.; LOFFLER, T.; BALTRUSCHAT, H. Formation of intermediates during methanol oxidation: A quantitative DEMS study. Journal of Applied Electrochemistry, v. 31, p. 759-765, 2001.

183. BATISTA, E. A.; MALPASS, G. R. P.; MOTHEO, A. J.; IWASITA, T. New insight into the pathways of methanol oxidation. Electrochemistry Communications, v. 5, p. 843$846,2003$.

184. BATISTA, E. A.; MALPASS, G. R. P.; MOTHEO, A. J.; IWASITA, T. New mechanistic aspects of methanol oxidation. Journal of Electroanalytical Chemistry, v. 571, p. 273-282, 2004.

185. WANG, H. S.; BALTRUSCHAT, H. DEMS study on methanol oxidation at poly- and monocrystalline platinum electrodes: The effect of anion, temperature, surface structure, $\mathrm{Ru}$ adatom, and potential. Journal of Physical Chemistry C, v. 111, p. 7038-7048, 2007.

186. ANASTASIJEVIC, N. A.; BALTRUSCHAT, H.; HEITBAUM, J. DEMS as a tool for the investigation of dynamic processes - Galvanostatic formic acid oxidation on a $\mathrm{Pt}$ electrode. Journal of Electroanalytical Chemistry, v. 272, p. 89-100, 1989.

187. HENDRIKSEN, B. L. M.; ACKERMANN, M. D.; VAN RIJN, R.; STOLTZ, D.; POPA, I.; BALMES, O.; RESTA, A.; WERMEILLE, D.; FELICI, R.; FERRER, S.;

FRENKEN, J. W. M. The role of steps in surface catalysis and reaction oscillations. Nature Chemistry, v. 2, p. 730-734, 2010. 
188. JENSEN, R.; ANDERSEN, T.; NIERHOFF, A.; PEDERSEN, T.; HANSEN, O.; DAHL, S.; CHORKENDORFF, I. Self-sustained carbon monoxide oxidation oscillations on size-selected platinum nanoparticles at atmospheric pressure. Physical Chemistry Chemical Physics, v. 15, p. 2698-2702, 2013.

189. CUESTA, A. Atomic ensemble effects in electrocatalysis: The site-knockout strategy. Chemphyschem, v. 12, p. 2375-2385, 2011.

190. TRIBUTSCH, H. The challenge of nonlinear and cooperative mechanisms for electrocatalysis. Electrochimica Acta, v. 39, p. 1495-1502, 1994.

191. VAN SANTEN, R. A. The complex paradox of science. Chemistry World, 2012. Dísponível em: <http://www.rsc.org/chemistryworld/2012/04/complex-paradox-science>. Acesso em: 13 out. 2013.

192. IMBIHL, R.; ERTL, G. Oscillatory kinetics in heterogeneous catalysis. Chemical Reviews, v. 95, p. 697-733, 1995.

193. Ertl center for electrochemistry and catalysis sediado no Gwangju institute of science and technology, Korea. Dísponível em: <http://env1.gist.ac.kr/ertl/new/ERTLCenter/>. Acesso em: 13 out. 2013.

194. VARELA, H. Da parte para o todo: auto-organização dinâmica em sistemas FísicoQuímicos. Ciência e Cultura, v. 63, p. 23-25, 2011.

195. MIYAKITA, Y.; NAKABAYASHI, S.; KARANTONIS, A. Spatiotemporal coding in an electrochemical oscillatory network. Physical Review E, v. 71, p. 056207, 2005.

196. KARANTONIS, A.; PAGITSAS, M.; MIYAKITA, Y.; NAKABAYASHI, S. Manipulation of spatio-temporal patterns in networks of relaxation electrochemical oscillators. Electrochimica Acta, v. 50, p. 5056-5064, 2005.

197. KARANTONIS, A.; PAGITSAS, M.; MIYAKITA, Y.; NAKABAYASHI, S. In-phase, anti-phase and fractured synchrony in ring networks of coupled relaxation electrochemical oscillators. Journal of Physical Chemistry B, v. 108, p. 5836-5846, 2004.

198. KARANTONIS, A.; PAGITSAS, M.; MIYAKITA, Y.; NAKABAYASHI, S. Synchronization phenomena in networks of coupled relaxation electrochemical oscillations. International Journal of Bifurcation and Chaos, v. 16, p. 1951-1960, 2006.

199. KARANTONIS, A.; KOUTALIDI, S. Locomotion determined and controlled by electrochemical networks A robotic application based on electrochemical oscillations. Journal of Applied Electrochemistry, v. 42, p. 689-698, 2012.

200. KRISCHER, K. Nonlinear Dynamics in Electrochemical Systems. In: ALKIRE, R. C.; KOLB, D. M. Advances in Electrochemical Science and Engineering. Weinheim: WileyVCH, 2003. v. 8. p. 90-203.

201. CHRISTOPH, J.; EISWIRTH, M. Theory of electrochemical pattern formation. Chaos, v. 12, p. 215-230, 2002. 
202. CHRISTOPH, J.; OTTERSTEDT, R. D.; EISWIRTH, M.; JAEGER, N. I.; HUDSON, J. L. Negative coupling during oscillatory pattern formation on a ring electrode. Journal of Chemical Physics, v. 110, p. 8614-8621, 1999.

203. FLATGEN, G.; KRISCHER, K. A general model for pattern formation in electrode reactions. Journal of Chemical Physics, v. 103, p. 5428-5436, 1995.

204. MAZOUZ, N.; KRISCHER, K. A theoretical study on turing patterns in electrochemical systems. Journal of Physical Chemistry B, v. 104, p. 6081-6090, 2000.

205. PLENGE, F.; VARELA, H.; KRISCHER, K. Asymmetric target patterns in onedimensional oscillatory media with genuine nonlocal coupling. Physical Review Letters, v. 94, p. 198301, 2005.

206. VARELA, H.; BETA, C.; BONNEFONT, A.; KRISCHER, K. A hierarchy of global coupling induced cluster patterns during the oscillatory $\mathrm{H}_{2}$ electrooxidation reaction on a $\mathrm{Pt}$ ring-electrode. Physical Chemistry Chemical Physics, v. 7, p. 2429-2439, 2005.

207. KRISCHER, K.; VARELA, H.; BIRZU, A.; PLENGE, F.; BONNEFONT, A. Stability of uniform electrode states in the presence of ohmic drop compensation. Electrochimica Acta, v. 49, p. 103-115, 2003.

208. KISS, I. Z.; WANG, W.; HUDSON, J. L. Experiments on arrays of globally coupled periodic electrochemical oscillators. Journal of Physical Chemistry B, v. 103, p. 1143311444, 1999.

209. LEE, J. Electro-oxidation of small organic molecules: Kinetic instabilities and spatiotemporal pattern formation. 2001. $171 \mathrm{f}$. Tese (Doutorado em Ciências Naturais) Fachbereich Biologie, Chemie, Pharmazie, Freien Universität Berlin, Freien Universität Berlin, Berlim, 2001.

210. SADEGHI, S.; THOMPSON, M. Temporal patterns and oscillatory voltage perturbation during an electrochemical process. Physical Chemistry Chemical Physics, v. 12, p. 6795-6809, 2010.

211. SADEGHI, S.; THOMPSON, M. Towards information processing from nonlinear physical chemistry: A synthetic electrochemical cognitive system. Biosystems, v. 102, p. 99$111,2010$. 
AneXos 

Rotina escrita em ambiente Matlab. Os resultados são mostrados na Figura 1.1.

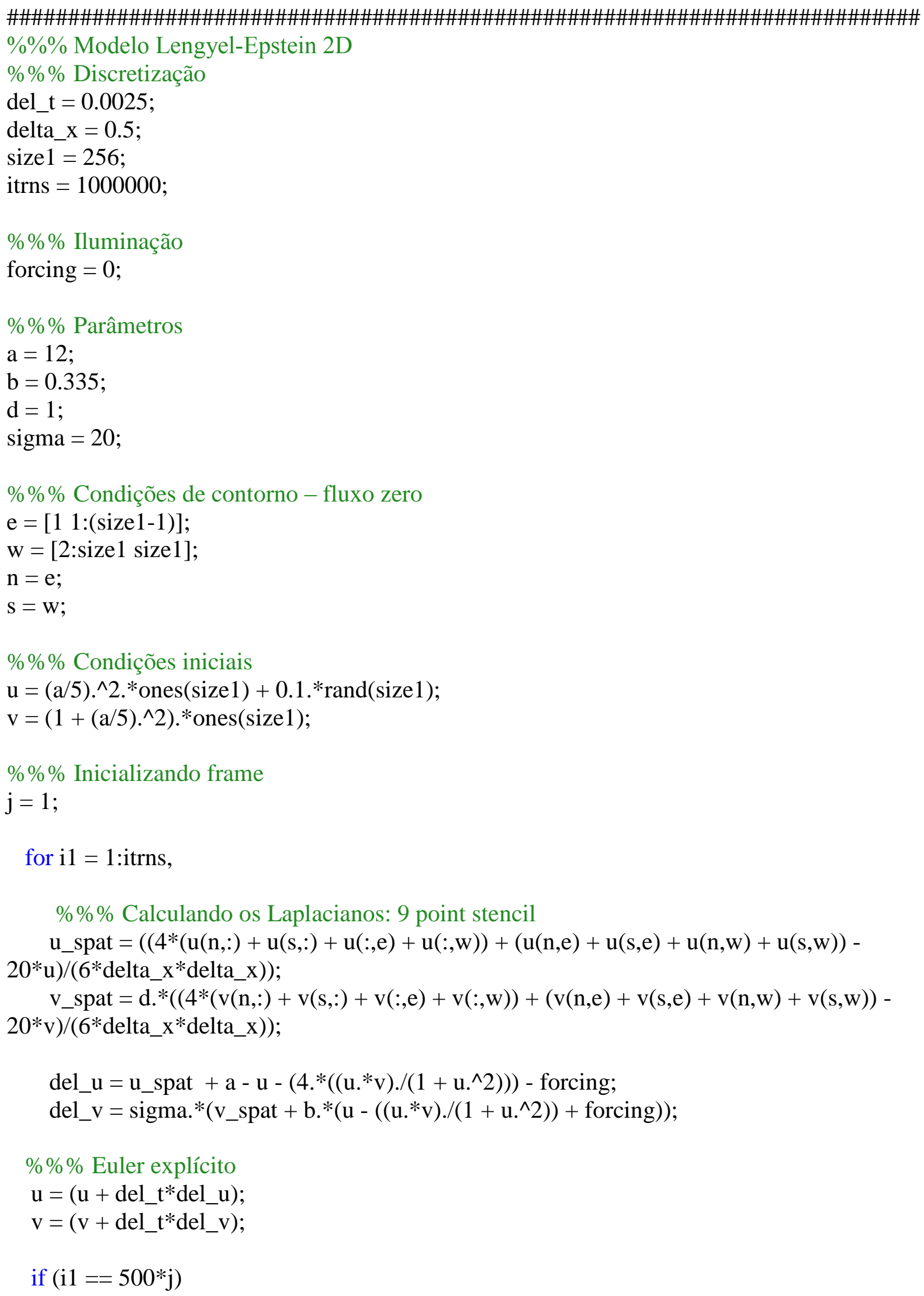


imagesc(u),

colormap('default'),

$\mathrm{u} 1 \mathrm{rec}(\mathrm{j})=$ getframe;

$\mathrm{j}=\mathrm{j}+1$;

end

end

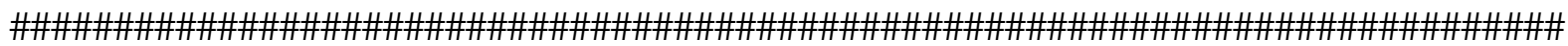


Rotina escrita em ambiente Matlab. Os resultados são mostrados na Figura 5.5.

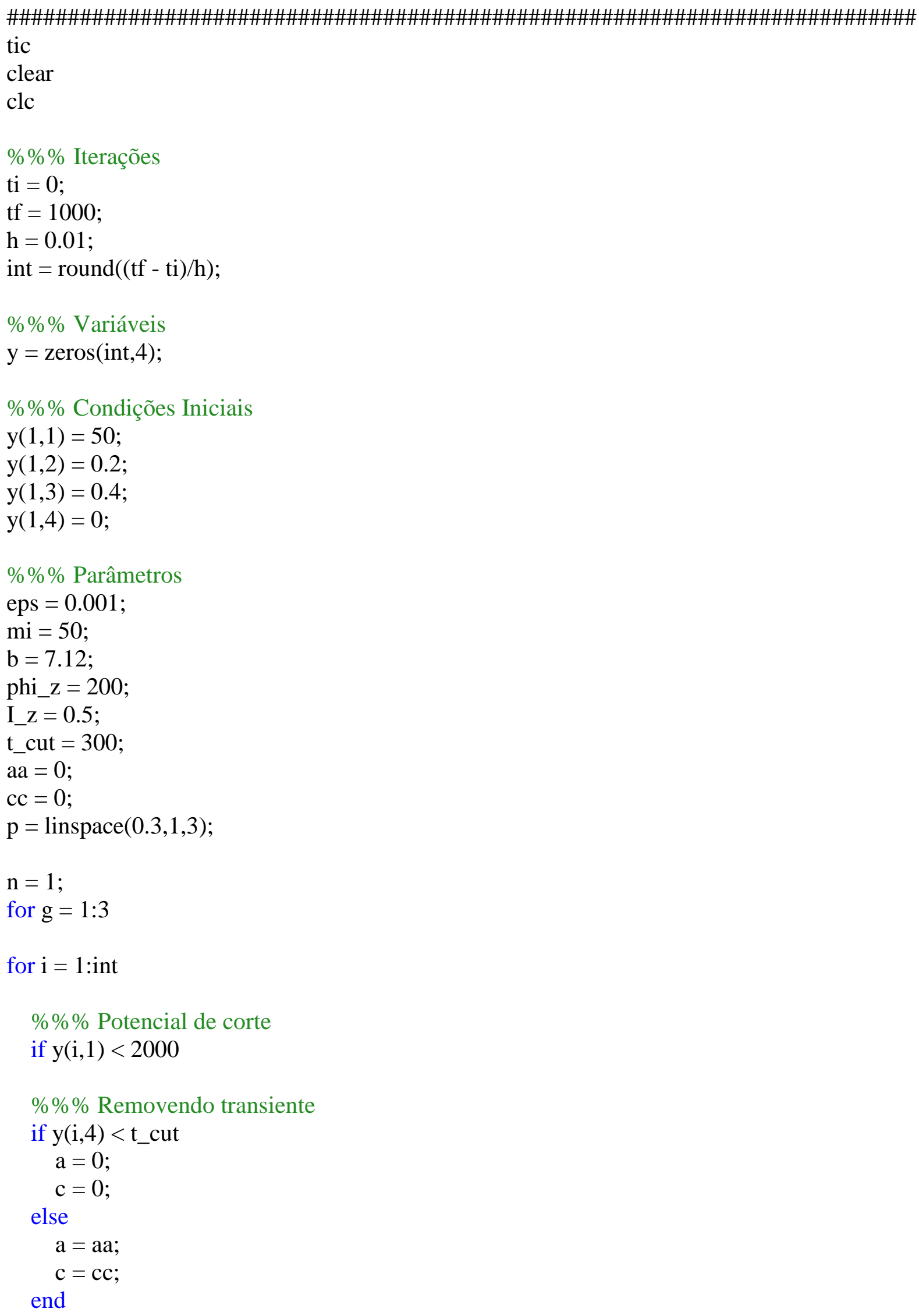




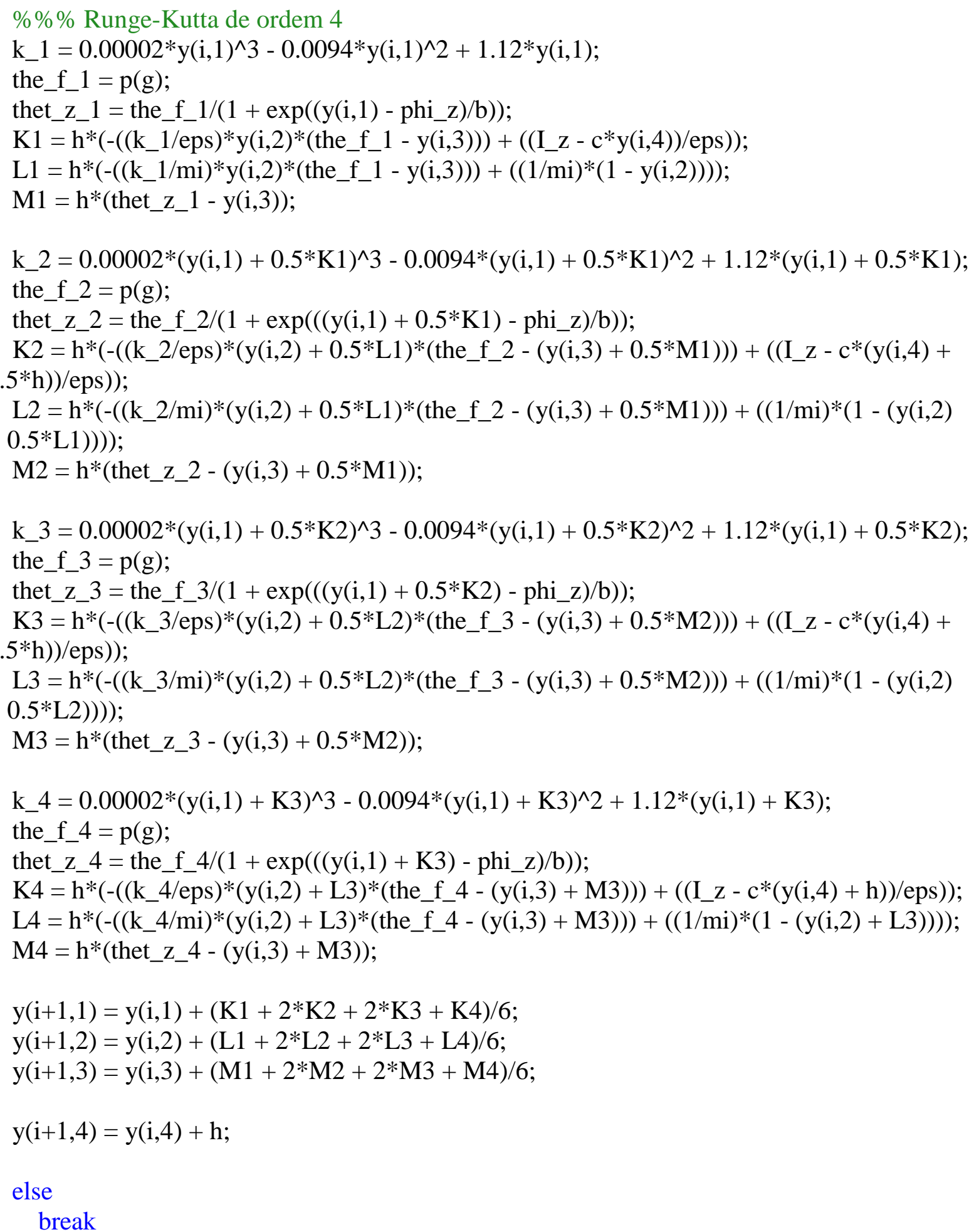

end

end

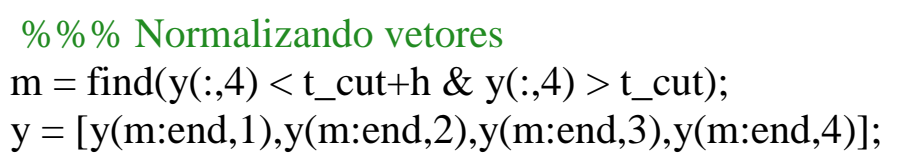


$\% \%$ Calculando pontos de máximo e mínimo

phi_t $=\mathrm{y}(2$ :end-1,1);

phi_left $=\mathrm{y}(1:$ end $-2,1)$;

phi_right $=\mathrm{y}(3$ :end, 1$)$;

$\mathrm{k} \_$max $=$find $(($phi_t $>$phi_left $) \&($ phi_t $>=$ phi_right $))$;

$\mathrm{k} \_$min $=$find $(($phi_t $<$phi_left $) \&($ phi_t $<=$ phi_right $))$;

$\% \%$ Calculando o potencial médio

phi_m $=$ zeros $\left(1,\left(\right.\right.$ length $\left.\left.\left(\mathrm{k} \_\max \right)-1\right)\right)$;

for i2 = 1:(length(k_max $)-1)$

phi_rec $=$ zeros $\left(1, \mathrm{k} \_\max (\mathrm{i} 2+1)-\mathrm{k} \_\max (\mathrm{i} 2)\right)$;

for $\mathrm{i} 1=1:\left(\mathrm{k} \_\max (\mathrm{i} 2+1)-\mathrm{k} \_\max (\mathrm{i} 2)\right)$

phi_rec(i1) $=\left(\left(y\left(\mathrm{k} \_\max (\mathrm{i} 2)+\mathrm{i} 1,4\right)-\mathrm{y}\left(\mathrm{k} \_\max (\mathrm{i} 2)+(\mathrm{i} 1-1), 4\right)\right) * \mathrm{y}\left(\mathrm{k} \_\max (\mathrm{i} 2)+\mathrm{i} 1,1\right)\right)$;

end

phi_m(i2) $=\operatorname{sum}($ phi_rec $) /\left(y\left(k \_m a x(i 2+1), 4\right)-y\left(k \_m a x(i 2), 4\right)\right)$;

end

$\% \% \%$ Figuras

hold on

subplot(3,1,4-n)

plot(y(k_max(2:end),4),phi_m,'-ro',y(:,4),y(:,1),'k');

xlabel('t')

ylabel('ıphi')

$\% \% \%$ Contador

$\mathrm{n}=\mathrm{n}+1$;

end

toc

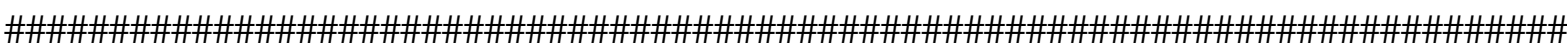


Rotina escrita em ambiente Matlab. Os resultados são mostrados na Figura 5.6.

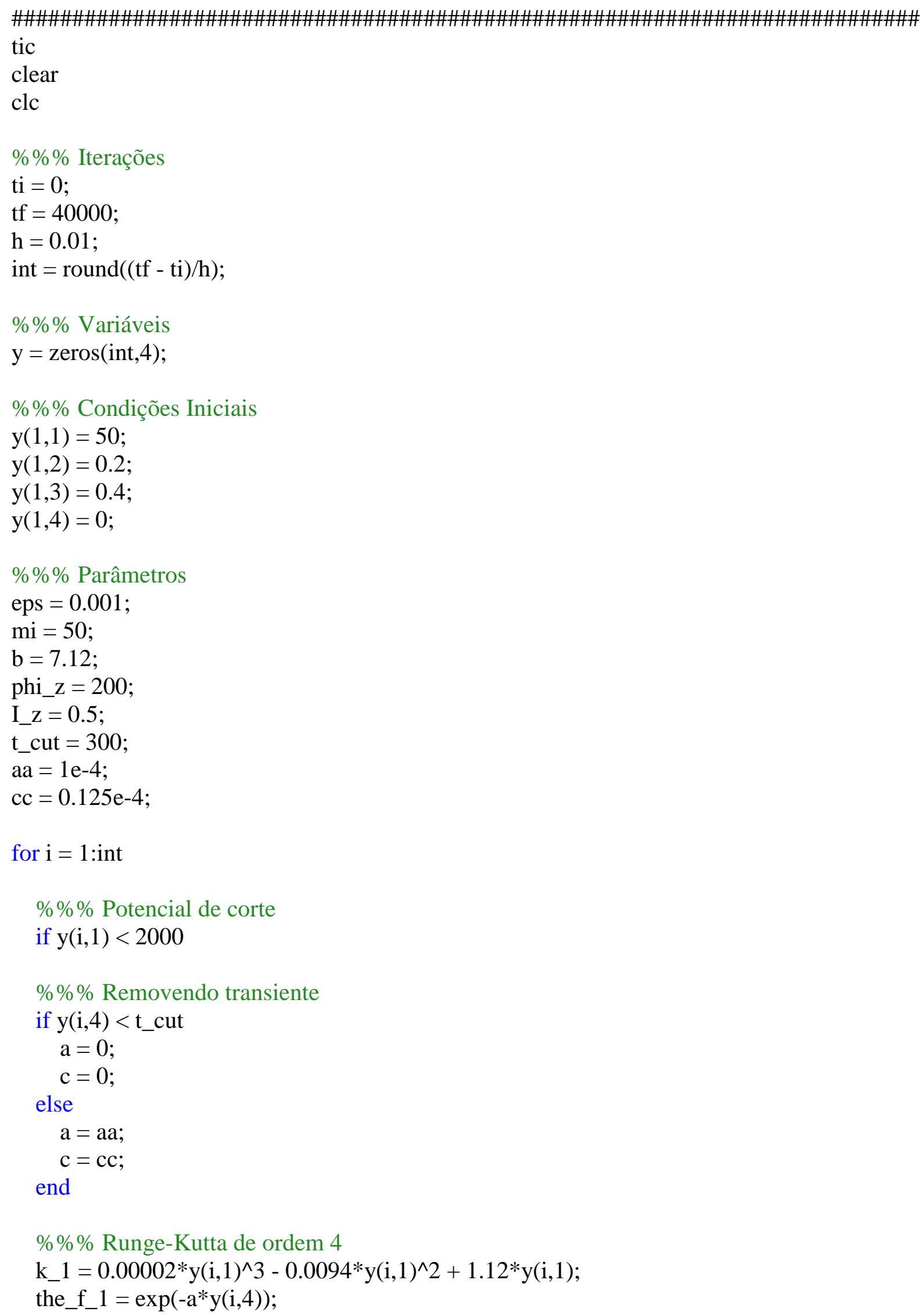


thet_z_1 = the_f_1/(1+exp $\left.\left(\left(\mathrm{y}(\mathrm{i}, 1)-\mathrm{phi} \_\mathrm{z}\right) / \mathrm{b}\right)\right)$;

$\mathrm{K} 1=\mathrm{h} *\left(-\left(\left(\mathrm{k} \_1 / \mathrm{eps}\right) * \mathrm{y}(\mathrm{i}, 2) *(\right.\right.$ the_f_1 $\left.\left.-\mathrm{y}(\mathrm{i}, 3))\right)+\left(\left(\mathrm{I} \_\mathrm{z}-\mathrm{c} * \mathrm{y}(\mathrm{i}, 4)\right) / \mathrm{eps}\right)\right)$;

$\mathrm{L} 1=\mathrm{h} *\left(-\left(\left(\mathrm{k} \_1 / \mathrm{mi}\right) * \mathrm{y}(\mathrm{i}, 2) *(\right.\right.$ the_f_1 $\left.\left.-\mathrm{y}(\mathrm{i}, 3))\right)+((1 / \mathrm{mi}) *(1-\mathrm{y}(\mathrm{i}, 2)))\right)$;

$\mathrm{M} 1=\mathrm{h} *($ thet_z_1 $-\mathrm{y}(\mathrm{i}, 3))$;

$\mathrm{k} \_2=0.00002^{*}\left(\mathrm{y}(\mathrm{i}, 1)+0.5^{*} \mathrm{~K} 1\right)^{\wedge} 3-0.0094^{*}\left(\mathrm{y}(\mathrm{i}, 1)+0.5^{*} \mathrm{~K} 1\right)^{\wedge} 2+1.12^{*}\left(\mathrm{y}(\mathrm{i}, 1)+0.5^{*} \mathrm{~K} 1\right)$; the_f_2 $=\exp \left(-\mathrm{a}^{*}\left(\mathrm{y}(\mathrm{i}, 4)+0.5^{*} \mathrm{~h}\right)\right)$;

thet_z_2 = the_f_2/(1+exp $(((\mathrm{y}(\mathrm{i}, 1)+0.5 * \mathrm{~K} 1)-$ phi_z $) / \mathrm{b}))$;

$\mathrm{K} 2=\mathrm{h} *\left(-\left(\left(\mathrm{k} \_2 / \mathrm{eps}\right) *(\mathrm{y}(\mathrm{i}, 2)+0.5 * \mathrm{~L} 1) *\left(\right.\right.\right.$ the_f $\left.\left.\_2-(\mathrm{y}(\mathrm{i}, 3)+0.5 * \mathrm{M} 1)\right)\right)+\left(\left(\mathrm{I} \_\mathrm{z}-\mathrm{c} *(\mathrm{y}(\mathrm{i}, 4)+\right.\right.$ $\left.\left.\left.\left.0.5^{*} \mathrm{~h}\right)\right) / \mathrm{eps}\right)\right)$;

$\mathrm{L} 2=\mathrm{h} *\left(-\left(\left(\mathrm{k} \_2 / \mathrm{mi}\right) *(\mathrm{y}(\mathrm{i}, 2)+0.5 * \mathrm{~L} 1)^{*}\left(\right.\right.\right.$ the $\_$f $\left.\left.\_2-(\mathrm{y}(\mathrm{i}, 3)+0.5 * \mathrm{M} 1)\right)\right)+((1 / \mathrm{mi}) *(1-(\mathrm{y}(\mathrm{i}, 2)$ $\left.\left.\left.\left.+0.5^{*} \mathrm{~L} 1\right)\right)\right)\right)$

$\mathrm{M} 2=\mathrm{h} *($ thet_z_2 $-(\mathrm{y}(\mathrm{i}, 3)+0.5 * \mathrm{M} 1))$

$\mathrm{k} \_3=0.00002 *\left(\mathrm{y}(\mathrm{i}, 1)+0.5^{*} \mathrm{~K} 2\right)^{\wedge} 3-0.0094 *(\mathrm{y}(\mathrm{i}, 1)+0.5 * \mathrm{~K} 2)^{\wedge} 2+1.12 *\left(\mathrm{y}(\mathrm{i}, 1)+0.5^{*} \mathrm{~K} 2\right)$; the_f_3 $=\exp \left(-\mathrm{a}^{*}\left(\mathrm{y}(\mathrm{i}, 4)+0.5^{*} \mathrm{~h}\right)\right)$;

thet_z_3 = the_f_3/(1+exp $(((\mathrm{y}(\mathrm{i}, 1)+0.5 * \mathrm{~K} 2)-$ phi_z $) / \mathrm{b}))$;

$\mathrm{K} 3=\mathrm{h} *\left(-\left(\left(\mathrm{k} \_3 / \mathrm{eps}\right) *(\mathrm{y}(\mathrm{i}, 2)+0.5 * \mathrm{~L} 2) *(\right.\right.$ the_f_3 $\left.-(\mathrm{y}(\mathrm{i}, 3)+0.5 * \mathrm{M} 2))\right)+\left(\left(\mathrm{I} \_\mathrm{z}-\mathrm{c} *(\mathrm{y}(\mathrm{i}, 4)+\right.\right.$ $0.5 * \mathrm{~h})) / \mathrm{eps}))$;

$\mathrm{L} 3=\mathrm{h} *\left(-\left(\left(\mathrm{k} \_3 / \mathrm{mi}\right) *(\mathrm{y}(\mathrm{i}, 2)+0.5 * \mathrm{~L} 2) *\left(\right.\right.\right.$ the $\left.\left.\_f \_3-(\mathrm{y}(\mathrm{i}, 3)+0.5 * \mathrm{M} 2)\right)\right)+((1 / \mathrm{mi}) *(1-(\mathrm{y}(\mathrm{i}, 2)$ $\left.\left.\left.\left.+0.5^{*} \mathrm{~L} 2\right)\right)\right)\right)$

$\mathrm{M} 3=\mathrm{h} *($ thet_z_3 $-(\mathrm{y}(\mathrm{i}, 3)+0.5 * \mathrm{M} 2))$;

$\mathrm{k} \_4=0.00002 *(\mathrm{y}(\mathrm{i}, 1)+\mathrm{K} 3)^{\wedge} 3-0.0094 *(\mathrm{y}(\mathrm{i}, 1)+\mathrm{K} 3)^{\wedge} 2+1.12 *(\mathrm{y}(\mathrm{i}, 1)+\mathrm{K} 3)$;

the_f_4 $=\exp \left(-\mathrm{a}^{*}(\mathrm{y}(\mathrm{i}, 4)+\mathrm{h})\right)$;

thet_z_4 = the_f_4/(1+exp $(((y(i, 1)+\mathrm{K} 3)-$ phi_z $) / b))$;

$\mathrm{K} 4=\mathrm{h} *\left(-\left(\left(\mathrm{k} \_4 / \mathrm{eps}\right) *(\mathrm{y}(\mathrm{i}, 2)+\mathrm{L} 3) *(\right.\right.$ the_f_4 $\left.\left.-(\mathrm{y}(\mathrm{i}, 3)+\mathrm{M} 3))\right)+\left(\left(\mathrm{I} \_\mathrm{z}-\mathrm{c} *(\mathrm{y}(\mathrm{i}, 4)+\mathrm{h})\right) / \mathrm{eps}\right)\right)$;

$\mathrm{L} 4=\mathrm{h} *\left(-\left(\left(\mathrm{k} \_4 / \mathrm{mi}\right) *(\mathrm{y}(\mathrm{i}, 2)+\mathrm{L} 3)^{*}(\right.\right.$ the_f_4 $\left.\left.-(\mathrm{y}(\mathrm{i}, 3)+\mathrm{M} 3))\right)+((1 / \mathrm{mi}) *(1-(\mathrm{y}(\mathrm{i}, 2)+\mathrm{L} 3)))\right)$;

M4 $=$ h*(thet_z_4 - $(\mathrm{y}(\mathrm{i}, 3)+\mathrm{M} 3))$;

$\mathrm{y}(\mathrm{i}+1,1)=\mathrm{y}(\mathrm{i}, 1)+(\mathrm{K} 1+2 * \mathrm{~K} 2+2 * \mathrm{~K} 3+\mathrm{K} 4) / 6$

$\mathrm{y}(\mathrm{i}+1,2)=\mathrm{y}(\mathrm{i}, 2)+(\mathrm{L} 1+2 * \mathrm{~L} 2+2 * \mathrm{~L} 3+\mathrm{L} 4) / 6$

$\mathrm{y}(\mathrm{i}+1,3)=\mathrm{y}(\mathrm{i}, 3)+(\mathrm{M} 1+2 * \mathrm{M} 2+2 * \mathrm{M} 3+\mathrm{M} 4) / 6$;

$y(i+1,4)=y(i, 4)+h ;$

else

break

end

end

$\% \% \%$ Normalizando vetores

$\mathrm{m}=$ find $\left(\mathrm{y}(:, 4)<\mathrm{t} \_\right.$cut $+\mathrm{h} \& \mathrm{y}(:, 4)>\mathrm{t} \_$cut $)$;

$\mathrm{y}=[\mathrm{y}(\mathrm{m}: \mathrm{end}, 1), \mathrm{y}(\mathrm{m}: \mathrm{end}, 2), \mathrm{y}(\mathrm{m}: \mathrm{end}, 3), \mathrm{y}(\mathrm{m}: \mathrm{end}, 4)]$; 
$\% \%$ Calculando pontos de máximo e mínimo

phi_t $=\mathrm{y}(2$ :end-1,1);

phi_left $=\mathrm{y}(1:$ end-2,1);

phi_right $=\mathrm{y}(3:$ end, 1$)$;

$\mathrm{k} \_$max $=$find $(($phi_t $>$phi_left $) \&($ phi_t $>=$ phi_right $))$;

$\mathrm{k} \_\min =\operatorname{find}(($ phi_t $<$ phi_left $) \&($ phi_t $<=$ phi_right $))$;

$\% \%$ Calculando potencial médio

phi_m $=$ zeros $\left(1,\left(\right.\right.$ length $\left.\left.\left(\mathrm{k} \_\max \right)-1\right)\right)$;

for $\mathrm{i} 2=1$ :(length(k_max $)-1)$

phi_rec $=$ zeros $\left(1, \mathrm{k} \_\max (\mathrm{i} 2+1)-\mathrm{k} \_\max (\mathrm{i} 2)\right)$;

for $\mathrm{i} 1=1:\left(\mathrm{k} \_\max (\mathrm{i} 2+1)-\mathrm{k} \_\max (\mathrm{i} 2)\right)$

phi_rec $(i 1)=\left(\left(y\left(k \_m a x(i 2)+i 1,4\right)-y\left(k \_m a x(i 2)+(i 1-1), 4\right)\right) * y\left(k \_m a x(i 2)+i 1,1\right)\right)$;

end

phi_m $($ i2 $)=\operatorname{sum}($ phi_rec $) /\left(y\left(k \_m a x(i 2+1), 4\right)-y\left(k \_m a x(i 2), 4\right)\right)$;

end

$y(:, 4)=y(:, 4)-300$

$\% \%$ Figuras

$\operatorname{plot}\left(\mathrm{y}(:, 4), \mathrm{y}(:, 1), \mathrm{k}^{\prime}, \mathrm{y}\left(\mathrm{k} \_\max (2: \mathrm{end}), 4\right), \mathrm{phi} \_\mathrm{m},{ }^{\prime}-\mathrm{ro}\right)$;

xlabel('t')

ylabel('\phi')

toc

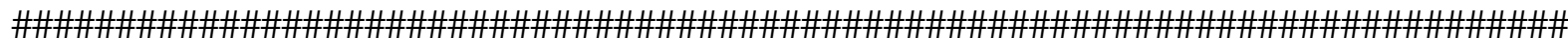


Rotina escrita em ambiente Matlab. Os resultados são mostrados na Figura 5.7.

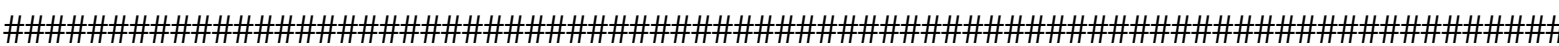

tic

clear

clc

$\% \%$ Dimensões da matriz

a1 $=200 ; \% \% \%$ múltiplos de 4 (processadores) aumenta a eficiência

$\mathrm{a} 2=201$

$\% \%$ Pré-alocando os vetores e matrizes

drift $=$ linspace $(0,1 \mathrm{e}-3, \mathrm{a} 1)$

ngs $=$ linspace $(0,4 \mathrm{e}-4, \mathrm{a} 2)$

cy $=$ zeros $(\mathrm{a} 2, \mathrm{a} 1, \operatorname{darray}())$;

$\% \% \%$ Paralelizando na coluna sempre o loop externo (pmode start local 4)

for $\mathrm{i}=$ drange $(1: \mathrm{a} 1)$;

$$
\text { for } \mathrm{j}=1: \mathrm{a} 2 \text {; }
$$

[cy0] = RK4_drift_ngs_vs1(drift(i),ngs(j));

$\operatorname{cy}(\mathrm{j}, \mathrm{i})=\operatorname{cy} 0$

clear('cy0');

end

end

cy = gather $(\mathrm{cy}, 1)^{\prime}$;

save('cycles_Iz05_200x200','cy','-ascii');

toc

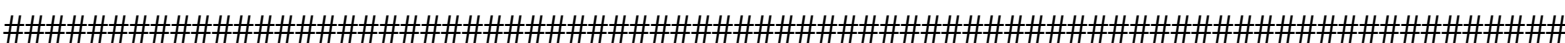

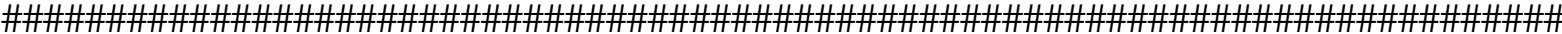

function [cy] = RK4_drift_ngs_vs1(aa,cc)

$\% \% \%$ Iterações

$\mathrm{ti}=0$;

$\mathrm{tf}=400000$

$\mathrm{h}=0.01$

int $=\operatorname{round}((\mathrm{tf}-\mathrm{ti}) / \mathrm{h})$;

$\% \%$ Variáveis

$\mathrm{y}=\operatorname{zeros}($ int, 4$)$; 


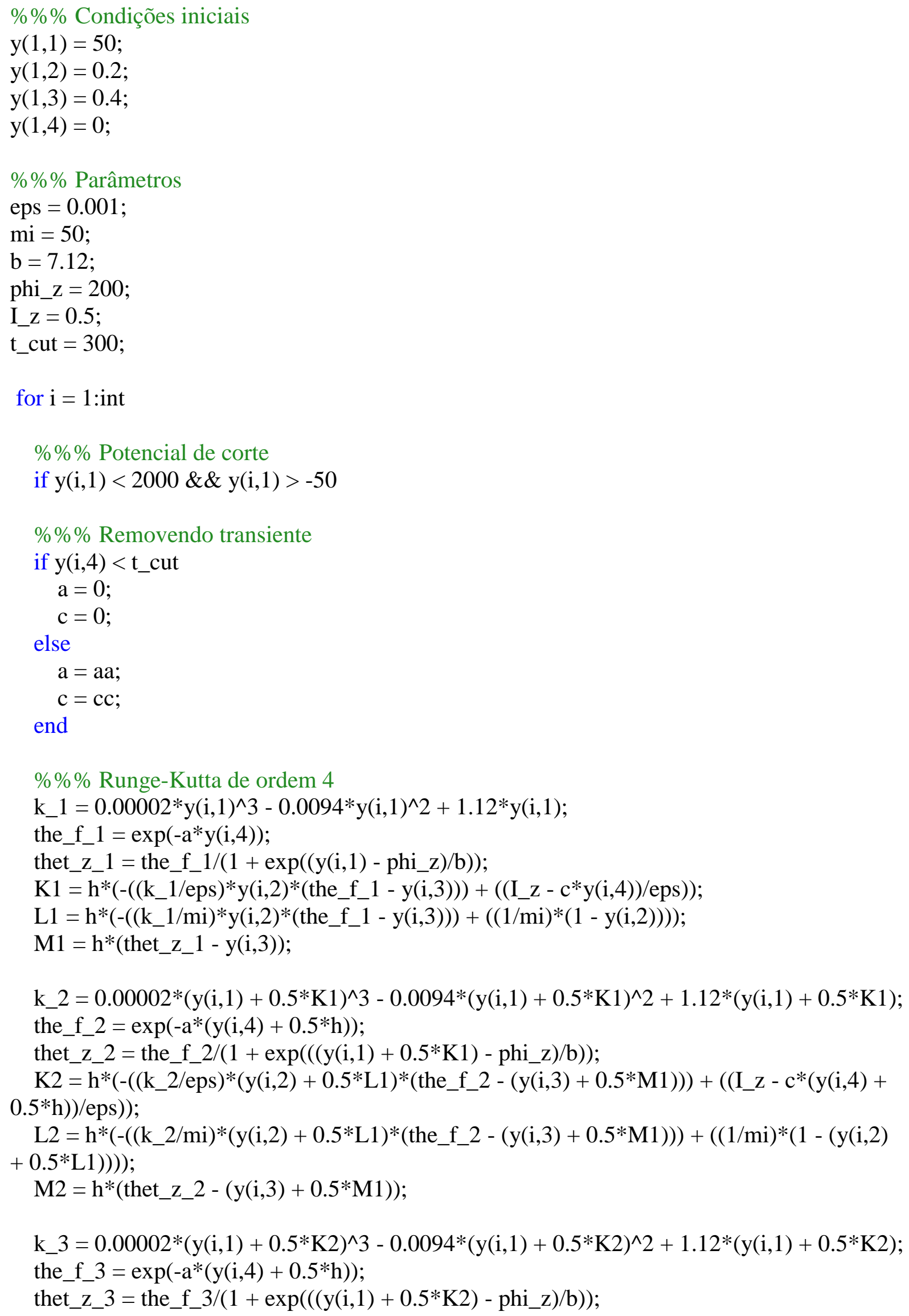




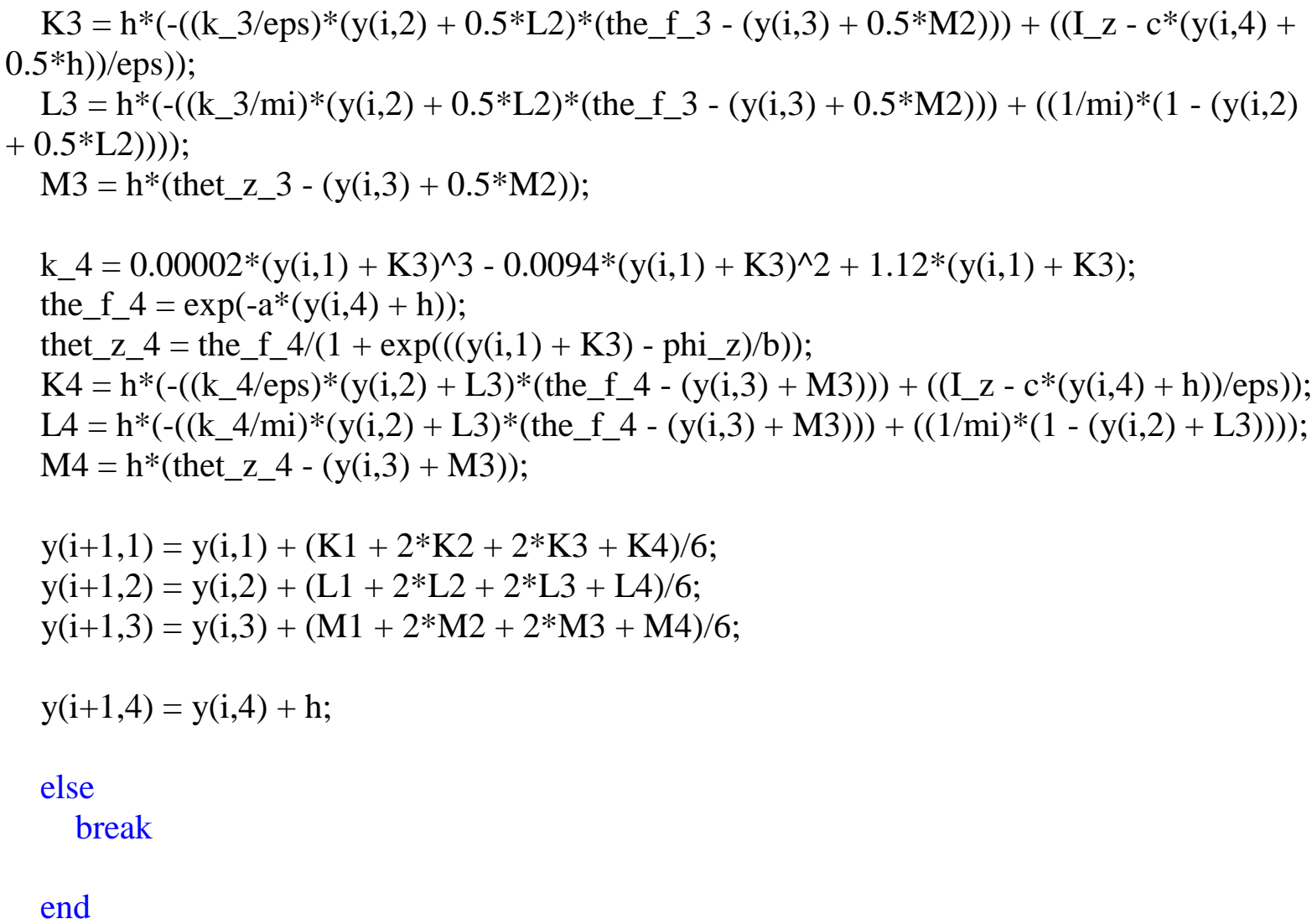

end

$\% \%$ Normalizando vetores

$\mathrm{m}=$ find $\left(\mathrm{y}(:, 4)<\mathrm{t} \_\right.$cut $+\mathrm{h} \& \mathrm{y}(:, 4)>\mathrm{t} \_$cut $)$;

$\mathrm{y}=[\mathrm{y}(\mathrm{m}: \mathrm{end}, 1), \mathrm{y}(\mathrm{m}: \mathrm{end}, 2), \mathrm{y}(\mathrm{m}: \mathrm{end}, 3), \mathrm{y}(\mathrm{m}: \mathrm{end}, 4)]$;

$\% \%$ Calculando pontos de máximo

phi_t $=\mathrm{y}(2$ :end-1,1);

phi_left $=\mathrm{y}(1:$ end-2,1);

phi_right $=\mathrm{y}(3$ :end, 1$)$;

$\mathrm{k} \_\mathrm{max}=$ find $(($ phi_t $>$ phi_left $) \&($ phi_t $>=$ phi_right $))$;

cy $=$ length $\left(\mathrm{k} \_\right.$max $)$;

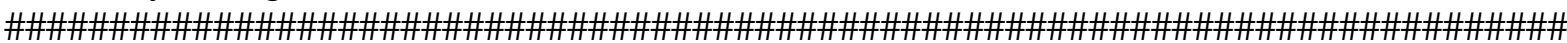


Rotina escrita em ambiente Mathematica. Os resultados são mostrados na Figura 6.4.

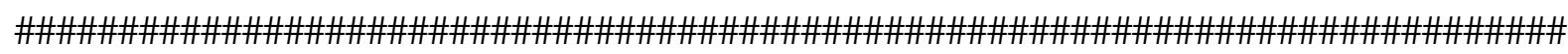

Clear[v1,v2,v3,v4,v5,v6,v7,v8,v9,v10,vF];

$$
\begin{aligned}
& \mathrm{k} 1=6 ; \\
& \mathrm{k} 2=5 ; \\
& \mathrm{k} 3=1 ; \\
& \mathrm{k} 4=4 ; \\
& \mathrm{k} 5=0.079 ; \\
& \mathrm{k} 6=50 ; \\
& \mathrm{k} 7=600 ; \\
& \mathrm{k} 8=30 ; \\
& \mathrm{k} 9=300 ; \\
& \mathrm{k} 10=0.1 ; \\
& \mathrm{w}=15 ;
\end{aligned}
$$

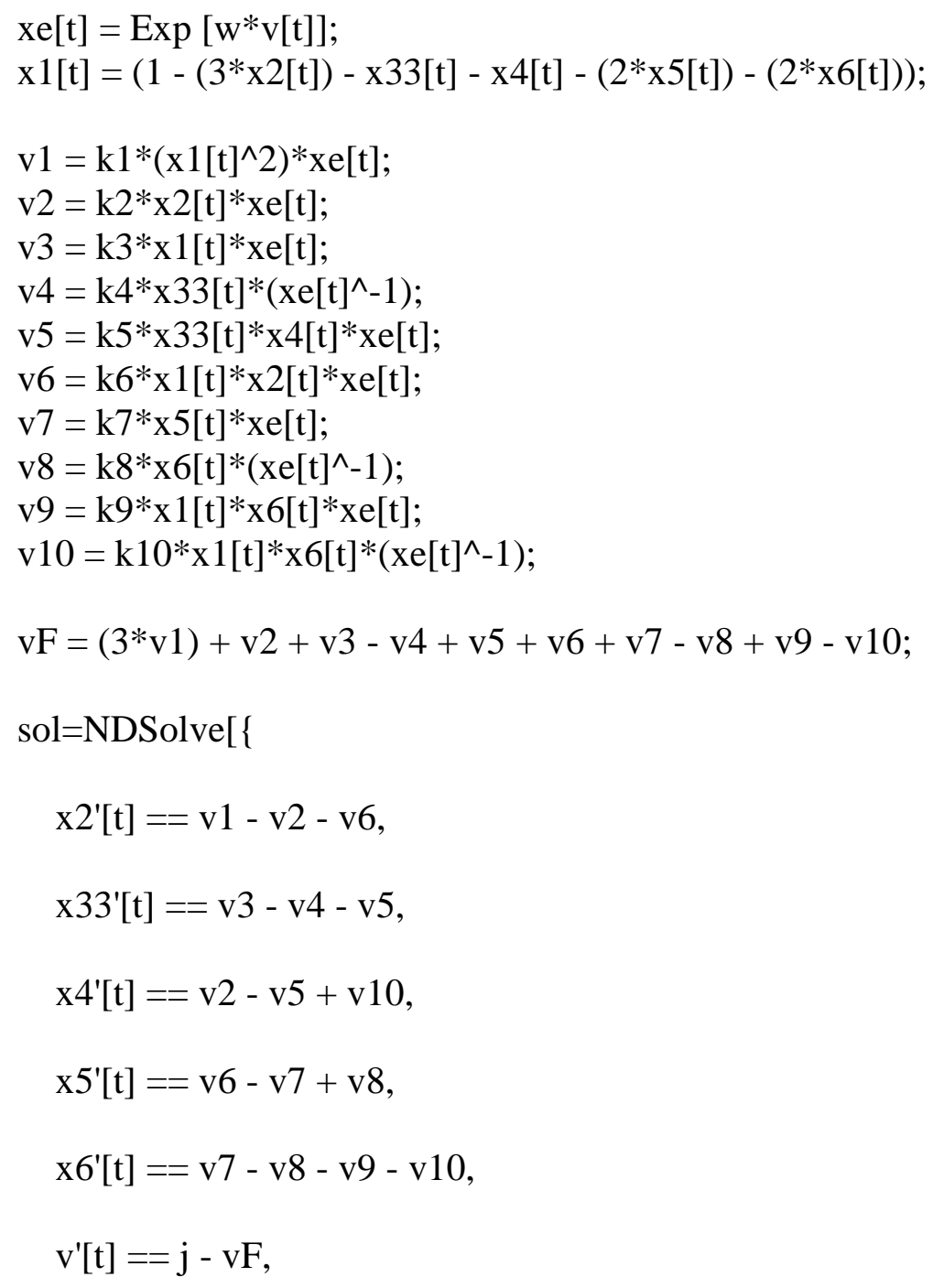


$\mathrm{x} 2[0]==0, \mathrm{x} 33[0]==0, \mathrm{x} 4[0]==0, \mathrm{x} 5[0]==0, \mathrm{x} 6[0]==0, \mathrm{v}[0]==0\}$, $\{\mathrm{x} 2, \mathrm{x} 33, \mathrm{x} 4, \mathrm{x} 5, \mathrm{x} 6, \mathrm{v}\},\{\mathrm{t}, 0,5000\}$, MaxSteps $\rightarrow$ Infinity $]$;

Plot[Evaluate[\{v[t]\}/.sol], \{t,3301,3369\},PlotRange $\rightarrow$ All $]$

Export["v.dat",TableForm[Table[\{t,Evaluate[v[t]]/.sol $\},\{t, 3301,3369,0.05\}]]]$

Plot[Evaluate[\{v5+v9\}/.sol], \{t,3301,3369\},PlotRange $\rightarrow$ All $]$

Export["v5+v9.dat",TableForm[Table[\{t,Evaluate[v5+v9]/.sol $\},\{t, 3301,3369,0.05\}]]]$

Plot[Evaluate[\{x2[t]\}/.sol], $\{\mathrm{t}, 3301,3369\}$, PlotRange $\rightarrow$ All $]$

Export["x2.dat",TableForm[Table[\{t,Evaluate[x2[t]]/.sol $\},\{t, 3301,3369,0.05\}]]]$

Plot[Evaluate[\{v5\}/.sol],\{t,3301,3369\},PlotRange $\rightarrow$ All]

Export["v5.dat",TableForm[Table[\{t,Evaluate[v5]/.sol $\},\{t, 3301,3369,0.05\}]]]$

Plot[Evaluate[\{v9\}/.sol],\{t,3301,3369\},PlotRange $\rightarrow$ All $]$

Export["v9.dat",TableForm[Table[\{t,Evaluate[v9]/.sol $\},\{t, 3301,3369,0.05\}]]]$

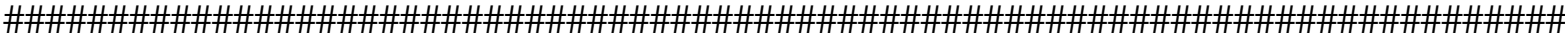


Figura A1 - Deconvolução dos picos de $\mathrm{CO}_{2}(\mathrm{~m} / \mathrm{z}=44)$ em solução aquosa de ácido (a) perclórico e (b) súlfurico com $\left[\mathrm{H}_{3} \mathrm{COH}\right]=2,0 \mathrm{~mol} \mathrm{~L} \mathrm{~L}^{-1} \mathrm{e} \mathrm{j}=0,30 \mathrm{~mA} \mathrm{~cm}{ }^{-2}$. $\left[\mathrm{HClO}_{4}\right]=\left[\mathrm{H}_{2} \mathrm{SO}_{4}\right]$ $=0,5 \mathrm{~mol} \mathrm{~L}^{-1}$ e $\mathrm{T}=20^{\circ} \mathrm{C}$. A deconvolução foi conduzida com uma linha de base no pico de mínimo local das oscilações. Este procedimento resultou na produção relativa de $\mathrm{CO}_{2}$ dada na Figura 6.8 .

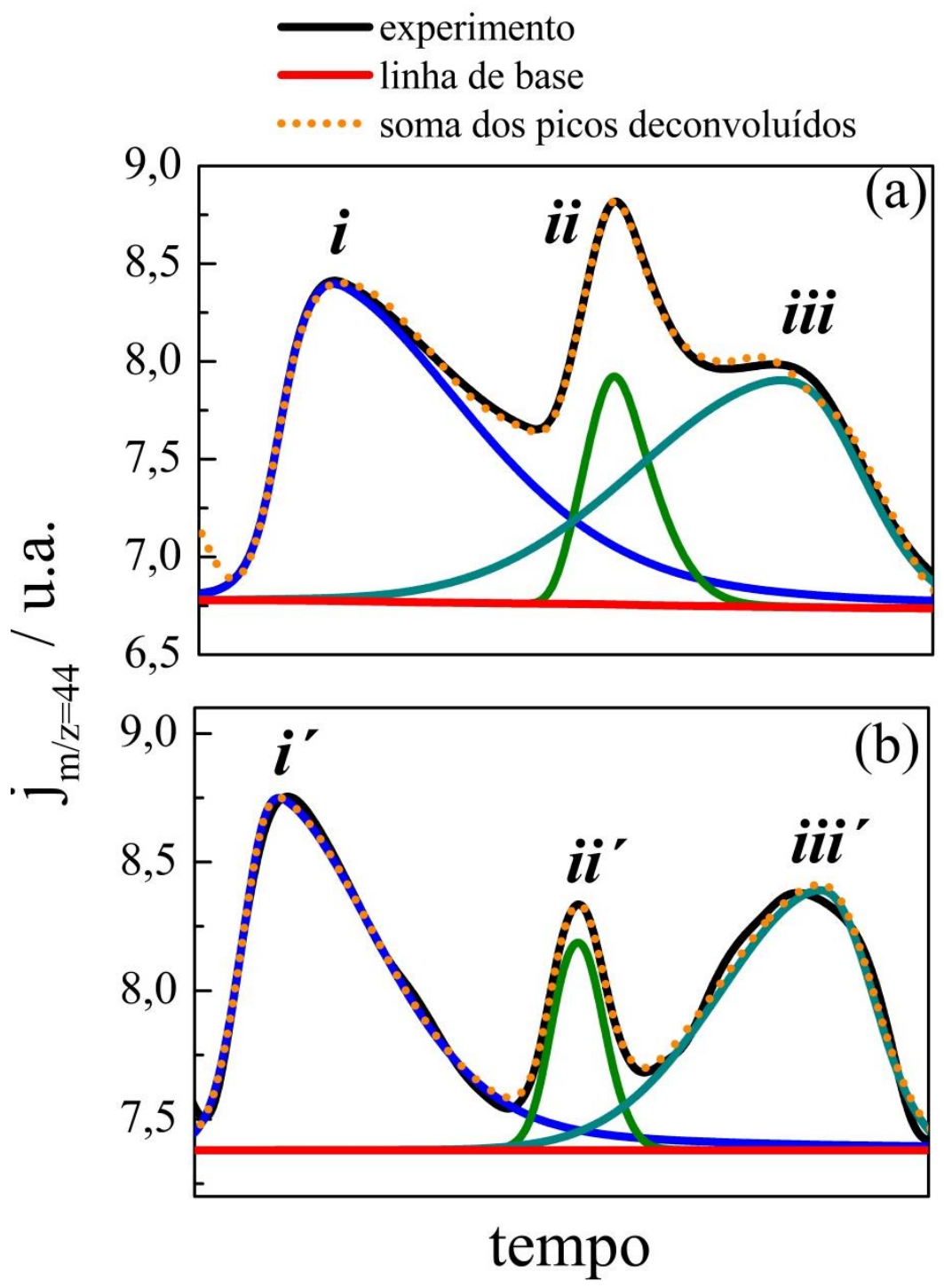

Os picos de $\mathrm{CO}_{2} i$, ii, iii (item (a)) e i', ii', iii' (item (b)) em regime oscilatório foram deconvoluídos pelo método dos mínimos quadrados em ambas as concentrações de metanol (i.e. 0.5 e $2.0 \mathrm{~mol} \mathrm{~L}^{-1}$ ). Uma combinação linear de funções Gaussianas-Lorentzianas (pseudoVoigt) foi empregada no processo da deconvolução. A soma dos picos deconvoluídos foi incluída na Figura A1 com a finalidade de comparação. Um excelente ajuste foi obtido. 
Figura A2 - Produção de $\mathrm{CO}_{2}$ em função da densidade de corrente aplicada em regime oscilatório à $\left[\mathrm{H}_{3} \mathrm{COH}\right]=2,0 \mathrm{~mol} \mathrm{~L}^{-1}$ em solução aquosa de ácido perclórico (item (a) e (b)) e sulfúrico (item (c) e (d)), $\left[\mathrm{HClO}_{4}\right]=\left[\mathrm{H}_{2} \mathrm{SO}_{4}\right]=0,5 \mathrm{~mol} \mathrm{~L}^{-1}$ e $\mathrm{T}=20^{\circ} \mathrm{C}$. A deconvolução foi conduzida com uma linha de base adotada em condições de circuito aberto (i.e. $\sim 0,33 \mathrm{~V}$ ).

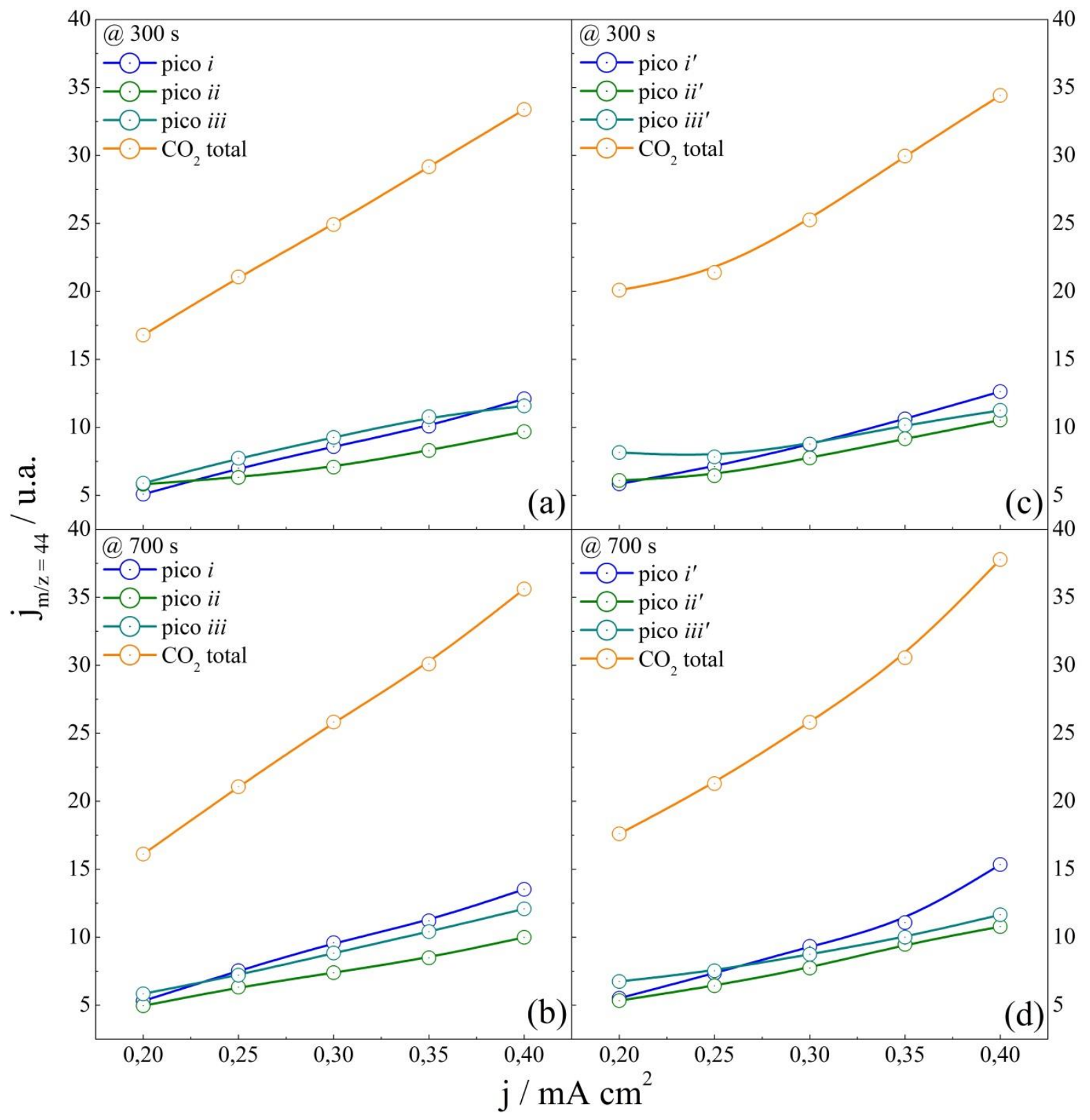


Figura A3 - Programação em diagrama de blocos construído em ambiente Labview para a calibração do ganho e linha de base individual dos canais.

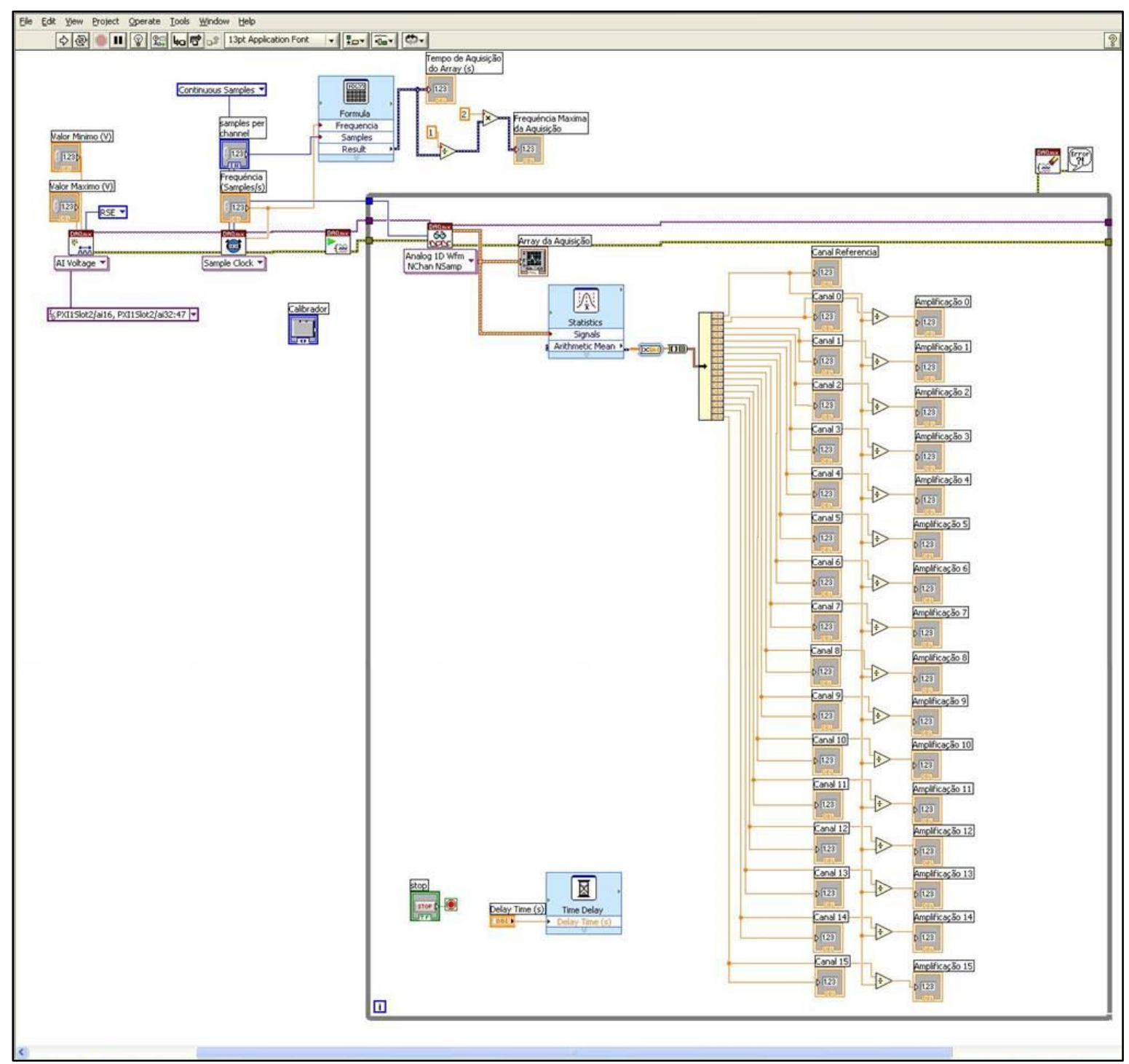


Figura A4 - Painel frontal utilizado como interface de usuário referente à programação dada na Figura A3. Nota-se o valor da amplificação e a posição da linha de base de cada canal.

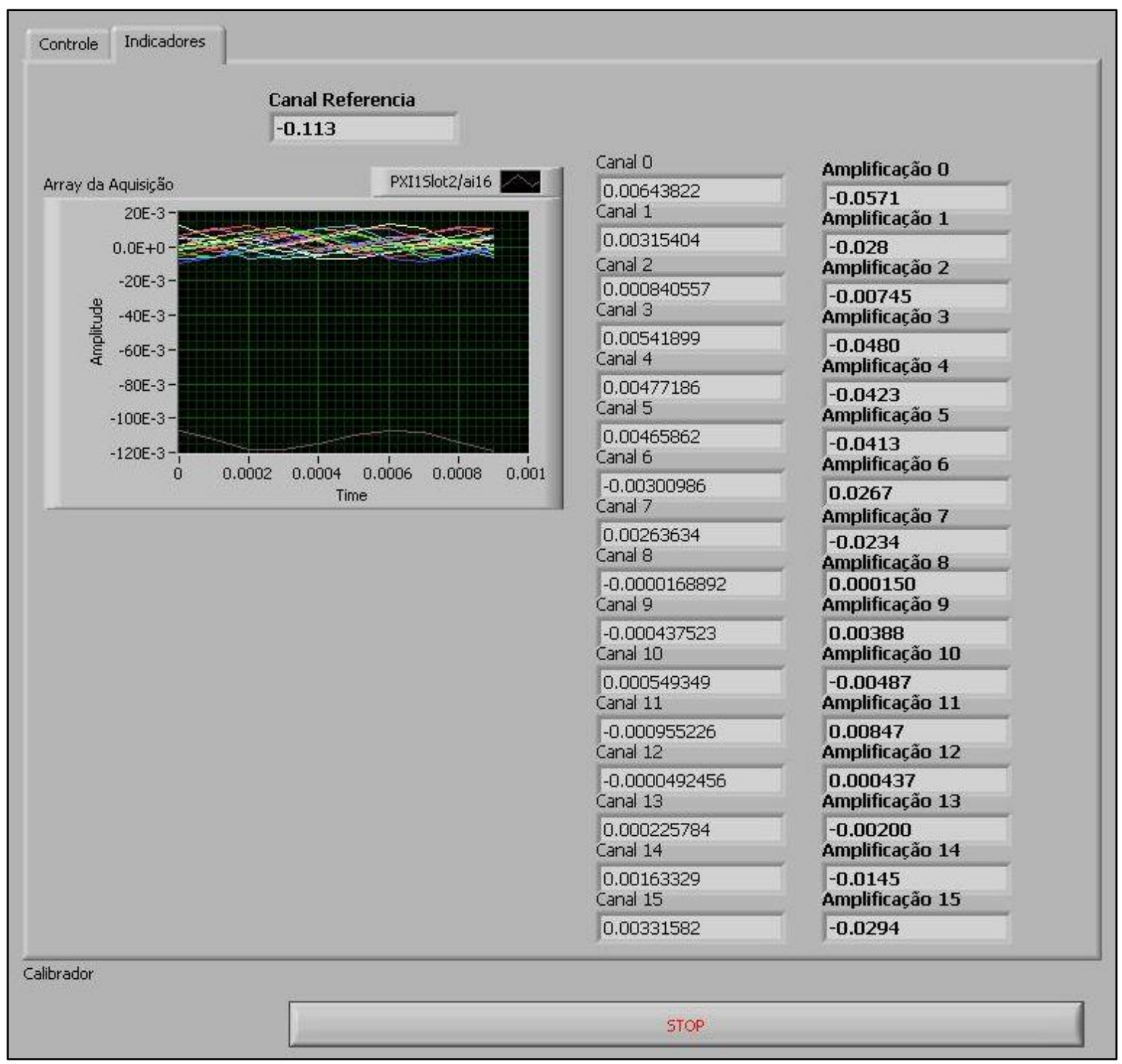


Figura A5 - Circuito elétrico pertencente ao STD. Controle do resistor shunt, amplificação e linha de base estão disponíveis nessa configuração.
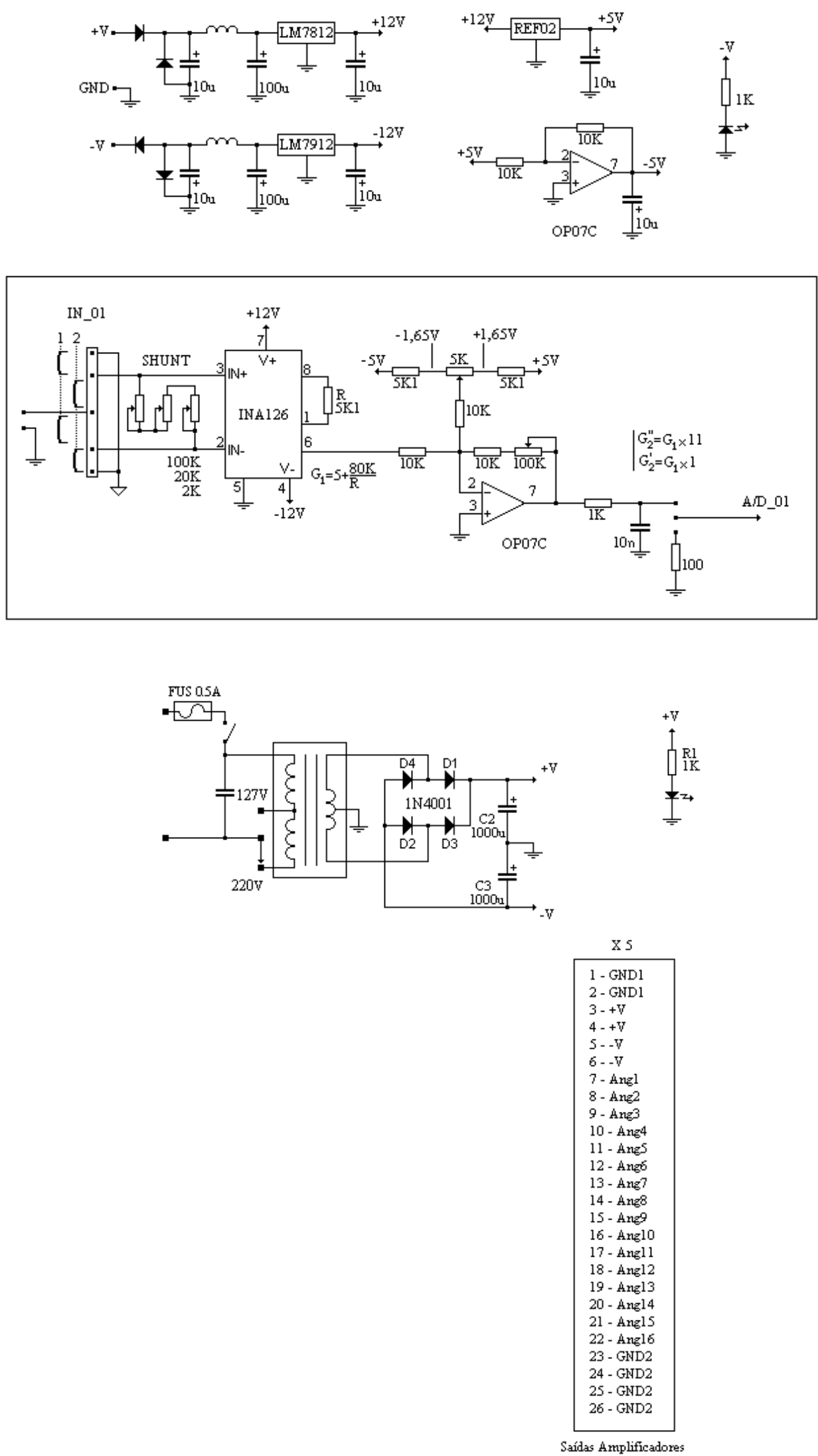


\section{Curriculum Vitae}

Pessoal

Nome Raphael Nagao de Sousa

Nascimento 16 de abril de 1984, São Paulo - SP, Brasil.

Filiação Ursulino Gomes de Sousa e Yuriko Nagao de Sousa

Formação Acadêmica

$2007-2009$

Bacharel em Química

Universidade de São Paulo, São Paulo, Brasil

2003 - 2006 Título: Auto-organização Temporal na Interface Sólido/Líquido: Eletrooxidação de Ácido Fórmico sobre Platina

Orientador: Prof. Dr. Hamilton Varela

Bolsista: Fundação de Amparo à Pesquisa do Estado de São Paulo

Mestre em Ciências (ênfase em Físico-Química)

Universidade de São Paulo, São Paulo, Brasil

Título: Efeito da Temperatura na Eletro-oxidação Oscilatória de Ácido

Fórmico sobre Platina: Experimentos e Simulações

Orientador: Prof. Dr. Hamilton Varela

Bolsista: Fundação de Amparo à Pesquisa do Estado de São Paulo

Doutor em Química (ênfase em Físico-Química)

Universidade de São Paulo, São Paulo, Brasil

2009 - atual

Título: Elucidação de Mecanismos Reacionais em Regime Longe do

Equilíbrio Termodinâmico

Orientador: Prof. Dr. Hamilton Varela

Bolsista: Fundação de Amparo à Pesquisa do Estado de São Paulo

Estágio doutoral em Sistemas Complexos

2011 - $2012 \quad$ Brandeis University, Massachusetts, Estados Unidos

Orientador: Prof. Dr. Irving R. Epstein

Bolsista: Coordenação de Aperfeiçoamento de Pessoal de Nível Superior 


\section{Prêmios e Títulos}

(1) Menção Honrosa, $12^{\circ}$ Simpósio Internacional de Iniciação Científica da Universidade de São Paulo, 2004.

(2) Viagem e inscrição isentas para à $57^{\circ}$ Reunião Anual da Sociedade Brasileira para o Progresso da Ciência, Jornada Nacional de Iniciação Científica, 2005.

(3) Convite para a publicação do trabalho: "Auto-catalysis and Dissipation during Metal Electrodeposition" na Revista de Iniciação Científica da USP, Centro de Tecnologia Educacional para Engenharia da Escola de Engenharia de São Carlos da USP, 2006.

(4) Candidatura selecionada para participação no Hands on Research on Complex Systems School, The Abdus Salam International Centre for Theoretical Physics, 2009.

(5) Convite para a publicação da dissertação de mestrado em forma de livro, VDM Verlag Dr. Müller, 2009.

(6) Quarto artigo mais baixado (top 25) no período de 01/2012-03/2012: A.L. Santos, R. Nagao, C.P. Oliveira, R.B. Lima, H. Varela. J. Electroanal. Chem. 2011, 660, 147152., Elsevier.

(7) Capa externa da revista PCCP: R. Nagao, D.A. Cantane, F.H.B. Lima, H. Varela Phys Chem Chem Phys 2012, 14, 8294 - 8298. Royal Society of Chemistry.

Lista de Publicações (asterisco indica os trabalhos relacionados com a tese)

(1) R. Nagao, H. Varela, E. R. Gonzalez, Auto-catalysis and Dissipation during Metal Electrodeposition. Revista de Iniciação Científica da USP, 2005, 7, 31 - 34.

(2) R. Nagao, I. R. Epstein, E. R. Gonzalez, H. Varela, Temperature (Over)Compensation in an Oscillatory Surface Reaction. J. Phys. Chem. A, 2008, 112,4617 - 4624.

(3) E. A. Carbonio, R. Nagao, E. R. Gonzalez, H. Varela, Temperature Effects on the Oscillatory Electro-oxidation of Methanol on Platinum. Phys. Chem. Chem. Phys., 2009, 11, 665 - 670 .

(4) E. Sitta, A. L. Santos, R. Nagao, H. Varela, Nanogravimetric Study of the Complex Voltammetric Response in the Electro-oxidation of Methanol on Platinum. Electrochim. Acta., 2009, 55, 404 - 409.

(5) *R. Nagao, E. Sitta, H. Varela, Stabilizing Nonstationary Electrochemical Time Series. J. Phys. Chem. C, 2010, 114, 22262 - 22268. 
(6) A. L. Santos, R. Nagao, C. P. Oliveira, R. B. Lima, H. Varela. The Role of $\mathrm{HBF}_{4}$ in Electro-catalysis: Arsenic Contamination and Anion Adsorption. J. Electroanal. Chem., 2011, 660, 147 - 152. (4º artigo mais baixado, top 25)

(7) A. L. Santos, R. Nagao, C. P. Oliveira, R. B. Lima, H. Varela. Reply to the Comment on the paper: The Role of $\mathrm{HBF}_{4}$ in Electro-catalysis: Arsenic Contamination and Anion Adsorption. J. Electroanal. Chem., 2012, 687, 1 - 2.

(8) *R. Nagao, D. A. Cantane, F. H. B. Lima, H. Varela, The Dual Pathway in Action: Decoupling Parallel Routes for $\mathrm{CO}_{2}$ Production during the Oscillatory Electrooxidation of Methanol. Phys. Chem. Chem. Phys., 2012, 14, 8294 - 8298. (destacado na capa externa da revista)

(9) D. Feldman, R. Nagao, T. Bansagi Jr., I. R. Epstein, M. Dolnik, Turing Patterns in the Chlorine Dioxide - Iodine - Malonic Acid Reaction with Square Spatial Periodic Forcing. Phys. Chem. Chem. Phys., 2012, 14, 6577 - 6583.

(10) *M. F. Cabral, R. Nagao, E. Sitta, M. Eiswirth, H. Varela, Mechanistic Aspects of the Linear Stabilization of Nonstationary Electrochemical Oscillations. Phys. Chem. Chem. Phys., 2013, 15, 1437 - 1442.

(11) *R. Nagao, D. A. Cantane, F. H. B. Lima, H. Varela Influence of Anion Adsorption on the Parallel Pathways in the Oscillatory Electro-oxidation of Methanol. J. Phys. Chem. C, 2013, 117, 15098 - 15105.

(12) E. Sitta, R. Nagao, H. Varela The Electro-oxidation of Ethylene Glycol on Platinum over a Wide pH Range: Oscillations and Temperature Effects. Plos One, 2013, 8, e75086: 1-10.

(13) R. Nagao, I. R. Epstein, M. Dolnik, Effect of Strong Visible Light on Turing Patterns. J. Phys. Chem. A, 2013, 117, 9120-9126.

Apresentação de Trabalhos em Conferências Científicas

Possui 17 participações em conferências científicas com 41 publicações de resumos em anais de congressos, sendo 9 destes como resumos expandidos e 3 apresentações orais em conferências nacionais e internacionais.

Apresentação Oral em Conferências Científicas

(1) H. Varela, R. Nagao, A. L. Martins, E. R. Gonzalez, Cinética Complexa em Eletrocatálise: Experimentos e Simulações. $16^{\circ}$ Congresso Brasileiro de Engenharia Química, 2006. 
(2) R. Nagao, I. R. Esptein, E. R. Gonzalez, H. Varela, Temperature (Over)Compensation in an Oscillatory Surface Reaction. $4^{\text {th }}$ Gerischer Symposium: Electrochemistry with Spatial and Temporal Resolution, 2008.

(3) R. Nagao, H. Varela, Mechanistic Aspects of the Nonlinear Electro-oxidation of Methanol: Experiments, Modeling and Numerical Simulations. $1^{\text {st }}$ IQSC Workshop on Theoretical Chemistry, 2012. 